\author{
UNIVERSIDADE DE SÃO PAULO \\ ESCOLA DE ENGENHARIA DE SÃO CARLOS \\ PROGRAMA DE PÓS-GRADUAÇÃO EM CIÊNCIAS DA \\ ENGENHARIA AMBIENTAL
}

\title{
INDICADORES DE BENCHMARKING DOS SERVIÇOS DE SANEAMENTO VOLTADOS A POPULAÇÕES VULNERÁVEIS
}

\author{
Tássia Gaspar Temóteo \\ Orientador: Prof. Dr. Tadeu Fabrício Malheiros
}

São Carlos - SP 


\title{
TÁSSIA GASPAR TEMÓTEO
}

\section{INDICADORES DE BENCHMARKING DOS SERVIÇOS DE SANEAMENTO} VOLTADOS A POPULAÇÕES VULNERÁVEIS

\author{
Dissertação apresentada à escola de Engenharia \\ de São Carlos da Universidade de São Paulo \\ para a obtenção de título de mestre em Ciências \\ da Engenharia Ambiental. \\ Área de Concentração: Ciências da Engenharia \\ Ambiental \\ Orientador: Prof. Dr. Tadeu Fabrício Malheiros
}

São Carlos - SP 
AUTORIZO A REPRODUÇÃO E DIVULGAÇÃO TOTAL OU PARCIAL DESTE TRABALHO, POR QUALQUER MEIO CONVENCIONAL OU ELETRÔNICO, PARA FINS DE ESTUDO E PESQUISA, DESDE QUE CITADA A FONTE.

Ficha catalográfica preparada pela Seção de Tratamento da Informação do Serviço de Biblioteca - EESC/USP

Temóteo, Tássia Gaspar

T281i Indicadores de Benchmarking dos serviços de saneamento voltados a populações vulneráveis / Tássia Gaspar Temóteo ; orientador Tadeu Fabrício Malheiros. -- São Carlos, 2012 .

Dissertação (Mestrado - Programa de Pós-Graduação em Ciências da Engenharia Ambiental) -- Escola de Engenharia de São Carlos da Universidade de São Paulo, 2012.

1. Gestão ambiental. 2. Indicadores de Benchmarking. 3. Serviços de abastecimento e esgotamento sanitário. 4. Populações vulneráveis. I. Título. 


\section{FOLHA DE JULGAMENTO}

\section{Candidata: Tecnóloga TÁsSIA GASPAR TEMÓTEO}

Título da dissertação: "Indicadores de Benchmarking dos serviços de saneamento voltados a populações vulneráveis".

Data da defesa: 04/04/2012

\section{Comissão Julgadora:}

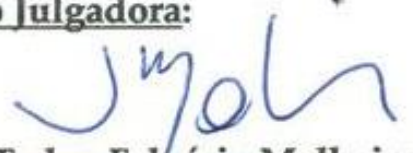

Prof. Dr. Tadeu Fabrício Malheiros (Orientador)

(Escola de Engenharia de Sã̃o Carlos/EESC)

Prof. Dr. Valdir Fernandes

(FAE Centro Universitário)

Prof. Dr. Severino Soares Agra Filho

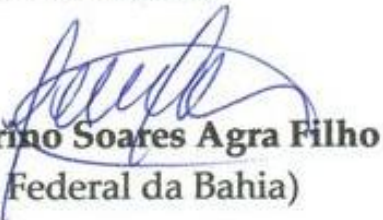

(Universidade Federal da Bahia)
Resultado:

$\triangle P R O V A D A$

\section{APROV $\triangle D A$}

Coordenador do Programa de Pós-Graduação em Ciências da Engenharia Ambiental:

Prof. Dr. Frederico Fabio Mauad

Presidente da Comissão de Pós-Graduação:

Prof. Associado Paulo Cesar Lima Segantine 


\section{AGRADECIMENTOS}

Sou muito grata

Ao Murilo, companheiro dos dias ensolarados e dos dias tempestuosos, pela paciência e amor

À minha mãe por me educar e me oferecer instrumentos que eu pudesse chegar até aqui

Aos meus amigos e familiares que me deram força

Ao Professor Tadeu pela orientação e por possibilitar o meu desenvolvimento

À UNESCO-IHE, em especial ao professor Maarten Blokland, coordenador do projeto PROBE, pela oportunidade de participar de um projeto com contribuições internacionais.

À Raquel dos Santos, doutoranda do projeto PROBE, pela animação e apoio

À Camila Elena Muza Cruz, funcionária da ARSESP, pela participação entusiasmada e apoio intenso durante a pesquisa

À todos as pessoas e instituições que contribuíram e participaram para a realização das oficinas de trabalho (ARSESP, SABESP, SEADE, ABES-SP, UNIÁGUAS, Prefeitura Municipal de São Paulo)

E principalmente à FAPESP pela bolsa de estudos e reserva técnica, financiamento o qual possibilitou a realização da pesquisa

À Deus por tudo isso 


\section{TEMÓTEO, T. G., Indicadores de benchmarking dos serviços de saneamento}

voltados a populações vulneráveis. 2012. 195 f. Dissertação (Mestrado). Escola de Engenharia de São Carlos (EESC), Universidade de São Paulo (USP). São Carlos, 2012.

\section{RESUMO}

Diante da realidade de segregação residencial existente no Brasil, determinada pela heterogeneidade de renda, de condições sociais entre bairros e distritos, evidenciase uma sociedade cada vez mais permeada por iniquidades sociais e ambientais. Somado a isto, há o fato do crescimento da concentração populacional em áreas urbanas. Este e outros fatores geram transformações nas estruturas das cidades acentuando conflitos referentes ao uso e ocupação do solo. Tais conflitos requerem agilidade de suprir demandas de fornecimento de serviços essenciais, tais como de abastecimento de água e esgotamento sanitário, especialmente quando se trata destes serviços às populações vulneráveis. Para apoio a medição e visualização desse cenário, de forma a elaborar políticas públicas e empresarias, é fundamental a utilização de indicadores, os quais, no entanto, não estão prontamente disponíveis. Emerge assim a necessidade de proposição de indicadores que mensurem o fornecimento dos serviços às populações vulneráveis em áreas urbanas. Neste contexto, com estudo de caso para o Estado de São Paulo, Brasil, a pesquisa teve como enfoque atuar na interface teórica e prática para proposição de indicadores. Foram realizadas, então, revisão bibliográfica, análise documental e discussão crítica com base no aprendizado do estudo de caso. Doze indicadores foram propostos e um sistema de indicadores de benchmarking dos serviços de abastecimento e esgotamento sanitário voltados às populações vulneráveis foi estruturado. O sistema e os indicadores foram identificados por meio do alinhamento de diferentes visões dos atores, o que permitiu que fossem condizentes com a realidade dos serviços, e posteriormente, mais facilmente implementados.

Palavras-chave: Indicadores, serviços de abastecimentos e esgotamento sanitário, populações vulneráveis, benchmarking. 


\title{
TEMÓTEO, T. G., Benchmarking indicators of water supply and sanitation
} services aimed at vulnerable populations. 2012. 195 p. Dissertation (Mester of Science). Escola de Engenharia de São Carlos (EESC), Universidade de São Paulo (USP). São Carlos, 2012.

\begin{abstract}
The income heterogeneity and social conditions between neighborhoods and districts show a society increasingly permeated by social and environmental inequities by means the reality of residential segregation that exists in Brazil. In addition, there is population growth occurred concentrated in urban areas, this and other factors that generate transformations in the structures of cities accentuating conflicts regarding the use and occupation. Such conflicts require flexibility to supply demands for essential services such as to provide water and sanitation services, especially aimed to vulnerable populations. For the measurement and visualization of this scenario, in order to produce the policies and business, it is essential to use of indicators, which, however, are not readily available. Thus emerges the need to propose indicators that measure the provision of services to vulnerable populations in urban areas. In this context, with case study in Sao Paulo State, Brazil, the research was focused on theoretical and practical interface to proposed indicators. Were performed also, literature review, document analysis and critical discussion based on the learning case study. Twelve indicators were proposed and a system of benchmarking indicators for the water supply and sanitation services to targeted vulnerable populations was structured. The framework and indicators were proposed by aligning different views of the actors, in a way to be consistent with the reality of services and more easily implemented.
\end{abstract}

Keywords: Indicators, water supply and sanitation services, vulnerable populations, benchmarking. 


\section{Lista de Figuras}

Figura 1. Representação de exemplo do conceito dinâmico de acesso aos SAA\&ES.

Figura 2. Exemplo de local sem acesso aos SAA\&ES e demais infraestruturas mínimas necessárias, município de São Paulo, Estado de São Paulo. Fonte: própria. Realizada em 28/05/2010.

Figura 3. Visualização de exemplo de urbanização irregular em grandes centros com adensamento populacional e falta de infraestrutura, município de São Paulo, Estado de São Paulo. Fonte: própria. Realizada em 28/05/2010.

Figura 4. Situação de risco da população vivendo em exposição direta a esgotos. Município de São Paulo, Estado de São Paulo. Fonte: própria. Realizada em 06/12/2011.

Figura 5. Exemplo de canalização residencial despejando esgoto diretamente no ambiente. Município de

São Paulo, Estado de São Paulo. Fonte: própria. Realizada em 06/12/2011 ........................................27

Figura 6. Representação das funções institucionais discriminadas na lei federal do saneamento básico ...29

Figura 7. Fluxograma das etapas metodológicas desenvolvidas. ........................................................45

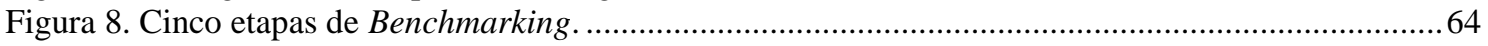

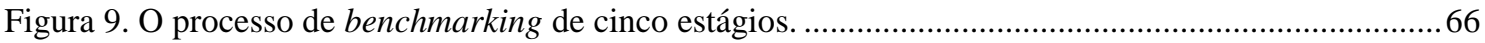

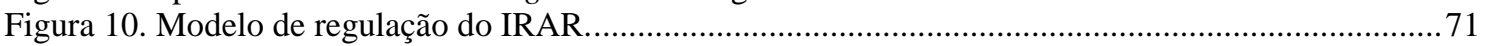

Figura 11. Modelo PEIR nos SAA\&ES voltados às populações vulneráveis. .......................................8 87

Figura 12. Representação do sistema de indicadores Balaton Group. .................................................93

Figura 13. Balanced Score Card, esquema e perspectivas..............................................................95

Figura 14. Perspectivas e indicadores de prestação de serviços de saneamento a populações vulneráveis

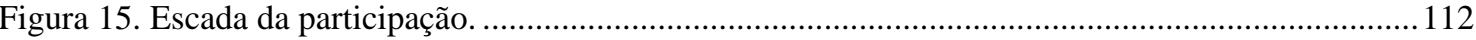

Figura 16. Estrutura teórica do conjunto de indicadores de benchmarking ....................................... 124

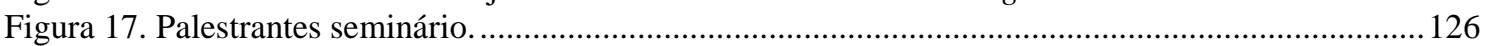

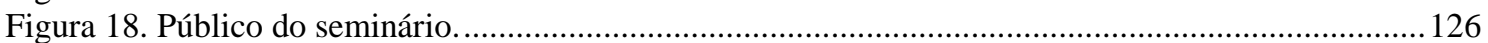

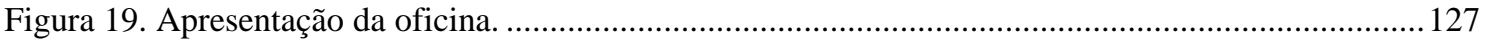

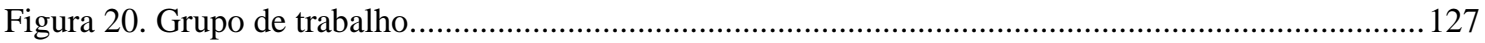

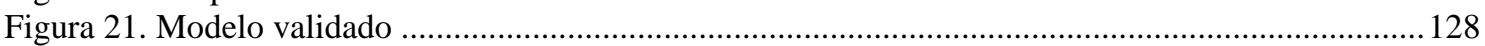

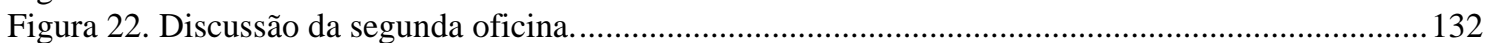

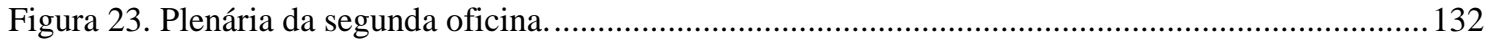




\section{Lista de Quadros}

Quadro 1. Parceiros do projeto

Quadro 2. Especificações do tema, subtema e principais autores da pesquisa bibliográfica realizada na etapa 1

Quadro 3. Itens e subitens da pesquisa bibliográfica realizados na etapa 2.

Quadro 4. Roteiro da oficina 1 da construção do Modelo de Avaliação. Fonte: Sampaio \& Fernandes (2007) 56

Quadro 5. Descrição das etapas da pesquisa e caracterização metodológica .........................................59

Quadro 6. Classificação e definições da ferramenta de Benchmarking................................................67

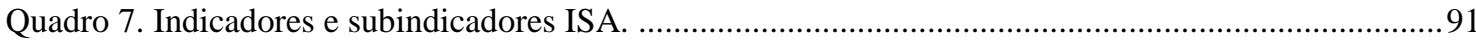

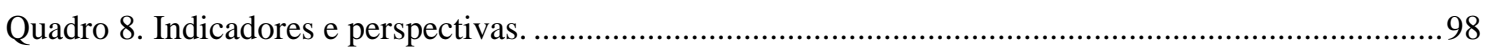

Quadro 9. Boas práticas no processo de escolha de indicadores. ........................................................ 100

Quadro 10. Erros comuns a serem evitados no processo da escolha de indicadores. ............................. 101

Quadro 11. Boas práticas de processos participativos...................................................................... 111

Quadro 12. Parceiros e atividades realizadas na etapa exploratória …...............................................117

Quadro 13. Dimensões e fatores necessários à melhoria do fornecimento dos serviços de saneamento às

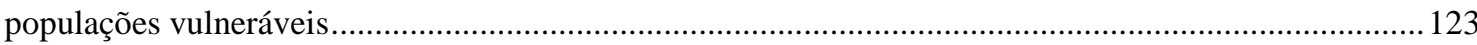

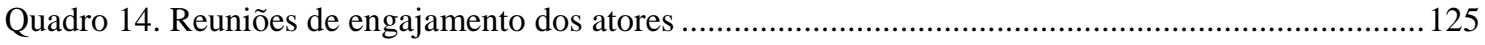

Quadro 15. Qualificação das dimensões realizadas pelos grupos durante oficina de trabalho .................128

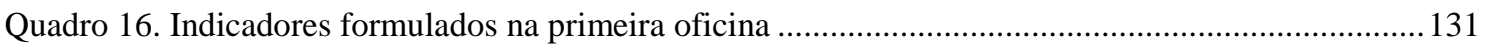

Quadro 17. Análise dos indicadores conforme critérios de análise pré-estabelecidos............................133

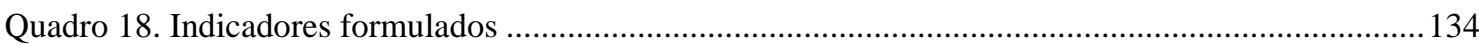

Quadro 19. Conjunto de indicadores finais, com o detalhamento dos objetivos, fórmula, unidade, definição e dados necessários. Estruturação da tabela baseada no modelo PNQS (2011).

Quadro 20. Comparação entre as dimensões do modelo elaborado por Ralda e o modelo da presente

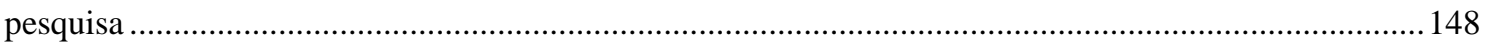

Quadro 21. Aplicação dos critérios e avaliação das boas práticas de indicadores..................................151

Quadro 22. Critérios de avaliação dos processos participativos .......................................................... 159 


\section{Lista de Tabelas}

Tabela 1 - População brasileira e distribuição da população nas regiões segundo Censo Demográfico 2010 e as formas de abastecimento de água no Brasil e nas regiões ...............................................................2 24

Tabela 2 - Existência de banheiro ou sanitário e tipo de esgotamento sanitário no Brasil e regiões ..........24 Tabela 3 - Situação brasileira dos SAA\&ES em comparação às metas dos Objetivos do Desenvolvimento do Milênio (ODM), para os anos de 2000 e 2010 .26

Tabela 4 - Classificação distribuição dos municípios no Estado de São Paulo segunda a natureza jurídico-

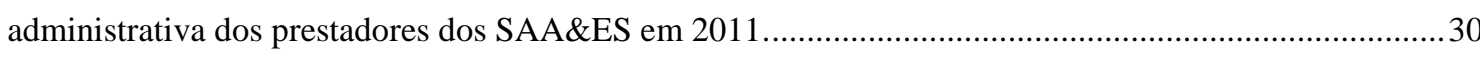

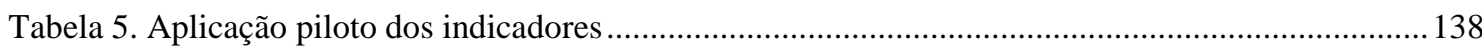




\section{SUMÁRIO}

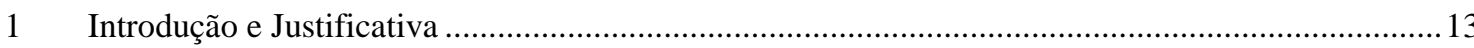

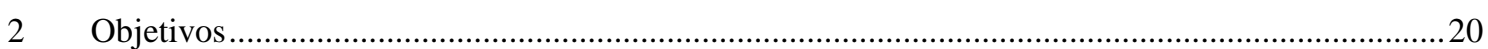

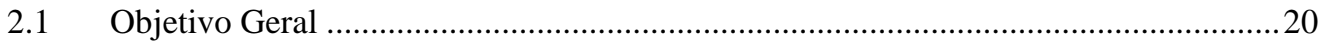

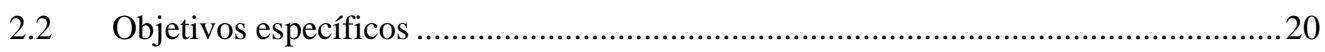

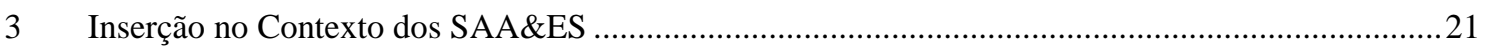

3.1 Situação dos serviços de abastecimento de água e esgotamento sanitário ...................21

3.1.1 Serviços de abastecimento de água e esgotamento sanitário no Mundo ...............22

3.1.2 Serviços de abastecimento de água e esgotamento sanitário no Brasil .................23

3.1.3 Serviços de abastecimento de água e esgotamento sanitário no Estado de São Paulo 26

3.2 Atores e Funções dos serviços de abastecimento de água e esgotamento sanitário no

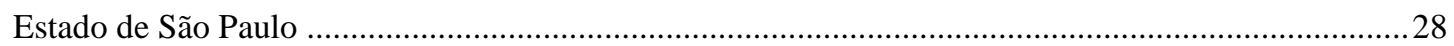

3.3 Regulação dos serviços de abastecimento de água e esgotamento sanitário ................30

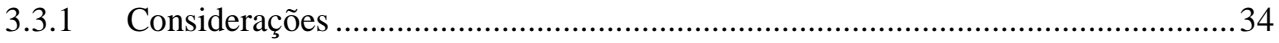

3.4 Populações pobres ou populações vulneráveis?...................................................... 35

3.5 Considerações acerca do contexto exposto ............................................................... 42

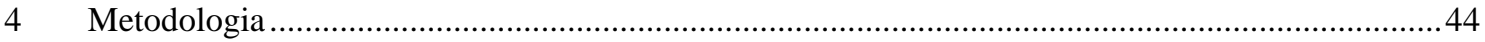

4.1 Projeto Internacional PROBE: Benchmarking Pro-poor Water Services Provision....46

4.2 Aspectos gerais da metodologia..................................................................... 47

Etapa I - Contextualização e estratégias de ação .................................................... 48

4.4 Etapa 2 - Estruturação teórica e engajamento dos atores ........................................51

4.5 Etapa 3 - Identificação, avaliação e seleção de indicadores .....................................53

Etapa 4 - Coleta de dados e análise .................................................................57

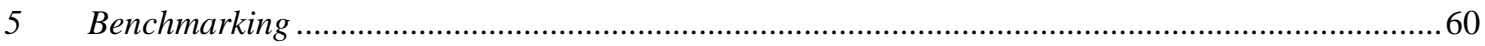

5.1 Benchmarking: ferramenta de melhoria dos serviços de abastecimento de água e

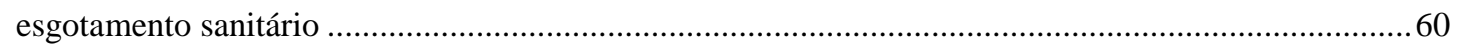

5.1.1 Descrição do processo de benchmarking ....................................................... 63

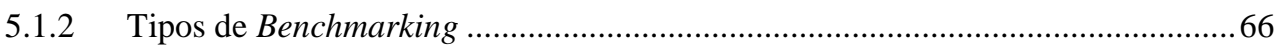

5.1.3 Práticas de benchmarking nos SAA\&ES no Brasil ............................................. 71

5.2 Considerações acerca do Capítulo de Benchmarking ............................................75

6.1 Incorporando as lentes da sustentabilidade nos indicadores de benchmarking dos SAA\&ES $\quad 82$

6.2 Sistema de indicadores .84

6.2.1 Modelo de análise Pressão-Estado-Impacto-Resposta (PEIR) .............................. 85

6.2.2 Sistema dos indicadores de desempenho IWA ................................................... 88

6.2.3 Indicador de Salubridade Ambiental - ISA ........................................................ 90

6.2.4 Modelo de Indicadores do grupo Balaton organizado por Donella Meadows ......92 
6.2.5 Modelo de indicadores PROBE - Sistema desenvolvido especifico dos SAA\&ES

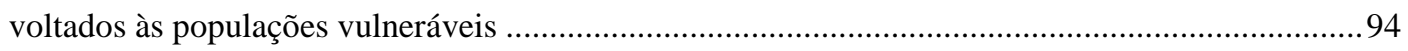

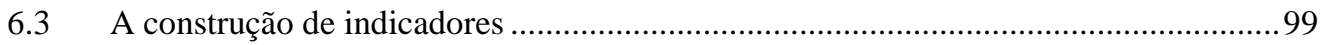

6.3.1 O processo participativo na formulação de indicadores .................................... 102

6.4 Considerações acerca do Capítulo dos Indicadores ................................................ 113

7 Indicadores de BenchmarKing dos SAA\&ES voltados às populações Vulneráveis ...................... 116

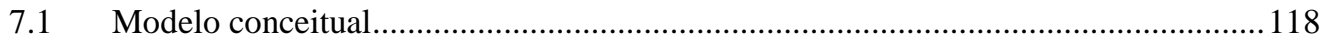

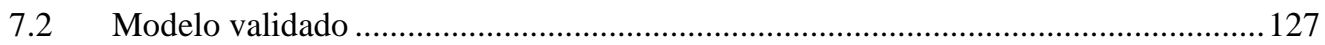

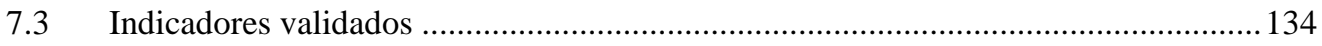

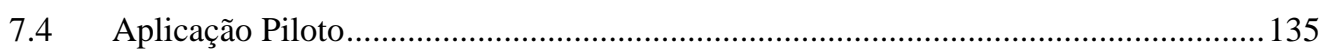

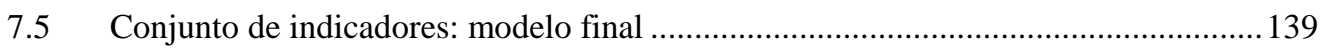

8 Contribuições e Aplicabilidade do Sistema de Indicadores ....................................................... 143

8.1 Benchmarking no auxílio da melhoria dos SAA\&ES às populações vulneráveis....... 143

8.2 Sistema de Indicadores: Análise do Modelo Final.............................................. 144

8.2.1 Estrutura de Benchmarking de Indicadores dos SAA\&ES voltados às populações vulneráveis do projeto PROBE .................................................................................................... 145

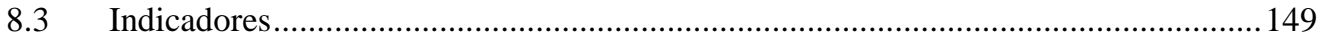

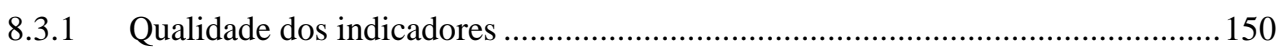

8.3.2 Implicações Regulatórias dos SAA\&ES ....................................................... 152

8.3.3 Processo de construção dos indicadores ...................................................... 154

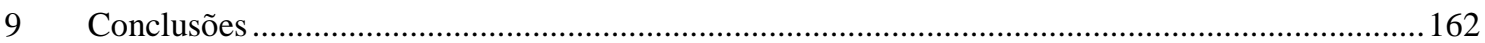

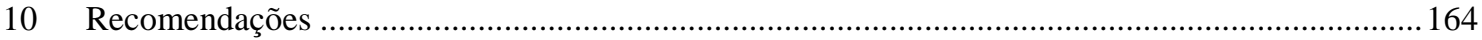

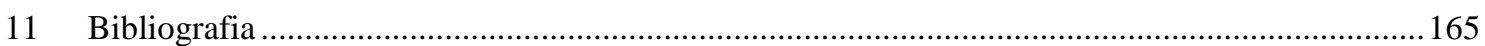

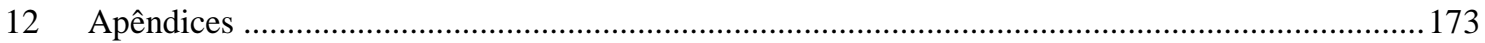




\section{INTRODUÇÃO E JUSTIFICATIVA}

Diante da realidade de segregação residencial ${ }^{1}$ existente no Brasil, marcada pela heterogeneidade de renda, de condições sociais entre bairros e distritos, pelo aumento do favelamento nas grandes metrópoles, e pelo crescimento dos chamados condomínios fechados, evidencia-se uma sociedade cada vez mais segregada residencialmente. Esta segregação pode ser entendida como o processo forçado de determinada população aglomerar-se em dada área, ocorrendo tanto por mecanismos do mercado de valorização ou desvalorização imobiliária como práticas efetivas de discriminação (TORRES, 2004).

Somado a esta segregação residencial, há o crescimento populacional ocorrido de maneira concentrada em áreas urbanas ${ }^{2}$, este e outros fatores geram transformações nas estruturas das cidades acentuando conflitos referentes ao uso e ocupação do solo. Tais conflitos requerem agilidade de suprir demandas por serviços de infraestrutura, incluindo-se, do fornecimento dos serviços de abastecimento de água e esgotamento sanitário (SAA\&ES).

Diante disso, cria-se um cenário que tem como resultado previsível a ocupação desordenada de áreas irregulares conhecidas como favelas ou invasões. Estas ocupações, muitas vezes, localizam-se em áreas de preservação permanente (APP), áreas de inundação, áreas de floresta, encostas íngremes, áreas de praia, manguezais, igarapés entre outras áreas menos propícias à urbanização, nomeados pelo Censo de 2010 de aglomerados subnormais ${ }^{3}$. Esta ocupação dos aglomerados subnormais foi

\footnotetext{
${ }^{1}$ Segregação residencial é o grau de aglomeração de um determinado grupo social/étnico em uma dada área. O termo segregação é tomado como sinônimo de desigualdade, exclusão e mesmo de pobreza (TORRES, 2004; SABATINI, 2001).

${ }^{2}$ Conforme o Censo 2000, 81\% dos brasileiros vivia em áreas urbanas, em 2010 esse índice passou a ser $84 \%$ da população (IBGE, 2012)

${ }^{3}$ O Censo 2010 classifica aglomerado subnormal como o conjunto constituído de, no mínimo, 51 unidades habitacionais carentes, muitas vezes, de serviços públicos essenciais, ocupando ou tendo ocupado, até período recente, terreno de propriedade alheia (pública ou particular) e estando dispostas, em ${ }^{2}$ Conforme o Censo 2000, 81\% dos brasileiros vivia em áreas urbanas, em 2010 esse índice passou a ser $84 \%$ da população (IBGE, 2012)

${ }^{3}$ O Censo 2010 classifica aglomerado subnormal como o conjunto constituído de, no mínimo, 51 unidades habitacionais carentes, muitas vezes, de serviços públicos essenciais, ocupando ou tendo ocupado, até período recente, terreno de propriedade alheia (pública ou particular) e estando dispostas, em geral, de forma desordenada e densa (IBGE, 2012).
} 
calculada em 6,0\% da população brasileira, totalizando 11,4 milhões de brasileiros que vivem desta maneira. Nestes aglomerados, 67,3\% dos domicílios possuem rede de coleta de esgoto ou fossa séptica e $88,3 \%$ são abastecidos por rede de água (IBGE, 2012).

Em comparação aos dados da população em geral (aglomerados subnormais, somado ao restante da população brasileira incluída no censo) observa-se que existe uma similaridade na porcentagem em relação ao esgotamento sanitário: 67,06\% tem rede de esgoto (IBGE, 2012). No entanto, em ambos os dados de aglomerados subnormais e população brasileira em geral, considera-se rede pluvial juntamente com rede de esgotamento sanitário, formato que deixa a desejar, devido à rede pluvial não ser um formato satisfatório e salubre de destinação do esgoto.

Em relação à rede de distribuição de água o valor é de $17,15 \%$ que não são servidos por rede de distribuição (IBGE, 2012), surpreendentemente maior que a falta do abastecimento nos aglomerados subnormais. Pode-se entender por meio destes indicadores, que nos aglomerados subnormais o atendimento aos SAA\&ES são proporcionalmente melhores que à população brasileira como um todo. Mas, será que estes estão conseguindo mostrar o que eles se propõem? Se a população dos aglomerados está sendo mais bem atendida, quem é a população que não está?

Entende-se nos casos supracitados que, talvez, os indicadores não estejam mostrando o que gostariam ou deveriam mostrar. Neles, por exemplo, a porcentagem de população que tem rede de esgoto, não necessariamente as utiliza, pois parte desta população não tem condições financeiras para o pagamento das tarifas. Do mesmo modo, a presença de rede de distribuição de água não significa necessariamente atendimento satisfatório, ele pode ocorrer de forma intermitente com quantidade e qualidade deficitárias (GALVÃO JÚNIOR, 2009).

Desta forma, inclui-se nesta discussão o conceito de acesso aos SAA\&ES. O acesso entendido como um conceito dinâmico que vem sendo alterado ao longo do tempo, devido a uma melhoria contínua que se desenvolve nos serviços. É um conceito que se transforma de acordo com os objetivos alcançados dos serviços. Em um primeiro momento, o acesso pode ser entendido como disponibilidade de rede de distribuição de 
água, em um segundo momento é possibilitar tarifas acessíveis aos que não usufruem de condições financeiras para pagar, em um terceiro momento o acesso ao abastecimento de água acontece sem interrupções e boa qualidade no atendimento (Figura 1). Vale destacar nesse conceito que, como é um conceito dinâmico, os indicadores devem acompanhar esta dinâmica, pois os indicadores que antes serviam para avaliar o aumento do acesso ao atendimento agora talvez não são válidos, precisam ser reformulados, incluindo o acesso com suas especificidades, utilizando indicadores mais finos, que atentem aos detalhes.

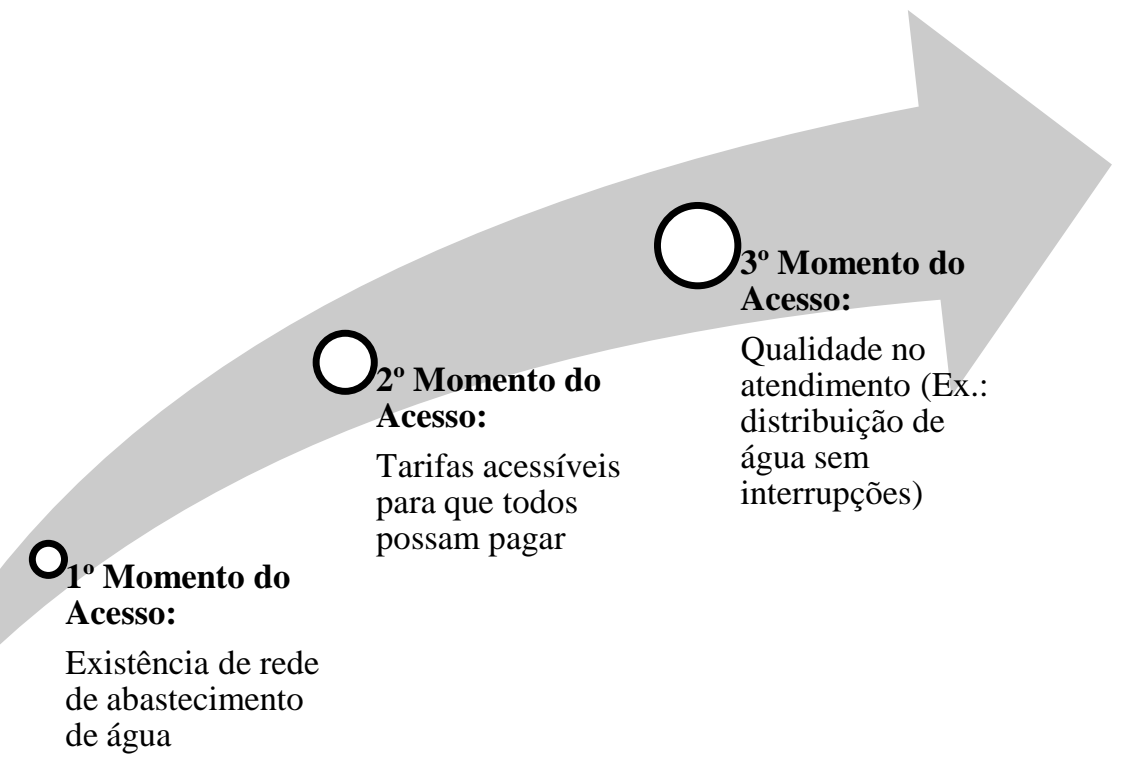

Figura 1. Representação de exemplo do conceito dinâmico de acesso aos SAA\&ES. Fonte: Elaboração própria

Ademais, 32,85\% da população brasileira sem os serviços de esgotamento sanitário, significa que, aproximadamente, 63 milhões de pessoas não desfrutam destes serviços (IBGE, 2012). A ausência de esgotamento sanitário pode ocasionar em despejos de esgotos em locais inadequados, proporcionando ambientes insalubres, contaminação em áreas de mananciais de abastecimento, comprometimento da saúde da população, assim como, sob visão das operadoras, pode onerar os sistemas e diminuir seu desempenho.

Em relação ao abastecimento de água, dos $17,15 \%$ da população que não possuem rede, $10,03 \%$ fazem uso de água de poço ou nascentes e 7,12\% utilizam outras formas de abastecimento (IBGE, 2012). A discrepância entre os serviços de água e 
esgoto estão associadas a um processo histórico dos SAA\&ES no Brasil. O modelo PLANASA, vigente no período de 1970 a 2002, estendeu os SAA\&ES para cerca de 70 milhões de pessoas, podendo ser considerado um dos modelos mais bem sucedidos neste quesito, porém observam-se disparidades no modelo (OGERA; PHILIPPI JR, 2005). Uma delas foi privilegiar o abastecimento de água em detrimento do esgotamento sanitário (HELLER, 2009).

Nota-se que os índices de abastecimento de água encontram-se em patamares mais elevados, mais próximos da universalização que os índices de esgotamento sanitário. No entanto, a universalização do abastecimento de água ainda representa um desafio, pois mesmo com substanciais investimentos, há uma grande dificuldade de aumentar índices de abastecimento de água (SNSA, 2010). Vale lembrar também que, historicamente os indicadores eram suficientes para suprir uma demanda de acompanhamento do crescimento dos serviços que o Modelo PLANASA conseguiu alcançar, para a situação atual percebe-se que estes indicadores não têm sido suficientes.

Após o modelo PLANASA, em 2003, foram promovidas significativas mudanças na estrutura política dos SAA\&ES, com a visão voltada à universalização, em especial aos setores mais desprivilegiados da população (HELLER, 2009). A universalização dos serviços consiste em estender a toda população, independentemente de contribuição financeira de determinada comunidade, o usufruto dos serviços apropriados às suas necessidades e à sua integralidade (MALHEIROS; COUTINHO; PHILIPPI JR, 2006). E conforme colocado por Heller (2009) a população menos atendida com os SAA\&ES, previsivelmente, são os com baixa renda, que vivem em situação de maior vulnerabilidade.

Desta forma, com o enfoque nos direitos humanos e na universalização dos SAA\&ES, em 2007, criou-se a Política Nacional de Saneamento Básico (Lei 11.445/07). Dentre outros aspectos, a Lei estabelece redefinições institucionais significativas, dando-se destaque à inserção da regulação nos acordos de concessão. Anterior à lei as operadoras se autoregulavam. Após o marco regulatório, foi necessária a criação de agências reguladoras, que fiscalizem as operadoras e apoiem tecnicamente as municipalidades. No Estado de São Paulo, local da presente pesquisa, institui-se a Agência Reguladora de Saneamento e Energia do Estado de São Paulo (ARSESP). 
Na prática, a delegação da regulação ocorre quando a municipalidade firma um convênio com a Agência Reguladora do Estado (ARSESP) ou com agência de regulação constituída pela própria municipalidade, ou mesmo com outros formatos de agência de regulação, por exemplo, em âmbito de um comitê de bacia hidrográfica, como no caso das bacias dos rios Piracicaba, Capivari e Jundiaí. Legalmente, somente depois de a municipalidade firmar um convênio e realizar o contrato de concessão dos serviços é que a agência reguladora pode atuar, realizando a fiscalização por meio de indicadores estabelecidos nos contratos. Os contratos são elaborados com duração em média de 2030 anos, estabelecendo delimitações de áreas urbanas, a depender de cada contrato de concessão. Este atendimento é fiscalizado pela reguladora por meio da população delimitada conforme estabelecidos no contrato da prestação dos serviços, e há casos em que estas delimitações não conseguem atingir a população total da localidade que necessitam dos serviços. Ou seja, pode acontecer, que algumas populações que habitam, por exemplo, loteamentos novos ou áreas irregulares, estejam sendo excluídas dos indicadores de atendimento. Deste modo, advertem-se possíveis lacunas nos contratos de concessão, assim como nos indicadores de cobertura utilizados, pois estes indicadores de cobertura de atendimento não refletem, necessariamente, a real cobertura que se está atingindo pela municipalidade.

Os SAA\&ES já possuem indicadores desenvolvidos e empregados historicamente para medição dos serviços. Há sistemas de indicadores como o Sistema Nacional de Informação do Saneamento (SNIS, desde 2002) contendo, aproximadamente, 84 indicadores e o Prêmio Nacional de Qualidade do Saneamento (PNQS, desde 2001) contendo 79 indicadores. Indicadores são rotineiramente empregados pelas reguladoras e operadoras para mensurar o desempenho dos SAA\&ES. Esta mensuração tem sido utilizada na diminuição de custos institucionais, melhoria do atendimento aos usuários e no monitoramento dos contratos de concessão. No entanto, eles não têm enfoque de visão integrada do sistema, focando-se, em geral, mais nos campos econômicos ou operacionais. Deste modo, nota-se que há lacunas quando estes indicadores destinam-se a medir e monitorar a universalização dos serviços, em especial, no contexto desta pesquisa, que tem como desafio o atendimento universal para populações em situação de vulnerabilidade social. Percebe-se que indicadores dos SAA\&ES voltados às populações vulneráveis não estão facilmente visíveis, eles 
necessitam abordar novas preocupações, auxiliando na identificação dos complexos interesses e relações.

É nesta perspectiva que surge a necessidade de indicadores e de um sistema que forneça informações sobre os rumos propostos e resultados esperados, entendendo o potencial de um adequado sistema de informações e indicadores de interface. Um sistema de indicadores possibilita aos reguladores, municipalidades, operadores e sociedade, a apropriação das informações relevantes dando maior credibilidade, transparência e aceitabilidade na gestão dos SAA\&ES. Ao mesmo tempo, estes indicadores possibilitam avaliar e pressionar políticas e ações no planejamento urbano, e a cooperação na viabilidade e gerenciamento dos SAA\&ES

Os indicadores têm como proposta observar as lacunas existentes, as quais ainda não são notadas nos sistemas de informação convencionalmente utilizados pelas operadoras. E para isto, é indispensável uma avaliação integrada que procure entender os processos institucionais, promovendo o entendimento das complexas relações existentes na realidade (MARZALL; ALMEIDA, 2000). E após realizar esta avaliação, pode-se comparar os resultados com outras empresas, permitindo o aprendizado com instituições de referência, desencadeando melhorias organizacionais. Esta prática é chamada de benchmarking (SLACK et al., 2002).

O uso da ferramenta de benchmarking nos SAA\&ES consiste em avaliar e melhorar o desempenho destes serviços. Apesar de existir estímulo ao uso da ferramenta, observa-se que os esforços centram-se na produtividade dos serviços, utilizando indicadores em relação ao desempenho, como: tarifas da água, produtividade do trabalho, custos operacionais, a cobertura do serviço na área de abastecimento designada, sem considerar o acesso e a qualidade às populações vulneráveis.

Incluir os serviços fornecidos às populações vulneráveis exige a escolha de tecnologias que beneficiem também os mais carentes, propiciando a acessibilidade às tarifas, taxas de conexão, subsídios, microcrédito, arranjos institucionais inovadores e que garanta a viabilidade financeira do serviço. Em todos estes aspectos da prestação de serviços, o benchmarking pode ser desenvolvido por meio de indicadores para medir o grau de prontidão desta prestação a estas populações (PROBE, 2009). Do mesmo modo, 
estes indicadores de benchmarking podem funcionar como mecanismo de divulgação pública da qualidade dos SAA\&ES, como também podem beneficiar tanto operadoras na escala do seu desempenho interno voltados ao atendimento às populações vulneráveis, como a instrumentalização de políticas públicas, por meio do regulador, incentivando e disseminando as boas práticas dos SAA\&ES voltadas às populações vulneráveis, e posteriormente, inclusão desses indicadores nos contratos de concessão e legislações.

Deste modo, o presente projeto de pesquisa tem como foco a proposição de indicadores em vista à utilização do benchmarking desses serviços, sendo formulada a seguinte pergunta de pesquisa: Quais são os indicadores que conseguem medir e avaliar a prestação de serviços de abastecimento de água e esgotamento sanitário às populações vulneráveis?

Para vencer este desafio, entre as diversas ações a serem implementadas, é fundamental a estruturação de um sistema de informações que possa mostrar e abranger as fragilidades e singularidades dessa situação e auxilie no processo de tomada de decisão dos SAA\&ES. É confiado à Agência Reguladora o papel importante de preencher, divulgar e disseminar os dados de melhoria dos sistemas. 


\section{OBJETIVOS}

\subsection{Objetivo Geral}

Propor indicadores de benchmarking dos sistemas de abastecimento de água e esgotamento sanitário destinados ao acesso e melhoria da qualidade dos serviços a populações vulneráveis no contexto do Estado de São Paulo.

\subsection{Objetivos específicos}

1. Identificar a utilização de benchmarking nos SAA\&ES e a maneira pela qual essa ferramenta pode auxiliar na melhoria desses serviços às populações vulneráveis

2. Identificar princípios de construção de indicadores que alinhem a visão de universalização

3. Entender e discutir a respeito do processo participativo na construção de indicadores no Estado de São Paulo

4. Caracterizar os fatores e interfaces dos SAA\&ES necessários para a melhoria dos serviços voltados às populações vulneráveis

5. Propor um modelo de indicadores dos SAA\&ES voltados às populações vulneráveis para ser utilizado pela Agência Reguladora do Estado de São Paulo 


\section{INSERÇÃO NO CONTEXTO DOS SAA\&ES}

Esse capítulo tem a finalidade de facilitar à pesquisa o entendimento do cenário no qual a temática está inserida. O mesmo encontra-se dividido em duas partes. A primeira parte refere-se à composição concisa da situação geral dos SAA\&ES no mundo, no Brasil e no Estado de São Paulo, e ainda como é realizada a administração e responsabilidades desses serviços no Estado de São Paulo, apresentando a legislação vigente a qual estabelece o marco regulatório e o controle social. Na segunda parte serão discutidos os termos populações pobres e populações vulneráveis, analisando e definindo o termo que melhor se adéqua à pesquisa, e, além disso, serão mostradas maneiras de mensuração.

Iniciando pelo subcapítulo onde será mostrado que, muito embora exista um crescimento no atendimento mundial aos SAA\&ES, ainda há populações excluídas deste acesso. No Brasil, há também esse cenário de crescimento no atendimento acompanhado de desigualdades. Esse panorama do estado dos SAA\&ES permite ver as diferenças entre as regiões e as especificidades existentes quando é tratada a temática. As desigualdades no atendimento estão tanto numa escala mundial e nacional como numa escala estadual e municipal.

\subsection{Situação dos serviços de abastecimento de água e esgotamento sanitário}

Foram adotados pelas Nações Unidas os Objetivos do Desenvolvimento do Milênio (ODM) no ano de 2000, impulsionando a erradicação da pobreza por meio da quantificação de metas a serem atingidas até 2015. Os ODM incluem metas específicas para a melhoria da cobertura dos serviços de água e esgotamento sanitário (metas 10 e 11), que consistem na redução pela metade do percentual de pessoas sem acesso a estes serviços.

Apesar do compromisso assumido pela comunidade internacional de atingir estas metas, o relatório do Joint Monitoring Programme (WHO; UNICEF, 2006) afirma que o mundo está no caminho certo para atingir ODM na meta relativa ao abastecimento de água potável, mas baseado nas tendências atuais, a meta relativa ao esgotamento sanitário não será atingida para mais de meio bilhão de pessoas. A situação em regiões 
ou países específicos pode ser muito diferente deste quadro geral. Por exemplo, na África Sub-Sahariana, no período 1990-2004 o número de pessoas sem acesso a água potável aumentou 23\% e o sem esgotamento sanitário aumentou mais de 30\% (WHO, 2006).

Do total da população mundial, existem aproximadamente 0,9 bilhões de pessoas sem acesso a água potável e 2,5 bilhões sem acesso ao esgotamento sanitário (WHO; UNICEF, 2008). Desta população mundial sem acesso aos serviços (correspondente a data de referência de 2008), habitam no Brasil 9,7 milhões de pessoas sem acesso ao fornecimento de água potável e 90,8 milhões de pessoas sem acesso ao esgotamento sanitário (SNSA, 2010).

Essa população sem acesso aos serviços apresenta-se distribuída geograficamente e economicamente de maneira distinta. As populações mais atingidas pela falta das situações corretas dos serviços são, previsivelmente, as de mais baixa renda. Estas geralmente moram em lugares periféricos onde a infraestrutura é precária ou inexistente (SNSA, 2008).

\subsubsection{Serviços de abastecimento de água e esgotamento sanitário no Mundo}

O relatório do Joint Monitoring Programme-JMP (WHO; UNICEF, 2008) mostra que $62 \%$ da população mundial utilizam sistemas de esgotamento sanitário, acima dos 54\% em 1990. Embora o relatório também confirme a situação de 2,4 bilhões de pessoas ainda estarão sem sistemas de esgotamento sanitário em 2015. O mesmo relatório também mostra que há vários países onde progresso significativo está sendo alcançado com relação à cobertura por sistemas de esgotamento sanitário. Nestes países, a proporção da população que teve acesso a estes serviços desde 1990 varia entre 27 e 68\%, mostrando que altos níveis de aceleração na ampliação destes serviços são possíveis.

África Sub-Sahariana, Ásia e Oceania, que em 2006 apresentavam coberturas de esgotamento sanitário de 31,33 e $52 \%$, respectivamente, representam as regiões geográficas que apresentam maior déficit. Em termos quantitativos, dos 2,5 bilhões de pessoas sem esgotamento sanitário em 2006, 1,1 milhões vivem na Ásia do Sul e 0,5 
bilhões na África Sub-Sahariana e os outros, principalmente no resto da Ásia (WHO; UNICEF, 2008).

No entanto, as estatísticas do $J M P$ mostram números relativos à cobertura da população total, mas não fornecem informações específicas sobre a situação das camadas desprivilegiadas da população. Para estes, a situação é ainda pior que a situação global nacional ou regional. Números disponíveis para diferentes quintis de riqueza numa base regional confirmam a desigualdade na distribuição do acesso a estes serviços. Por exemplo, no Sul e Sudeste Asiático, o quintil mais rico é quatro vezes mais propenso a ter acesso a serviços de esgotamento sanitário do que o quintil mais pobre, e uma vez e meia mais propenso a ter acesso a sistemas de abastecimento de água (WORLD BANK, 2004; WHO; UNICEF, 2008).

Confirmando este quadro, o Programa Unificado de Monitoramento (PRUM), da OMS/UNICEF que regularmente retrata a cobertura desses serviços, também considera que a expansão dos serviços de abastecimento de água e esgotamento sanitário está abaixo da faixa desejável. Praticamente aqueles que não são servidos por estes serviços estão em desvantagem, como as pessoas carentes vivendo em áreas urbanas e rurais nos países em desenvolvimento, particularmente na América Latina, Ásia e na África. Quando o PRUM consegue rastrear as alterações na cobertura de água potável e esgotamento sanitário nos diversos países que adotaram os ODM, não mede de qual modo essas mudanças afetam a provisão dos SAA\&ES para populações carentes. Além disso, as instituições doadoras não detêm conhecimento suficiente sobre quanto dos recursos financeiros provenientes dos ODM para melhoria dos SAA\&ES, realmente resultaram em benefício para as populações vivendo nestes bairros desprivilegiados (PROBE, 2009).

\subsubsection{Serviços de abastecimento de água e esgotamento sanitário no Brasil}

No Brasil, o atendimento dos SAA\&ES apresenta-se distribuído de maneira desigual nas regiões brasileiras. Cada região possui características físicas, culturais e econômicas próprias, e isso tem efeitos sobre o abastecimento de água e o esgotamento sanitário. Estados mais urbanizados como os da região Sudeste, possuem porcentagem de rede de distribuição de água mais elevados que Estados da região Norte e Nordeste, 
como pode ser observado na Tabela 1. Em relação à coleta de esgotos a discrepância é similar, como pode segue na Tabela 2 (IBGE, 2012).

Tabela 1 - População brasileira e distribuição da população nas regiões segundo Censo Demográfico 2010 e as formas de abastecimento de água no Brasil e nas regiões

\begin{tabular}{ccccccc}
\hline $\begin{array}{c}\text { Brasil e } \\
\text { Regiões }\end{array}$ & $\begin{array}{c}\text { Número de } \\
\text { Habitantes }\end{array}$ & $\begin{array}{c}\text { População } \\
\text { em área } \\
\text { urbana }\end{array}$ & $\begin{array}{c}\text { População } \\
\text { em área } \\
\text { rural }\end{array}$ & $\begin{array}{c}\text { Rede Geral } \\
\text { de } \\
\text { distribuição } \\
\text { de água }\end{array}$ & $\begin{array}{c}\text { Poço ou } \\
\text { nascente na } \\
\text { propriedade }\end{array}$ & Outros \\
\hline Brasil & 190.755 .799 & $84,4 \%$ & $15,6 \%$ & $82,85 \%$ & $10,03 \%$ & $7,12 \%$ \\
\hline Norte & 15.864 .454 & $73,5 \%$ & $26,5 \%$ & $54,48 \%$ & $31,59 \%$ & $6,61 \%$ \\
Nordeste & 53.081 .950 & $73,1 \%$ & $26,9 \%$ & $76,61 \%$ & $7,92 \%$ & $15,47 \%$ \\
Sudeste & 80.364 .410 & $92,9 \%$ & $7,1 \%$ & $90,28 \%$ & $6,76 \%$ & $2,95 \%$ \\
Sul & 27.386 .891 & $84,9 \%$ & $15,1 \%$ & $85,48 \%$ & $10,80 \%$ & $3,72 \%$ \\
Centro-Oeste & 14.058 .094 & $88,8 \%$ & $11,2 \%$ & $81,76 \%$ & $14,95 \%$ & $3,29 \%$ \\
\hline
\end{tabular}

Fonte: IBGE, 2012

Pode-se constatar, por meio dos dados, que em áreas menos urbanizadas, como a região Norte, o abastecimento de água é feito por poço ou nascente na propriedade, e se este abastecimento for feito dentro das especificações de boa qualidade de água, também pode ser considerada uma forma saudável e correta de abastecimento. $\mathrm{O}$ cuidado deve-se ao fato de locais com possíveis contaminações por vetores de doenças, por despejos de esgotos em locais próximos à coleta de água, ou mesmo contaminação química, dependendo da atividade humana no local.

Tabela 2 - Existência de banheiro ou sanitário e tipo de esgotamento sanitário no Brasil e regiões

\begin{tabular}{ccccc}
\hline \multirow{2}{*}{ Brasil e Regiões } & \multicolumn{2}{c}{ Com existência de banheiro ou sanitário } & $\begin{array}{c}\text { Sem existência de } \\
\text { banheiro ou } \\
\text { sanitário }\end{array}$ \\
\cline { 2 - 4 } & $\begin{array}{c}\text { Rede de esgoto ou } \\
\text { pluvial }\end{array}$ & Fossa séptica & Outros & $2,64 \%$ \\
\hline Brasil & $55,45 \%$ & $11,61 \%$ & $30,30 \%$ & $4,62 \%$ \\
Norte & $13,98 \%$ & $18,84 \%$ & $62,55 \%$ & $7,81 \%$ \\
Nordeste & $33,97 \%$ & $11,24 \%$ & $46,98 \%$ & $0,38 \%$ \\
Sudeste & $81,06 \%$ & $5,45 \%$ & $13,10 \%$ & $0,47 \%$ \\
Sul & $45,78 \%$ & $25,68 \%$ & $28,07 \%$ & $0,63 \%$ \\
Centro-Oeste & $38,38 \%$ & $13,15 \%$ & $47,84 \%$ & \\
\hline
\end{tabular}

Fonte: IBGE, 2012

A Tabela 2 mostra uma situação alarmante da realidade brasileira. Destaca-se que $7,81 \%$ da população do Nordeste não possuem banheiro ou sanitário, em comparação a outras regiões como Sul, Sudeste e Centro-Oeste, as quais as porcentagens de pessoas sem banheiro ou sanitário não chegam a somar $1 \%$. Isto permite notar as disparidades brasileiras, disparidade esta que pode ser vista também em relação à cobertura de rede de esgoto e fossa séptica nas regiões Norte, Nordeste e 
Centro Oeste em relação às regiões Sul e Sudeste. As Figuras 2 e 3 mostram algumas das situações ainda presentes na realidade brasileira.

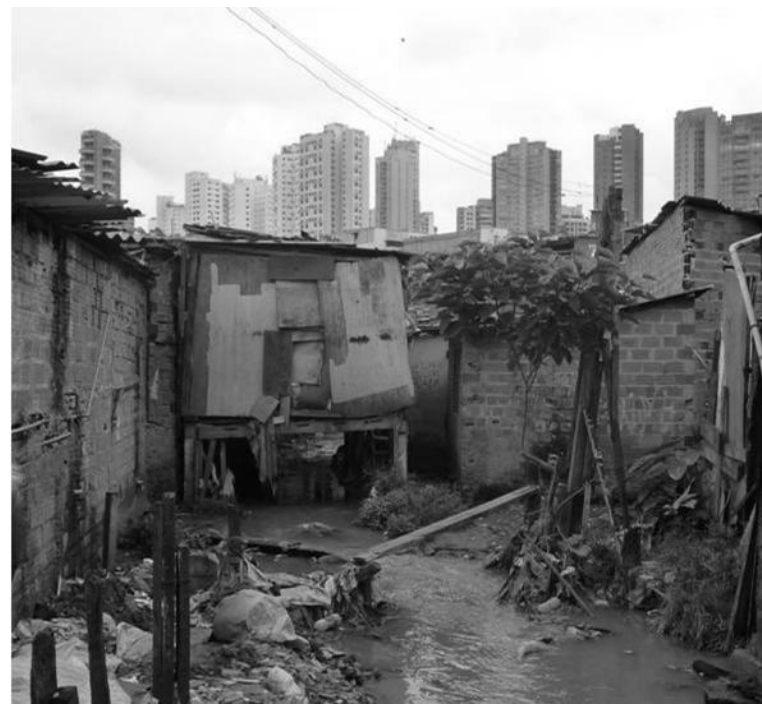

Figura 2. Exemplo de local sem acesso aos SAA\&ES e demais infraestruturas mínimas necessárias, município de São Paulo, Estado de São Paulo. Fonte: própria. Realizada em 28/05/2010.

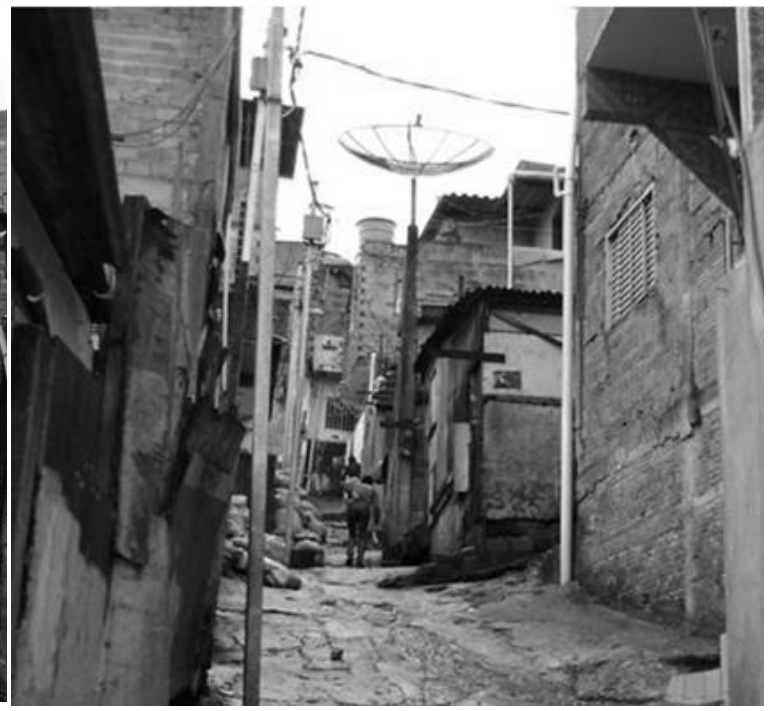

Figura 3. Visualização de exemplo de urbanização irregular em grandes centros com adensamento populacional e falta de infraestrutura, município de São Paulo, Estado de São Paulo. Fonte: própria. Realizada em 28/05/2010.

A situação dos SAA\&ES tem mostrado um crescimento significativo em relação a anos anteriores (SNSA, 2010). No entanto, esse crescimento no fornecimento dos serviços não tem atendido as expectativas do cumprimento da meta estabelecida num âmbito global, pela Organização das Nações Unidas, a qual o Brasil é signatário, de "Garantir a sustentabilidade ambiental", e diminuir pela metade (ano base 2000) o percentual das pessoas sem acesso à água potável e esgotamento sanitário até 2015 (UNITED NATIONS, 2008). Ou seja, embora haja esse crescimento gradual ao longo do tempo do fornecimento dos serviços, o Brasil ainda não tem conseguido atingir o propósito estabelecido pelos Objetivos do Desenvolvimento do Milênio (IPEA, 2010). Na Tabela 3 pode-se observar a situação brasileira no atendimento dos Objetivos do Desenvolvimento do Milênio (ODM), os quais ainda estão aquém das metas estabelecidas.

Em pesquisa realizada pela Secretaria Nacional de Saneamento Ambiental, calculou-se a probabilidade de cumprimento das Metas do Milênio, chegando aos seguintes resultados: a probabilidade de atingir a meta relacionada ao abastecimento de 
água é de 71,39\% e do cumprimento da meta relacionado aos serviços de esgotamento

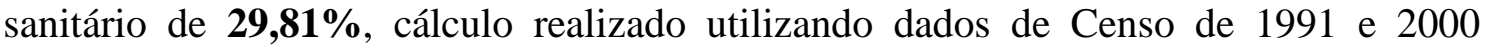
(SNSA, 2008).

Tabela 3 - Situação brasileira dos SAA\&ES em comparação às metas dos Objetivos do Desenvolvimento do Milênio (ODM), para os anos de 2000 e 2010

\begin{tabular}{cccc}
\hline & $\mathbf{2 0 0 0}$ & $\mathbf{2 0 1 0}$ & Meta ODM para 2015 \\
\hline $\begin{array}{c}\text { Rede Geral de } \\
\text { distribuição de água } \\
\begin{array}{c}\text { Rede de esgoto ou } \\
\text { pluvial e Fossa Séptica }\end{array}\end{array}$ & $77,82 \%$ & $82,85 \%$ & $88,91 \%$ \\
\hline
\end{tabular}

Fonte: Elaboração própria, calculado pelos dados fornecidos pelo IPEA (2010)

Apesar de ainda não ter atingido a meta estabelecida, o Brasil tem-se manifestado, tanto na sociedade como nas políticas públicas, o interesse em intensificar a melhoria desses serviços. Melhoria esta que deseja alcançar as metas do milênio e também ultrapassá-las, fornecendo os serviços para todos, a chamada universalização. Essa tendência da sociedade em exigir e trabalhar pela universalização podem ser notados por importantes eventos atuais do setor, como o congresso promovido pela Associação Brasileira de Engenharia Sanitária e Ambiental (ABES) em 2011, cujo tema central foi "Saneamento Ambiental: a excelência da gestão como caminho para a universalização" e também o Congresso Nacional de Saneamento e Ambiente, em 2012, cujo tema central será "Como prover saneamento para todos?", ambos possuem como tema central a universalização dos serviços.

\subsubsection{Serviços de abastecimento de água e esgotamento sanitário no Estado de} São Paulo

São Paulo é o Estado com a maior cobertura dos SAA\&ES. Em termos de abastecimento de água, possui 95,05\% dos habitantes com rede geral de distribuição, $3,62 \%$ utilizam poço ou nascente na propriedade e 1,32\% outro tipo de abastecimento. Em relação ao esgotamento sanitário, possui $86,73 \%$ de população atendida por rede de esgoto, $4,71 \%$ da população utilizando fossas sépticas e 8,56\% com outro tipo (IBGE, 2012). Isso deve-se tanto a intensa urbanização, pois São Paulo é o Estado brasileiro com o maior grau de urbanização $(95,9 \%)$ (IBGE, 2012).

O Estado possui especificidades por se tratar do maior adensamento populacional (41.262.199 habitantes) do Brasil (IBGE, 2012). Especificidades estas que 
fazem com que o Estado, apesar de ter uma porcentagem pequena de não atendimento aos SAA\&ES em comparação ao Brasil, continua sendo uma quantidade significativa de pessoas. Além disso, por ter atingido a uma quantidade de atendimento privilegiada em relação a outros Estados deve se atentar a outros objetivos de melhoria dos SAA\&ES, como por exemplo, a evidente necessidade de melhorar o tratamento de esgoto 47\% (SNSA, 2010), indicando ainda fragilidades no sistema em relação à qualidade sanitária a ser alcançada.

Além disso, cabe lembrar que essa porcentagem pequena da população do Estado de São Paulo que não possui acesso aos serviços, é a mais difícil em atendimento, pois trata-se de populações que ocupam em áreas irregulares, áreas de proteção ambiental, áreas de difícil fornecimento dos serviços, ou seja, para alcançar a universalização dos serviços será necessário sanar problemas relacionados a questão do crescimento crônico das cidades informais (Figuras 4 e 5), e incluindo condições desprivilegiada dessas populações de baixa renda, inclusive com impossibilidades de pagar pelos serviços.
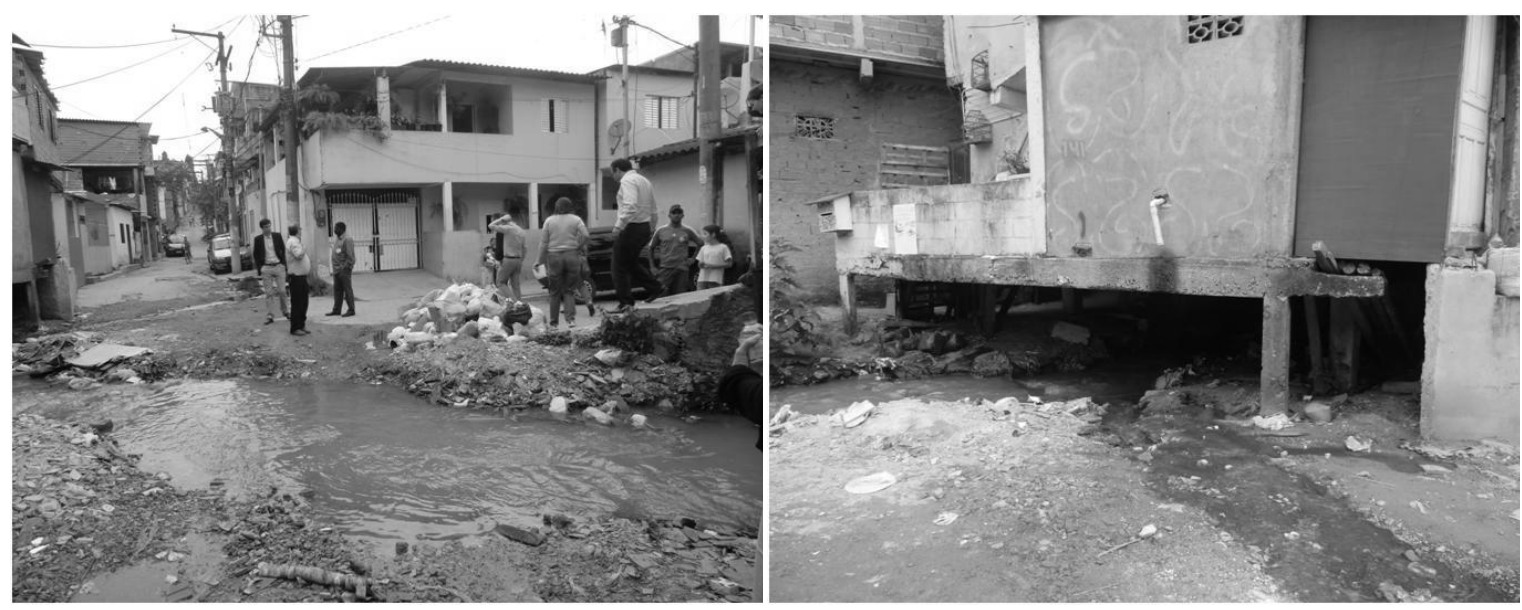

Figura 4. Situação de risco da população vivendo em exposição direta a esgotos. despejando esgoto diretamente no ambiente. Município de São Paulo, Estado de São Paulo. Município de São Paulo, Estado de São Paulo. Fonte: própria. Realizada em 06/12/2011. Fonte: própria. Realizada em 06/12/2011.

É indispensável salientar que o Estado goza de situação específica de atendimento a população aos SAA\&ES e essa realidade não pode ser equiparada a outros Estados sem o conhecimento das diferenças. 
Esse cenário dos SAA\&ES tem sido construído pelas amarrações dos aspectos administrativos, de planejamento, de distribuição de responsabilidades entre os atores e legislativos dos SAA\&ES. O próximo subcapítulo trata dos atores, dimensão das responsabilidades e determinações das legislações vigentes para compreender as interligações e complexidade existente no sistema.

\subsection{Atores e Funções dos serviços de abastecimento de água e esgotamento sanitário no Estado de São Paulo}

No Brasil, na Lei do Saneamento Básico (n $11.445 / 07)$ que institui as diretrizes básicas nacionais para o saneamento, define o saneamento básico como "conjunto de serviços, infraestruturas e instalações operacionais de abastecimento de água potável, esgotamento sanitário, limpeza urbana, manejo de resíduos sólidos e drenagem e manejo das águas pluviais". A partir da definição dessa lei foi ampliada a visão do saneamento restrita aos serviços de abastecimento de água e esgotamento sanitário, estabelecendo o saneamento básico como agente de promoção da saúde pública, proteção ambiental e melhoria da qualidade de vida. Para fins desta pesquisa, os serviços abrangerão somente abastecimento de água potável e esgotamento sanitário.

$\mathrm{Na}$ Lei Federal $\mathrm{n}^{\circ}$ 11.445/07, entre outros princípios contidos, foram introduzidas providências destinadas à ascensão da democratização do setor do saneamento básico, como (i) acesso a um ambiente saudável como um bem público; (ii) determinação do saneamento como um dever do estado; (iii) o estado é incumbido de fornecer saneamento básico como um serviço universal, com equidade; os serviços de saneamento básico constituem um integrado conjunto de atividades que precisam ser reguladas e submetidas ao planejamento e monitoramento; e (iv) a delegação dos serviços de saneamento básico deve ser submetida a orientações claras (HELLER, 2009). Além dos princípios de universalidade, integridade, controle e participação social.

Essa legislação tem criado condições de um novo estado de políticas brasileiras do saneamento básico com mudanças significativas para a prestação dos serviços de saneamento, dentre elas a separação das funções de planejamento, regulação e prestação dos serviços, assim como a separação dos atores que executam essas atividades. O 
planejamento ficou a cargo do município, a prestação dos serviços cabe ao ente público municipal ou a uma concessionária pública ou privada e a regulação e fiscalização deve ser executadas por entidade independente, com autonomia administrativa, financeira e decisória, e com capacitação técnica para esta finalidade (Figura 6) (ARSESP, 2010).

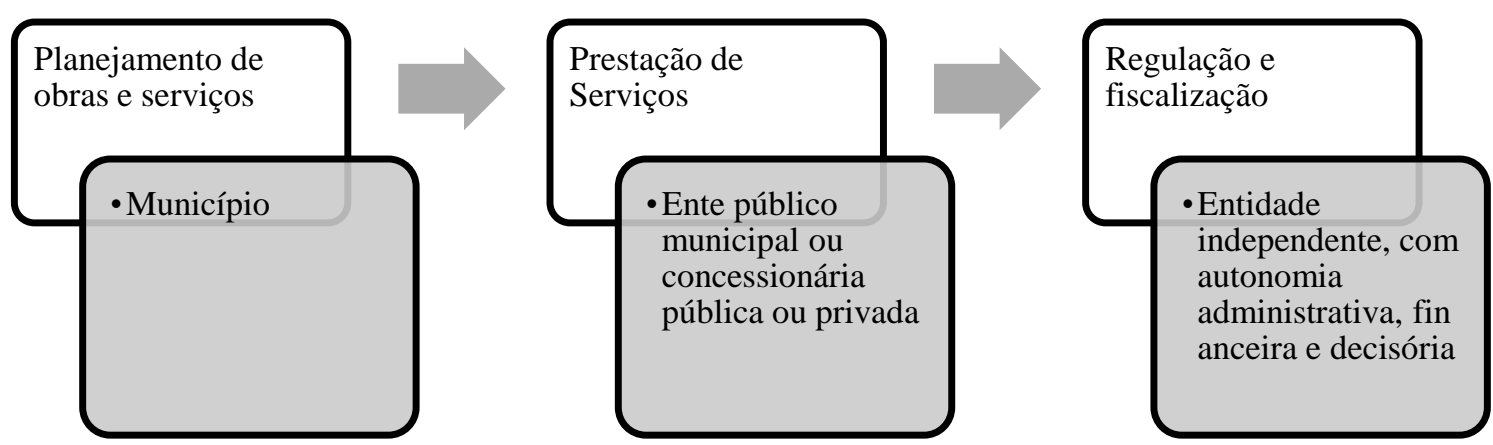

Figura 6. Representação das funções institucionais discriminadas na lei federal do saneamento básico

Para a prestação dos serviços de saneamento básico, a administração possui as seguintes alternativas (ARSESP, 2010, SNSA, 2011):

(i) Execução direta dos serviços por secretarias, departamentos ou outros órgãos da administração pública direta ou autarquias, que são entidade com personalidade jurídica de direito público, criada por lei específica, com patrimônio próprio, atribuições públicas específicas e capacidade de se auto administrar sob controle federal, estadual ou municipal;

(ii) Delegação da prestação dos serviços a um terceiro, que poderá ser:

(a) a uma empresa privada, que celebrará um contrato de concessão, ou seja, empresa com capital predominante ou integralmente privado, administrada exclusivamente por particulares; ou

b) a uma empresa estatal de outro ente federativo, que celebrará um contrato de programa. Pode ser uma sociedade de economia mista com administração pública ou uma empresa pública. A sociedade de economia mista com administração pública caracteriza-se como entidade paraestatal, criada por lei, com capital público e privado, gestão exclusivamente pública, com todos os dirigentes indicados pelo poder público. A empresa pública caracteriza-se como entidade paraestatal, criada por lei, com personalidade jurídica de direito 
privado, com capital exclusivamente público, de uma só ou de várias entidades, mas sempre capital público.

A Tabela 4 mostra como ocorre a distribuição dos operadores dos serviços de saneamento no Estado de São Paulo, referente à natureza jurídico-administrativa (SNSA, 2011).

Tabela 4 - Classificação distribuição dos municípios no Estado de São Paulo segunda a natureza jurídico-administrativa dos prestadores dos SAA\&ES em 2011.

\begin{tabular}{|c|c|c|}
\hline Natureza Jurídico administrativa & $\begin{array}{l}\text { Quantidade de } \\
\text { Municípios }\end{array}$ & $\begin{array}{c}\text { Porcentagem } \\
\text { no Estado (em } \\
n^{\circ} \text { de } \\
\text { municípios) }\end{array}$ \\
\hline $\begin{array}{l}\text { Sociedade de economia mista com administração pública } \\
\text { estadual (SABESP) }\end{array}$ & 363 & $56 \%$ \\
\hline Administração Pública Direta & 104 & $16 \%$ \\
\hline Autarquia & 76 & $12 \%$ \\
\hline Empresa Privada & 7 & $1 \%$ \\
\hline $\begin{array}{l}\text { Sociedade de economia mista com administração pública } \\
\text { municipal e Empresa pública }\end{array}$ & 6 & $1 \%$ \\
\hline Não participaram do levantamento de dados & 90 & $14 \%$ \\
\hline Número total de municípios no Estado de São Paulo & 645 & $100 \%$ \\
\hline
\end{tabular}

Fonte: SNSA, 2011

As diretrizes da política federal priorizam ações que promovam a equidade social e territorial no acesso ao saneamento básico, condições estas que se relacionam a problemática do saneamento com a problemática da vulnerabilidade das populações. A situação de vulnerabilidade das populações limita o acesso aos serviços, esse acesso entendido não apenas como as ligações de rede da população, mas do mesmo modo a possibilidade de pagamento das taxas estabelecidas pelas operadoras dos serviços.

Conforme exposto anteriormente, cabem às entidades diferentes o planejamento, a prestação de serviços e a regulação. A regulação e fiscalização deverão ser executadas por entidade autônoma e para atender a esta exigência no Estado de São Paulo foi criada a ARSESP - Agência Reguladora de Saneamento e Energia do Estado de São Paulo. A agência reguladora é foco da utilização dos indicadores que estão sendo propostos, pelo papel que desempenha, o qual está exposto conforme segue.

\subsection{Regulação dos serviços de abastecimento de água e esgotamento sanitário}

A função da agência reguladora, segundo a Associação Brasileira de Agências de Regulação - ABAR é a correção de falhas do mercado e do modelo. A reguladora, 
apesar de fazer parte do Estado, possui independência orçamentária, e deve ser diferenciada do poder executivo. Tem função ainda de buscar a equidade, concorrência saudável e justiça, com a postura de incentivar a sociedade a assumir maior protagonismo na busca de universalização dos serviços (FREITAS, 2009).

Vargas (2008) descreve os principais objetivos da atividade regulatória:

- Evitar ou coibir abuso de posição de mercado por parte de empresas monopolistas ou cartéis, impedindo a cobrança de tarifas exorbitantes;

- Evitar ou coibir práticas corporativistas (empreguismo, populismo tarifário, mordomias, etc.) entre os operadores públicos;

- Incentivar a eficiência produtiva e o desenvolvimento tecnológico;

- Assegurar o equilíbrio econômico-financeiro da atividade;

- Reduzir riscos e custos de transação, buscando manter o fluxo de investimentos públicos e privados no setor;

- Promover a universalização do acesso a serviços essenciais;

- Garantir a sustentabilidade sócio-econômica e ambiental da atividade.

Segundo a ARSESP (2011) a regulação tem a intenção de aumentar a economia de escala nos municípios, ou seja, auxiliar as operadoras na organização do processo produtivo, de maneira que baixem os custos de produção e desenvolvam os bens e serviços, assim como aumentar a economia de escopo, que é produzir os produtos e serviços juntamente, baixando os custos. O aumento dessas economias beneficia principalmente municípios de pequeno porte, pois estes não têm possibilidades de ter pessoal capacitado para essas atividades, uma vez delegada à entidade reguladora, o município tem o direito de usufruir da equipe técnica qualificada e empenhada na melhoria dos serviços de saneamento.

Outra função da regulação é o contato com a sociedade, na manutenção do diálogo, da ciência das necessidades e das reclamações dos usuários a respeito dos serviços que as operadoras estão prestando, assim como elaboração de instrumentos de regulação e fiscalização da qualidade e eficiência do prestador de serviços, emitindo relatórios de desempenho que funcionam como incentivadores para a melhora crescente dos serviços. (ARSESP, 2011). 
Os itens elencados acima, das funções da regulação, estão instituídos pela Lei Federal do Saneamento Básico ( $\mathrm{n}^{\mathrm{o}} 11.445 / 07$, Artigo 22) a qual estabelece que a regulação tem como objetivo:

(i) estabelecer padrões e normas para a adequada prestação dos serviços e para a satisfação dos usuários;

(ii) garantir o cumprimento das condições e metas estabelecidas;

(iii) prevenir e reprimir o abuso do poder econômico, ressalvada a competência dos órgãos integrantes do sistema nacional de defesa da concorrência;

(IV) definir tarifas que assegurem tanto o equilíbrio econômico e financeiro dos contratos como a modicidade tarifária, mediante mecanismos que induzam a eficiência e eficácia dos serviços e que permitam a apropriação social dos ganhos de produtividade.

Além disso, a Lei Federal (Artigo 23) institui à reguladora a função de editar os seguintes componentes:

I - padrões e indicadores de qualidade da prestação dos serviços;

II - requisitos operacionais e de manutenção dos sistemas;

III - as metas progressivas de expansão e de qualidade dos serviços e os respectivos prazos;

IV - regime, estrutura e níveis tarifários, bem como os procedimentos e prazos de sua fixação, reajuste e revisão;

V - medição, faturamento e cobrança de serviços;

VI - monitoramento dos custos;

VII - avaliação da eficiência e eficácia dos serviços prestados;

VIII - plano de contas e mecanismos de informação, auditoria e certificação;

IX - subsídios tarifários e não tarifários;

$\mathrm{X}$ - padrões de atendimento ao público e mecanismos de participação e informação;

XI - medidas de contingências e de emergências, inclusive racionamento.

Um componente importante na regulação, e estabelecido pela lei federal, é o controle social. O controle social é uma maneira dos processos decisórios dos serviços de água e esgoto serem mais transparentes e participativos. Possibilita que os usuários e o poder concedente exijam dos operadores a melhoria da qualidade dos serviços. 
Segundo Galvão Junior (2006) existem três tipos de instrumentos de controle social pela regulação: ouvidorias, audiências públicas e indicadores de desempenho.

As ouvidorias na regulação são responsáveis por receber, examinar e encaminhar as reclamações, denúncias, sugestões, elogios, críticas dos cidadãos, de instituições, agentes públicos, quanto aos serviços prestados, assegurando a participação da sociedade, a transparência, o conhecimento dos problemas pelas operadoras dos serviços de saneamento e como resultado, o aprimoramento da qualidade dos serviços e proteção e defesa dos usuários dos serviços públicos.

A audiência pública é um instrumento do diálogo entre sociedade e nesse caso a operadora dos serviços de saneamento, que tem como objetivo ouvir informações junto à sociedade, bem como oferecer aos interessados a oportunidade de encaminhamento de seus pleitos, opiniões e sugestões relativas ao assunto. É um espaço de abertura para que os cidadãos construam juntos soluções para problemas indicados pela própria comunidade (MINISTÉRIO PÚBLICO, 2011). O processo de audiência pública pode ser realizado através de sessões públicas presenciais, para a manifestação de viva voz, sessão não presencial, apenas com o envio das contribuições por meio eletrônico ou por documentos protocolados.

Galvão Junior (2006) descreve a importância da participação das partes interessadas no impacto direto na melhoria dos serviços, e esta feita com qualidade, de forma crítica, consciente e reflexiva. Ela ocorre através do entendimento dos indicadores de desempenho, pois os mesmos mostram a qualidade e eficiência dos serviços à população. Estes indicadores devem ser de fácil compreensão da população para que a mesma consiga acompanhar e decidir juntamente com o responsável de realização dos serviços. Mas, como deixar os indicadores acessíveis a todos os tipos de populações? O autor expõe que é necessário manter os canais de comunicação abertos, além disso, as agências reguladoras podem capacitar agentes replicadores do conhecimento da situação sanitária, que entendam as informações utilizadas, oficinas de capacitação, distribuição de cartilhas dos indicadores, entre outros, os quais forem necessários para a compreensão do receptor. 
Desde modo, tanto o controle social a ser desempenhado pela reguladora, como as demais atividades a serem desenvolvidas pelos atores dos SAA\&ES supracitados são necessárias na resolução da problemática complexa da melhoria dos serviços. Deste modo, o engajamento dos atores e entendimento das relações e responsabilidades existentes entre eles mostra-se raiz quando relacionada à aplicação de indicadores e à ferramenta de benchmarking.

\subsubsection{Considerações}

O destaque dado à regulação nestes subcapítulos deve-se ao fato de que a utilização dos indicadores será mais bem aplicada e valorizada se seguirem os princípios o qual a reguladora foi criada, de controle social, equidade e monitoramento das prestadoras de serviços. E, além disso, o aspecto monopolista do setor requer ajustes de conduta e correções do mercado, o que também é responsabilidade da regulação.

Os indicadores foram desenvolvidos com o foco de utilização pela Agência Reguladora de Saneamento do Estado de São Paulo - ARSESP. Devem ser utilizados, em um primeiro momento, com o objetivo de mostrar e incentivar boas práticas do setor e lacunas ainda por serem resolvidas. Isto caracteriza o perfil de benchmarking como indução da competição entre concessionárias. Em um segundo momento deve ser utilizado na inserção de exigências em contratos de concessão, e finalmente, serem incluídos em exigências sob a forma de leis.

A proposta de utilização dos indicadores pela reguladora e a parceria com a reguladora faz-se necessária devido à visão geral e imparcial que esse ator deve possuir, visando o equilíbrio de interesse entre diferentes atores. Os demais atores predominantemente focados aos próprios interesses, a exemplo disso, observam-se as concessionárias com veemência dos interesses nos aspectos da eficiência econômica e usuários com o interesse na qualidade dos serviços. O regulador dispõe do papel de analisar estes diferentes atores, os diversos interesses intrínsecos e tentar realizar o equilíbrio desses.

Apesar da reguladora ser um importante ator na melhoria dos SAA\&ES, a regulação dos SAA\&ES no Estado de São Paulo foi só recentemente constituída (há 2 
anos) o que ainda requer cuidados a respeito do desenvolvimento da força de ação nos processos de tomada de decisão. Esse é um contexto importante quando é tratada a inserção de indicadores direcionados ao atendimento às populações vulneráveis nesse sistema.

Além do contexto regulatório e administrativo dos SAA\&ES, é necessário definir qual tipo de população é que está sendo classificada como populações vulneráveis, qual a definição dessa terminologia? Neste intuito, o próximo subcapítulo oferta contribuições a respeito da temática.

\subsection{Populações pobres ou populações vulneráveis?}

A pesquisa iniciou com a denominação das populações como pobres. Esta denominação foi dada pelo projeto internacional PROBE. Ao longo da pesquisa bibliográfica constatou-se que o termo era insuficiente para definir as pessoas as quais o projeto se remete. No entanto, não existe uma denominação a qual haja consenso, existe uma diversidade de denominações (pobres, situação de pobreza, população de baixa renda, populações vulneráveis) e para cada denominação uma forma diferenciada de pensar a pobreza/vulnerabilidade. Desse modo, colocou-se a pergunta de que população está sendo tratada? Qual a melhor denominação, se tratando desse caso específico dos SAA\&ES?

Diante destes questionamentos foi vista a necessidade de conceituação e definição da melhor denominação a ser utilizada na presente pesquisa, pois nos SAA\&ES no Estado de São Paulo não foram encontradas maneiras específicas de classificação, cada municipalidade tem a sua maneira de classificar. Assim, foram pesquisadas formas de definir e medir a pobreza/vulnerabilidade da população, e conseguintemente, pôde-se ampliar o conhecimento a respeito da temática, e observar que ainda é uma temática que necessita de estudos e aprofundamento de conhecimento. Nesse subcapítulo pôde-se aprender a respeito do tema e escolher o termo que se adéqua ao presente trabalho.

Inicialmente, as denominações e conceitos a respeito desta temática estão relacionados às diferentes maneiras e utilidades dessas classificações. Por isso, para 
chegar as utilizações práticas, pesquisou-se quais são os instrumentos utilizados na classificação dessas populações. A renda per capita da população é um dos instrumentos mais conhecidos mundialmente para classificar as populações de acordo com o que pode se chamar de grau de pobreza: Pobreza absoluta e pobreza extrema. São definidas faixas de rendimento médio domiciliar per capita, no Brasil esse rendimento é de até meio salário mínimo mensal é considerado pobreza absoluta e de até um quarto de salário mínimo mensal é considerado pobreza extrema (IPEA, 2011). O governo do Estado de São Paulo, por meio da Secretaria Estadual de Assistência e Desenvolvimento Social (resolução ${ }^{\circ}$ 010) também considera família em situação de pobreza aquela com renda mensal familiar per capita de até meio salário mínimo nacional, ou seja, $\mathrm{R} \$$ $273,00^{4}$.

Outra maneira de medir e caracterizar a pobreza são a paridade de poder de compra (PPC), adotada pelas Organizações das Nações Unidas para estimativas de pobreza global em 2009 e usada no Relatório Global de Acompanhamento dos Objetivos do Milênio em 2010, a linha da pobreza internacional é de US\$ PPC 1,25/dia por pessoa (IPEA, 2010). O fator de paridade de compra é empregado para converter a unidade monetária dos países para Dólar dos Estados Unidos. Expressa quantas unidades monetárias locais são necessárias para comprar em um país o que seria comprado nos Estados Unidos por US\$ 1. O PPC brasileiro foi estimado em 1,57, o que significa que em 2005 seriam necessários $\mathrm{R}$ 1,57 para comprar no Brasil o mesmo que se comprava nos Estados Unidos com US\$1. A atualização do PPC para os outros anos é feita pela razão entre a inflação média anual no país e a inflação média anual nos Estados Unidos, medidas por índices nacionais de preços ao consumidor (PNUD, 2010; IPEA, 2010).

A pobreza, nos casos acima relatados, é definida pela insuficiência de renda para satisfazer as necessidades básicas. As necessidades básicas da família brasileira são estabelecidas pelo consumo, e segundo Barros, Henriques e Mendonça (2000), incluem a dimensão das condições habitacionais. Assim, nessa definição a consumo concentra-se

\footnotetext{
${ }^{4}$ Valor estimado em janeiro de 2012, por meio de consulta ao site do Ministério do Trabalho
} 
na alimentação, vestuário, transporte, higiene, assistência a saúde, educação, recreação e cultura, fumo, despesas pessoais e despesas diversas, e as condições de habitação, podendo ser chamado também como infraestrutura urbana, se concentram em abastecimento de água, esgotamento sanitário, coleta de lixo, calçamento e asfaltamento (BARROS, HENRIQUES, MENDONÇA, 2000).

Em outro tipo de análise da pobreza no Brasil, foram classificadas diferentes situações de pobreza por Kageyama e Hoffmann (2006), incluindo na medida tradicional, baseada na renda e outros aspectos relativos ao bem-estar $\mathrm{e}$ desenvolvimento social. Classificaram as situações de pobreza em três grupos: (i) essencialmente insuficiência de renda - pobre tipo I; (ii) falta de acesso a pelo menos dois de três equipamentos básicos (água canalizada, banheiro e luz elétrica) - pobre tipo II; e, (iii) baixa renda combinada com a ausência dos três equipamentos básicos extremamente pobre. Descrevem que a pobreza "refere-se a algum tipo de privação, que pode ser somente material ou incluir elementos de ordem cultural e social, em face dos recursos disponíveis de uma pessoa ou família." (KAGEYAMA; HOFFMANN, 2006, p. 80). Esta definição, similar à definição anterior, inclui a dimensão da renda e as condições habitacionais.

Outra classificação foi feita pela Inglaterra, no centro de pesquisas em Pobreza e Desenvolvimento Humano (The Oxford Poverty and Human Development Initiative OPHI), o Índice de Pobreza Multidimensional (MPI, sigla em inglês). Esse índice considera o acesso da população a dez itens relacionados à saúde, à educação e ao padrão de vida, ou seja, a definição inclui outras dimensões. O MPI considera pobres aqueles que têm privações em três ou mais dos dez itens. O índice mostra que no mundo, a pobreza abrange 1,7 bilhão de pessoas, 400 milhões a mais do que na medição da pobreza absoluta pelos critérios do Banco Mundial (OPHI, 2010).

Ferreira, Dini e Ferreira (2006) estão de acordo que a situação de pobreza é mais bem caracterizada quando não se resume apenas a renda que a pessoa recebe, pois notase diferenciação entre pessoas que recebem a mesma quantidade, contudo possuem acesso aos serviços essenciais (além dos serviços habitacionais, serviços de educação, saúde), possibilitando condições elevadas de sair do estado em que se encontram. Assim, no trato da situação de pobreza, é necessário considerar a complexidade de 
relações de carências e a mensuração da pobreza também exige a consideração dessa complexidade existente à temática.

Por isso, foi incorporada à discussão a concepção de vulnerabilidade, entendida como uma combinação de fatores que possam produzir uma deterioração do bem-estar pela exposição a determinados tipos de riscos, comprometendo planos distintos deste termo. Esse enfoque incorpora ao conceito de pobreza as condições de vida: a dimensão espacial e as dimensões subjetivas que interferem no nível de bem-estar dos indivíduos (FERREIRA; DINI; FERREIRA, 2006).

A precariedade do saneamento, saúde, moradia, renda, educação, trabalho, é o que constitui a somatória de privações e caracteriza de vulnerabilidade de populações. Estas privações influenciam a capacidade do indivíduo ou grupo social mudar a realidade em que se encontra (SEADE, 2010). Famílias com a mesma renda, mas com condições de saneamento, educação e trabalho melhores, podem ter potenciais diferenciados de transformação da realidade vivenciada (FERREIRA; DINI; FERREIRA, 2006). Na tentativa de melhorias das condições de vida de populações vulneráveis, é necessária a aplicação de ações que mudem este contexto de desigualdades.

As diferenças entre pobreza e vulnerabilidade estão relacionadas ao fato de que a pobreza é medida de forma estática, a vulnerabilidade é medida de forma dinâmica. A vulnerabilidade é um conceito utilizado devido às incertezas que são causadas por eventos e pela ausência de gerenciamento. Ribas (2007) expõe que existe uma transitoriedade na situação de pobreza, classificando como pobres crônicos e pobres transitórios. Assim famílias que não são pobres, podem estar vulneráveis à pobreza.

A vulnerabilidade é descrito como um conceito relevando a análise de bem estar da população. Valendo-se de Ribas (2007, p. 300):

(A vulnerabilidade) se refere à relação entre pobreza, risco e esforços para o gerenciamento desse risco. Vulnerabilidade é, consensualmente, definida como a perda de bem-estar causada pela incerteza de eventos. Em termos de análise, vulnerabilidade pode ser decomposta em componentes de uma chamada "cadeia de risco": risco ou incerteza de 
eventos; opções de gerenciamento ou respostas ao risco; e resultados em termos de perda de bem-estar.

Ribas (2007) descreve a importância de não focar políticas públicas apenas em indivíduos que estão na pobreza, mas em indivíduos que, devido a algum acontecimento, podem chegar a pobreza, como por exemplo a perda de um emprego, um acidente, e estão sujeitas às privações futuras, até mesmo eventos relacionados às mudanças climáticas.

Do mesmo modo, o Banco Mundial (2001) define a vulnerabilidade como a perda de bem estar, causada pela incerteza de eventos, associados a ausência de instrumentos apropriados para gerenciá-la. Confluindo também com a definição utilizada por Busso (2001), que é a definição adotada pelo Estado de São Paulo:

[...] risco ou probabilidade do individuo, família ou comunidade ser lesionada, afetado ou atingido perante mudanças ou permanência de situações externas e/ou internas. A vulnerabilidade social se expressa de várias formas, pode ser como a fragilidade diante de mudanças do entorno, debilidade interna para enfrentar concretamente as mudanças necessárias do individuo ou família, como insegurança permanente que paralisa, incapacita e desmotiva a possibilidade de pensar estratégias e atuar para no futuro alcançar melhores níveis de bem-estar. (p.8)

Utilizar o termo vulnerabilidade abrange a pobreza e outros aspectos que quando usado o termo pobreza não são relacionados. A pobreza e vulnerabilidade não são as mesmas coisas, mas estão relacionadas. A identificação da vulnerabilidade é mais complexa que da pobreza por renda, pois a vulnerabilidade depende das pressões e choques que as pessoas estão expostas. Indivíduos considerados pobres hoje podem não ser pobres amanhã, e indivíduos que não são pobres, mas são vulneráveis, dependendo das situações e adversidades sofridas, estão sujeitos a serem pobres (RIBAS, 2007).

É utilizado pelos autores Ferreira, Dini e Ferreira (2006) o termo vulnerabilidade social. Neste trabalho o termo utilizado será apenas vulnerabilidade, entendendo que a mesma abrange a vulnerabilidade social, ambiental e econômica, e também por ser uma nomenclatura que Ribas (2007) e o Banco Mundial (2001) utilizam para se referir ao mesmo significado. 
Ao mesmo tempo, o conceito de vulnerabilidade tem sua importância por causa da volatilidade de renda entre os mais pobres. Existe o que é chamado de pobreza transitória, que é a oscilação de renda que o indivíduo ou família recebe ao longo do tempo, que pode variar, fazendo passar por situações de pobreza e situações em que sai da situação de pobreza em um período de tempo de meses; há também a chamada pobreza crônica, que é quando o indivíduo ou família mantém constante a situação de pobreza. O exemplo disso, pesquisas de indivíduos que residiam em famílias pobres em 2005, 31\% não eram mais pobres um mês depois e 50\% não o eram um ano depois. No intervalo de um mês, quase $12 \%$ da população entraram ou saíram da pobreza, já entre 2005 e 2006 mais de 15\% da população trocaram de posição. Então, se considerar este número de pessoas que foram pobres, ao menos uma vez em dois meses, a taxa de vulnerabilidade à pobreza foi em torno de $30 \%$ maior que a taxa de pobreza observada em um único mês. Utilizando-se um período de 12 meses e o mesmo critério, essa taxa de vulnerabilidade é, ao menos, $40 \%$ maior que a taxa de pobreza observada em um único mês (SOARES; RIBAS; SOARES, 2009).

O número de pessoas que estão sujeitas à vulnerabilidade é maior do que as que se encontram na linha da pobreza, pois estas não são as mesmas pessoas. Há uma oscilação entre as pessoas que estão abaixo da linha da pobreza, que dependendo de alguma situação sai, mas tem chance de voltar. Ou mesmo pessoas que não estão nesse momento na linha de pobreza, mas que já estiverem e que em um futuro poderão estar novamente. Como mostrado por Soares, Ribas e Soares (2009), a taxa de retorno à situação de pobreza é alta. Em 2005, 46\% das pessoas que saíram da pobreza retornaram um mês depois e outros $14 \%$, em dois meses e $51 \%$ das pessoas que entraram na pobreza saíram desta situação um mês depois. Como descrito pelos autores, muitas famílias cruzam a linha da pobreza com frequência em uma ou outra direção, de acordo com os acontecimentos de sua vida.

A vulnerabilidade não deve ter uma visão essencialmente negativa, pois ela reside na constituição dos espaços, na vida das pessoas, nos grupos sociais, precisando ser entendida como processo e outros conceitos como risco, perigo, resiliência, adaptação, desastres, fragilidade permitem auxiliar o entendimento da vulnerabilidade, assim "Cada um destes termos nos permite ver facetas e momentos específicos da 
vulnerabilidade, e por isso precisam ser tomados em conjunto para que possamos ir em direção a uma ideia abrangente da vulnerabilidade.” (MARANDOLA JR.; 2011, p. 18).

Visto a importância de considerar uma avaliação multifacetada, a Fundação Sistema Nacional de Análise de Dados (SEADE) criou o Índice Paulista de Vulnerabilidade Social (IPVS), que caracteriza a vulnerabilidade à pobreza. Considera a privação de renda, composição familiar, condições de saúde, acesso aos serviços médicos, acesso e a qualidade do sistema educacional, possibilidade de obter trabalho com qualidade e remuneração adequadas e a existência de garantias legais e políticas (SEADE, 2010). O IPVS permite uma visão detalhada das condições de vida da população residentes em todos os municípios do Estado de São Paulo, com a identificação e localização espacial das áreas que abrigam os segmentos mais vulneráveis à pobreza (FERREIRA; DINI; FERREIRA, 2006).

Esse índice foi criado considerando o processo de crescimento do país, concentrador, excludente e produtor da fragmentação do espaço urbano. Caracteriza-se pela segregação acentuada entre as concentrações de pobreza extrema e as porções dos territórios ocupados pelos segmentos sociais com elevado padrão de vida (SEADE, 2010). Pois a vulnerabilidade tem relação direta com o uso e ocupação do solo. Os indivíduos ocupam os territórios de acordo com o poder de escolha e as oportunidades, não residem em locais com risco de desmoronamento, como encostas de moro, em locais onde não possuem infraestrutura de abastecimento de água e esgotamento sanitário.

Por isso, a seguridade maior é significativa na vida dessas pessoas, e nesse contexto entra a funcionalidade dos SAA\&ES. Indivíduos expostos a situações de falta dos SAA\&ES e ambientes degradados estão mais vulneráveis às doenças e depois destas doenças, suas capacidades de trabalho podem diminuir e aumentar o risco em relação à vida desse indivíduo, mostrando a importância de políticas voltadas não somente aos pobres, mas a melhor qualidade sanitária, ambiental e social.

No setor dos SAA\&ES, alguns municípios possuem seus próprios métodos de mapeamento da pobreza, com estudos específicos da região, e já utiliza dessa metodologia para escolher áreas prioritárias para a implantação de esgotamento 
sanitário e abastecimento de água esgotos, o que permite a utilização de dados mais detalhados para atendimento de uma população ou mesmo regiões mais vulneráveis. $\mathrm{O}$ mapeamento detalhado requer mais informações e dados, e consequentemente mais demorado de ser realizado. Em vista disto, ressaltando a importância, ao mesmo tempo, de ter mecanismo mais imediatos de analisar quem são as pessoas necessitadas de auxílio, como é utilizada em alguns municípios com renda familiar, consumo de energia elétrica e tamanho da residência.

\subsection{Considerações acerca do contexto exposto}

A contextualização da situação dos SAA\&ES e as denominações de populações vulneráveis permitem elencar a complexidade de variáveis envolvidas na problemática do setor e fazer conexões, traçando linhas que ligam diferentes informações, formando uma rede, a qual mostra um panorama geral do sistema. Com a exemplificação da diversidade de informações de indicadores de abastecimento de água e esgotamento sanitário utilizados no contexto mundial, federativo e estadual, as legislações existentes, concepções administrativas, definição de populações vulneráveis.

$\mathrm{Na}$ sequência, foi possível organizar estas informações e sistematizá-las. Aproximando o pesquisador, cada vez mais, do objeto de estudo. Esta contextualização está longe da competência de dar respostas à complexidade do problema que foi apresentado, e está próxima de introduzir a pesquisa à dinâmica do setor, elencando os aspectos-chave e as particularidades para seu entendimento. Além disso, ao longo da contextualização foram feitos questionamentos com o caráter de incitar o pesquisador à problemática que se quer responder. Sabendo-se que não poderão ser respondidas todas as perguntas por meio dessa pesquisa, mas os questionamentos possibilitaram aprofundar e refletir os estudos.

É evidente que há significantes estudos e dados no setor, como também há uma indispensabilidade de colocá-los de forma mais simples e clara de ser visualizável mais facilmente pelos gestores que necessitam de instrumentos dinâmicos de gestão.

O mapeamento dos gestores do setor dos SAA\&ES e o entendimento das forças que dirigem o setor, assim como a verificação das leis vigentes, que distribuem as 
responsabilidades e permitiu visualizar os papéis e as funções destes atores no setor. Notou-se a importante função do regulador, de corrigir as falhas do mercado e de trabalhar equilibrando os interesses entre operador, municipalidade e usuário, e ao mesmo tempo, o desafio da regulação de operadores que historicamente se autoregulavam. Ou seja, a regulação é um passo novo na historia dos SAA\&ES, isso trás tanto a oportunidade de melhorias, como também dificuldades iniciais de quem nunca foi regulado ser regulado agora, e cumprir com a necessidade de sanar falhas do mercado.

A Lei Federal 11.445/07 trouxe o marco regulatório que transformou a dinâmica de gestão do setor, colocando metas de universalização e uma visão social fortemente embutida pelo caráter de priorização de atendimento aos mais necessitados e também de estabelecer processos decisórios participativos. As metas de universalização dos serviços são estabelecidas por lei, mas o formato e a maneira de atingi-la são emergentes no setor. Ressalta-se, deste modo, a consonância de interesses com o objetivo da pesquisa desenvolvida, e, inclusive, mostra a relevância e necessidade da pesquisa.

Para alcançar a universalização, sabe-se que o foco deve ser dado ao atendimento às populações vulneráveis, isto é, aos grupos desfavorecidos. E do mesmo modo, colaborar com a promoção do desenvolvimento humano. O relatório do Programa de Desenvolvimento das Nações Unidas (UNDP, 2011) reforça que investimentos que melhorem a equidade no acesso ao abastecimento de água e esgotamento sanitário possibilitam avançar o desenvolvimento humano.

Pode-se verificar que há dados e ações no sentido da universalização, e ainda, um histórico desenvolvido no setor dos SAA\&ES. Isto é, já existem estudos, definições e um fórum acerca dos temas estudados. No entanto, informações sistematizadas que relacionem abastecimento de água e esgotamento sanitário com a vulnerabilidade das populações e a gestão do setor mostra-se ainda como um campo a ser consolidado. 


\section{METODOLOGIA}

A escolha da metodologia foi feita valendo-se de experiências metodológicas de diversas fontes, e principalmente, de autores com experiências metodológicas em processos de criação de indicadores. A metodologia foi dividida em etapas, para melhor visualização, e dentro dessas etapas existem os passos metodológicos que estão numerados no esquema apresentado na Figura 7. Cada etapa e cada passo da pesquisa estão mais bem explicados e detalhados ao longo da escrita da metodologia. Inicialmente apresenta-se o esquema para que o leitor ambiente-se com a estrutura metodológica, por meio de uma breve explicação introdutória da metodologia para depois aprofundar a explicação.

A metodologia constitui-se de quatro etapas elaboradas por meio de influências metodológicas desenvolvidas por Quivy e Campenhoudt (1998), e também pelas metodologias de construção de indicadores desenvolvidas por Quiroga ${ }^{5}$ (2005) e Reed et al. (2006). As etapas dividem-se em: (1) Contextualização e estratégias de ação; (2) Estruturação teórica e engajamento dos atores; (3) Identificação, avaliação e seleção dos indicadores; e (4) Coleta de dados e análise. Subdividindo-se nos seguintes passos metodológicos: a Etapa 1 constitui-se pela identificação dos atores (1), a realização de reuniões com parceiros e visitas a campo (2) e a Contextualização institucional dos SAA\&ES (3); a Etapa 2 consistiu-se na revisão bibliográfica dos fatores de melhoria dos SAA\&ES às populações vulneráveis (4), reuniões de aproximação (5), elaboração do modelo teórico (6) e a elaboração do material utilizado durante as oficinas (7); a Etapa 3 consistiu-se na avaliação e validação participativa do modelo (8), elaboração e validação participativa dos indicadores (9) e análise da qualidade dos indicadores (10); e a Etapa 4 consistiu-se na coleta e preenchimento de dados (11), análise dos indicadores (12) e sugestões de melhoria do processo (13). O desenvolvimento das etapas está representado no fluxograma apresentado na Figura 7.

5 QUIROGA, R. Workshop de Desenvolvimento de Indicadores de Desenvolvimento Sustentável, 2005. 


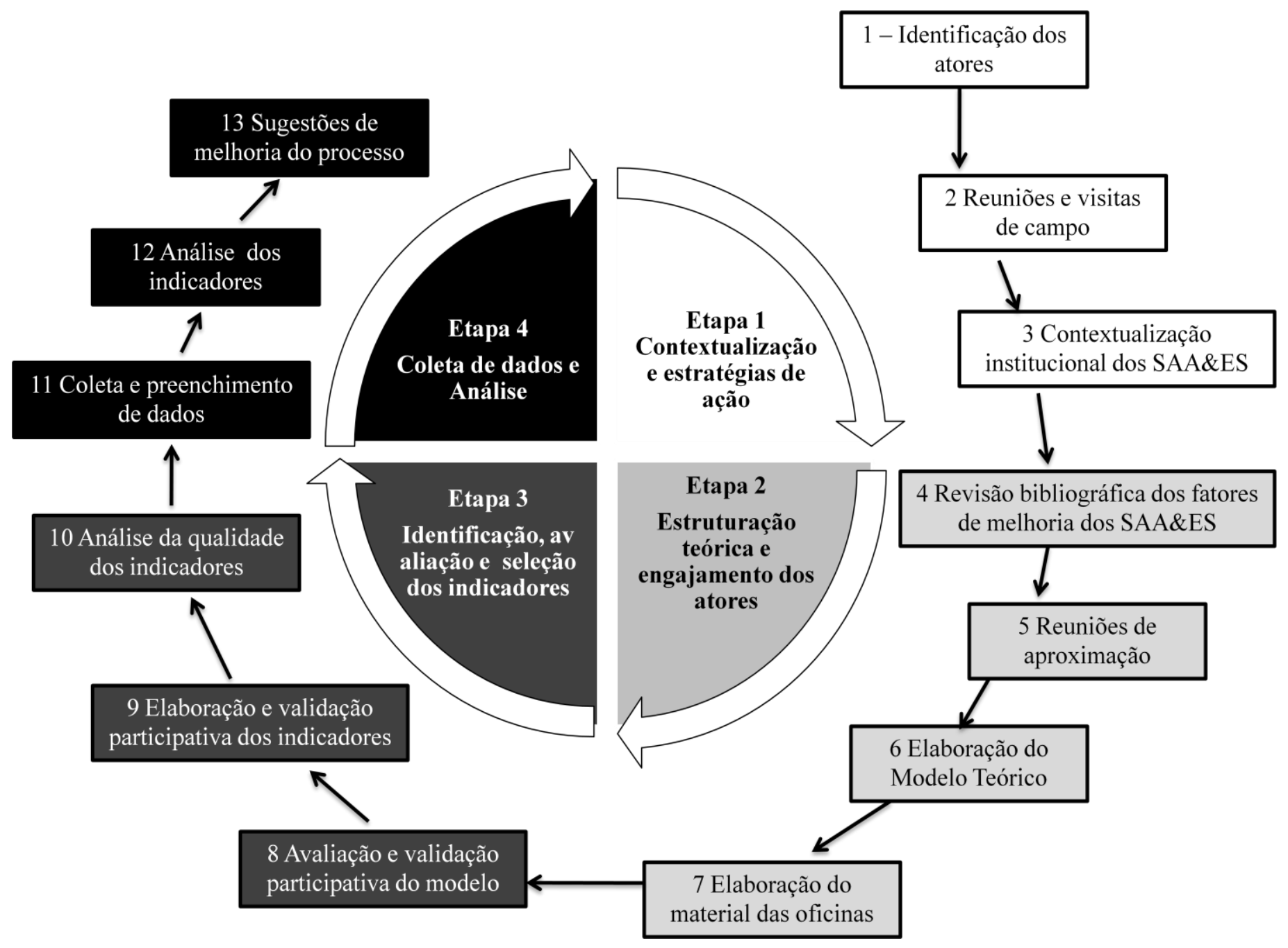

Figura 7. Fluxograma das etapas metodológicas desenvolvidas. 


\subsection{Projeto Internacional PROBE: Benchmarking Pro-poor Water Services Provision}

Este projeto de pesquisa está inserido no projeto internacional "Benchmarking for Pro-Poor Water Services Provision- PROBE”, o qual busca a integração e o compartilhamento dos conhecimentos e tecnologias investigadas, concebido devido à necessidade da abordagem conjunta para a resolução da problemática complexa que atinge diversas partes do mundo.

Por meio de parcerias envolvendo quatro instituições acadêmicas: Instituto de Educação para Água (UNESCO-IHE Institute for Water Education), localizado na Holanda, EESC/USP (Escola de Engenharia de São Carlos - Universidade de São Paulo, Brasil),), KNUST (Kwame Nkrumah University of Science and Technology, Gana) e PWUT (Power and Water University of Technology, Irã) tendo como posterior participante a Índia.

Além destas instituições de ensino, também são parceiros neste projeto, a UNICEF (Fundo das Nações Unidas para a Infância) e a OMS (Organização Mundial de Saúde). No Brasil, destaca-se a participação de agências de regulação e prestação de serviços de saneamento nacionais e internacionais: SABESP (Companhia de Saneamento Básico do Estado de São Paulo), a ARSESP (Agência Reguladora de Saneamento e Energia do Estado de São Paulo), a ARCE (Agência Reguladora de

Serviços Públicos do Estado do Ceará) e a CAGECE (Companhia de Água e Esgoto do Estado do Ceará), AQUA-VITENS, NWWEC (National Water and Wastewater Engineering Company), Grupo SUEZ; sob facilitação e suporte de importantes instituições do setor de águas: IWA (International Water Association), VEWIN (Associação de Companhias de água da Holanda).

O resultado esperado deste projeto será o desenvolvimento de metodologia para apoio na promoção do acesso aos SAA\&ES pelas populações vulneráveis, visando contribuir para atingir as metas 10-11 das "Metas de Desenvolvimento do Milênio"reduzir pela metade a proporção de pessoas sem acesso a estes serviços entre 20002015. 
O PROBE se concentra em quatro áreas: 1) Mapeamento das populações pobres com pouca cobertura de saneamento; 2) Indicadores da prestação de serviços às populações pobres; 3) Incentivos para a prestação de serviços às populações empobrecidas; 4) Experiências bem sucedidas que impulsionaram a prestação de serviços às populações pobres.

A presente pesquisa de mestrado se concentra na área 2, Indicadores de prestação de serviços de saneamento à populações pobres, teve uma pesquisa de mestrado elaborada nessa área por Ralda (2010), na UNESCO-IHE, na Holanda, que arquitetou uma estrutura teórica de avaliação do desempenho e doze indicadores relativo ao fornecimento dos serviços de saneamento às populações pobres. Ainda na área de indicadores foram concluídos mais três mestrados: Ndlovu (2011), Mutai (2011), Rachmadyanto (2010). Essas referências foram utilizadas como apoio à pesquisa, assim como as dissertações desenvolvidas por Barbosa (2010) da área 3 Incentivos para a prestação de serviços às populações empobrecidas; e Bamidele (2010) e Murungi (2011) na área 4 - Experiências bem sucedidas que impulsionaram a prestação de serviços às populações pobres.

Foram realizadas três oficinas no âmbito do projeto PROBE (Maio de 2010, Outubro 2011, dezembro 2011), as quais serviram de insumo a presente pesquisa, contribuindo com a metodologia por meio de sugestões de mudanças, discussões e críticas dos professores e estudantes da instituição envolvida. Esse elemento da metodologia proporcionou uma melhoria contínua no projeto de pesquisa e até mesmo da própria metodologia, pois na segunda oficina, que aconteceu na Holanda, foi oferecido um curso de metodologia de pesquisa, no qual se pode escolher e aprimorar os alicerces o qual a pesquisa foi feita.

$\mathrm{Na}$ sequência está o detalhamento da pesquisa conforme os objetivos, instrumentos utilizados e fases.

\subsection{Aspectos gerais da metodologia}

Tendo em vista o contexto e o objetivo estabelecido pela pesquisa, a mesma caracteriza-se como exploratória, visando fornecer subsídios confiáveis e úteis para 
lidar com a complexidade inerente às instituições prestadoras dos SAA\&ES. A exploração foi feita por meio de investigação de sistemas de informações existentes, leituras e entrevistas exploratórias, e deste modo, assegurar a qualidade da problematização e auxiliar no contato com a realidade vivida pelos atores do sistema (QUIVY; CAMPENHOUDT, 1998).

Complementarmente, a pesquisa caracteriza-se como aplicada, pois se desenvolveu de forma participativa junto aos atores do processo e por meio de estudos de caso, um conjunto de indicadores de avaliação dos SAA\&ES a populações urbanas vulneráveis no Estado de São Paulo. Ou seja, a pesquisa aplicada permitiu a verificação na prática, de indicadores que mensurem as dimensões no fornecimento dos SAA\&ES a essas populações.

Uma abordagem qualitativa, descritiva e exploratória foi utilizada. Os dados primários e secundários coletados, de natureza descritiva, qualitativa e quantitativa, foram analisados sob a luz da revisão de literatura, bem como considerando as experiências dos parceiros envolvidos no projeto. Ou seja, a estratégia de triangulação foi aplicada para interpretar os dados por meio da combinação de informações teóricas e práticas com a revisão bibliográfica (LAKATOS; MARCONI, 2008). Possibilitou unir diferentes visões de mundo dos atores envolvidos, com múltiplos procedimentos técnico-científicos e base teórica (PAULILO, 1999).

Com relação aos procedimentos técnico-científicos utilizados (GIL, 2009), a pesquisa incluiu revisão bibliográfica, análise documental, pesquisa participante e estudo de caso. Na sequência, apresenta-se o detalhamento referente a cada etapa, que se divide em quatro: (i) exploratória, contextualização e estratégias de ação; (ii) estrutura teórica e engajamento dos atores; (iii) escolha participativa do modelo e dos indicadores; e (iv) aplicação piloto dos indicadores e análise.

\subsection{Etapa I - Contextualização e estratégias de ação}

Essa etapa consistiu-se pela realização de reuniões com parceiros, visitas a campo e identificação dos atores, realizando-se de entrevistas exploratórias com interlocutores válidos: docentes que conhecem o tema e que têm experiência de 
investigação, pessoas chamadas "testemunhas privilegiadas" que pela sua posição, ação ou responsabilidades, tem um bom conhecimento do problema. As entrevistas foram gravadas e as perguntas foram feitas de forma aberta, conforme sugerem Quivy e Campenhoudt (1998).

Esta etapa foi realizada por meio do procedimento técnico da pesquisa participante, como proposta de buscar a unidade entre a reflexão e prática da pesquisa (BRANDÃO, 2005). É a interação entre a ciência, as políticas e as ações práticas administrativas no setor dos SAA\&ES. A pesquisa participante possibilitou uma pesquisa condizente com a forma mais real de agir e resolver os problemas. Analisando situações complexas e encaminhando possíveis soluções (THIOLLENT, 1997).

Na etapa 1, foi realizado o levantamento da situação existente, por meio da pesquisa de campo, para conhecer a realidade situação dos SAA\&ES para as populações vulneráveis e foram realizadas reuniões de trabalho com o objetivo de envolvimento dos atores e entendimento da contextualização institucional deles na pesquisa. Foi feita a abordagem do problema e foram trazidas as bases essenciais da pesquisa, a visão dos diferentes atores a respeito do problema e os conceitos-chave. Nessas reuniões e visitas à campo consideraram-se duas fontes de informação: o discurso enquanto informação e o discurso enquanto processo. Discurso como fonte de informação realizou-se com a reflexão das dimensões e dos aspectos de um dado problema, excluindo possibilidades da pesquisa ser lançada em falsos problemas, de pressupostos e promoções errôneas. E o discurso enquanto processo realizou-se considerando a vivência ou percepção dos atores a respeito do tema e fazendo uma análise do conteúdo das entrevistas de acordo com a inserção no processo conforme sugerem Quivy e Campenhoudt (1998).

Realizou-se, dessa forma, a consolidação de parcerias no projeto, o Quadro 1 mostra a consolidação dessas parcerias ocorridas, que funcionaram também como fontes de informações no desenvolvimento da pesquisa. 


\begin{tabular}{|c|l|}
\hline Tipo de Instituição & \multicolumn{1}{c|}{ Nome da Instituição } \\
\hline \multirow{3}{*}{ Instituições acadêmicas } & USP (Universidade de São Paulo) \\
\cline { 2 - 2 } & UNESCO IHE (Institute for Water Education) \\
\cline { 2 - 2 } & UFCE (Universidade Federal do Ceará) \\
\hline \multirow{2}{*}{ Agências reguladoras } & ARSESP (Agência Reguladora do Estado de São Paulo) \\
\cline { 2 - 2 } & ARCE(Agência Reguladora do Ceará) \\
\hline \multirow{4}{*}{ Operadores } & SABESP (Companhia de Saneamento Básico do Estado de São Paulo) \\
\cline { 2 - 2 } & SAAE (Serviço Autônomo de Água e Esgoto) - Município de São Carlos \\
\cline { 2 - 2 } & SSAE (Secretaria de Serviços de Água e Esgoto) - Município de Descalvado \\
\cline { 2 - 2 } & Foz do Brasil - Operadora do Município de Limeira \\
\hline Governo no Estado & SEADE (Fundação Sistema Estadual de Análise de Dados) \\
\hline
\end{tabular}

Quadro 1. Parceiros do projeto

Após consolidação das parcerias, juntamente com os atores envolvidos, realizouse a contextualização da problemática do fornecimento dos SAA\&ES às populações vulneráveis. A participação do pesquisador, do regulador e operadores dos serviços (membros que trabalham na resolução prática das situações do fornecimento dos serviços), contribuíram na diversidade de perspectivas consideradas e a facilitação de resoluções mais próximas da realidade e das necessidades da coletividade.

Conjuntamente às visitas a campo e reuniões com os parceiros, realizou-se a análise documental e levantamento bibliográfico (análise de publicações científicas), as quais auxiliaram na melhoria da metodologia, nas definições de conceitos-chave, na confirmação das áreas mais convenientes para desenvolver os estudos de caso e, na seleção e/ou confirmação das unidades de análise de resultados. A etapa I ocorreu no primeiro período da pesquisa (março à agosto de 2010).

A análise documental foi feita por meio de estudo da legislação, políticas, procedimentos e dados das seguintes intuições: Governo do Estado de São Paulo, prefeituras municipais do Estado de São Paulo, empresas prestadoras de serviços públicos de saneamento básico, Agência Reguladora de Saneamento e Energia do Estado de São Paulo (ARSESP), Companhia de Saneamento Básico do Estado de São Paulo (SABESP), Fundação SEADE (Sistema Estadual de Análise de Dados) e IBGE (Instituto Brasileiro de Geografia e Estatística). Esse estudo do material institucional e experiências apresentadas nas reuniões permitiram realizar a contextualização da situação do fornecimento dos SAA\&ES (Capítulo 3).

O levantamento bibliográfico foi feito com o levantamento das informações em livros de referência, publicações em revistas nacionais e internacionais, utilizando base 
de dados da Capes, Science Direct, Scielo, Elsevier, Scopus e outros. Foram ainda consultadas websites e publicações de órgãos reconhecidos internacionalmente.

Como resultado dessa etapa tem-se subsídios à estruturação do trabalho como um todo, e mais especificamente o Capítulo da Contextualização, os quais podem ser encontrados especificações do capítulo e os principais autores utilizados no Quadro 2.

\begin{tabular}{|c|c|c|}
\hline Tema & Subtema & $\begin{array}{c}\text { Principais autores ou publicações } \\
\text { de órgãos reconhecidos }\end{array}$ \\
\hline & & IBGE (2012), WHO e UNICEF \\
Contextualização & Situação dos SAA\&ES - Item 3.1, p. 19 & $(2006 / 2008)$, SNSA (2008/2010), \\
(Capítulo 3) & Conceituação das populações vulneráveis - & IPEA (2010), PNUD (2010), \\
& Item 3.4, p. 32 & Ferreira, Dini e Ferreira (2006) e \\
& & Soares, Ribas e Soares (2009). \\
\hline
\end{tabular}

Quadro 2. Especificações do tema, subtema e principais autores da pesquisa bibliográfica realizada na etapa 1

A leitura do material bibliográfico seguiu quatro fases: (i) busca do assunto reconhecimento; (ii) seleção de informações - seletiva; (iii) reconhecimento e avaliação das informações e intenções do autor - reflexiva; e (iv) compreender as ideias do autor e relacionar com as questões de pesquisa - interpretativa (LAKATOS, 2007).

\subsection{Etapa 2 - Estruturação teórica e engajamento dos atores}

A etapa 2 consistiu-se na revisão bibliográfica dos fatores de melhoria dos SAA\&ES às populações vulneráveis, reuniões de aproximação, elaboração do modelo teórico e a elaboração do material utilizado durante as oficinas. Essa etapa realizou-se durante o $2^{\circ}$ e $3^{\circ}$ semestre do mestrado (agosto de 2010 a agosto de 2011).

Inicialmente efetuou-se a revisão bibliográfica dos fatores relevantes da prática dos SAA\&ES voltados às populações vulneráveis. A partir desse arcabouço, os fatores foram agrupados em dimensões, as quais possuem a finalidade de indicar quais os aspectos mais relevantes na prática do setor (item 7.1, Subcapítulo Modelo Conceitual).

As bases conceituais pesquisadas durante a revisão bibliográfica estão descritas no Quadro 3, subdivididas em itens e subitens, assim como estão descritos alguns autores que foram relevantes dentro de cada temática. O levantamento de material bibliográfico serviu para a construção do embasamento conceitual e assim tem auxiliado como base às discussões a serem realizadas em forma de seminário e oficinas de 
trabalho, tanto no tema dos indicadores de benchmarking quanto no tema da inclusão da população vulnerável no sistema dos SAA\&ES, e dessa forma fortalecer a validação da análise.

\begin{tabular}{|c|c|c|}
\hline Tema & Subtema & $\begin{array}{l}\text { Principais autores ou publicações } \\
\text { de órgãos reconhecidos }\end{array}$ \\
\hline $\begin{array}{l}\text { Benchmarking } \\
\text { (Capítulo 5) }\end{array}$ & $\begin{array}{l}\text { Descrição do processo de benchmarking - } \\
\text { Item 5.1.1, p. } 62 \\
\text { Tipos de benchmarking - Item 5.1.2, p. } 65 \\
\text { Práticas de benchmarking nos SAA\&ES no } \\
\text { Brasil - Item 5.1.3, p. } 70\end{array}$ & $\begin{array}{c}\text { Slack et al. (2002) Camp (1993), } \\
\text { Bhutta e Huq (1999), Spendolini } \\
\text { (1993), Blokland (2009) e Berg } \\
\text { (2007). }\end{array}$ \\
\hline $\begin{array}{l}\text { Indicadores } \\
\text { (Capítulo 6) }\end{array}$ & $\begin{array}{c}\text { Sistema de indicadores - Item 6.2, p. } 83 \\
\text { A construção de indicadores - Item 6.3, p. } 97\end{array}$ & $\begin{array}{c}\text { Meadows (1998), Bossel (1999), } \\
\text { Quiroga (2007), Malheiros, Philippi } \\
\text { Jr e Coutinho (2006), Reed (2008), } \\
\text { Chess e Purcell (1999) e Tippett et } \\
\text { al. (2005) }\end{array}$ \\
\hline $\begin{array}{c}\text { Fatores relevantes } \\
\text { da prática dos } \\
\text { SAA\&ES }\end{array}$ & Modelo Conceitual - Item 7.1, p. 116 & $\begin{array}{l}\text { Nascimento e Heller (2005), } \\
\text { Morais, Fortes e Ferreira (1999), } \\
\text { Moises et al. (2010), Galvão Jr } \\
\text { (2009), Alegre et. al, } 2006 \text { e Piza, } \\
2000\end{array}$ \\
\hline
\end{tabular}

Quadro 3. Itens e subitens da pesquisa bibliográfica realizados na etapa 2

Após a revisão bibliográfica foi elaborado o modelo de avaliação conceitual, considerando os critérios de qualidade científica e concepção crítica do trabalho, por meio de análise dos seguintes parâmetros: fundamentação teórica com a descrição do método, funcionamento, suas características, as vantagens e desvantagens; e considerações críticas acerca da ferramenta de avaliação (Subcapítulo Modelo Conceitual, item 7.1).

Na sequencia, foram realizadas reuniões de aproximação, que são desde reuniões via skype como reuniões presenciais com os atores, para que os mesmos conseguissem entender a proposta e que fosse algo realmente participativo. Foram feitas reuniões com os parceiros para o engajamento, diálogo e acordos interinstitucionais. Essa etapa mostra-se necessária e importante no processo de pesquisa participante, pois é neste momento em que os parceiros devem se sentir participantes ativos no processo, e como consequência o interesse e disponibilidade de participação. Isso demandou tempo e disposição, tento em vista que os atores possuem diferentes objetivos e interesses e foi necessário conciliá-los.

Nessa etapa foi elaborado ainda um material de apoio para as oficinas, com a agenda das atividades, apresentação do projeto de mestrado, entre outros, os quais 
podem ser vistos nos APÊNDICES (A, B, C, D e E) que foram feitos por uma junção de materiais teóricos e práticos, de forma a possibilitar uma dinâmica nas oficinas que foram aplicadas na etapa 3.

\subsection{Etapa 3 - Identificação, avaliação e seleção de indicadores}

A Etapa 3 consistiu-se na avaliação e validação participativa do modelo, elaboração e validação participativa dos indicadores e análise da qualidade dos indicadores. Realizou-se por meio da pesquisa participante, no $3^{\circ}$ e $4^{\circ}$ semestre do desenvolvimento do mestrado (fevereiro de 2011 à fevereiro de 2012). Consistiu-se em diálogo para encontrar caminhos na superação das dificuldades. Segundo Argumedo (1999), a pesquisa participante possui as dimensões da produção do conhecimento para orientar a prática. Por meio da participação, realizar o processo de criação do conhecimento e colocá-lo em prática.

Esta pesquisa foi feita junto às instituições. As instituições caracterizam-se por atuarem em delimitado campo, recortando uma realidade global para determinar sua função específica. Uma vez distribuídas, procurou-se integrar as ações institucionais (ARGUMEDO, 1999). Para isto, foi necessário compreender a lógica dinâmica e, por vezes, contraditória do discurso dos atores e de seus relacionamentos com os outros atores. Por isto, a pesquisadora se envolveu na dinâmica dos processos institucionais, adotando uma dupla postura de observador crítico e de participante ativo, conforme sugere Oliveira e Oliveira (2006).

Na sequência, foi realizado um seminário com o tema central "Saneamento $e$ Populações Vulneráveis”. O seminário teve como objetivo apresentar o projeto, mostrar as possibilidades de participação nele, convidar para as atividades subsequentes da pesquisa, e a discussão a respeito das temáticas: conceituação das populações vulneráveis, benchmarking como ferramenta auxiliadora, o papel da agência reguladora na melhoria dos serviços às populações vulneráveis, boas práticas no atendimento as populações vulneráveis. O material preparado que contém a agenda com a programação e o cartaz de divulgação podem ser vistos no APÊNDICE A. 
A atividade contou com a participação dos atores relacionados à temática da prestação dos SAA\&ES: representantes da Agência Reguladora de Saneamento e Energia do Estado de São Paulo (ARSESP); empresas prestadoras de serviços públicos do setor de saneamento básico como a SABESP; a Secretaria de Saneamento e Recursos Hídricos de São Paulo, Associação Brasileira de Engenharia Sanitária (ABES- SP), Universidade de São Paulo (USP) e Fundação Sistema Nacional de Análise de Dados (SEADE).

Após o seminário foram realizadas duas oficinas de trabalho. A realização de oficinas foi no intuito de validar o modelo de indicadores (1) e propor os indicadores junto às instituições envolvidas (2). Os resultados delas podem ser vistos no subcapítulo Modelo Validado (Item 7.1) e Indicadores Validados (Item 7.3), respectivamente.

A utilização das oficinas como método foi feita por possuir os pressupostos da construção coletiva, baseado no diálogo e na troca de saberes da pedagogia Freiriana (FREIRE, 1979; 1980). E por ser uma prática de intervenção adaptável a diversos contextos (CARVALHO et al., 2005).

As oficinas tiveram a duração de 5 horas e foram feitas de acordo com metodologia de Sampaio e Fernandes (2007). O roteiro utilizado está dividido nos períodos da manhã e da tarde, e consistiu nas seguintes atividades:

(1) No período da manhã foi feita a abertura da oficina, com a apresentação do projeto de pesquisa, a apresentação dos resultados obtidos no seminário, e da metodologia a ser efetuada durante as oficinas. Em seguida, foi feita a distribuição dos participantes em grupos e feita a escolha de um coordenador (responsável por distribuir as falas das pessoas, controlar o tempo da atividade e obter resultados) e um relator (responsável por anotar o histórico do diálogo e os resultados obtidos no grupo). Na sequencia foi distribuído o material suporte sobre o modelo proposto teoricamente (APÊNDICE B) e proposto três momentos: primeiro momento um raciocínio individual a respeito do material, um segundo momento o diálogo em grupo e um terceiro momento de apresentação e diálogo em plenária, com todos os participantes.

(2) No período da tarde, os grupos já estavam distribuídos e modelo validado, assim foram distribuídos três temas-chave por grupo, os quais elaboraram indicadores de acordo com a ficha de preenchimento de indicadores (APÊNDICE C). As escolhas 
do coordenador e do relator foram mantidas e foi dada a mesma sequencia do período da manhã: raciocínio individual a respeito do material, um segundo momento o diálogo em grupo e um terceiro momento de apresentação e diálogo em plenária, com todos os participantes.

Foi realizada a distribuição do material elaborado na etapa 2 de acordo com cada momento da oficina, como pode ser visualizado em detalhes no Quadro 3, neste mesmo quadro está especificado cada etapa realizada a maneira que foi conduzida.

A elaboração do modelo de avaliação e indicadores junto aos participantes caracteriza a pesquisa participante conforme ressalta Oliveira e Oliveira (2006), ou seja, não foi feita apenas a partir da visão do pesquisador, foi construída coletivamente com todos os participantes da oficina. 


\begin{tabular}{|c|c|c|c|c|}
\hline \multicolumn{5}{|c|}{ Período da Manhã: Validação da estrutura dos indicadores dos SAA\&ES voltados às populações vulneráveis } \\
\hline Atividade & Participação & $\begin{array}{l}\text { Período/ } \\
\text { Duração }\end{array}$ & Procedimentos & Modelo \\
\hline Explicação da Metodologia & Plenária & $15 \mathrm{~min}$ & $\begin{array}{l}\text { - Exposição da metodologia e o objetivo da Etapa } \\
\text { - Distribuição em grupos }\end{array}$ & \\
\hline $\begin{array}{l}\text { Explicação da Dinâmica de } \\
\text { grupo }\end{array}$ & Plenária & $15 \mathrm{~min}$ & $\begin{array}{l}\text { - Apresentação da dinâmica de grupo; } \\
\text { - Distribuição dos participantes nas salas, controle da logística e do tempo. } \\
\text { - Parada do Café }\end{array}$ & \\
\hline Listar Individualmente & Grupos/ Salas de aula & $15 \mathrm{~min}$ & $\begin{array}{l}\text { - Distribuição do material a ser preenchido pelos participantes. Escolha de um líder e } \\
\text { uma relator para cada grupo. } \\
\text { - O líder ficou incumbido de solicitar que os participantes executassem a tarefa e } \\
\text { controlar do tempo } \\
\text { - O relator ficou incumbido de preparar o que seria exposto na plenária. }\end{array}$ & Apêndice B \\
\hline Registrar diálogo & Grupos/ Salas de Aula & $30 \mathrm{~min}$ & - Solicitação que os participantes dialoguem & \\
\hline Compatibilizar & Plenária & $30 \mathrm{~min}$ & $\begin{array}{l}\text { - Exposição dos resultados } \\
\text { - Discussão dos resultados } \\
\text { - Resultados Finais }\end{array}$ & \\
\hline \multicolumn{5}{|c|}{ Período da Tarde: Proposição dos indicadores dos SAA\&ES voltados às populações vulneráveis } \\
\hline $\begin{array}{l}\text { Explicação da Dinâmica de } \\
\text { grupo }\end{array}$ & Plenária & $15 \min$ & $\begin{array}{l}\text { - Apresentação da dinâmica de grupo; } \\
\text { - Distribuição dos participantes nas salas, controle da logística e do tempo. }\end{array}$ & \\
\hline Listar Individualmente & Grupos/ Salas de aula & $15 \mathrm{~min}$ & $\begin{array}{l}\text { - Distribuição do material a ser preenchido aos participantes. } \\
\text { - O líder solicita que os participantes executassem a tarefa e controla o tempo } \\
\text { - O relator prepara o que seria exposto na plenária. }\end{array}$ & Apêndice C \\
\hline Registrar diálogo & Grupos/ Salas de Aula & $30 \mathrm{~min}$ & - Solicitação que os participantes dialoguem & \\
\hline Compatibilizar & Grupos/ Salas de Aula & $30 \mathrm{~min}$ & $\begin{array}{l}\text { - Exposição dos resultados } \\
\text { - Discussão dos resultados } \\
\text { - Resultados Finais }\end{array}$ & \\
\hline Encerramento da etapa & Plenária & $15 \mathrm{~min}$ & - Encerramento dos trabalhos explicando as próximas etapas da pesquisa & \\
\hline Avaliação da etapa & & $15 \mathrm{~min}$ & - Preenchimento da ficha de avaliação & Apêndice D \\
\hline
\end{tabular}

Quadro 4. Roteiro da oficina 1 da construção do Modelo de Avaliação. Fonte: Sampaio \& Fernandes (2007). 
A segunda oficina foi feita da mesma maneira que a primeira. A diferença esteve apenas no objetivo, pois foi uma complementação e continuidade da primeira oficina. Então a proposta foi avaliar os indicadores propostos e propor novos indicadores para os temas-chave que ainda não possuíam indicadores. O material utilizado durante a segunda oficina foi elaborado pela autora e pode ser visto no Apêndice E.

As oficinas foram mediadas pela pesquisadora, pelo professor orientador Tadeu Fabrício Malheiros e pela parceria com a Agência Reguladora, Camila Elena Muza Cruz, que tiveram como responsabilidade o diálogo igualitário, a participação e o estímulo para proporcionar a valorização do encontro dos saberes. Esta etapa confirmou a busca de transformar a diversidade em fator positivo (uma vez que os diversos parceiros envolvidos possuíam diferentes formações, variadas concepções conceituais e compreensões da realidade pesquisada). Como parte da pesquisa foi do tipo qualitativo, as oficinas de trabalho foram também utilizadas para auxiliar na análise dos resultados.

\subsection{Etapa 4 - Coleta de dados e análise}

A Etapa 4 consistiu-se na coleta e preenchimento de dados, análise dos indicadores e sugestões de melhoria do processo. Ocorreu no $4^{\circ}$ semestre do mestrado (agosto de 2011 à fev de 2012). Nesta etapa, foi realizada a aplicação piloto do conjunto de indicadores propostos, e por meio de estudo de caso. Há três tipos de estudos de caso de acordo com suas finalidades: intrínseco, instrumental e coletivo. De acordo com a finalidade do presente projeto, o estudo de caso a ser desenvolvido é o coletivo, pois a partir do estudo de um conjunto de casos, poder-se-á alcançar "melhor compreensão, ou mesmo teorização, sobre um conjunto ainda maior de casos” (ALVES-MAZZOTTI, 2006, p. 642). Estudo de caso é adequado para quando o estudo não provará nada, permite refletir sobre conceitos mais amplos, teorias, políticas, mas essa reflexão deve ser em um contexto específico do caso analisado.

Os critérios de seleção do estudo de caso foram:

(1) O estudo de caso poder auxiliar a encontrar os objetivos porque traz (i) uma informação orientada para o objetivo a ser respondido, ao em vez de uma amostragem aleatória (ii) caber dentro do quadro conceitual/teórico, pois não pode ser pesquisado o 
que não existe (iii) acesso a informação e suporte institucional - a operadora dos SAA\&ES possui disponibilidade de informação; e

(2) Interesse em participação.

Após a escolha dos municípios, os indicadores foram preenchidos com os dados, através da análise documental de procedimentos e dados.

Posteriormente a aplicação piloto, foi realizada a análise composta pelos critérios estabelecidos na Etapa 2. A análise dos indicadores foi feita baseada na revisão bibliográfica, por meio de: correções necessárias advindas da inaplicabilidade de determinado indicador; revisão dos indicadores escolhidos, com o relato da atuação na tomada de decisão e as dificuldades encontradas, em busca de explicar a razão destas possíveis inaplicabilidades; e o desempenho em realizar comparações entre operadores dos SAA\&ES às populações vulneráveis.

Foi realizada também a análise do processo participativo e sugestões de melhoria do processo, feito através da avaliação dos procedimentos e apresentando os resultados, pondo em evidência os novos conhecimentos e as consequências práticas, conforme sugerem Quivy e Campenhoudt (1998).

Nessa etapa foi feita a conclusão da pesquisa, a escrita e publicação de artigo científico. Foi elaborada a apresentação dos resultados de toda a pesquisa, por meio da compilação dos principais aspectos conceituais e empíricos trabalhados ao longo da pesquisa, bem como a elaboração das discussões e análises. Complementarmente, os resultados foram compartilhados com os outros parceiros do projeto e a comunidade científica, por meio de working papers, descrevendo as orientações e recomendações das boas práticas da utilização do conjunto de indicadores, assim como, sugestões de melhoria no processo desenvolvido.

Assim, com base nas etapas descritas montou-se o Quadro 5, o qual contém as etapas, a descrição das atividades realizadas, os procedimentos técnico-científicos utilizados e os produtos obtidos. 


\begin{tabular}{|c|c|c|c|}
\hline Etapa & Descrição das atividades & $\begin{array}{c}\text { Procedimentos } \\
\text { Técnico-científicos }\end{array}$ & Produtos \\
\hline $\begin{array}{l}\text { I. Contextualização } \\
\text { e estratégia de ação }\end{array}$ & $\begin{array}{l}\text { Identificação dos atores, reuniões } \\
\text { e visitas de campo e } \\
\text { contextualização institucional }\end{array}$ & $\begin{array}{c}\text { Revisão } \\
\text { bibliográfica, } \\
\text { análise documental } \\
\text { e pesquisa } \\
\text { participante }\end{array}$ & $\begin{array}{c}\text { Estabelecimento de } \\
\text { diretrizes e } \\
\text { delineamento da } \\
\text { pesquisa } \\
\text { Capítulo de } \\
\text { Contextualização dos } \\
\text { SAA\&ES e } \\
\text { conceituação das } \\
\text { populações vulneráveis }\end{array}$ \\
\hline $\begin{array}{l}\text { II. Estruturação } \\
\text { teórica e } \\
\text { engajamento dos } \\
\text { atores }\end{array}$ & $\begin{array}{l}\text { Revisão bibliográfica dos fatores } \\
\text { de melhoria dos SAA\&ES às } \\
\text { populações vulneráveis, reuniões } \\
\text { de aproximação, elaboração do } \\
\text { modelo teórico e elaboração do } \\
\text { material utilizado durante as } \\
\text { oficinas }\end{array}$ & $\begin{array}{l}\text { Revisão } \\
\text { bibliográfica, } \\
\text { pesquisa } \\
\text { participante }\end{array}$ & $\begin{array}{c}\text { Capítulos de } \\
\text { Benchmarking e } \\
\text { Indicadores e material } \\
\text { da oficina }\end{array}$ \\
\hline $\begin{array}{l}\text { III. Identificação, } \\
\text { avaliação e seleção } \\
\text { de indicadores }\end{array}$ & $\begin{array}{c}\text { Avaliação e validação } \\
\text { participativa do modelo, } \\
\text { elaboração e validação } \\
\text { participativa dos indicadores e } \\
\text { análise da qualidade dos } \\
\text { indicadores } \\
\end{array}$ & $\begin{array}{c}\text { Pesquisa } \\
\text { participante }\end{array}$ & $\begin{array}{l}\text { Modelo validado, } \\
\text { indicadores } \\
\text { formulados e validados } \\
\text { Capítulos dos } \\
\text { Resultados e discussão }\end{array}$ \\
\hline $\begin{array}{l}\text { IV. Coleta de dados } \\
\text { e análise }\end{array}$ & $\begin{array}{c}\text { Coleta e preenchimento de dados, } \\
\text { análise dos indicadores e } \\
\text { sugestões de melhoria do } \\
\text { processo }\end{array}$ & $\begin{array}{l}\text { Revisão } \\
\text { bibliográfica, } \\
\text { estudo de caso }\end{array}$ & $\begin{array}{l}\text { Indicadores Aplicados } \\
\text { Conjunto final de } \\
\text { indicadores } \\
\text { Capítulos dos } \\
\text { Resultados e discussão }\end{array}$ \\
\hline
\end{tabular}

Quadro 5. Descrição das etapas da pesquisa e caracterização metodológica 


\section{BENCHMARKING}

\subsection{Benchmarking: ferramenta de melhoria dos serviços de abastecimento de água e esgotamento sanitário}

Este capítulo se divide em quatro partes. A primeira parte explica o conceito e a origem da ferramenta de benchmarking, criada em um contexto empresarial, para posterior inserção em outros contextos, como o setor público, e até chegar ao contexto dos SAA\&ES. A segunda parte explica o processo de desenvolvimento da ferramenta. A terceira parte aborda os tipos de benchmarking existentes, e qual pode ser mais bem utilizado no setor. E na quarta e última parte é feita a exemplificação de algumas experiências práticas que permitem o entendimento da aplicabilidade do benchmarking no setor, e especificamente, das possibilidades e expectativas da aplicação desta ferramenta na melhoria dos SAA\&ES às populações vulneráveis.

A utilização da ferramenta de benchmarking foi iniciada pela busca da melhoria da qualidade de produtos e serviços no meio empresarial. A qualidade entendida em termos empresariais como a satisfação dos clientes, tanto nas necessidades explícitas como implícitas (TOLEDO; CARPINETI, 2000)

A qualidade global de um produto ou serviço é a somatória das qualidades parciais, pois um produto tem qualidades e não apenas uma qualidade. Principais parâmetros para medir as qualidades são: Desempenho técnico ou funcional, facilidade de conveniência de uso, disponibilidade, confiabilidade, manutenibilidade, durabilidade, conformidade, instalação e orientação de uso, assistência técnica, interface com o usuário, interface com o meio ambiente, estética, qualidade percebida e imagem da marca. Para que haja a qualidade do produto ou serviço é necessária a qualidade do gerenciamento da organização produtiva (TOLEDO; CARPINETI, 2000).

Existem ferramentas que possibilitam a melhoria da qualidade do gerenciamento das organizações. Melhoria esta que deve ser contínua para que a qualidade seja mantida ao longo do tempo, ou seja, um processo de transformações da cultura organizacional, das maneiras antigas de operar para realizar novas maneiras, de acordo com os objetivos da organização. Não importa se os melhoramentos sucessivos são pequenos, o que importa é que sempre ocorram (SLACK et al., 2002). 
O benchmarking é um processo de aperfeiçoar continuamente a qualidade de gerenciamento das organizações, pois é uma ferramenta de identificação da melhor prática (benchmark, ou padrão de referência), e com o conhecimento aprendido pelo exemplo da prática mais adequada, modificar o conhecimento no sentido de melhorar o desempenho da organização (CAVALCANTE; FARIA, 2009). Portanto, enquanto benchmark é definido como sendo o padrão de referência, o termo benchmarking representa o processo de comparação (MAZO, 2003).

Bhutta e Huq (1999) comentam uma definição de benchmarking de $1951^{6}$, mostrando que a temática já existia, mas a prática e a popularização ocorreram posteriormente com a organização Xerox, no mercado de copiadoras.

A empresa americana possuía o monopólio do setor, quando empresas japonesas entraram no mercado com copiadores, com qualidade similar, a preço de custo das copiadoras da empresa Rank Xerox. Os americanos acreditavam que através do que havia sido feito no passado, do conhecimento já adquirido, podiam fazer mudanças. Os japoneses pensavam diferente e invadiram o mercado americano com produtos melhores e com o mesmo custo. Os japoneses acreditavam e incluíram a cultura de que era necessário novos processos, métodos e práticas para serem mais competitivos (CAMP, 1993).

Eles fizeram viagens de estudo no exterior, com o propósito de conhecer o que estava sendo feito em outros países, estudar quais os métodos estavam sendo utilizados. Eles sabiam que tecnologias utilizadas em indústrias distintas poderiam ser utilizadas, a exemplo do código de barras que era utilizado na indústria alimentícia e foi instalada na época para o controle dos processos de máquina de escrever (CAMP, 1993). Na época em que isso ocorria (década de 80) não era dado o nome de benchmarking. No entanto, atualmente pode-se constatar que foi realizado estudo comparativo, benchmarking competitivo, e foi descoberto que a empresa Xerox possuía nove vezes mais fornecedores, dez vezes mais rejeitos e utilizava o dobro de tempo na fabricação. Assim,

\footnotetext{
${ }^{6}$ Feigenbaum, A.V. (1951), Total Quality Control. Mc-Graw Hill, New York, NY
} 
a empresa conseguiu verificar atividades possíveis de melhoria utilizando a ferramenta de benchmarking, auxiliando nas estratégias, estabelecendo padrões de desempenho e observando as melhores práticas e métodos operacionais (SLACK et al., 2002).

O benchmarking é uma ferramenta de identificação das melhores práticas para serem aplicadas no desempenho da organização. Bhutta e Huq (1999) definem o benchmarking como sendo o reconhecimento das próprias deficiências e a oportunidade de aprender com o outro que esteja fazendo um trabalho melhor, como um ato de humildade.

O benchmarking é definido também como uma ferramenta de comparação de ideias e práticas entre organizações e/ou entre partes da mesma organização, com o objetivo de melhorar continuamente o desempenho das mesmas. A comparação é feita por meio de práticas consideradas de desempenho superior - práticas de referência - e propiciam o aprendizado e estímulos a criatividade na implantação dessas melhorias (SLACK et al., 2002).

Segundo Camp (1993) existem várias bases sobre as quais o benchmarking pode ser definido, o autor descreve três tipos: a formal (ampla), do dicionário e a operacional. A formal estabelece o benchmarking como um "processo contínuo de medição de produtos, processos e práticas em relação aos mais fortes concorrentes, ou às empresas reconhecidas como líderes em suas indústrias". Da qual estabelece o benchmarking como um processo gerencial que precisa ser contínuo para ser eficaz. As práticas precisam ser constantemente monitoradas, para que haja sempre mudanças e descobertas de melhores práticas (CAMP, 1993, p.8).

A segunda definição de benchmarking descrita pelo autor é segundo o dicionário Webster como a "A marca deixada por um agrimensor... em uma posição predeterminada... e usada como ponto de referência ... padrão pelo qual uma coisa pode ser medida ou julgada." (CAMP, 1993, p. 10). Na definição atual do dicionário Webster (2011) benchmarking é: “(1) A busca por melhores práticas que conduzem ao desempenho superior de uma empresa; e (2) O processo contínuo de medição de produtos, serviços e práticas empresariais contra maiores concorrentes do seu programa ou com as empresas reconhecidas como líderes da indústria." 
A terceira definição descrita é a operacional, definição feita por um participante do processo na prática: “é a busca das melhores práticas na indústria que conduzem ao desempenho superior." (CAMP, p. 10).

Ainda sobre a definição de benchmarking, Spedolini (1993) realizou estudo consultando 57 empresas que praticavam o benchmarking e fez entrevista se elas possuíam e qual era a definição utilizada para benchmarking. Destas, 49 possuíam definição para o termo, definições diferentes, mas com similaridades. O autor reuniu todas essas definições, e criou uma definição que mais se aproxima dos dados observados, "Um processo contínuo e sistemático para avaliar produtos, serviços e processos de trabalho de organizações que são reconhecidas como representantes das melhores práticas, com a finalidade de melhoria organizacional.” (p. 10).

A definição de benchmarking colocada por Spedolini é condizente com as definições expostas anteriormente, as quais seguem uma mesma proposta de um processo de melhoria contínua, que por meio de comparações de práticas e produtos superiores, aprender e aprimorar suas práticas e produtos. O que se comparar e como realizar esse processo está descrito nos subcapítulos seguintes.

\subsubsection{Descrição do processo de benchmarking}

Segundo Camp (1993) existem quatro passos essenciais para o sucesso utilizando o benchmarking: (i) conhecer a sua própria operação, saber as potencialidades e fragilidades, para saber se defender dos concorrentes; (ii) conhecer os líderes da indústria, pois somente conhecendo e comparando com as melhores práticas é que se pode chegar à melhor prática; (iii) Incorporar o melhor que foi pesquisado e descobrir como foi conseguido aquele desempenho, sem receio de copiar ou modificálos nas operações, e (iv) a conquista da superioridade, através dessas investigações e aplicação das melhores práticas e da correção das fraquezas. As constatações verificadas no benchmarking devem ser compreendidas pela organização para que elas sejam efetivamente aplicadas, através do compromisso da organização. 
O ciclo do benchmarking segue o ciclo do PDCA ${ }^{7}$. Robert Camp descreve este ciclo em cinco etapas, as quais são basicamente às quatro fases do PDCA. O autor a subdivide em 10 etapas, que podem ser visualizadas na Figura 8.

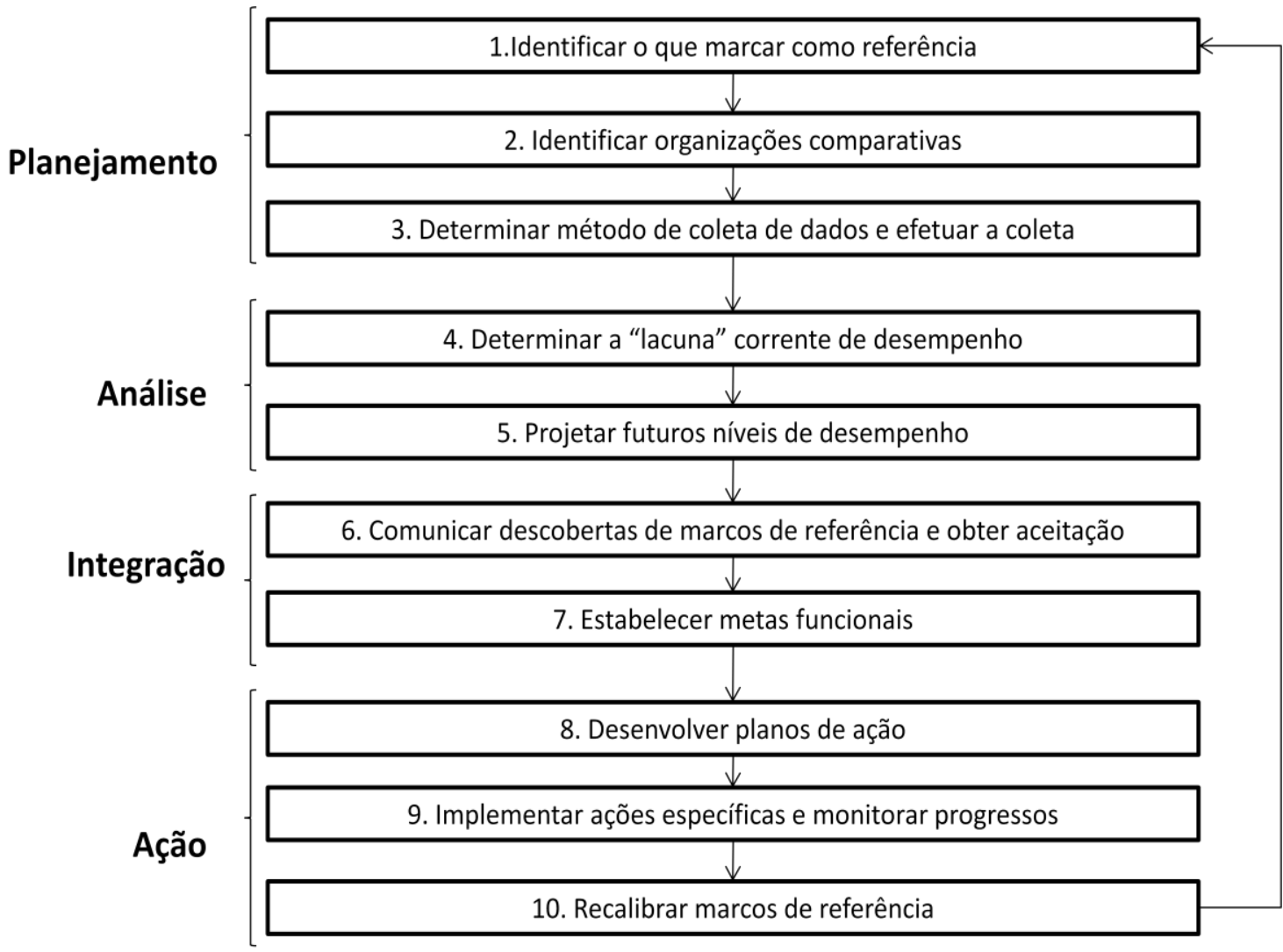

Maturidade $\left\{\begin{array}{l}>\text { Posição de liderança atingida } \\ >\text { Práticas plenamente integradas aos processos }\end{array}\right.$

Figura 8. Cinco etapas de Benchmarking.

Fonte: Camp, 1993

Durante o planejamento deve ser delineado do que será feito benchmarking, descrevendo o produto esperado (um pedido, uma remessa, um serviço). Nesta etapa é visto com quem será feito a comparação, mapeando os líderes, o benchmark referente ao produto pesquisado. Neste momento também deve ser descrito como será feita a coleta de dados, visualizando a combinação de formas e informações necessárias à comparação.

7 Termo amplamente conhecido utilizado como base para a Melhoria Contínua. O termo é advindo das palavras em inglês: Plan - Planejar; Do - Fazer; Check - Checar e Act - Agir. 
Posterior a etapa de planejamento é necessário coletar e efetuar a análise dos dados. Nesta etapa é necessária a compreensão tanto dos processos das organizações pesquisadas como da organização que está pesquisando, pois se trata de uma ferramenta de comparação. A análise é feita observando internamente os pontos fortes e fracos em comparação às organizações, ponderando o que se destaca, explicando o porquê, quanto é superior e como as práticas podem ser aplicadas na organização.

A etapa seguinte é a integração. Esta etapa consiste em estabelecer metas de mudanças nas organizações, obtendo a aceitação operacional e gerencial das descobertas realizadas. As descobertas devem ser comunicadas em todas as escalas da organização e devem ter argumentos claros e convincentes para a mudança e serem, consequentemente, convertidos em ações. Juntamente com a implementação de ações é necessário haver as medições e avaliações periódicas. Como se caracteriza por ser um ciclo, após a implementação é necessário prosseguir tanto com calibrações das ações e com novas pesquisas comparativas de benchmarking. E após a incorporação das melhores práticas na cultura organizacional, em todos os processos, a maturidade será alcançada.

A representação gráfica das etapas do benchmarking é mais bem exemplificada no formato circular, pois demonstra a reciclagem e continuidade do processo (Figura 9). Devido ao ciclo se assemelhar ao ciclo do PDCA, foi chamado por Spendolini (1993) por PDCA do benchmarking. 


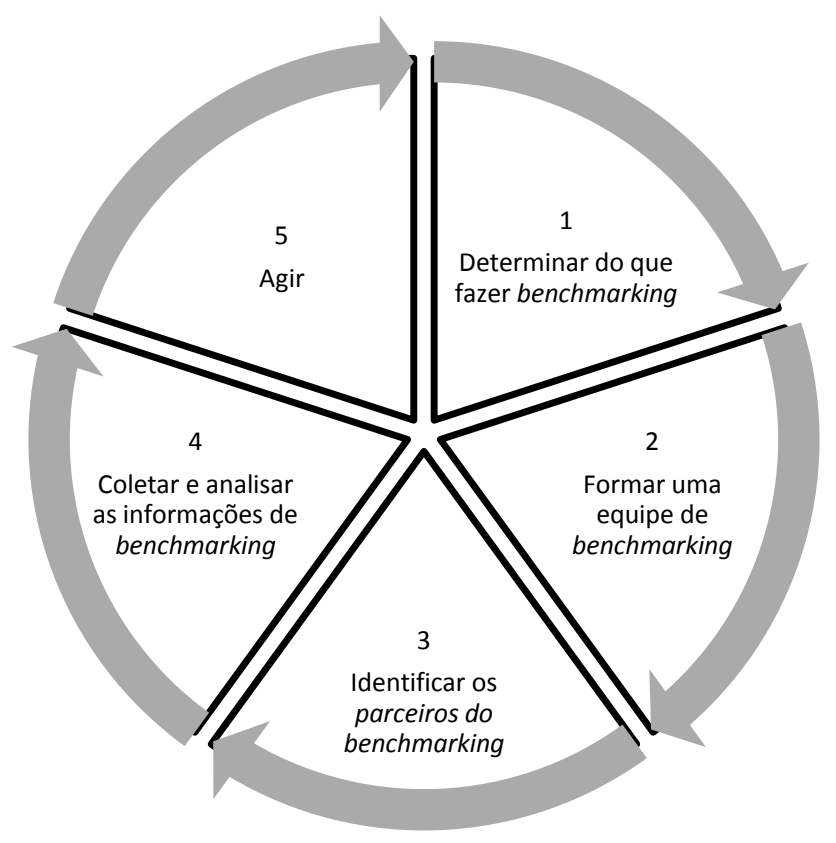

Figura 9. O processo de benchmarking de cinco estágios. Fonte: Spendolini (1993) e Bhutta e Huq (1999)

\subsubsection{Tipos de Benchmarking}

Existem diferentes tipos de benchmarking, classificados de acordo com a natureza da referência e de acordo com o conteúdo a ser comparado. Em relação à natureza de referência, a comparação subdivide-se em: interno, competitivo, atividade, genérico e global (Quadro 6). Benchmarking interno é a comparação entre operações dentro da mesma organização; Benchmarking competitivo é a comparação direta entre concorrentes; Benchmarking por atividade é a comparação entre negócios que não são concorrentes, observa-se formas de utilizar recursos e gerenciar clientes; do tipo genérico, compara serviços ou programas distintos cujo principal objetivo é observar os fatores de sucesso; e o global é a comparação entre organizações de diferentes países (BLOKLAND, 2009).

De acordo com o conteúdo de benchmarking (Quadro 6), pode ser dividido em: processo, desempenho, funcional e estratégico. Benchmarking de processo pode ser utilizado para mostrar o progresso, a avaliação é feita com base em processos e sistemas operacionais; Benchmarking de desempenho é expresso em medidas de produção, aqueles que podem ser quantificadas, como: pessoal com formação universitária, taxas (de câmbio) e os impostos; estas medidas de produção são usados para comparar a 
execução de atividades com outras organizações da mesma ou diferentes natureza; Benchmarking funcional é comparar as funções de negócios em duas ou mais organizações; Benchmarking estratégico está diretamente envolvida no nível gerencial, que é a avaliação das estratégias, em vez de condições operacionais (BLOKLAND, 2009).

\begin{tabular}{|c|c|c|}
\hline Classificação & Tipos & Definições \\
\hline \multirow{5}{*}{$\begin{array}{l}\text { Natureza das } \\
\text { referências }\end{array}$} & Interno & $\begin{array}{l}\text { Comparação entre uma organização sobre o desempenho de unidades } \\
\text { de negócios similares ou processos }\end{array}$ \\
\hline & Competitivo & $\begin{array}{l}\text { Comparação entre concorrentes diretos, alcançando ou mesmo } \\
\text { ultrapassando o seu desempenho geral }\end{array}$ \\
\hline & Atividade & $\begin{array}{l}\text { Comparação entre corporações na mesma atividade, incluindo não } \\
\text { concorrentes }\end{array}$ \\
\hline & Genérico & $\begin{array}{l}\text { Comparação com uma organização a qual se estende além das } \\
\text { fronteiras da mesma atividade }\end{array}$ \\
\hline & Global & $\begin{array}{l}\text { Comparação com uma organização quando a localização geográfica } \\
\text { estende além das fronteiras nacionais }\end{array}$ \\
\hline \multirow{4}{*}{$\begin{array}{l}\text { Conteúdo do } \\
\text { Benchmarking }\end{array}$} & Processo & $\begin{array}{l}\text { Relativo aos processos dos diferentes trabalhos e aos processos de } \\
\text { sistemas operacionais }\end{array}$ \\
\hline & Funcional & $\begin{array}{l}\text { Comparar diferentes funções administrativas em duas ou mais } \\
\text { instituições }\end{array}$ \\
\hline & Desempenho & $\begin{array}{l}\text { Em relação às características de resultados, quantificáveis em termos } \\
\text { de preço, velocidade, confiabilidade, etc. }\end{array}$ \\
\hline & Estratégico & Envolve a avaliação de assuntos estratégicos mais do que operacionais. \\
\hline
\end{tabular}

Quadro 6. Classificação e definições da ferramenta de Benchmarking.

Fonte: Blokland (2009)

Nos serviços públicos, o benchmarking é utilizado para aumentar a responsabilidade, para reduzir custos, conseguir mais resultados com os mesmos recursos e aumentar a qualidade com uma mudança comportamental (BLOKLAND, 2009).

Pesquisas têm sido realizadas sobre o impacto do benchmarking. Em análises desenvolvidas por diferentes acadêmicos foi descoberto que o exercício de benchmarking holandês resultou em uma "Acentuada melhoria" no desempenho, aumentou eficiência em mais de $20 \%$ e melhorou a transparência. Também nos países em desenvolvimento, o benchmarking tem sido visto como melhora de desempenho. 
Embora estes estudos sugiram que o benchmarking é uma ferramenta poderosa para melhorar o desempenho, a maneira que a ferramenta é usada atualmente possui limitações (PROBE, 2009).

Segundo Berg (2007) benchmarking é essencial para implementação e desenvolvimento da política dos serviços. No sentido de documentar desempenhos, estabelecer linhas bases de medição da melhoria da produtividade e fazer comparações entre operadores dos serviços. As classificações podem informar as políticas dos fabricantes, o fornecimento de fundos de investimentos e vendedores de referência de custos efetivos de diferentes serviços. Além de conhecerem melhor a sua própria organização.

A ferramenta de benchmarking possibilita a regulação do setor de SAA\&ES, pois devido à comparação do desempenho constante sobre os serviços e inclusive comparações de desempenho entre diferentes países. Demonstrando ser uma oportunidade de criar uma ponte entre as pesquisas acadêmicas e a prática comercial dos operadores dos serviços, além de proporcionar o diálogo entre políticas e programas de incentivos com a realidade vivenciada pelos SAA\&ES (BERG, 2007).

Benchmarking permite quantificar o progresso para os objetivos da organização, verificar organizações com boas práticas para que possam ensinar e permite que reguladores desenvolvam metas e incentivos (BERG, 2007). E assim pode ser caracterizada como uma ferramenta de regulação no setor público, setor que se caracteriza por ser monopolista, o benchmarking mostra-se um caminho os quais as pressões competitivas podem ser exercidas (BLOKLAND, SCHOUTEN; SCHWARTZ, 2010).

O sistema holandês de abastecimento de água utiliza benchmarking baseado em indicar e envergonhar as ineficiências das companhias, e dessa maneira promover a produtividade. Essa técnica é chamada de regulação por 'constrangimento' ou regulação por 'brilho'. Se as companhias se importam com os efeitos da reputação, os melhores resultados será uma espécie de recompensa (BLOKLAND, SCHOUTEN; SCHWARTZ, 2010). 
As razões econômicas e institucionais também explicam a utilização do benchmarking no setor público. A razão econômica é baseada na eficiência e eficácia no setor, vendo o benchmarking como um substituto das forças do mercado, sentindo pressão em agir no caso de desempenhos ruins em comparação com companhias do mesmo setor. A razão institucional é derivada da teoria de recursos dependentes e principalmente na transparência e legitimidade social (BLOKLAND, SCHOUTEN; SCHWARTZ, 2010).

No setor empresarial existem duas principais influências que decidem os objetivos da melhoria do desempenho: as necessidades e preferências dos consumidores e as atividades concorrentes. No setor da utilidade pública os objetivos estão pautados na necessidade de atendimento, mas são caracterizadas pela pouca competitividade, pois frequentemente a posse é exclusiva de apenas um operador e o usuário não possui a disponibilidade de escolher o serviço da operadora. Como esses SAA\&ES não possuem consumidores e "competidores", se faz necessária a regulação dos serviços, e que essa faça a comparação e estabeleça padrões de referência da qualidade de serviços que são constantemente atualizados de acordo com as melhorias e transformações das operadoras.

As características monopolistas do setor podem acarretar em acomodação e distanciamento do ideal de atendimento dos SAA\&ES. A ferramenta de benchmarking pode acelerar e incentivar o processo de melhoria das organizações no sentido de superar as fragilidades das estruturas monopolistas. A experiência de regulação em Portugal mostra essa possibilidade de utilização da ferramenta de benchmarking para a melhoria dos SAA\&ES.

A agência reguladora dos SAA\&ES em Portugal, chamado Instituto Regulador de Águas e Resíduos (IRAR) adota o modelo de benchmarking igual ao sistema holandês, baseado em indicar ou envergonhar as organizações, a técnica chamada de regulação por 'brilho', baseado na comparação, discussão e publicação do desempenho dos serviços de água e de águas residuais das concessionárias (MARQUES; SILVA, 2008). 
Para a aplicação desse modelo de benchmarking, o IRAR desenvolveu um conjunto de indicadores de desempenho, de forma participativa com os atores do setor, e após avaliação do cálculo dos indicadores, da interpretação, da análise do benchmarking e da produção do relatório de síntese, tornou público esses resultados e por meio da livre competição, promoveu a melhoria da qualidade dos serviços (ALEGRE et al., 2005).

Alegre et al. (2005) descreve que a regulação econômica é a mais importante forma de regulação dos comportamentos das entidades gestoras, pois quando se trata de monopólios, os preços tendem a ser mais altos que dos mercados competitivos, e assim, preços mais baixos dependem da regulação e da relação entre a sustentabilidade econômica, financeira e uma situação justa de pagamento das taxas, assim como assegurar uma adequada política de investimentos.

Assim, o benchmarking utilizado avalia o desempenho e ainda compara com resultados de outras entidades gestoras similares atuantes de outras áreas. Esses resultados devem ser divulgados publicamente, proporcionando incentivo às entidades gestoras melhorarem a sua eficiência e se apresentarem em posição favorável, e tendo como consequência a melhoria dos serviços aos usuários, finalidade de todo o processo estabelecido (ALEGRE et. al., 2005). A Figura 10 demonstra o modelo de benchmarking de regulação do IRAR, esse modelo assemelha-se à proposta de utilização da ferramenta de benchmarking nesse estudo. 


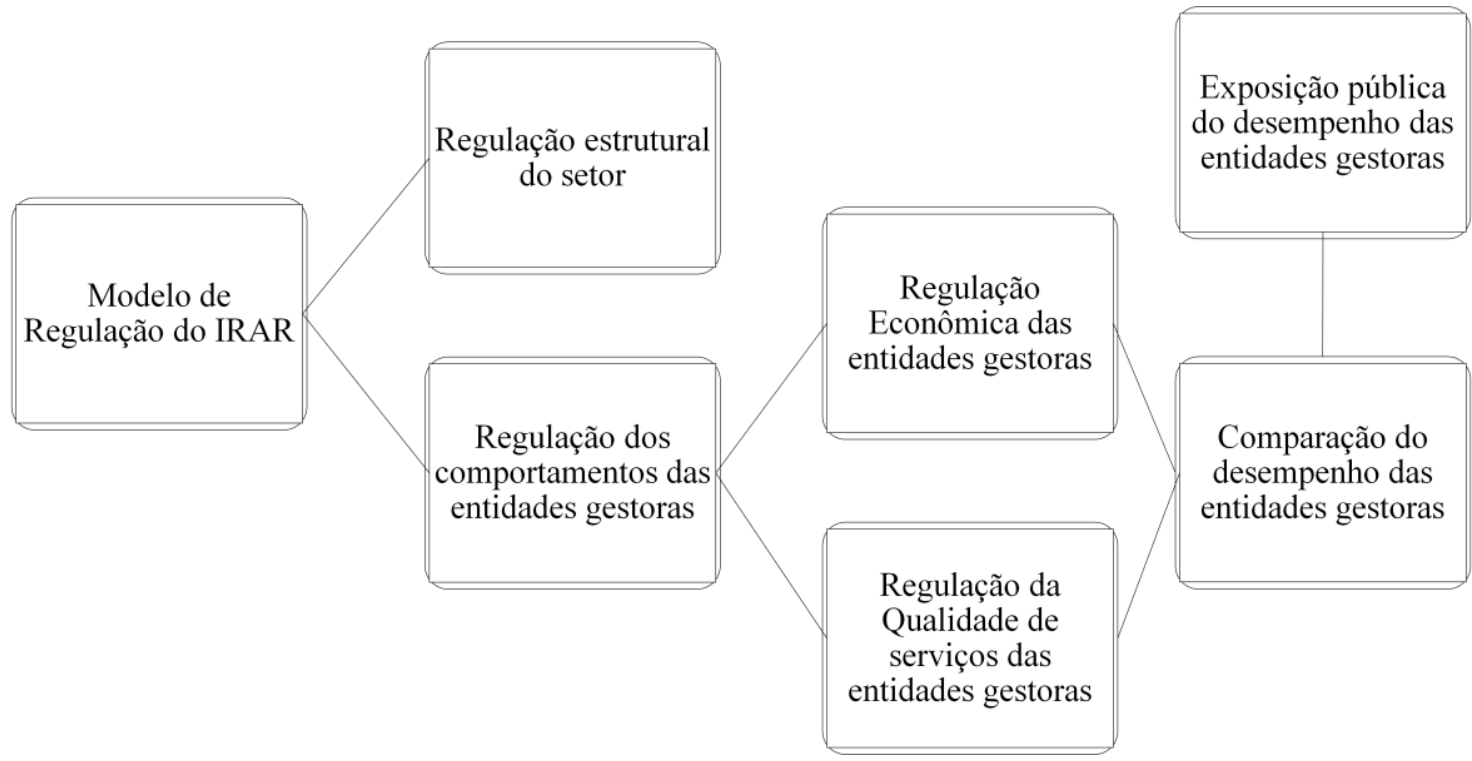

Figura 10. Modelo de regulação do IRAR.

Fonte: Alegre et al., 2005

Esse tipo de benchmarking constitui-se como uma ferramenta que pode auxiliar a regulação dos SAA\&ES. No Brasil a regulação ainda é incipiente, e consequentemente, a utilização de instrumentos de gestão também são. Deste modo, o benchmarking dos SAA\&ES no Brasil não é desenvolvido pelas agências reguladoras, ele é desenvolvido por meio da Associação Brasileira de Engenharia Sanitária - ABES e pelo governo federal. Conforme segue, são detalhadas essas práticas.

\subsubsection{Práticas de benchmarking nos SAA\&ES no Brasil}

\subsubsection{Prêmio Nacional de Qualidade em Saneamento - PNQS}

O Prêmio Nacional de Qualidade em Saneamento (PNQS) é uma iniciativa instituída pela ABES (Associação Brasileira de Engenharia Sanitária e Ambiental) em 1997 e tem por objetivo estimular a busca e aplicação de boas práticas de gestão por organizações do setor de saneamento, reconhecer organizações de destaque pela utilização das práticas e apresentam resultados competitivos de desempenho, divulgar práticas das organizações conhecidas, mostrando ser um verdadeiro benchmarking do setor (PNQS, 2011).

O PNQS tem como missão "Estimular a prática de modelos gerenciais compatíveis com os melhores exemplos mundiais, por meio da promoção e do reconhecimento dos casos de sucesso que auxiliem no aprimoramento do setor de 
saneamento ambiental e no aumento da qualidade de vida da população.” (PNQS, 2011, p. 6).

Em 2001 o PNQS estabeleceu como sua visão "Consagrar-se como um instrumento de referência na avaliação e condução contínuas dos serviços de saneamento ambiental" a ser alcançada em 2005. Focado na qual, inseriu novos instrumentos para avaliar, sobretudo, o sistema de gestão das organizações. Desta forma, foi implementado o Guia de Referência para Medição do Desempenho GRMD como base para desenvolver o Diagnóstico do Desempenho Atual das organizações. O GRMD solicita a apresentação de resultados relevantes na forma de séries históricas, com referenciais comparativos pertinentes. Trata-se de assegurar a prática efetiva de um sistema de medição de desempenho aplicável a todas as organizações, de todas as áreas de saneamento.

O primeiro GRMD estava composto de 30 indicadores de desempenho organizados em sete dimensões: indicadores relativos aos clientes e ao mercado, financeiros, relativos às pessoas, relativos aos fornecedores e parceiros, relativos aos produtos e serviços, ao meio ambiente e aos processos de apoio e organizacionais. Estes indicadores deviam se reportar junto com a medida do último exercício, focando nos resultados e valores agregados, além de aferir a situação anterior e posterior à aplicação dos critérios de avaliação (PNQS, 2001).

Ao longo do tempo, o GRMD tem sido revisado, complementado e melhorado, levando em consideração as novas políticas e normas nacionais referentes ao saneamento, através da inclusão de novas categorias e indicadores. É o caso da categoria Sociedade e o Indicador de Desenvolvimento Social, que apareceram em 2003 com o propósito de medir o engajamento no desenvolvimento social. Em 2005 são incluídos quatro indicadores a mais na categoria Sociedade, um dos quais é o Índice de comprometimento da renda família, que tem o propósito de medir a responsabilidade social quanto impacto social das tarifas. Esse dinamismo tem permitido maior clareza para os concorrentes além de evidenciar o comprometimento do PNQS com seu propósito de se tornar em um instrumento de referência para atingir a qualidade. 
Já em 2006 foram apontados quais indicadores são mandatários para os níveis I e II do prêmio e quais indicadores são sugeridos. Posteriormente em 2007 surgiu o nível III Quíron Platina, e os indicadores se classificaram em estratégicos, operacionais e sugeridos, com o qual se pretende orientar melhor a tomada de decisões para obter os melhores resultados e atender às necessidades.

As organizações candidatas podem ser provenientes do setor público ou setor privado com ou sem finalidade de lucro e durante a avaliação é mantido o sigilo, tratados de forma confidencial pelos membros da banca examinado, esses atuam de forma voluntária, sem remuneração.

Os critérios do PNQS têm como meta avaliar a maturidade dos processos gerenciais e os resultados das organizações. Os critérios são conceitos conhecidos internacionalmente e estabelecidos pela Fundação Nacional da Qualidade (FNQ) Fundamentos de Excelência: Pensamento sistêmico, aprendizado organizacional, cultura de inovação, liderança e constância de propósitos, orientação por processos e informações, visão de futuro, geração de valor, valorização das pessoas, conhecimento sobre o cliente e o mercado, desenvolvimento de parcerias e responsabilidade social.

Possui um sistema de pontuação para avaliar o desempenho das organizações e o estado de maturidade em que elas se encontram, baseado em conceitos conhecidos internacionalmente, estabelecidos pela Fundação Nacional da Qualidade. Eles são divididos nas dimensões de processos gerenciais (enfoque, aplicação, aprendizado e integração) e resultados organizacionais (relevância, tendência e nível atual) (PNQS, 2011).

As organizações premiadas apresentam as boas práticas de gestão em seminário realizado pela ABES e participam de atividade de benchmarking no exterior, que consiste na visita de organizações referência em gestão do saneamento no mundo, trazendo a experiência ao setor do saneamento no Brasil.

O benchmarking realizado pelo PNQS a partir de 2002 foi através de indicadores, antes disso era feito por comparação de gestão de forma empírica. Os indicadores foram sendo melhorados e utilizados na mediação. Este é o melhor exemplo 
de benchmarking dos SAA\&ES que existe no Brasil, apesar da participação ainda ser pequena das concessionárias.

\subsubsection{Sistema Nacional de Informação do Saneamento - SNIS}

O SNIS é o sistema nacional de informações do saneamento, vinculado à secretaria nacional de saneamento ambiental do Ministério das Cidades, do governo federal. Tem o objetivo de mostrar a situação do saneamento e, consequentemente, realiza uma comparação entre os sistemas, tanto entre estados e municípios e formas de administração e abrangência (Prestadores de Serviços de Abrangência Regional, Microrregional, Local de Direito Público, Local de Direito Privado). É um diagnóstico que apresenta informações e indicadores, e faz algumas análises. Os dados são coletados anualmente. Possui indicadores econômicos - financeiros e administrativos, operacionais, de balanço e de qualidade.

O SNIS mostra-se importante ferramenta para o mapeamento nacional da situação do saneamento, sendo o maior banco de dados dos SAA\&ES existente. É possível visualizar tendências e traçar estratégias de intervenção. Os dados são altamente representativos, representando $97,2 \%$ e $77,6 \%$ da população urbana total do país, referente à informação de água e esgoto, respectivamente (SNIS, 2011).

O SNIS tem sido um dos incentivadores de melhores práticas, pois mostra possibilidades bem sucedidas de gestão, de qualidade, de perdas e os aspectos que incluem esse tipo de gestão melhor desenvolvida. E o governo, de alguma maneira, torna-se um incentivador de melhores práticas, assim como verificador das áreas mais necessitadas de investimentos. No SNIS as informações são divulgadas colocando-se os nomes das operadoras.

Participam da pesquisa 1.064 organizações (SNIS, 2011) o que mostra o potencial de benchmarking nesse tipo de pesquisa. No entanto é necessário explicar que o SNIS ainda não é utilizado como uma ferramenta de benchmarking diretamente, pois ele é a possibilidade de se fazer isso e é feito de forma informal, pois o objetivo do governo federal é o mapeamento da situação dos SAA\&ES. Ou seja, ele possui uma quantidade significativa de indicadores e de concessionárias que repassam as 
informações dos indicadores, mas é utilizado de forma fragmentada e por iniciativa das próprias operadoras como ferramenta de benchmarking.

O PNQS, diferentemente do SNIS, mostra-se uma ferramenta legítima de benchmarking e importante prática no Brasil. Porém, tanto o PNQS como o SNIS utilizam-se de indicadores para o mapeamento da situação e posterior comparação e a medição por meio de indicadores é aspecto importante do benchmarking.

\subsection{Considerações acerca do Capítulo de Benchmarking}

Esse capítulo traduz como o benchmarking pode ser um instrumento simples e de fácil implementação e, ao mesmo tempo, proporciona melhorias significativas às organizações. É um instrumento que possui suas origens empresariais e foi transposto a realidade dos SAA\&ES, isto é, conecta a experiência da competitividade do mercado com a cooperação no aprendizado mútuo para a universalização dos serviços. Desta forma, verifica-se a aplicação favorável desse tipo de ferramenta nesse setor constitutivamente monopolista, e que ainda tem muito a aprender com seus similares.

O capítulo possibilita entender o que é a ferramenta de benchmarking e a diversidade de aplicações no processo de melhoria contínua das organizações, mostrando que a escolha do tipo de benchmarking deve se adequar a cada situação a ser aplicada.

As forças do mercado que impulsionam empresas a melhorarem continuamente a sua eficiência, eficácia e, consequente, a lucratividade, para que consigam permanecer competitivas no mercado geralmente não é aplicado nos SAA\&ES, pois é caracterizado por não haver competitividade devido ao monopólio das concessionárias, e em decorrência disso, explica-se alguns comportamentos de concessionárias com baixa eficiência e eficácia no oferecimento dos seus serviços. O benchmarking é uma ferramenta utilizada inicialmente pelo mercado competitivo com objetivos de lucro, que se associado aos interesses de regulação do serviço podem ser utilizados para corrigir as falhas do mercado. A apreciação que se faz é que o mesmo mercado monopolista que muitas vezes exclui tem a capacidade de criar boas ferramentas que, se aplicadas pelo 
regulador que tem a função de trazer o equilíbrio dos monopólios, podem corrigir falhas do mercado.

Em casos em que as operadoras visam à lucratividade, e tem objetivos de serem competitivas, algumas vezes não tem a priorização de atendimento às populações vulneráveis, pois o atendimento nessas áreas pode ser de custos mais elevados e de baixo retorno monetário, isto é, como ainda não há uma obrigatoriedade de atendimento das populações vulneráveis ou mesmo da universalização, a priorização do atendimento não está acontecendo.

É importante ressaltar que já há sistemas de benchmarking implementados e em funcionamento para os SAA\&ES, e que, até mesmo, são utilizados na regulação desses serviços, como a experiência relatada do IRAR, os quais utilizam indicadores e um formato bem apropriado. O PNQS também é um formato interessante de uso da ferramenta de benchmarking, e acredita-se que, se feito de maneira mais institucionalizada e extensiva pode produzir bons resultados.

No entanto, esta aplicação da ferramenta não está prontamente disponível na universalização e no atendimento às populações vulneráveis, ela precisa ser desenvolvida por meio de sistemas de indicadores que permitam essa comparação nessa temática. Uma iniciativa de realizar benchmarking voltado à universalização foi lançada pela ABES como uma nova categoria de premiação no PNQS, a chamada Gestão Orientada à Universalização (GOU). A GOU ainda não é aplicada em função de revisão e adequação de critérios técnicos (informação pessoal) ${ }^{8}$, mas já mostra o interesse e pertinência da aplicação desses instrumentos no setor.

Não há meios de avaliar um benchmarking sem informações do que está sendo administrado e gerenciado. Os dados são importantes para visualizar a situação. A tomada de decisões é baseada nas informações que o decisor tem contato (FERNANDES, 2004).

${ }^{8}$ ABES. Informações da Gestão Orientada a Universalização (GOU). Mensagem recebida por abesmg@abes-mg.org.br em 26 de Agosto de 2011 
Esta medição é feito pelos indicadores. Indicador entendido, neste caso, como uma medida reservada para a descrição ou representação de um dado evento ou fenômeno (ROZADOS, 2005), entretanto, existem diversos entendimentos do que se caracteriza um indicador, estas caracterizações serão apresentadas no próximo capítulo. 


\section{INDICADORES}

Esse capítulo tem a finalidade de dissertar a respeito dos indicadores, tanto da sua importância, como das possibilidades de utilização e formulação. Este capítulo se divide em quatro partes: (i) as definições de um indicador e suas denominações; (ii) Sistemas de indicadores; (iii) boas práticas na formulação de indicadores; (iv) as potencialidades e fragilidades do processo participativo na proposição de indicadores.

Inicialmente, procurou-se a origem da palavra "indicador". Essa palavra é originada do latim indicare, significa apontar para, desvendar, estimar, colocar preço ou trazer a conhecimento público. Esse significado da origem da palavra já possibilita ao leitor uma noção geral do que se tratam indicadores. Posteriormente, buscou-se definições de autores que fazem uso de indicadores em suas pesquisas, encontrando-se diversas definições as quais estão relatadas conforme seguem:

Indicadores são definidos como os valores medidos ou derivados de mensurações quantitativas e/ou qualitativas, passíveis de padronização e comparáveis entre si. Segundo Marzall e Almeida (2000), indicadores podem ser definidos como uma parte da informação a qual é usada para medir e acompanhar a situação e progresso de um sistema complexo, ou seja, uma "ferramenta que permite a obtenção de informações sobre uma dada realidade. Tem como principal característica a de poder sintetizar um conjunto complexo de informações, retendo apenas o significado essencial dos aspectos analisados." (p. 44).

Os indicadores caracterizam as atividades humanas, identificam as relações existentes e comunicam as informações de forma compreensível (BOSSEL, 1999; MARZALL; ALMEIDA, 2000). São componentes que evidenciam informações para a compreensão do mundo e tomadas de decisões, funcionando como pontos de influência e ascensão do sistema. A sua presença ou ausência influenciam o comportamento de um sistema, para melhor ou para pior, mostrando-se como bom instrumento de transformação e paralelamente uma das maneiras mais fáceis de fazer alterações no sistema (não exige demissão de pessoas, mudanças nas estruturas físicas, inovação tecnológica ou impor novos regulamentos), ou seja, os indicadores permitem visualizar o cenário existente, cenários possíveis de acordo com a continuidade da mesma 
dinâmica do sistema, e almejar cenários melhores, estabelecendo metas e formas de alcançar estes novos cenários. (MEADOWS, 1998). Eles permitem construir uma imagem do estado do ambiente em que se possam basear decisões inteligentes para proteger e promover o que se considerar relevante (BOSSEL, 1999).

A utilização dos indicadores é feita no cotidiano da vida das pessoas - durante a educação formal, no ambiente pessoal, no ambiente profissional - eles são úteis para a tomada de decisão a todo o momento. A escolha da utilização dos indicadores e de quais são utilizados é em virtude dos significados existentes dos mesmos para quem os utiliza, depende do valor que é dado a eles, ou seja, os indicadores são uma expressão de valores (BOSSEL, 1999). Este conceito está em consonância ao explicado por Meadows (1998) de que indicadores surgem de valores, e que para avaliar a situação de um sistema ou um ambiente usam-se critérios baseados em valores que as pessoas carregam dentro de si, existem valores que são dos lugares ou cultura específica e existem outros comuns para toda a humanidade. A autora coloca que além de surgir de valores eles ainda criam valores. Não somente é medido o que é avaliado, como é avaliado o que é medido.

Os indicadores permitem quantificar fenômenos complexos, simplificar mecanismos e lógicas atuantes, determinar como as ações humanas afetam seu entorno, alertar para as situações de risco, e consequente, mobilização dos atores envolvidos em prever situações futuras, informar e guiar decisões políticas. Constituindo-se como instrumento para auxiliar no processo de tomada de decisão na gestão.

No entanto, indicadores não refletem o sistema real, tenta-se aproximar da realidade, mas os indicadores são imperfeitos, defeituosos, possuem falhas. São importantes e ao mesmo tempo perigosos porque estão no centro do processo de tomada de decisão. Quando os indicadores são escolhidos erroneamente eles podem causar sérios problemas de funcionamento do sistema. Um indicador que mede diversas coisas pode ser uma armadilha. O PIB (Produto Interno Bruto) é um exemplo, não consegue medir tudo que propõe. Ao administrar a economia nacional para maximizar o PIB, não necessariamente há justiça, liberdade, qualidade ambiental e saúde (MEADOWS, 1998). Estas imperfeições e armadilhas estão melhor expostas no item 6.3 (A Construção de Indicadores). 
A conceituação de indicadores não é consensual, possuem diversos entendimentos do que eles são e de qual modo classificados. Algumas das classificações de indicadores são: indicadores de desempenho dos SAA\&ES, indicadores ambientais, indicadores de desenvolvimento sustentável, indicadores de sustentabilidade e indicadores de benchmarking. Estas classificações estão definidas na sequencia. Procurou-se definir os tipos de indicadores existentes, para que seja possível ver em qual destes indicadores estão representados ou são mais bem utilizados no caso da melhoria da qualidade dos SAA\&ES.

Inicialmente procurou-se entender o que são indicadores de desempenho, pois são os indicadores mais comumente utilizados na avaliação dos SAA\&ES. Eles se caracterizam por serem medidas quantitativas da prestação dos serviços, proporcionando uma avaliação da eficiência ou de eficácia do serviço prestado pela entidade gestora. A eficiência mensura como os recursos são utilizados, de modo otimizado, para a produção do serviço e a eficácia mede até que ponto os objetivos de gestão definidos são cumpridos (ALEGRE et. al. 2005, GALVÂO JUNIOR, 2006).

Esses tipos de indicadores estão limitados ao acompanhamento da gestão das operadoras e estão menos preocupadas com a visão do cenário como um todo dos SAA\&ES. Outra limitação destes indicadores é que eles são exclusivamente quantitativos, e nesta pesquisa adotou-se a premissa de que indicadores podem ser qualitativos. Os indicadores quantitativos são objetivos e mais facilmente validados e comunicados, estão sob o olhar da visão científica utilitarista, mas existem situações que é necessário informações e avaliações subjetivas, qualitativas. Valendo-se das palavras de Meadows (1998, p 9-10):

“A visão científica do mundo é apenas uma maneira de ver o mundo, muito útil, mas não abrangente o suficiente para ser usado exclusivamente. A escolha de prestar atenção apenas ao que é mensurável é em si uma escolha subjetiva, e não um sábio. Todo ser humano sabe que algumas das coisas mais importantes na vida - a liberdade, amor, esperança, harmonia, até mesmo a beleza da precisão científica - não são qualidades, quantidades.

Todos os indicadores são pelo menos parcialmente subjetivos. A própria escolha de um indicator baseia-se em cima de algum valor, algum 
propósito interior humano que nos diz o que é importante medir. A escolha do que é importante é inerentemente subjetiva."

Neste caso específico da presente pesquisa, os indicadores de desempenho foram considerados insuficientes para a caracterização que está sendo proposta.

Posteriormente, foram classificados os indicadores ambientais, de desenvolvimento sustentável e de sustentabilidade, por meio da definição colocada pelo autor Quiroga (2007), o qual descreve as três gerações existentes de indicadores. Pôdese compreender a existência de algumas diferenças básicas entre indicadores denominados como indicadores ambientais, indicadores de desenvolvimento sustentável e indicadores de sustentabilidade.

A primeira geração de indicadores, iniciada nos anos oitenta e utilizados até o presente momento, são os chamados Indicadores Ambientais ou Indicadores de Sustentabilidade Ambiental. Estes indicadores surgiram na tentativa de caracterizar a esfera ambiental do setor produtivo na mineração, agricultura, silvicultura, e fenômenos constituíam a complexidade ambiental como a poluição dos recursos naturais. Alguns exemplos de indicadores ambientais são colocados pelo autor: cobertura do solo por florestas, qualidade de ar de uma cidade, contaminação da água por coliformes, indicadores de desmatamento, etc.

Indicadores da primeira geração não possuem relação com as complexas dinâmicas sócio-econômicas, e com a incorporação do discurso do Desenvolvimento Sustentável. Estes indicadores foram considerados parciais e insuficientes, mas do mesmo modo continuam sendo necessários para alimentar o rigor ambiental os indicadores da segunda geração (QUIROGA, 2007).

Indicadores de segunda geração iniciaram nos anos noventa e perduram até o presente momento, denominados os Indicadores de Desenvolvimento Sustentável. Estes indicadores têm uma abordagem multidimensional, com o intuito de integrar mais de uma dimensão do desenvolvimento sustentável, sendo assim compostos por indicadores das dimensões ambientais, sociais, econômicos e institucionais. Porém, os indicadores da segunda geração que não se vinculam entre as dimensões e entre eles, não são indicadores transversais ou sinérgicos. Que é a tentativa dos indicadores da terceira 
geração, denominados Indicadores de sustentabilidade, ainda estão por serem desenvolvidos.

Os indicadores da terceira geração transcendem as duas gerações de indicadores descritos anteriormente, pois tem o sentido de produzir indicadores transversais, que relacionem as dimensões presentes na sustentabilidade (os aspectos ambiental, social, econômico e institucional) colocando-os todos juntos em um sistema. Ainda se caracteriza como um desafio. Desenvolver indicadores vinculantes, sinérgicos, que apresentam relações claras com os demais, indicando as diversas manifestações de um sistema.

Outro tipo de nomeação de indicadores são os indicadores de benchmarking. Eles são utilizados para realizar a comparação entre processos e produtos. Estes indicadores são, em alguns casos estudados da aplicação da ferramenta de benchmarking, indicadores de desempenho (IWA, IRAR), e em outros casos, indicadores de desempenho associados à indicadores ambientais e indicadores mais qualitativos (PNQS), não existindo uma definição para indicadores de benchmarking, esses indicadores são classificados dessa forma devido ao objetivo de utilização dos mesmos.

Os indicadores utilizados no presente trabalho são indicadores de benchmarking, devido ao objetivo de utilização dos mesmos, acrescidos das lentes da sustentabilidade (indicadores da terceira geração). Os SAA\&ES necessitam de indicadores transversais, que se vinculem em um sistema maior que considere dimensões as quais compreendam a realidade complexa dos serviços, ou seja, coloca-se o enfoque nos indicadores de sustentabilidade, esta conceituação está detalhada no subcapítulo seguinte.

\subsection{Incorporando as lentes da sustentabilidade nos indicadores de benchmarking dos SAA\&ES}

Os indicadores dos SAA\&ES devem ser pautados na visão da sustentabilidade, essa visão inclui as populações que por vezes são excluídas dos sistemas do crescimento a qualquer custo, que privilegia poucos em detrimento de muitos. Por isso a necessidade de indicadores e sistema de informação que possam ir além das informações puramente 
financeiras e operacionais, como é mais comumente considerada pela forma de vida adotada pela sociedade, auxiliando a sociedade no sentido de encontrar vias de vislumbrar o desenvolvimento e a sustentabilidade. Essa opinião é compartilhada e bem colocada por Malheiros, Philippi Jr e Coutinho (2006, p. 96):

“... a escolha de indicadores que dêem suporte ao processo de tomada de decisão deve possibilitar enfoque na eficiência, equidade e qualidade de vida, não podendo este desenvolvimento ser confundido com crescimentos apenas, mas sim a possibilidade da geração atual e a de seus filhos viverem uma vida feliz, sem dilapidar a saúde e a base de recursos naturais."

Teoricamente esta concepção é correta e adequada para vencer os desafios da atualidade, sob este enfoque dos SAA\&ES, no entanto essa concepção ainda não é praticada. O desafio que se mostra na construção e na utilização desses indicadores é que eles sejam ao mesmo tempo simples, que transpareçam a ideia, que sejam fáceis de preencher e entender os seus significados, e também mostrem a complexidade, a visão do todo em um sistema que possui diversas faces. Assim como a absorção e utilização desses nos processos de melhoria e mudanças da cultura organizacional, pois os indicadores mostram cenários, mas a proposta de melhoria e transformação deve vir das organizações. (MALHEIROS; PHILIPPI JR; COUTINHO, 2006).

Nesse caso dos indicadores dos SAA\&ES, são de caráter multidimensional, ou seja, a tendência dos indicadores é que por meio das lentes da sustentabilidade, multidimensionais, possa haver o entendimento da problemática dos serviços, indicadores que relacionem as dimensões.

As metas de universalização dos SAA\&ES devem estar de acordo com a sustentabilidade. A regulação dos serviços e as escolhas feitas pelas concessionárias devem seguir a mesma direção. Desta forma, os indicadores que estão sendo utilizados caracterizam-se como indicadores de benchmarking com a tendência a serem indicadores de sustentabilidade, ou seja, se aproximam mais dos indicadores de sustentabilidade sob a luz do benchmarking. Indicadores de sustentabilidade da segunda geração, com a tentativa de desenvolvimento para que se aproximem dos indicadores da terceira geração. Indicadores que podem proporcionar uma visão integrada do 
funcionamento dos SAA\&ES, considerando a rede complexa de inter-relações, e possibilitar a exposição das fragilidades e potencialidades dos serviços. Estes indicadores diferem dos tradicionais indicadores de desempenho.

Após a classificação dos indicadores, percebeu-se a necessidade destes indicadores estarem vinculados a um sistema de indicadores, a uma estrutura que possibilitasse a visão por meio da organização dos indicadores e que eles pudessem ser avaliados em conjunto. A explicação da importância e os tipos de sistemas de indicadores estão abrangidos a seguir.

\subsection{Sistema de indicadores}

Sistemas de indicadores podem proporcionar a visão integrada do funcionamento dos SAA\&ES e expor as fragilidades e potencialidades dos serviços, avaliando os fatores que orientam as ações para o funcionamento dos serviços, a pressão exercida das diversas partes envolvidas, o impacto das ações de mudança e as respostas a partir de determinadas ações. É elemento necessário para contextualizar, qualificar os indicadores, os quais são necessários para realizar uma decisão apropriada (MEADOWS, 1998; BOSSEL, 1999; ALEGRE et al, 2006).

Para avaliar uma situação tentando aproximá-la da realidade dos SAA\&ES, no tocante à qualidade e fornecimento às populações vulneráveis, é necessária observar as diversas relações existentes, e para lidar com tantas informações e reconhecer quais realmente são mais relevantes, é preciso o auxílio dos sistemas de indicadores, para poder-se visualizar sob o olhar das multirrelações existentes, e ao mesmo tempo, de forma mais simples, organizada e enxuta.

Os sistemas de indicadores permitem unir em um mesmo sistema paradigmas de diferentes autores, diferentes problemas que necessitam de tipos variados de informações, e tendo como consequência positiva a informação de níveis de tomadores de decisão com finalidades variadas. Para isto, é necessário que a escolha do sistema e proposição dos indicadores seja feita com a pluraridade de opiniões, que esta pluraridade não seja apenas reconhecida, mas apreciada (MEADOWS, 1998; BOSSEL, 1999). 
No entanto, não são todos os sistemas que possuem as características descritas acima. Os sistemas são criados e utilizados de acordo com a necessidade e finalidade. As perguntas que se expõem são: Qual o sistema que melhor atende as exigências para medir a qualidade e o fornecimento dos SAA\&ES às populações vulneráveis? Quais são as informações necessárias de serem mostradas, que permita a melhoria dos serviços? E valendo-se também das perguntas feitas por Meadows (1998, p. 40), a respeito da construção de sistemas de indicadores:

"Que sistema faz sentido intuitivamente, captura as importantes relações entre os vários indicadores e ilustram suas relações com outros? O que poderia ser mostrado do ritmo, direção da situação presente, que poderia alterar o ritmo, a direção e as forças políticas de mudanças?” (Tradução própria)

Ou seja, o sistema deve contemplar essas perguntas e ser capaz de incluir apenas a informação fundamental, com a visão de que realmente é essencial. A quantidade de indicadores e as perspectivas a serem considerados no sistema de indicadores devem ser estabelecidas por meio de princípios os quais permitam aproximar o máximo possível das complexas relações existentes na realidade, destacando a necessidade do enfoque sistêmico (MEADOWS, 1998; BOSSEL, 1999; MALHEIROS, PHILIPPI JR, COUTINHO, 2006). A seguir, apresentam-se alguns sistemas existentes.

\subsubsection{Modelo de análise Pressão-Estado-Impacto-Resposta (PEIR)}

A matriz PEIR é um instrumento analítico que permite estabelecer um vínculo lógico entre seus componentes de forma a dirigir a avaliação do estado do meio ambiente, desde os fatores que estabelecem uma pressão sobre os recursos naturais (e que podem ser entendidos como as "causas" do seu atual estado), até cada uma das respostas locais acerca de como lidar com os problemas ambientais, incluindo os SAA\&ES.

A matriz se divide em indicadores de Pressão, Estado, Impacto e Resposta (PEIR). Os indicadores de pressão (P) descrevem que ações ou situações que estão causando os problemas no sistema. É considerada a motivação, sob a perspectiva política, para atender as questões ambientais. Os indicadores de estado (E) constituem- 
se de indicadores com a função de mostrar a situação em que se encontra determinado sistema, a partir da pressão exercita, descrevendo o efeito sobre a saúde humana, sobre o ambiente, a sociedade. Os indicadores de impacto (I) visam medir as mudanças no estado do sistema, podendo auxiliar evitando novos impactos no sistema e os indicadores de resposta $(\mathrm{R})$ mostram as atitudes que estão sendo tomadas no sentido de modificar o cenário do sistema atual e/ou prevenir danos. Atitudes que podem ser em escalas individuais, coletivas, políticas, como a mudança de hábitos nocivos, regulamentação de leis, mudança de estratégias de gestão, exigência de informações públicas (PINTÈR, 2000; PNUMA, 2004).

A matriz PEIR permite analisar por meio de uma lógica linear os componentes que incidem sobre os SAA\&ES, por ser um instrumento útil e eficaz para discutir e avaliar temas como a democratização das políticas públicas, a descentralização da gestão do estado e a universalização dos serviços públicos (PNUMA, 2004).

Esses indicadores permitem traçar cenários futuros. Tanto positivos, de acordo com as respostas e ações das variadas formas de participação, como negativas, caso existam pressões e impactos maiores que as respostas dadas. A construção de cenários de análise possibilita a tomada de postura a respeito de situações antes de transcorrê-las, visto que possam ser situações desagradáveis, e até mesmo, irreversíveis. Direcionando decisões voltadas à sustentabilidade, de maneira acessível ao entendimento dos tomadores de decisão e à sociedade (PINTÊR, 2000).

O modelo consegue expor os vínculos existentes entre as causas e os efeitos, explorando a análise geral do sistema, com as diversas dimensões da tomada de decisão, possibilitando que sejam feitas escolhas apropriadas para a modificação da situação em vista da melhoria, realizando um ciclo contínuo de melhoria.

O PEIR vem sendo bastante utilizado na metodologia dos relatórios GEOGlobal Environment Outlook, produzidos periodicamente com apoio do PNUMA desde 1995, com informações sobre o estado do meio ambiente em nível global, regional, subregional, nacional e local. Destaque é dado ao GEO - Cidades, que tem como objetivo fundamental promover melhor entendimento da interação entre o desenvolvimento urbano e o meio ambiente, de forma a subsidiar governos locais - formuladores de 
políticas públicas e o público em geral - com informações precisas venham a auxiliar no planejamento e na gestão urbano-ambiental (PNUMA, 2004). Diversas cidades no mundo e no Brasil, tais como São Paulo, Rio de Janeiro, Manaus, adotaram esta metodologia. Portanto, a proposta do seu uso enfocando a universalização dos SAA\&ES surge na perspectiva de complementar a proposta presente no programa do PNUMA.

Em relação ao fornecimento dos SAA\&ES às populações vulneráveis, o modelo pode verificar: a pressão exercida, com indicadores do aumento do número de pessoas em situação de vulnerabilidade que necessitam serem atendidas pelos serviços $(\mathrm{P})$; o estado, com indicadores da situação da infraestrutura dos serviços existentes (E); o impacto, com indicadores do bem estar da população (I) e a resposta, com indicadores de melhoria da situação, como as implementações de políticas e disponibilização de subsídios econômicos. A figura 11 mostra a matriz PEIR aplicada aos SAA\&ES voltados às populações vulneráveis.

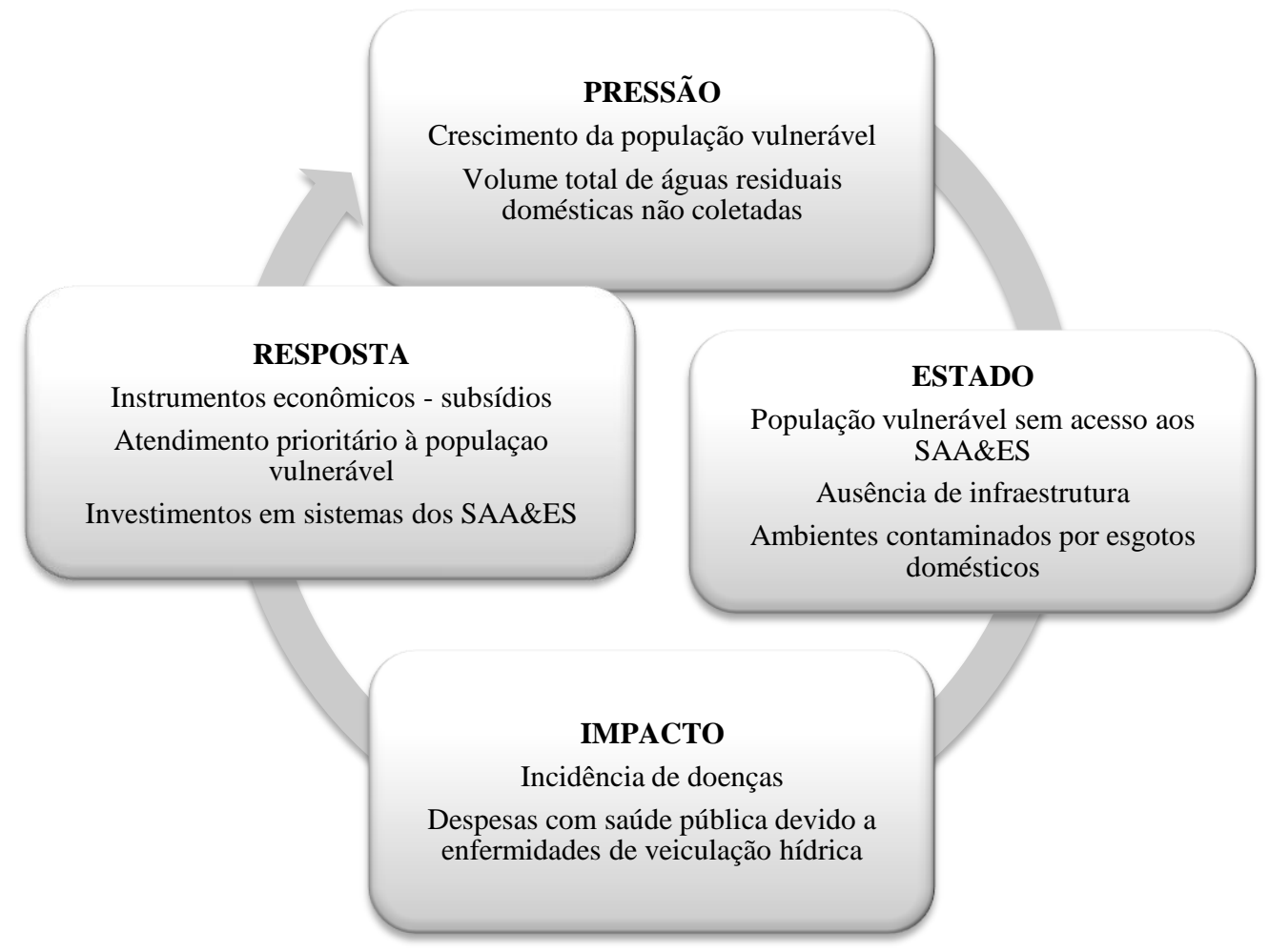

Figura 11. Modelo PEIR nos SAA\&ES voltados às populações vulneráveis.

Fonte: Elaboração própria

Os desafios do sistema estão relacionados à obtenção de dados e a utilização do instrumento pelas operadoras dos serviços, agências reguladoras, instituições 
governamentais e pela sociedade. Além disso, o GEO Cidades ainda não possui indicadores que possam dar respostas às expectativas referentes à universalização dos SAA\&ES, nem mostrar os desafios a enfrentar para dar cobertura dos SAA\&ES às populações vulneráveis.

Apesar do modelo ser de fácil visualização, entendimento e aplicação, este apresenta fragilidade por ter uma lógica linear, não abrangendo a complexidade sistêmica existente. Não conseguem mostrar os relacionamentos e a dinâmica da realidade, é uma abordagem de cadeias isoladas de causa e efeito (BOSSEL, 1999). O modelo expõe vínculos entre causas e efeitos, mas numa lógica linear, avaliando o problema (efeito) em função de sua causa, e a partir desta, a busca da solução. Estes fatores podem levar a uma interpretação simplificada das inter-relações (MARZALL e ALMEIDA, 2000). E, ainda, em determinados casos, as distribuições de pressão, estado e resposta se confundem.

\subsubsection{Sistema dos indicadores de desempenho IWA}

O sistema IWA de indicadores faz uso de indicadores de desempenho. Este sistema é resultado das diferentes visões dos atores de diversos países no setor de abastecimentos e esgotamento sanitário, levando em consideração as companhias, os usuários, o ambiente, e toda a área que será monitorada pelo sistema (ALEGRE et al., 2006).

Utilizam indicadores de desempenho para medir a eficiência e eficácia dos serviços avaliados de acordo com a combinação de variáveis e comparados ao objetivo a ser alcançado (benchmark). Os indicadores de desempenho podem mostrar a situação atual e comparar com os objetivos de melhoria e ser feito o monitoramento da melhoria. A IWA apresenta em seu manual um sistema de indicadores de desempenho, que pode ser usado da maneira que foi elaborado ou pode ser completado ou simplificado de acordo com as necessidades particulares (ALEGRE et al., 2006).

O sistema IWA estabelece critérios de qualidade para os indicadores individualmente como também critérios de qualidade a serem atendidos pelo sistema. Os critérios a serem cumpridos pelos indicadores individualmente são: ser definido 
claramente, com significado conciso; ser exequível; ser auditável; ser mais universal possível e promover a medição que seja independente de uma condição particular dos serviços; ser simples e fácil de entender; e ser quantificável para fornecer um objetivo mensurável para o serviço, evitando qualquer avaliação pessoal ou subjetiva. E os critérios a serem cumpridos coletivamente são: todos os indicadores de desempenho devem fornecer informação significantemente diferente de outro indicador de desempenho do sistema; definições dos indicadores devem ser inequívocas; somente o indicador considerado essencial para a efetiva avaliação do desempenho deve ser estabelecido (ALEGRE et al., 2006).

Os objetivos do sistema IWA de indicadores são baseados: (i) No fornecimento de indicadores consistentes, que sejam priorizados e úteis às operadoras; (ii) Ser um sistema o mais universal possível; e (iii) Ser útil para todos os atores que desempenham papel no setor dos SAA\&ES, mas voltados especificamente a utilização das operadoras. E descreve que, ao contrário do que geralmente acreditam, o sistema IWA deve ser considerado como uma ferramenta muito flexível e adaptável (ALEGRE et al., 2006).

A estrutura do sistema é organizada de acordo com seis dimensões: recursos hídricos, pessoal, físico, operacional, qualidade dos serviços e econômico e financeiro. Cada uma destas dimensões está explicada conforme segue:

A dimensão de Recursos Hídricos - Esta dimensão tem o foco de verificar as características de qualidade e quantidade dos recursos hídricos utilizado. As características dos recursos hídricos variam de caso a caso, tanto em quantidade quanto qualidade. Os indicadores IWA são limitados aos aspectos comuns de interesse.

A dimensão Pessoal - Essa dimensão refere-se a avaliação da eficiência dos recursos humanos em termos de qualificação, treinamentos, saúde, segurança do trabalho e horas extras.

A dimensão Física - Esta dimensão faz a avaliação do estado e funcionamento do sistema. Os principais componentes considerados nessa dimensão são: tratamento, armazenamento, bombeamento e redes de transmissão e distribuição. 
A dimensão Operacional - Esta dimensão se refere a manutenção e operação do sistema. Parte da eficiência das operadoras dos SAA\&ES pode ter prejuízo ou ser melhorada com essas atividades. Para a melhoria contínua do sistema os gestores necessitam monitorar as atividades planejadas por inspeção, manutenção preventiva e reabilitação.

A dimensão da Qualidade dos Serviços - Esta dimensão refere-se ao bom funcionamento dos serviços, sendo a avaliação da qualidade necessária na administração do sistema. Indicadores de qualidade dos serviços são recomendados principalmente para conhecer a extensão da cobertura dos serviços dentro da área de influência da operadora e o desempenho dos serviços em termos de qualidade e quantidade.

A dimensão Econômico-financeira - Esta dimensão refere-se ao controle dos aspectos econômicos e financeiros mais descritivos de receitas, custos, investimentos, encargos da água, e outra parte possui aspectos de eficiência, sistemas de alavancagem, rentabilidade e perdas de água.

Das seis dimensões que possuem no sistema IWA, pode-se observar que é abrangente e complexa a estrutura, ela é composta por mais de 140 indicadores, no entanto, o sistema IWA não faz nenhum tipo de menção referente ao controle social dos serviços. Além disto, o sistema IWA tem como foco a utilização dos indicadores pela operadora, na melhoria do desempenho e não na melhoria ou universalização dos serviços, não fazendo nenhuma referência a priorização de atendimento de determinadas populações ou tarifas sociais aplicáveis às populações menos privilegiadas. Vale lembrar que este sistema é utilizado principalmente por países desenvolvidos (países da Europa e Canadá), os quais possuem um cenário de desigualdade mais amena da realidade vivenciada no Brasil.

\subsubsection{Indicador de Salubridade Ambiental - ISA}

Este sistema foi criado com o objetivo de uniformizar os dados, informações, critérios e formas de cálculos relacionados à salubridade ambiental. Salubridade entendido como "qualidade ambiental capaz de prevenir a ocorrência de doenças 
veiculadas pelo meio ambiente e de promover o aperfeiçoamento das condições mesológicas favoráveis à saúde da população urbana e rural" (Lei 7750, artigo $2^{\circ}$, inciso II).

Procura representar o estágio de salubridade de acordo com a infraestrutura de saneamento, controle de vetores e agrotóxicos, condições socioeconômicas relativas à saúde pública, renda e educação. O objetivo também da criação do ISA é a comparabilidade entre municípios, possibilidade de colocar pesos às ponderações e a necessidade de limitar os dados e as informações a serem utilizadas sistematicamente disponíveis com a frequência desejada e aos facilmente tabuláveis (PIZA, 2000).

Ele serve para mostrar quais lugares devem ser mais rapidamente atendidos, quais lugares estão mais necessitados de salubridade e precisam de mudanças. O sistema ISA é composto por seis indicadores: água, esgoto, resíduos sólidos, vetores, recursos hídricos e socioeconômico. Dentro de todos os indicadores tem o que o autor chama de subindicadores, estão descritos no quadro seguinte.

\begin{tabular}{|c|c|}
\hline Indicadores ISA & Subindicadores ISA \\
\hline \multirow{3}{*}{ Indicador de abastecimento de água } & Cobertura \\
\hline & Qualidade da água distribuída \\
\hline & Saturação do sistema produtor \\
\hline \multirow{3}{*}{ Indicador de Esgoto sanitário } & Cobertura de coleta de esgoto e tanques sépticos \\
\hline & Esgoto tratado e tanques sépticos \\
\hline & Saturação do tratamento \\
\hline \multirow{3}{*}{ Indicador de resíduos sólidos } & Coleta de lixo \\
\hline & Tratamento e disposição final \\
\hline & Saturação da disposição final \\
\hline \multirow{3}{*}{ Indicador de controle de vetores } & Dengue \\
\hline & Esquistossomose \\
\hline & Leptospirose \\
\hline \multirow{3}{*}{ Indicador de recursos hídricos } & Água bruta \\
\hline & Disponibilidade dos mananciais \\
\hline & Fontes isoladas \\
\hline \multirow{3}{*}{ Indicador sócio-econômico } & Saúde pública \\
\hline & Renda \\
\hline & Educação \\
\hline
\end{tabular}

Quadro 7. Indicadores e subindicadores ISA.

Fonte: Piza, 2000

O ISA possui indicadores que tem como princípio a representação do estágio de salubridade que os municípios se encontram. Não possui dimensões definidas, mas tem princípios que podem ser considerados como norteadores das dimensões, que em sua essência poderiam inclusive ser denominados de dimensões. Esses princípios estão 
focados em representar a situação sanitária atual, mas não possuem outros interesses relacionados à transformação do cenário como princípios/dimensões relacionadas a melhoria da gestão, mobilização social, mecanismos políticos, então é focada na saúde pública e nos recursos hídricos.

\subsubsection{Modelo de Indicadores do grupo Balaton organizado por Donella Meadows}

Esse modelo de indicadores é baseado no diagrama criado há mais de 20 anos. Ele retrata a relação entre a economia humana e a terra em um caminho que é lógico,

sistemático e explicativo. É chamado de "Triângulo de Daly". O triângulo relata as riquezas naturais para as propostas humanas no direcionamento da tecnologia, economia, políticas e ética, dando uma estrutura simples de integração. Daly, originalmente desenhou isso como um triângulo ou pirâmide, entretanto a figura não reflete a lógica colocada por ele, e nos seus últimos textos ele simplificou a figura em uma linha vertical. Na presente pesquisa, a representação será feita pela linha vertical, e também utilizando a representação gráfica de uma flor (Figura 12), como é utilizada no relatório Balaton (MEADOWS, 1998). 


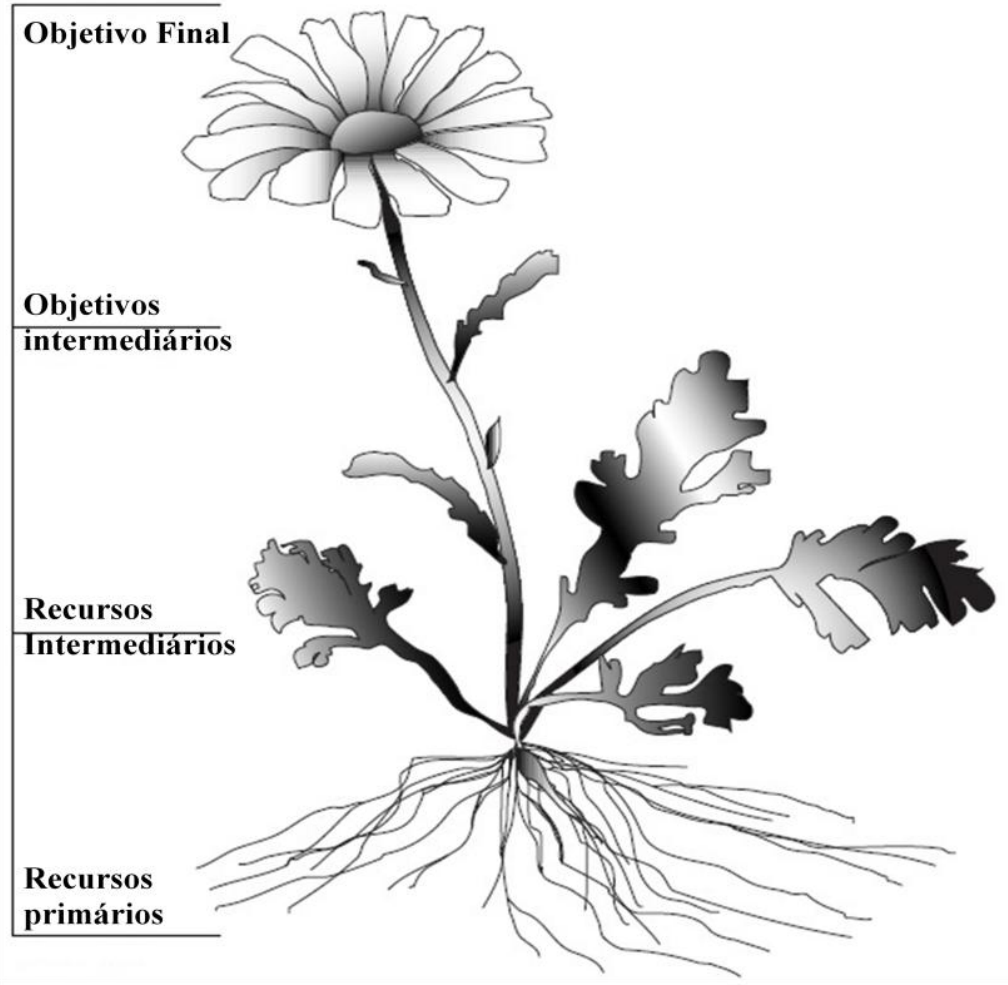

Figura 12. Representação do sistema de indicadores Balaton Group. Fonte: Meadows (1998, tradução própria).

Nas raízes da planta (inicialmente representada como a base do triângulo de Daly) chamou-se de recursos primários, os quais toda a vida e toda a transação econômica estão construídas e sustentadas, o também chamado de capital natural, são eles: energia solar, os ciclos biogeoquímicos, os ecossistemas e as informações genéticas.

Os recursos Intermediários, representado pelas folhas da planta, definem a capacidade de produção da economia, são chamados de capital de construção e capital humano, são: ferramentas, máquinas, laboratórios especializados, materiais processados e energia. É necessário, mas não suficiente para realizar todas as aspirações da outras dimensões relatadas.

O caule que sustenta a flor é chamado de objetivos intermediários. Representa as metas que se espera serem oferecida pelos governos e pela economia: saúde, comunicação, conhecimento, transporte. É o que todos precisam, mas não garante satisfação. Isso foi observado em sociedades em que os objetivos intermediários são 
abundantes, mas as pessoas ainda sentem as suas vidas incompletas. Isso é porque os objetivos intermediários não fins em si mesmos, mas instrumentos pra alcançar algo maior (objetivos finais). "A conversão depende de uma ética efetiva, ou religião, ou filosofia que pode responder que tipo as questões: o que é saúde? O que é riqueza? O que é educação? E qual o motivo de ser saudável? De ser rico? De ser educado? Que tipo de educação é essa?" (MEADOWS, 1998, p. 43).

A flor da planta, chamado de objetivos finais, é definido pelas palavras: felicidade, harmonia, autorealização, identidade. Demonstrando a discussão da qualidade e dos aspectos imateriais. Essa dimensão exige a existência de todas as outras dimensões (estruturas da planta) materiais para sustentá-lo. Ou seja, esse sistema mostra uma hierarquia, colocando graus de prioridades, a qual a prioridade principal se baseia na saúde da natureza e o bem-estar humano (MEADOWS, 1998).

Observa-se que, tanto na sociedade como um todo, e especificam nos SAA\&ES, existem mais indicadores do capital de construção e capital humano. Isso demonstra o modelo atual de desenvolvimento, que ainda está na lógica do sistema econômico que prioriza o capital de construção, capital humano, a priorizar o capital natural e o bemestar humano. Ou seja, esse modelo permite observar que a qualidade de vida não é priorizada e não possui indicadores de objetivo final de satisfação imaterial, pois ainda se mostra distante da realidade. E para o mesmo quadro de dimensões, existe objetivo final que é a melhoria da qualidade de vida de determinada população. Vale ressaltar a existência da dificuldade de medição dessas características que são subjetivas e qualitativas.

\subsubsection{Modelo de indicadores PROBE - Sistema desenvolvido especifico dos SAA\&ES voltados às populações vulneráveis}

Esse modelo foi especificamente desenvolvido com o objetivo de utilizar como ferramenta de benchmarking dos SAA\&ES para a melhoria de atendimento voltados às populações vulneráveis. Ele foi desenvolvido por Ralda (2011) baseado na estrutura de benchmarking desenvolvida por Kaplan e Norton (1990) chamada Balanced Score Card (BSC). Posteriormente, aperfeiçoada para o chamado Sustainability Balanced Score Card-(SBSC). 
A estrutura do Balanced Score Card foi criada para atualizar as estratégias de negócios dentro de uma organização, apontar os objetivos da organização para os orçamentos anuais, permitir a mudança organizacional e aumentar a compreensão da visão e missão da instituição. A realização disso é feita por meio de um conjunto de objetivos e medidas de desempenho que possam ser quantificadas e avaliadas para observar se a gestão está conseguindo os resultados desejados (Kaplan e Norton, 1996). Essa avaliação é feita com quatro perspectivas diferentes - financeira, cliente, negócios internos e inovação e aprendizagem, que se inter-relacionam, conforme pode ser vista na Figura 13.

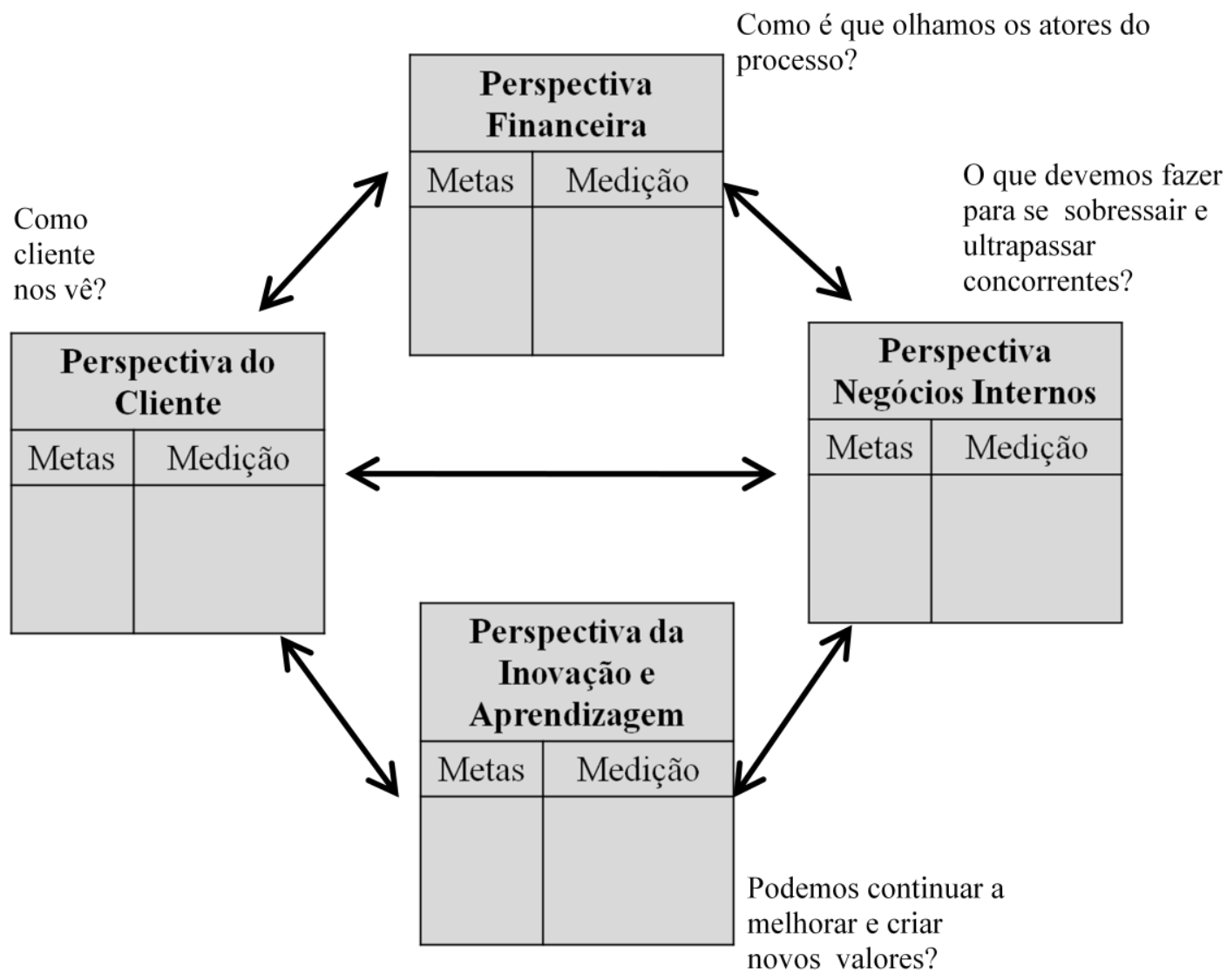

Figura 13. Balanced Score Card, esquema e perspectivas.

Fonte: Kaplan e Norton (1992, tradução própria).

Balanced Score Card é a combinação de três componentes:

(1) Sistema de medição: traduzir a visão e estratégia através dos objetivos e medidas definidos. Metas e objetivos mensuráveis são os fatores mais importantes para uma estratégia bem sucedida. 
(2) Sistema de gestão estratégica: alinhar as ações a curto prazo com a estratégia e remover as barreiras para a implementação estratégica a longo prazo.

(3) Ferramenta de Comunicação: descrever as estratégias e trazer ciência aos trabalhadores. Uma vez conscientes das estratégias, pode contribuir para o objetivo global.

O BSC consiste de um conjunto de indicadores que são agregados em perspectivas, que tem sido utilizado como uma ferramenta de benchmarking pela VEWIN (Sigla em inglês de associação de empresas de abastecimento de água da Holanda), em aplicação ao setor da água, com o objetivo de fornecer informações para melhorar os processos de empresas de abastecimento de água. Eles empregam quatro categorias para medir o desempenho: indicadores de qualidade da água, qualidade do serviço, impactos ambientais, financeiros e de eficiência (BLOKLAND, 2009).

A estrutura do BSC foi melhorada, sendo incluídas duas perspectivas: social e ambiental. Formou-se assim o Sustainability Balanced Score Card (SBSC). O BSC e SBSC são ambas abordagens conceituais para medir o desempenho organizacional.

Baseado nestas estruturas foi desenvolvido por Tynan e Kingdom (2002) um sistema para medir o desempenho organizacional, mais especificamente, para medir o bom desempenho de serviços públicos de abastecimento de água e esgotamento sanitário. A estrutura desenvolvida possui o caráter da simplicidade. Seu esquema de benchmarking é composto por sete perspectivas, cada uma destas perspectivas tem apenas um indicador, o que torna o sistema muito prático. As categorias do sistema são: eficiência operacional, recuperação de custos, desempenho comercial, cobertura e acesso, gerenciamento de ativos da qualidade dos serviços, preço e acessibilidade.

O quadro dos sistemas citados acima reflete a base que Ralda (2010) criou o sistema de benchmarking dos SAA\&ES direcionada às populações vulneráveis. Mostrando um arranjo que prioriza pela simplicidade e clareza, e também por princípios que regem a prestação dos SAA\&ES justo e equitativa, sustentável em termos ambientais, econômico e social. Além disto, a estrutura foi criada após a listagem de fatores de sucesso dos SAA\&ES. 
O modelo é composto por cinco perspectivas que mostraram-se essenciais para integrar em um arranjo lógico a lista dos fatores, visto o propósito da estrutura é uma ferramenta prática e simples. A formação e organização deste quadro é semelhante aos apresentados por Tynan e Kingdom, bem como Kaplan e Norton, composto por perspectivas e indicadores dentro delas. Estas são as perspectivas do modelo: preparação, colaboração, ferramentas, sustentabilidade e prestação de serviços.

Essas perspectivas estão interagindo umas com as outras, elas podem ser representadas por cinco círculos sobrepostos (Figura 14), que representam as perspectivas em integração, ou seja, representam atividades que precisam ser realizadas com os mesmos objetivos compartilhados por diferentes atores, atividades que necessitam de sobreposição para canalização e maximização de recursos, que irá impedir o surgimento e aparecimento de atividades isoladas (RALDA, 2010).

A perspectiva de preparação deve fornecer informações sobre as iniciativas e suporte político, a capacidade de organização do governo local e a capacidade das prestadoras dos serviços de água e esgoto; a perspectiva de colaboração deve gerar dados sobre o trabalho conjunto entre agências e participação do usuário final; a perspectiva ferramentas deve produzir informações sobre o mapeamento da pobreza, mecanismos financeiros e de tecnologias dos serviços de saneamento voltadas às população em situação de pobreza; a perspectiva de sustentabilidade deve trazer informações sobre a inovação, aprendizagem e durabilidade dos serviços de água e esgoto; e, a perspectiva prestação de serviços deve obter dados sobre a qualidade dos serviços de saneamento às populações em situação de pobreza e da qualidade dos serviços de abastecimento de água servidos à essa população (RALDA, 2010) 


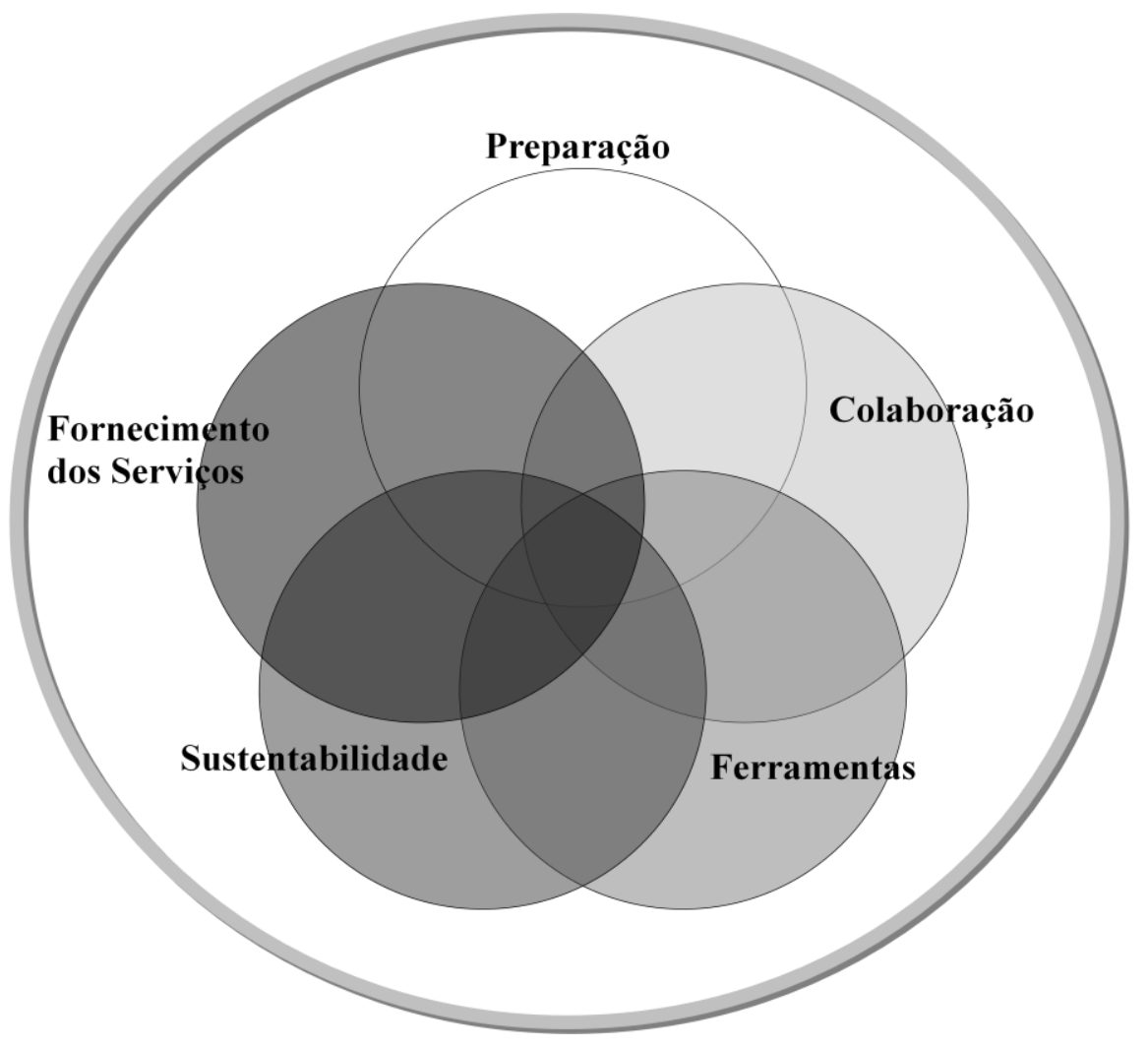

Figura 14. Perspectivas e indicadores de prestação de serviços de saneamento a populações vulneráveis. Fonte: Ralda (2010, tradução própria).

Cada uma destas perspectivas possui indicadores, totalizando 12 deles. Os quais podem ser vistos no Quadro 8.

\begin{tabular}{|c|l|}
\hline Perspectiva & \\
\hline \multirow{2}{*}{$\begin{array}{c}\text { Estado de } \\
\text { Preparação }\end{array}$} & 1. Suporte e iniciativa Política \\
\cline { 2 - 2 } & 2. Capacidade de organização do governo local \\
\cline { 2 - 2 } Colaboração & 3. Capacidade das operadoras em fornecer os SAA\&ES \\
\cline { 2 - 2 } & 4. Colaboração entre agências \\
\cline { 2 - 2 } Ferramentas & 6. Usuário final ou Participação comunitária \\
\cline { 2 - 2 } & 7. Instrumentonto da Pobreza \\
\cline { 2 - 2 } & 8. Tecnologianceiros de atendimento aos pobres \\
\hline \multirow{2}{*}{ Sustentabilidade } & 9. Inovação e aprendizagem \\
\cline { 2 - 2 } & 10. Durabilidade \\
\hline Fornecimento dos & 11. Qualidade dos serviços de esgotamento sanitário no atendimento aos pobres \\
\cline { 2 - 2 } serviços & 12. Qualidade dos serviços de abastecimento de água no atendimento aos pobres \\
\hline
\end{tabular}

Quadro 8. Indicadores e perspectivas.

Fonte: Ralda (2010, tradução própria).

Este modelo foi construído para ser usado por múltiplas partes interessadas (operadores dos SAA\&ES, governos locais e usuários dos serviços), com o intuito de medir o grau de conhecimento, atitudes e valores está sendo desenvolvido para a 
promoção dos SAA\&ES às populações vulneráveis, assim como o monitoramento destas ações.

Conforme exposto anteriormente, a formulação de modelos permite um olhar sistêmico do que se quer avaliar, permite a inserção de indicadores estratégicos em elucidar as situações da realizadade presente. Dessa forma pode-se vislumbrar avaliações melhor estruturadas, embasadas e mais possíveis de obter boas respostas. A construção ou escolha de sistemas de indicadores é parte importante do processo de utilização de indicadores. Outra parte relevante é o processo de formulação dos indicadores, as definições de como eles devem ser construídos e as caraterísticas de qualidade de indicadores. Essa explicação pode ser visto no subcapítulo seguinte.

\subsection{A construção de indicadores}

Para que os indicadores atendam a boa qualidade há uma diversidade de recomendações necessárias a serem consideradas no processo de elaboração. O processo de construção de indicadores é trabalhoso e de difícil alcance da qualidade ideal, mesmo seguindo todas as recomendações necessárias, os indicadores ainda podem ter incertezas. Apesar das dificuldades e incertezas na elaboração, os indicadores são necessários. As fragilidades na elaboração devem ser consideradas para que os indicadores se aproximem cada vez mais de indicadores ideais (MEADOWS, 1998).

A criação de indicadores deve estar vinculada a um sistema de informação que proporcione uma visão mais complexa e real da situação. A escolha destes indicadores devem obedecer a princípios colocados no Quadro 9, onde as características e propriedades desejáveis são descritas para aplicação de indicadores por Malheiros,

Philippi Jr e Coutinho (2006). Cabe lembrar que estas características expostas no Quadro 9 é comumente utilizada para caracterizar bons indicadores por diversos autores (OECD, 1993; GALLOPÍN, 1997; MEADOWS, 1998; BOSSEL, 1999; GEO, 2008). 


\begin{tabular}{|l|l|l|}
\hline & Critérios & Explicação \\
\hline 1 & $\begin{array}{l}\text { Claro, compreensível e } \\
\text { interessante }\end{array}$ & $\begin{array}{l}\text { Evitar incertezas em relação ao que é bom e ruim, fácil de entender, } \\
\text { com unidades que tenham sentido, e sugestivos para a efetiva ação }\end{array}$ \\
\hline 2 & Relevante & Politicamente relevantes para todos os participantes do sistema \\
\hline 3 & Viável & Custo adequado de aquisição e processamento de dados e comunicação \\
\hline 4 & Suficiente & Fornecer a medida certa de informação \\
\hline 5 & Oportuno & Oportuno temporalmente, integrado com o planejamento \\
\hline 6 & Apropriado na escala & Apropriado a diferentes usuários potenciais \\
\hline 7 & Democrático & $\begin{array}{l}\text { Diversidade e ampla participação na escolha e acesso aos resultados. } \\
\text { Os indicadores não devem ser determinados por um pequeno grupo de } \\
\text { especialistas, mas devem envolver lideranças políticas e pessoas da } \\
\text { comunidade. Especialistas são importantes na definição de } \\
\text { metodologias e cálculos, porém, deve-se balancear o que é } \\
\text { tecnicamente possível com o que é politicamente desejável }\end{array}$ \\
\hline 8 & Medida Física & $\begin{array}{l}\text { Balancear, na medida do possível, unidades físicas (tonelada de óleo, } \\
\text { anos de vida saudável) e monetárias }\end{array}$ \\
\hline 9 & $\begin{array}{l}\text { Preventivo e proativo } \\
\text { Deve conduzir para a mudança, fornecendo informação em tempo para } \\
\text { poder agir }\end{array}$ \\
\hline 10 & $\begin{array}{l}\text { Não deve pretender ser } \\
\text { uma } \\
\text { estanque }\end{array}$ & $\begin{array}{l}\text { Deve estar inserido num processo de melhoria contínua, passível de } \\
\text { discussão, de aprendizado e de mudança }\end{array}$ \\
\hline
\end{tabular}

Quadro 9. Boas práticas no processo de escolha de indicadores.

Fonte: Malheiros, Philippi Jr e Coutinho (2006)

Lembrando que os indicadores são reflexos parciais da realidade, baseados em modelos incertos e imperfeitos. Pois os indicadores não formulados por pessoas ou grupos de pessoas, as quais criam os indicadores carregamos os modelos mentais, suposições, hipóteses a respeito do mundo, com base em suas personalidades, cultura, língua, formação e experiência. Ou seja, os indicadores são imperfeitos. O objetivo é reduzir as incertezas (MEADOWS, 1998).

Deste modo, deve existir prudência na escolha dos indicadores, pois quando indicadores são escolhidos de maneira imprudente, podem causar funcionamentos prejudiciais ao sistema, sendo determinante crítico do comportamento do sistema. Meadows (1998) relata que o processo de escolha dos indicadores possui armadilhas e ameaças que devem ser considerados no momento de escolha e desenvolvimento de indicadores, as quais se visualizam as fragilidades e dificuldades deles e possibilita projetar melhores indicadores. Estas fragilidades na elaboração, descritas no Quadro 10, devem ser consideradas para que se aproximem cada vez mais de indicadores ideais. 


\begin{tabular}{|l|l|l|}
\hline 1 & Erros comuns & Explicação \\
\hline Agregação exagerada & $\begin{array}{l}\text { Se muitos dados forem reunidos, a mensagem final que ele acarreta } \\
\text { pode ser indecifrável. Um bom exemplo é o PIB (produto interno } \\
\text { bruto), que junta tanto o fluxo monetário por mudanças boas (educação, } \\
\text { saúde, etc), quanto pelas mudanças ruins (aumento do número de } \\
\text { internações, do crime, etc) }\end{array}$ \\
\hline 2 & $\begin{array}{l}\text { Medir o que é } \\
\text { mensurável em } \\
\text { detrimento de medir o } \\
\text { que é importante }\end{array}$ & $\begin{array}{l}\text { Como exemplo clássico tem-se a medida da riqueza das pessoas em } \\
\text { valores monetários, em vez de medi-la pela qualidade de vida }\end{array}$ \\
\hline 3 & $\begin{array}{l}\text { Depender de falsos } \\
\text { modelos }\end{array}$ & $\begin{array}{l}\text { Por exemplo, pensar que a taxa de natalidade reflete a disponibilidade } \\
\text { de programas de planejamento familiar, quando, na verdade, reflete a } \\
\text { liberdade da mulher em utilizar tais programas }\end{array}$ \\
\hline 4 & $\begin{array}{l}\text { Falsificação deliberada } \\
\text { Se um índice carrega más notícias, alguns maus governantes são } \\
\text { tentados a perdê-los ou suprimi-los, mudando seus termos e definições. } \\
\text { O Brasil (IBGE, 2002) conta como desempregadas somente as pessoas } \\
\text { que efetivamente procuram por emprego, e não computam os que, } \\
\text { embora ainda desempregados, desistiram de procurar }\end{array}$ \\
\hline 5 & $\begin{array}{l}\text { Desviar a atenção da } \\
\text { experiência direta }\end{array}$ & $\begin{array}{l}\text { Percepções e experiências devem ser adequadamente inseridas na } \\
\text { escolha, análise e comunicação dos indicadores }\end{array}$ \\
\hline 6 & $\begin{array}{l}\text { Confiar demais nos } \\
\text { indicadores }\end{array}$ & $\begin{array}{l}\text { Levar em consideração a possibilidade de que os indicadores possam } \\
\text { estar incorretos }\end{array}$ \\
\hline 7 & $\begin{array}{l}\text { Ser um reflexo parcial da realidade, podem deixar de apresentar } \\
\text { detalhes }\end{array}$ \\
\hline
\end{tabular}

Quadro 10. Erros comuns a serem evitados no processo da escolha de indicadores.

Fonte: Meadows (1998)

Bossel (1999) coloca ainda alguns requisitos básicos da qualidade de bons indicadores, entre eles: (1) O número de indicadores deve ser o menor possível, mas não menor do necessário. Ou seja, deve ser ao mesmo tempo abrangente e compacto, cobrindo todos os aspectos relevantes; (2) Os indicadores devem ser claramente definidos, reprodutível, sem ambiguidades, compreensível e prático e (3) Devem refletir os interesses e pontos de vista dos diferentes atores.

Dentro deste aspecto, dos indicadores refletirem os interesses e pontos de vista dos diferentes atores, destaca-se a essencialidade de construí-los participativamente com diversas partes interessadas (GALLOPÍN, 1997; MEADOWS, 1998; BOSSEL, 1999; SANTOS, 2004; ALEGRE et. al. 2005; MALHEIROS; PHILIPPI JR; COUTINHO, 2006; REED, 2008). O próximo subcapítulo trata do processo de construção de indicadores por meio do processo participativo, a importância e as boas práticas de desenvolvê-lo. 


\subsubsection{O processo participativo na formulação de indicadores}

O conceito de participação está associado à democracia deliberativa, sendo entendida como um processo continuado de democratização da vida dos cidadãos (JACOBI, 2005). A palavra democracia tem sua origem na Grécia Antiga: demo (povo) e kracia (governo). Os gregos construíam a base de uma teoria a qual o governo fosse controlado por todo o povo, o povo partilhando direitos, deveres e responsabilidades e participando pessoalmente do exercício do poder (LEROY, PACHECO, 2005)

A democracia é um sistema que supõe e nutri a diversidade de interesses e de ideias. Desenvolve-se e é construída por meio da pluralidade, mostrando ser um sistema inacabado, composto de carências e lacunas (MORIN, 2000). O desenvolvimento da democracia na sociedade brasileira ainda é um desafio, isso pode ser devido ao histórico de exploração, repressão e de anulação dos sujeitos, submissos ao poder (FREIRE, 1980). Histórico este que mostra-se contrário à prática da democracia que caracteriza a política em que o homem participe, pois antes de ser forma política é forma de vida. A civilização tecnológica e antidemocrática traz à população a rigidez mental e deixa de assumir uma consciência crítica, massificando-se. Por este motivo a importância da reflexão e transição de pensamentos e ações como essência:

“A própria essência da democracia envolve uma nota fundamental, que lhe é intrínseca: a mudança. Os regimes democráticos se nutrem na verdade de termos em mudança constante. São flexíveis, inquietos, devido a isso mesmo, deve corresponder ao homem desses regimes, maior flexibilidade de consciência." (FREIRE, 1980, p. 90).

Leroy e Pacheco (2005) lembram que a democracia é um processo, que tem como cenário as circunstâncias dadas que nos cercam e que estão sempre em mutação contínua.

Para Jacobi (2005) são importantes valores como a igualdade e o pluralismo políticos, a deliberação e a solidariedade no processo participativo para que seja exercida a democracia com legitimidade. Da mesma forma, Reed (2008) enfatiza que o processo participativo precisa ser sustentado pela autonomia, igualdade, confiança e aprendizado entre as pessoas. Esses valores devem ser praticado da seguinte forma: (i) 
mediação das pessoas no processo participativo, ou seja, assegurar que os participantes tenham realmente o poder de influenciar as decisões, (ii) que os participantes tenham a capacidade técnica e entendimento da linguagem para participar efetivamente das decisões e (iii) se alguma decisão já foi feita ou não, pode realmente ser influenciada pelas partes interessadas, o processo participativo não deve ser realizado.

A participação é um processo que necessita de flexibilidade, adaptando-se às diferentes circunstâncias e mudanças, respondendo rapidamente aos contextos dinâmicos, e para isto é necessário um embasamento forte para orientar o desenvolvimento do processo.

Durante o processo participativo, existe uma série de atividades e cuidados que devem ser realizados, que propiciam o sucesso do processo participativo. No entanto, de que sucesso está sendo falado? O que considera-se sucesso no processo participativo? e estão descritos no decorrer do texto.

\subsubsection{Sucesso do processo participativo}

O desenvolvimento de uma única definição de sucesso no processo participativo é problemática por causa da diversidade de perspectivas sobre as metas de participação. Deste modo, colocou-se duas linhas orientadoras na definição e avaliação do sucesso: (1) participação com metas no resultado e (2) participação com metas no processo. Ambas utilizadas por Chess e Purcell (1999) em artigo direcionado à participação pública.

\section{(1) A participação como meta o resultado.}

A participação é avaliada de acordo com os resultados, e os próprios resultados é que julgam se os meios de participação foram bem sucedidos. Há variações consideráveis na definição de resultados positivos, pois vão depender do objetivo da participação, que podem ser desde o envolvimento dos cidadãos para políticas de desenvolvimento, programas de participação pública para construir planos. Cabe ressaltar que a avaliação dos resultados deve ser cuidadosa, pois a participação do público pode ser influenciada por outros eventos simultâneos, como as eleições, o contexto social em que as atividades ocorrem. 


\section{(2) A participação como meta o processo.}

Em vez de definir o sucesso de participação do público pelos resultados, pode ser definido pelo processo participativo utilizado. De acordo com essa perspectiva, as características dos significados são melhores que o resultados utilizados em programas de participação do público para definir o sucesso. A participação avaliada como processo explora questões como a justiça, a troca de informações, processos de grupo e procedimentos utilizados.

Essas duas definições permitem avaliar a participação em formatos distintos. $\mathrm{O}$ formato comumente avaliado é a meta nos resultados, o que mostra que a avaliação com meta no processo precisa ser desenvolvida. Deve-se chegar ao equilíbrio entre metas nos resultados e nos processos, ou seja, nem o processo "bom" nem resultado "bom" são suficientes por si só, o sucesso está na boa qualidade dos resultados e dos processos (CHESS, PURCELL, 1999).

\subsubsection{Objetivos construídos coletivamente}

A participação dos atores desde o início do processo é um dos cuidados para o sucesso do processo participativo. Quanto mais cedo iniciada a participação e o envolvimento nas tomadas de decisões, maior a possibilidade do processo participativo ter sucesso, a participação deve iniciar nas fases de preparação, planejamento e idealização do projeto a ser realizado. O envolvimento posterior pode ser prejudicial e não funcional (ESTRELLA; GAVENTA, 2000). Ou seja, é essencial garantir o engajamento dos atores nos processos participativos desde o início, pois a consequência desse cuidado são decisões de alta qualidade e duráveis (CHESS, PURCELL, 1999; REED, 2008). A incapacidade de assegurar uma representação adequada dos atores, pode levar a decisões que estão sendo vistos como falta de legitimidade. Também pode levar a uma falta de cooperação na execução por parte daqueles que foram "excluídos" do processo (TIPPETT et al., 2005).

Se as partes interessadas não forem convidadas a participar incorporando sugestões no desenho do projeto, pode acontecer que no momento que começarem a participar não concordem com as prioridades e necessidades estabelecidas. E como 
resultado previsível, será dificultado a motivação do envolvimento no processo de tomada de decisão, assim como os que estão envolvidos desde o início, são questionados a respeito de decisões que já foram finalizados (CHESS; PURCELL, 1999).

Outro aspecto importante no processo participativo de formulação de indicadores, é ter objetivos claros do que se quer alcançar, a fim de projetar um processo apropriado com o uso de ferramentas relevantes. Isto está intimamente ligada ao início do processo participativo, onde as fronteiras do sistema e os problemas são identificados ao lado daqueles que detêm a informação do que acontece com o sistema sob investigação. Isto pode exigir negociação, e os interessados podem ter diferentes objetivos, inclusive inconciliáveis (CHESS, PURCELL, 1999; REED, 2008).

\subsubsection{Participação dialogada}

A negociação deve ser realizada baseada no diálogo entre as partes interessadas, tomando uma abordagem deliberativa, os participantes definem os problemas e estabelecem a finalidade do diálogo. Entende-se por diálogo um espaço aberto de falas, que se dá de forma democrática. O diálogo proporciona a experiência da soma, da experiência compartilhada, ou seja, é a base da construção coletiva, e até mesmo da criação de ações com potencial de mudanças efetivas. Dessa forma, o diálogo não finalizava com um vencedor, com o possuidor da verdade, esse conceito se dá à discussão (BOHM, 2005). Embora muitas vezes é assumido que o objetivo do diálogo das partes interessadas deve ser a construção de consenso (SUSSKIND et al, 2003), tal ênfase pode suprimir a diversidade de opiniões e valores, e levar a um foco sobre os princípios gerais e facilmente resolvidos.

Neste contexto, Steinman et al. (2002) sugerem que em vez de buscar consenso, os processos participativos devem adotar o "princípio" da diversidade compartilhada em que reconhece que os conflitos de escolha são inerentes à tomada de decisão. Esta abordagem enfoca a comunicação e a argumentação, em vez de negociação, explorando a diversidade de posições e suposições realizadas pelos participantes. Leroy e Pacheco (2005, p. 132) confirmam que é "exatamente o conflito - tão temido por uns, tão criticado por outros - é parte essencial e substancial para a constituição da democracia", 
conforme citado pelos autores, existe a falsa unanimidade, utilizando a denominação de "democracia do consenso", a qual não considera a diversidade de opiniões, considera um acordo entre todos, que nem sempre comporta todas as reivindicações. Assim, a democracia só é construída a partir da heterogeneidade, dos dissensos, das divergências de opinião e das diversidades culturais (LEROY; PACHECO, 2005).

Se as metas são desenvolvidas utilizando-se do diálogo democrático entre os participantes, eles são mais propensos a tomar posse do processo, a construção de parceria será mais provável, e os resultados são mais propensos a ser mais relevantes para as necessidades e prioridades das partes interessadas, incentivando seu engajamento ativo no processo (REED, 2008).

\subsubsection{O papel do facilitador no processo}

Outro aspecto relevante durante o processo participativo é ser facilitado por pessoas altamente qualificadas para o gerenciamento de conflitos. Facilitadores diferentes podem usar as mesmas ferramentas com resultados radicalmente diferentes, dependendo do seu nível de habilidade (REED, 2008). Um facilitador de sucesso precisa ser percebido como imparcial, aberto a múltiplas perspectivas e acessível. Precisa ser capaz de manter a dinâmica de grupo positiva, atenta para evitar possíveis manipulações ou lidar com indivíduos ofensivos, incentivar os participantes a questionar suposições e reavaliar posições arraigadas, e tirar o máximo proveito de indivíduos reticente. Essas habilidades são difíceis de aprender e tendem a ser desenvolvido ao longo de anos de experiência, intuição e empatia (RICHARDS et al., 2004; REED, 2008).

Na continuidade de exposição minunciosa das características necessárias para o sucesso no processo e nos resultados da participação, há uma série de recursos que podem ser atendidos e considerados. A análise e informação científica é um desses recursos. Serve para informar os interessados, identificado-se como um ingrediente essencial em qualquer processo participativo (TIPPETT et al, 2007, REED, 2008), e ainda a utilização do chamado conhecimento prático (ou local). No entanto, a utilização destes dois tipos de conhecimentos não se mostram prontamente fácil, a percepção e a valorização é atributo desenvolvido por poucos. 


\subsubsection{O fio unificador entre conhecimento prático e conhecimento científico}

A dicotomia entre o conhecimento prático e conhecimento científico pode reforçar a percepção de conhecimento como algo que precisa ser investigado. Há uma disputa entre o conhecimento "certo" e o conhecimento "errado", onde este julgamento é baseado na maneira que o conhecimento em questão é classificado. Isso envolve questões como o conhecimento é construído, e o que distingue o conhecimento prático do conhecimento científico. Murdoch e Clark (1994) explicam esta distinção não é pertinente. A pertinência está na relação constituída, explicada por eles como "um fio unificador" de que o conhecimento prático é "contaminado" pelo conhecimento científico, e o conhecimento científico possui fundamentações empíricas. Sendo a intenção desconstruir estas distinções. Isto pode facilitar uma compreensão mais sofisticada de como, na prática, ambos são combinados dentro dos mundos de atores.

Isto sugere que todo o conhecimento é composto por uma mistura heterogênea de conhecimentos tácito e implícito a partir de fontes diferentes que é impossível desemaranhar (MURDOCH, CLARK, 1994; CLARK, MURDOCH, 1997; REED, 2008)

A fim de contextualizar o surgimento destas duas categorias de conhecimento científico e prático/local, deseja-se situar a discussão de que o conhecimento científico não tem se distinguido significativamente de outras práticas de conhecimento. Os mundos demarcados por pesquisadores, cientistas sociais, artistas, políticos, industriais, etc, parecem estar colidindo e misturando-se em uma base "híbrida" (MURDOCH, CLARK, 1994).

Sabe-se que existe a mistura, mas também existe a particularidade de tipos de conhecimento, e saber que na fonte elas não se diferem tanto, para que se consiga combinar, sem pressupostos, o conhecimento prático e o conhecimento acadêmico. Esta combinação pode contribuir para uma compreensão mais abrangente da complexidade e dinâmico dos sistemas. Por triangulação de diferentes fontes de conhecimentos, é possível investigar incertezas e suposições, e desenvolver uma compreensão mais rigorosa da realidade (JOHNSON et al., 2004). As decisões baseadas na diversidade de conhecimentos torna o processo e os resultados da participação mais eficazes e mais 
duráveis (CHESS, PURCELL, 1999; REED et al., 2006;. STRINGER; REED, 2007, HEALY, 2009, REED, 2008).

Além do compartilhamento do conhecimento, Tippett et al. (2005) advertem da consideração que deve ser dada ao uso de uma variedade de tipos de ferramentas de comunicação, com a tentativa de encontrar formas diferentes para representar informações técnicas, tornando o processo mais acessível a uma ampla gama de interessados. As informações, se apresentadas com um formato técnico, distante da realidade dos receptores, pode funcionar como uma barreira à participação e o aprendizado social. E, ao mesmo tempo, a atenção para garantir que os participantes não sejam sobrecarregados com informações, deve-se utilizar as informações essenciais, que sejam complementares a compreensão de todos, sem omissão de informações valiosas.

Durante a participação será exigido o desenvolvimento da capacidade crítica, a capacidade de refletir sobre suposições e as interações entre estes pressupostos e comportamento (tanto organizacional como individual). Esta capacidade de crítica pode precisar ser incentivada através de técnicas de facilitação e desenho dos processos. Todos os atores envolvidos terão que aprender a reconhecer e respeitar diferentes pontos de vista, técnicas específicas podem auxiliar estes processos, como fazer quadros e suposições implícitas visíveis para os diferentes atores (TIPPETT et al., 2005).

\subsubsection{A institucionalização da participação}

A aplicação prática da valorização desses tipos de conhecimentos não é prontamente verificada. Um desafio fundamental para a participação é assegurar a integração equitativa dos possuidores de conhecimento prático e os possuidores de conhecimento científico. Isso requer processos capazes de combinar criativamente perspectivas divergentes. Um pré-requisito fundamental para isto é a resolução das assimetrias no poder, recursos e confiança entre os atores (HEALY, 2009), e, complementarmente, ser consciente da cultura tecnocrática, na qual é baseada a organização política e social do predomínio dos técnicos. Os especialistas não estão familiarizados em falar com as diferentes partes interessadas, em termos que eles possam se relacionar, pode impedir a comunicação construtiva com os atores. Essas diferenças de abordagem podem ser profundamente enraizadas em contextos culturais que conferem status de acordo com conhecimentos técnicos adquiridos. Por este motivo, 
algumas estruturas institucionais tradicionais podem não apoiar suficientemente aos processos participativos, e inclusive torná-los de difícil continuidade de interação com os atores (TIPPETT et al., 2005).

Ou seja, a continuidade a longo prazo de processos participativos depende da incorporação institucional da participação dos interessados. Embora a participação é cada vez mais incorporados às políticas, os requisitos de processos participativos estão em desacordo com muitas das estruturas institucionais encarregadas da execução dessas políticas. Muitas das limitações com experiência em processos participativos têm suas raízes nas culturas organizacionais de quem patrocina ou participa delas, pois em muitos casos, realizar processos participativos representa uma mudança radical na cultura organizacional das instituições (REED, 2008).

Espera-se com a institucionalização que a participação não seja apenas a tomada de decisão do alto escalão delegando tarefas a representantes, que podem não estar efetivamente envolvidos e interessados em participar dos processos, e, além disso, representantes que não se sentem capazes de negociar, pois ocupam lugares com pouco poder de decisão (REED, 2008).

Os atores devem comprometer-se em criar um ambiente que permita $o$ aprendizado, isto pode exigir mudanças na estrutura, muito embora os facilitadores e organizadores dos processos podem ajudar a apoiar estas mudanças. Os organizadores precisam mostrar entusiasmo, comprometimento e unidade (TIPPETT et al., 2005).

Vale ressaltar que, a qualidade de decisões tomadas por meio da participação dos atores depende da natureza do processo que estas decisões são conduzidas. Reed (2008) permite elucidar que o fracasso dos processos participativos que levam à desilusão dos atores, muitas vezes, é gerado a partir do foco nas ferramentas de participação, ao invés do foco no processo em que elas são inseridas. Estas limitações devem ser identificadas e sinalizadas no início de qualquer processo participativo, isto permite fortalecer o processo e ainda evitar frustrações e os conflitos potenciais. 


\subsubsection{Empoderamento e confiança}

Qualquer processo participativo deve ser sustentado pelos valores de empoderamento e confiança (REED, 2008; DE STEFANO, 2010). As partes interessadas precisam perceber que sua voz pode ser ouvida, e que eles podem ter a chance real de influenciar as decisões. Isto requer um envolvimento precoce no processo, para evitar que o processo participativo comece quando as decisões já foram tomadas. Além disto, todas as informações relevantes devem ser fornecidas em tempo útil e ser expressa de uma forma que seja acessível aos destinatários (TIPPETT et al, 2005; REED, 2008; DE STEFANO, 2010).

Os atores precisam ser reconhecidos e, quando possível, conseguir criar uma plataforma justa para o envolvimento. Pode ser difícil para manter o interesse durante os períodos de tempo necessário para desenvolver a aprendizagem social e planos de longo prazo. Manter o interesse e a construção da confiança no processo requer o desenvolvimento e implementação de pequenas soluções 'ganha-ganha', de modo que os interessados possam ver a evidência da mudança no início do processo (TIPPETT et al., 2005).

A falta de confiança e apreço pode impedir a aprendizagem social. Exemplos de outros projetos de sucesso ajudam a superar estas barreiras, mas tem que considerar que este pode ser um processo lento. A falta de clareza sobre papéis, responsabilidades e processos de decisão podem agravar a desconfiança e pode levar a expectativas não atendidas e frustração (TIPPETT et al., 2005).

Iniciativas de empoderamento ocorrem por meio da promoção da interação dos atores, gestão de conflitos e incentivos ao desenvolvimento de soluções mutuamente benéficas, as quais potencializam o aprendizado social. Atenção contínua as estruturas e processos de interação dos atores requer o acordo a respeito de modo proceder a processos apropriados para a tomada de decisão. Mecanismos de apoio, tais como a definição de regras básicas comumente aceitas, a comunicação transparente e gravação da fala dos participantes, ajudam as pessoas a entender o que é permitido e necessário e deste modo, constrói a confiança no processo (TIPPETT et al., 2005). 


\subsubsection{Tempo de realização}

Estes fatores levam tempo para se desenvolver, ou seja, proporcionar o tempo suficiente para participar o envolvimento inicial dos atores é fator-chave na promoção do aprendizado social (TIPPETT et al., 2005).

Deste modo, o tempo pode ser uma das potenciais barreiras para a aprendizagem social. Prazos são muitas vezes apertadas, metas ambiciosas, o que pode acarretar na aceleração dos processos participativos, de forma que os participantes sentem que não estão sendo envolvidos de forma significativa na tomada de decisões (TIPPETT et al., 2005).

\subsubsection{Síntese das boas práticas de processos participativos}

Conforme o exposto a respeito do sucesso do processo participativo pôde-se sintetizar em um quadro (Quadro 11) as boas qualidades de um processo participativo. Esse quadro concede a possibilidade de avaliações de processos participativos.

\begin{tabular}{|l|l|l|}
\hline & Característica & Explicação \\
\hline 1 & Objetivos Comuns & $\begin{array}{l}\text { Construção coletiva e compartilhamento de interesses, responsabilidades } \\
\text { desde o início do processo participativo. }\end{array}$ \\
\hline 2 & $\begin{array}{l}\text { Participação } \\
\text { dialogada }\end{array}$ & $\begin{array}{l}\text { Espaços (oficinas, reuniões, assembleias) que permitam a explanação } \\
\text { democrática dos atores envolvidos. }\end{array}$ \\
\hline 3 & $\begin{array}{l}\text { Facilitadores } \\
\text { qualificados }\end{array}$ & $\begin{array}{l}\text { O mediador deve ser capacitado a lidar com conflitos, com habilidades em } \\
\text { distribuição de tempo de explanação e não ser tendencioso. }\end{array}$ \\
\hline 4 & $\begin{array}{l}\text { Compartilhamento } \\
\text { dos saberes }\end{array}$ & $\begin{array}{l}\text { Respeito e valorização dos diferentes saberes (práticos e teóricos) e também } \\
\text { atenção a linguagem utilizadas para que seja entendida por todos. }\end{array}$ \\
\hline 5 & $\begin{array}{l}\text { Institucionalização } \\
\text { da participação }\end{array}$ & $\begin{array}{l}\text { Comprometimentos institucionais permitem o processo participativo se } \\
\text { sustentem ao longo do tempo. }\end{array}$ \\
\hline 6 & $\begin{array}{l}\text { Empoderamento e } \\
\text { Confiança }\end{array}$ & $\begin{array}{l}\text { Os envolvidos no processo participativo devem se perceber atores no } \\
\text { processo, que suas contribuições são relevantes, aplicadas e podem ser } \\
\text { claramente observadas. }\end{array}$ \\
\hline 7 & $\begin{array}{l}\text { Disponibilização de } \\
\text { tempo }\end{array}$ & $\begin{array}{l}\text { Os processos participativos de democratização dos diálogos demandam } \\
\text { tempo e disposição dos envolvidos. }\end{array}$ \\
\hline
\end{tabular}

Quadro 11. Boas práticas de processos participativos.

Fonte: Elaboração própria

No entanto, percebeu-se ainda a necessidade de uma avaliação da graduação no alcance destas características, e para isso, inclui-se nesse item a conceituação da Escada de Participação, formulada por Arnstein, em 1969, mas com a temática veementemente atual. 
Arnstein (1969) adverte que existem tipos de ações que são consideradas participação mas que nem todas são efetivamente. Algumas ações chamadas de participação estão mais relacionadas a construção de imagens por interesses políticos de cumprir metas de participação do que realmente a participação.

Existem diferenças entre um ritual vazio de participação e a participação influenciando realmente os processos e os resultados. Em um processo participativo, pode ser que todos os participantes tenham algum nível de poder de decisão, mas estes níveis nem sempre são distribuídos igualitariamente. Por isso, coloca-se que existem níveis de poder de decidir os resultados nos processos participativos, e esses níveis podem ser classificados por tipos de participação e tipos de "não participação". Arnstein (1969) coloca esses tipos de participação e não participação como degraus, onde cada degrau é um nível na escada da participação. Descreve que existem oito degraus na escada da participação, conforme pode ser visto na Figura 15.

\begin{tabular}{|c|c|c|}
\hline 8 & Controle Cidadão & \multirow{3}{*}{$\begin{array}{c}\text { Níveis de poder do } \\
\text { cidadão }\end{array}$} \\
\hline 7 & Delegação de Poder & \\
\hline 6 & Parceria & \\
\hline 5 & Pacificação & \multirow{3}{*}{$\begin{array}{l}\text { Níveis de concessão } \\
\text { mínima de poder }\end{array}$} \\
\hline 4 & Consulta & \\
\hline 3 & Informação & \\
\hline 2 & Terapia & \multirow{2}{*}{ Não Participação } \\
\hline 1 & Manipulação & \\
\hline
\end{tabular}

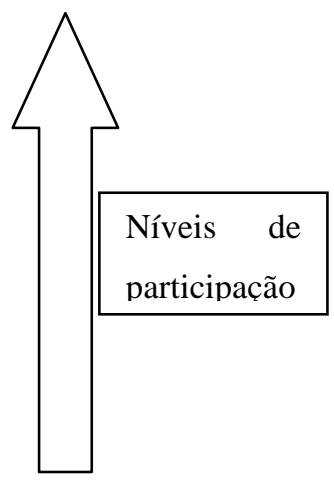

Figura 15. Escada da participação.

Fonte: Arnstein, 1969.

Os degraus 1 e 2 descrevem os níveis de "não participação", tem o intuito de calar os participantes, iludir quanto ao processo de participação. Os degraus 3, 4 e 5 avançam no sentido de consultar os participantes, em deixá-los ouvir e serem ouvidos pelos reais tomadores de decisão, mas não significa que vão considerar as contribuições, apenas se for concluído por eles ser contribuições pertinentes e facilmente incluídas. Os degraus 6,7 e 8 permitem as pessoas participarem com poder de decisão dos processos participativos, com o poder de negociação e de influência nos resultados (ARNSTEIN, 1969). 
Dessa forma, utilizando o quadro de boas práticas (Quadro 11) e a estrutura da escada da participação (Figura 15), pode-se compor critérios de avaliação e qualificação dos processos participativos, ou seja, possibilita verificar os níveis de participação (Não Participação, Níveis de concessão mínima de poder, Níveis de poder do cidadão) em cada uma das características elencadas.

\subsection{Considerações acerca do Capítulo dos Indicadores}

Os modelos estudados permitem responder as diversas relações existentes nos cenários vividos e pode-se notar similaridades entre os modelos, apesar de cada modelo ter a sua especificidade. Nenhum dos modelos foi desenhado especificamente para benchmarking dos SAA\&ES para o Brasil, com vistas às populações vulneráveis, e que para isso necessita-se do foco social.

Deste modo, concebeu-se que não seria indicada a utilização de modelos préarquitetados, pois os modelos estudados não atendem as especificidades relevantes e sabe-se que adaptação de modelos que são construídos com um foco para outro foco pode ser perigoso. A seguir vê-se uma breve explicação dos motivos de não utilização dos modelos estudos, além dos já elencados anteriormente.

O modelo PEIR é adequado para medir a qualidade ambiental, para realizar o diagnóstico ambiental de municípios, Estado, Países, mas nota-se que ele tem fragilidades para mostrar e avaliar a temática da gestão. O ISA é apropriado para observação do estado da salubridade ambiental do local a ser aplicado, mas não consegue observar outras dimensões, com os aspectos institucionais. O IWA é um modelo específico do setor dos SAA\&ES, renomado e utilizados por diversos países, mas não possui um foco social de atendimento às populações vulneráveis, porque inclusive ele foi criado dentro de uma realidade de países desenvolvidos, onde a priorização do atendimento não é necessária. O modelo do Grupo Balaton, descrito pela Meadows, é um modelo mais adequado à medição da sustentabilidade, de difícil adaptação à realidade dos SAA\&ES. O modelo elaborado pelo Ralda é o único modelo que chega mais próximo desta demanda específica para os SAA\&ES voltados às populações vulneráveis, porém ele foi feito para ser utilizado por diversos atores dos 
serviços sem foco no regulador dos serviços e foi feito dentro de um formato teórico, sem o questionamento com os atores que utilizarão o modelo.

Por isto, emergiu a necessidade de criar um modelo específico que enxergasse as especificidades dos SAA\&ES voltados às populações vulneráveis no Brasil, Estado de São Paulo, e, além disso, a necessidade de criação do modelo deu-se também para que os atores que utilizassem esse modelo se sentissem pertencentes e mais próximas da utilização do modelo e dos indicadores.

No entanto, mesmo não utilizando nenhum dos modelos descritos no presente Capítulo, todos foram incorporados como entrada para a criação do novo modelo, isto é, aproveitou-se partes deles para a estruturação do novo modelo de benchmarking dos SAA\&ES direcionados às populações vulneráveis. Vale ressaltar que a criação e validação de um novo modelo é mais trabalhosa que a utilização de modelos já previamente formulados, e esta escolha foi feita pautada na explicação supracitada.

O Capítulo também mostra o que deve ser considerado e realizado para que seja feita uma construção adequada dos indicadores. Essa revisão bibliográfica utilizada como parâmetros da avaliação dos indicadores construídos coletivamente.

Conforme também exposto nesse Capítulo, a participação é cada vez mais incorporada às políticas. No contexto dos SAA\&ES no Brasil, está em andamento o processo participativo do Plano Nacional de Saneamento Básico (PLANSAB), o qual ainda não foi avaliando os graus de participação que ele está proporcionando, mas pode ser considerada iniciativas de processos participativos, conforme é incentivada pela Política Nacional de Saneamento Básico (Lei 11.445/07), a qual estabelece a participação como princípio e como um importante instrumento de articulação entre os 
atores sociais. A lei também tem como princípios fundamentais o controle social ${ }^{9}$, e determina participação dos órgãos colegiados ${ }^{10}$ no controle social.

Outro aspecto da participação estabelecido pela lei refere-se à responsabilidade da reguladora editar normas em relação aos mecanismos de participação e informação, e o titular dos serviços deve estabelecer mecanismos de controle social. A exemplo disso, tem-se a aplicação realizada pelo IRAR em Portugal nos SAA\&ES, com a realização de processo participativo para a formulação de um sistema de indicadores dos serviços e a utilização dos mesmos no processo de benchmarking. Esta metodologia foi utilizada pela convicção existente que é apenas através dos atores que realizam as atividades na prática que pode haver melhorias e evolução no setor (ALEGRE et al., 2005).

Desta forma, o processo participativa também torna-se um instrumento de mobilização e de melhor aplicação de indicadores em processos de benchmarking, ou seja, o processo participativo permite auxiliar no aprendizado das boas práticas do setor, conforme inspira a ferramenta de benchmarking.

Mas é evidente que o processo participativo possui limitações, as quais foram expostas no decorrer deste Capítulo, como a necessidade de tempo que é exigido dos processos, uma boa aderência dos participantes ao processo, as parcerias institucionais, entre outros. Saber as limitações sugere que atente-se para que o processo chegue o mais próximo possível do ideal de processos participativos.

9 Conjunto de mecanismos e procedimentos que garantem à sociedade informações, representações técnicas e participações nos processos de formulação de políticas, de planejamento e de avaliação relacionados aos serviços públicos de saneamento básico.

10 Órgãos colegiados são aqueles em que há representações diversas e as decisões são tomadas em grupo, com o aproveitamento de experiências diferenciadas. São conhecidos pelos nomes de Conselhos, Comitês, Juntas, Câmaras, Colégios, Comissões, Equipes, Grupos de Trabalho, além de outros. Seus representantes podem ter origem no setor público ou no setor privado, segundo a natureza da representação. É comum aos órgãos colegiados possuírem uma secretaria-executiva, encarregada de colocar em prática suas decisões, papel que também pode ser conferido a um órgão já existente. (BRASIL, 2012) 


\section{INDICADORES DE BENCHMARKING DOS SAA\&ES VOLTADOS ÀS POPULAÇÕES VULNERÁVEIS}

O objetivo principal desta pesquisa é propor indicadores de benchmarking dos SAA\&ES destinados à melhoria da qualidade dos serviços às populações vulneráveis. Para se chegar a isto foi necessário o desenvolvimento de enfoques que contribuíram na discussão e encaminhamento de resultados satisfatórios, como verificar os fatores que devem ser observados quando se quer atender as populações vulneráveis, entender a maneira efetiva da ferramenta de benchmarking pode auxiliar neste atendimento, e, entender e aplicar da maneira mais adequada a construção de indicadores.

Estes enfoques foram desenvolvidos participativamente, por meio de oficinas, reflexões em grupo de pesquisa, facilitando a futura aplicabilidade dos indicadores. A apresentação dos resultados está ordenada de acordo com as etapas metodológicas formuladas. Os produtos obtidos serão detalhados a seguir:

A pesquisa iniciou-se em março de 2010. Em maio foi realizada as visitas a campo e reuniões exploratórias, onde foram apresentados alguns conceitos a respeito de benchmarking e indicadores. Foi feita a proposta do projeto de mestrado a qual foi aceita pelos participantes, mas ainda não exposto exatamente as funções e papéis de cada um dentro do projeto.

$\mathrm{Na}$ sequencia houve reuniões de alinhamento de ideias e considerações a respeito do projeto e as linhas que o mesmo seguiria. A preparação e mobilização dos atores foram aspectos fundamentais e considerados uma potencialidade para a pesquisa.

Foram feitas nove reuniões, que auxiliaram na problematização do tema e a constatação da realidade vivida pelos atores. Nestes encontros foram notadas as diferenciações de forma de visão entre os atores envolvidos a respeito da mesma temática. O Quadro 12 mostra as visitas a campo, reuniões realizadas e as instituições envolvidas, na primeira etapa exploratória. 


\begin{tabular}{|c|c|c|c|}
\hline & Datas & Parceiros envolvidos & Atividade \\
\hline 1 & $\begin{array}{l}\text { 27de maio de } \\
2010\end{array}$ & USP, UNESCO IHE, UFC & Reunião dos pesquisadores do projeto PROBE \\
\hline 2 & $\begin{array}{l}27 \text { de maio de } \\
2010 \\
\end{array}$ & $\begin{array}{l}\text { USP, UNESCO-IHE, } \\
\text { UFC, ARSESP, SABESP }\end{array}$ & $\begin{array}{l}\text { Reunião de apresentação e parcerias com } \\
\text { contribuições ao projeto }\end{array}$ \\
\hline 3 & $\begin{array}{l}28 \text { de maio de } \\
2010\end{array}$ & $\begin{array}{l}\text { USP, UNESCO IHE, UFC, } \\
\text { SABESP }\end{array}$ & Visita à campo Favela de Paraisópolis \\
\hline 4 & $\begin{array}{l}28 \text { de maio de } \\
2010\end{array}$ & $\begin{array}{l}\text { USP, UNESCO IHE, UFC, } \\
\text { ARSESP, SABESP }\end{array}$ & Reunião de aproximação com os parceiros \\
\hline 5 & $\begin{array}{l}29 \text { de maio de } \\
2010\end{array}$ & USP, UNESCO IHE, UFC & Reunião do grupo de pesquisa \\
\hline 6 & $\begin{array}{l}29 \text { de maio de } \\
2010\end{array}$ & $\begin{array}{l}\text { USP, UNESCO IHE, UFC, } \\
\text { SABESP }\end{array}$ & $\begin{array}{l}\text { Visita ao Cruzeiro do Sul, região de antigas favelas } \\
\text { e agora urbanizada }\end{array}$ \\
\hline 7 & $\begin{array}{l}31 \text { de maio de } \\
2010\end{array}$ & $\begin{array}{l}\text { UNESCO IHE, USP, USP, } \\
\text { SAAE }\end{array}$ & $\begin{array}{l}\text { Visita à comunidade mais vulnerável de São Carlos } \\
\text { - bairro Gonzaga e Cidade Araci. }\end{array}$ \\
\hline 8 & $\begin{array}{l}1 \text { de junho de } \\
2010\end{array}$ & $\begin{array}{l}\text { UNESCO IHE, USP, } \\
\text { SSAE. }\end{array}$ & $\begin{array}{l}\text { Visita ao SSAE Descalvado, e visita a região mais } \\
\text { vulnerável da cidade }\end{array}$ \\
\hline 9 & $\begin{array}{l}2 \text { de junho de } \\
2010\end{array}$ & $\begin{array}{l}\text { UNESCO IHE, USP, } \\
\text { Sandro - Empresa Foz do } \\
\text { Brasil, }\end{array}$ & $\begin{array}{l}\text { Visita à região mais vulnerável de Limeira - } \\
\text { Empresa Foz do Brasil }\end{array}$ \\
\hline
\end{tabular}

Quadro 12. Parceiros e atividades realizadas na etapa exploratória

Posterior às visitas e reuniões exploratórias, realizou-se a revisão bibliográfica, que permitiu a formulação de um arcabouço teórico conceitual que relaciona os temas amplos. O enfoque da revisão foram os temas benchmarking e indicadores, (Capítulo 5 e 6) as demais temáticas pesquisadas foram utilizadas na contextualização dos SAA\&ES às populações vulneráveis (Capítulo 3) e nos resultados e nas discussões (Capítulos itens 7 e 8).

Foi feita a revisão bibliográfica dos fatores relevantes da prática do setor dos SAA\&ES visando à universalização dos serviços e especificamente ao atendimento das populações vulneráveis. A partir deste arcabouço, os fatores foram agrupados em dimensões, as quais possuem a finalidade de indicar quais os aspectos mais relevantes na prática do setor de saneamento, e posteriormente, foram selecionadas as dimensões e fatores que estão vinculadas diretamente ao fornecimento dos SAA\&ES às populações vulneráveis.

As dimensões e os fatores estão colocados no item seguinte, as quais apontam as necessidades a serem atendidas para a melhoria dos serviços, e que, portanto, compuseram a estrutura dos indicadores de benchmarking, orientando a direção em que os tomadores de decisão no setor dos SAA\&ES devem seguir para incluir as populações vulneráveis no escopo da priorização de atendimento, conforme descrito a seguir. 


\subsection{Modelo conceitual}

Os critérios de melhoria do atendimento dos SAA\&ES voltados à universalização e em específico às populações vulneráveis são definidos através de critérios que compõem as dimensões: institucional, operacional, recursos hídricos, gestão, social, financeira, controle e fiscalização. A elaboração dos critérios foi feita através de pesquisa bibliográfica da área de esgotamento sanitário e abastecimento de água, os itens foram selecionados analisando as particularidades do setor. Os conceitos utilizados estão descritos na sequencia e podem ser visualizados no Quadro 13.

A dimensão institucional são os mecanismos políticos que responsabilizam os atores, direcionam a priorização na resolução de problemas e na utilização de verbas do Estado. Essa utilização de verbas está diretamente relacionada à vontade política, assim mostra-se central a vontade política no sentido da universalização dos SAA\&ES, pois é necessário querer sanar esta problemática inicialmente, e posteriormente, estabelecer maneiras de agir. Essa vontade política deve estar sempre de acordo com a demanda da sociedade (MORAIS; FORTES; FERREIRA; 1999).

As situações vividas pelas populações que não possuem SAA\&ES são, simultaneamente, a exclusão social, habitação e educação deficitária, ausência da qualidade ambiental e da geração de renda (HELLER; NASCIMENTO; PAIVA; 2000 e NASCIMENTO; HELLER, 2005). Estes problemas acontecem de maneira sincrônica e devem ser tratados com iniciativas institucionais que direcionem as decisões e proporcionam ações integradas (GALVÃO JUNIOR, 2009).

A dimensão operacional é o desenvolvimento de técnicas que acompanhem os sistemas estabelecidos, como tratamentos diferenciados de esgotos e águas servidas (NASCIMENTO; HELLER, 2005 e MORAIS; FORTES; FERREIRA; 1999). Além disto, o desenvolvimento tecnológico pode propiciar a eficácia da infraestrutura instalada (Galvão JUNIOR, 2009) que muitas vezes não são bem monitoradas e mantidas ocasionando em desperdícios e funcionamento precário, e quando tratadas em áreas pobres, esta deficiência pode ser ainda maior devido às especificidades dos locais e materiais que são feitas as instalações. 
Os projetos de redes de abastecimento e esgotamento sanitário devem estar subsidiados de conhecimento do crescimento populacional e as perspectivas de mudança do quadro de usuários dos serviços, pois o crescimento populacional tem sido rápido e os SAA\&ES, se não planejado visando esta característica, acarretam em obsolescência destes projetos e necessidade de novo planejamento (NASCIMENTO; HELLER, 2005). Essas estratégias de planejar, prever, considerar variáveis diversas, pesquisando o sistema de forma complexa é o que demonstra o compromisso com a sustentabilidade do sistema.

A demanda de água para o abastecimento e a necessidade de se pensar na sustentabilidade desse bem essencial a vida dos seres humanos requer o estabelecimento da dimensão dos recursos hídricos. A responsabilidade pelo uso dos mesmos deve ser extensamente discutida enquanto a sua real necessidade de utilização, importância e escassez. Assim, o controle de perdas, controle e troca de redes envelhecidas, micro e macro medição, inovação de materiais e métodos de recuperação com vantagens econômicas e operacionais significativas é imperativo (NASCIMENTO; HELLER, 2005).

Outro aspecto a ser considerado é o desenvolvimento de ações do uso consciente da água o qual requer a transformação no comportamento e costumes cotidianos das pessoas. O uso consciente dos recursos deve estar associado a mecanismos de reuso da água, coleta de água de chuva, modificação de peças sanitárias, proporcionando economias, assim como a preocupação com o uso e conservação da água ser ampliado ao uso da terra, em locais produtores de água (NASCIMENTO; HELLER, 2005).

A dimensão da gestão constitui a utilização de instrumentos gerenciais, informacionais, de planejamento e a capacitação de recursos humanos para que seja mantida a qualidade da gestão e a constante melhoria dos processos. Assim como, a utilização de sistemas de informação que auxiliem a tomada de decisão, com a construção de indicadores e base de dados que permitam auxiliar a gestão urbana e gestão das águas (NASCIMENTO; HELLER, 2005; MORAIS; FORTES; FERREIRA, 1999). 
É dever da sociedade participar como proponente de melhorias nos processos da gestão dos SAA\&ES, e para isso, as operadoras devem estar preparadas para esse novo modelo de convivência, incorporando as opiniões da sociedade, cria-se então a dimensão social.

A mobilização social vem em caráter inovador, pois ainda não faz parte da realidade cultural que vivemos atualmente, ainda são incipientes as operadoras que ouvem as necessidades da comunidade, suas queixas, seus pedidos, suas opiniões e as sugestões de melhoria no processo de priorização de atendimento. É necessário que seja feita uma mudança na cultura das organizações para a inclusão e estímulo da participação da população. Considerar que a população é parte integrante do processo e que deve ter o seu poder de expressão verbal. Deve ser construído um modelo de gestão com a participação, preparando os funcionários para uma nova convivência, no mundo social e do trabalho, incorporando novos conteúdos, trabalhando em função aos anseios e necessidades da comunidade (MORAIS; FORTES; FERREIRA; 1999, MOISÈS et al., 2010).

Na dimensão econômica inclui-se o estabelecimento de incentivos que possam subsidiar tarifas dos serviços oferecidos, criação de linhas de financiamento específicas que asseguram recursos permanentes de educação e mobilização social para o saneamento.

Os incentivos financeiros devem ser feitos, por exemplo, com a estruturação de fundos de investimento com recursos próprios e controle social (MORAIS; FORTES; FERREIRA, 1999), assegurando recursos que se direcionem a diversidade cultural, ao saber popular e a recursos permanentes de educação em saúde e ambiental e mobilização social em saneamento (MOISES et al.; 2010)

Não menos importante do que os itens citados é o financiamento na expansão, recuperação, inovação de sistemas, de modernização da infraestrutura e gestão (NASCIMENTO; HELLER, 2005)

A dimensão de controle e fiscalização é para entender em quais cenários estão ocorrendo as interações para que sejam traçados objetivos vindouros. Saber qual é a 
situação do saneamento: cobertura, formas de tratamentos, caracterização da saúde, renda e educação, qualidade dos serviços e demais influências sobre esse Estado (PIZA, 2000). 


\begin{tabular}{|c|c|c|c|c|c|c|}
\hline Institucional & Operacional & Recursos Hídricos & Gestão & Social & Econômico & $\begin{array}{l}\text { Controle } \\
\text { Fiscalização }\end{array}$ \\
\hline $\begin{array}{l}\text { Políticas integrativas } \\
\text { coordenadas } \\
\text { destinadas a combater } \\
\text { a exclusão social, que } \\
\text { contemplem } \\
\text { habitação, a } \\
\text { educação, geração de } \\
\text { renda e melhoria da } \\
\text { qualidade ambiental } \\
(1),(2)\end{array}$ & 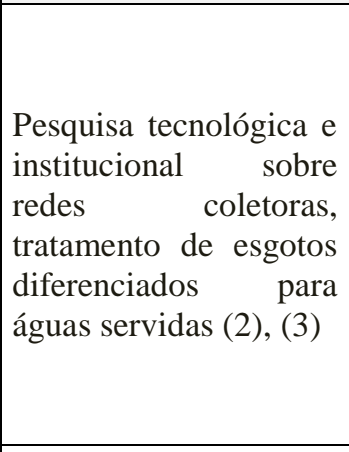 & $\begin{array}{l}\text { Controle de perdas, } \\
\text { redes envelhecidas, } \\
\text { micro e r macro } \\
\text { medição, inovação de } \\
\text { materiais e métodos de } \\
\text { recuperação r com } \\
\text { vantagens } \\
\text { eronômicas } \\
\text { significativas (2) }\end{array}$ & \begin{tabular}{|lr} 
Construção & de \\
indicadores e bases de \\
dados que permitam \\
auxiliar a gestão \\
urbana e & gestão das \\
águas (2) & \\
Indicadores & de \\
desempenho & como \\
instrumento & de \\
controle gerencial (3)
\end{tabular} & $\begin{array}{|lr|}\text { Construção participativa } \\
\text { de modelo de gestão, } \\
\text { preparando } & \text { os } \\
\text { funcionários para nova } \\
\text { convivência, no mundo } \\
\text { social e do trabalho, } \\
\text { incorporando novos } \\
\text { conteúdos, em função } \\
\text { das necessidades da } \\
\text { comunidade (3), (4) }\end{array}$ & $\begin{array}{l}\text { Respeito à diversidade } \\
\text { cultural e ao saber } \\
\text { popular, com a criação } \\
\text { de linhas especificas de } \\
\text { financiamento rue } \\
\text { assegurem recursos } \\
\text { permanentes r de } \\
\text { educação em saúde e } \\
\text { ambiente e mobilização } \\
\text { social em saneamento } \\
\text { (4) }\end{array}$ & $\begin{array}{l}\text { Qualidade dos serviços } \\
\text { de esgotamento e } \\
\text { fornecimento de água } \\
(8)\end{array}$ \\
\hline $\begin{array}{l}\text { Integração } \\
\text { políticas públicas } \\
(5)\end{array}$ & $\begin{array}{l}\text { Eficácia da } \\
\text { infraestrutura instalada } \\
(5)\end{array}$ & $\begin{array}{l}\text { Qualidade deteriorada } \\
\text { das águas (2) }\end{array}$ & $\begin{array}{l}\text { Instrumentos } \\
\text { regulação (5) }\end{array}$ & \begin{tabular}{|lr} 
Sensibilização & e \\
promoção das & pessoas \\
$(6)$ &
\end{tabular} & $\begin{array}{l}\text { Eficácia na alocação de } \\
\text { recurso, qualidade do } \\
\text { gasto público (5) }\end{array}$ & $\begin{array}{ll}\text { Caracterização } & \text { sócio- } \\
\text { econômica: } & \text { saúde } \\
\text { pública, } & \text { renda, } \\
\text { educação (10) } & \\
\end{array}$ \\
\hline $\begin{array}{l}\text { Articulação entre } \\
\text { ministérios que atuam } \\
\text { em saneamento (4) }\end{array}$ & $\begin{array}{lr}\text { Mudança } & \text { de } \\
\text { paradigma } & \text { dos } \\
\text { sistemas de } & \text { esgotos } \\
\text { sanitários (2) } & \end{array}$ & \begin{tabular}{ll}
\multicolumn{2}{l}{ Consumo de água } \\
Uso consciente da \\
água \\
Mudança no \\
comportamento (2)
\end{tabular} & $\begin{array}{lr}\text { Instrumentos } & \text { de } \\
\text { aprimoramento } & \text { de } \\
\text { gestão urbana e } & \text { Planejamento urbano } \\
\text { integrado (2) } & \end{array}$ & \begin{tabular}{|lr|}
\multicolumn{3}{|c|}{ Construção participativa } \\
de programas de \\
educação em saúde e \\
controle social na gestão \\
das políticas do \\
saneamento (4) \\
\end{tabular} & $\begin{array}{l}\text { Redução do subsidio e } \\
\text { criação da tarifa social } \\
\text { (3), Subsídios às tarifas } \\
\text { (5) }\end{array}$ & $\begin{array}{l}\text { Cobertura de coleta de } \\
\text { esgoto e tanques } \\
\text { sépticos, esgoto tratado } \\
\text { e tanques sépticos, } \\
\text { saturação do } \\
\text { tratamento (10) } \\
\end{array}$ \\
\hline $\begin{array}{l}\text { Vontade política (6), } \\
\text { De acordo com a } \\
\text { demanda social (3) }\end{array}$ & $\begin{array}{l}\text { Projetos } \text { urbanos } \text { e } \\
\text { planos setoriais em } \\
\text { vista ao rápido } \\
\text { crescimento (2) }\end{array}$ & $\begin{array}{l}\text { Modelagem } \\
\text { matemática de controle } \\
\text { da qualidade dos } \\
\text { corpos receptores (2) }\end{array}$ & $\begin{array}{l}\text { Continuidade } \\
\text { administrativa e de } \\
\text { mecanismos de ações } \\
(2)\end{array}$ & $\begin{array}{l}\text { Atenção às preferências } \\
\text { do consumidor }(6)\end{array}$ & $\begin{array}{l}\text { Garantir serviços aos } \\
\text { pobres, incentivos para o } \\
\text { abastecimento de água } \\
(7)\end{array}$ & $\begin{array}{l}\text { Cobertura, qualidade } \\
\text { da água distribuída, } \\
\text { saturação do sistema } \\
\text { produtor (10) }\end{array}$ \\
\hline $\begin{array}{l}\text { Cooperação } \\
\text { intermunicipal (2) }\end{array}$ & $\begin{array}{l}\text { Inovação } \\
\text { aprendizado (8) }\end{array}$ & \begin{tabular}{|lr} 
Água & bruta, \\
disponibilidade & dos \\
mananciais, & fontes \\
isoladas de água & $(10)$
\end{tabular} & $\begin{array}{lrr}\text { Aprimorar } & & \text { o } \\
\text { Planejamento e } & \text { criar } \\
\text { instrumentos } & & \\
\text { gerenciais } & & \text { e } \\
\text { regulamentares } & & \\
\text { inovadores (2) } & & \end{array}$ & $\begin{array}{|lrr|}\begin{array}{l}\text { Educação } \\
\text { educação }\end{array} & \text { ambiental } & \text { e } \\
\text { mobilização } & \text { sáde, } \\
\text { processos } & \text { de } & \text { apoio à } \\
\text { sociedade } & & \text { para } \\
\text { democracia } & \text { do } & \text { controle } \\
\text { social em } & \text { ações } \\
\text { sanitárias (4) } & & \\
\end{array}$ & $\begin{array}{l}\text { Financiamento na } \\
\text { expansão, recuperação e } \\
\text { inovação de sistemas e } \\
\text { de modernização da } \\
\text { infra-estrutura e gestão } \\
(2)\end{array}$ & $\begin{array}{l}\text { Qualidade dos serviços } \\
\text { (9) }\end{array}$ \\
\hline
\end{tabular}




\begin{tabular}{|c|c|c|c|c|c|c|}
\hline Institucional & Operacional & Recursos Hídricos & Gestão & Social & Econômico & $\begin{array}{l}\text { Controle } \\
\text { Fiscalização }\end{array}$ \\
\hline $\begin{array}{l}\text { Fortalecimento do } \\
\text { quadro institucional } \\
(6)\end{array}$ & & $\begin{array}{l}\text { Preocupação do uso da } \\
\text { terra em locais } \\
\text { produtores de água (2) }\end{array}$ & $\begin{array}{l}\text { Avaliação da } \\
\text { efetividade e correções } \\
\text { de ações empreendidas } \\
\text { (2) }\end{array}$ & $\begin{array}{|lcr|}\text { Empoderamento } & \text { dos } \\
\text { grupos sociais para } & \text { a } \\
\text { efetiva inserção } & \text { e } \\
\text { intervenção } & \text { nos } \\
\text { processos (4) } & \\
\end{array}$ & $\begin{array}{l}\text { Criação de fundos de } \\
\text { investimento com } \\
\text { recursos próprios e } \\
\text { controle social (3) }\end{array}$ & \\
\hline $\begin{array}{l}\text { Preparação do governo } \\
\text { local (8) }\end{array}$ & & $\begin{array}{l}\text { Reuso da água, coleta } \\
\text { de água de chuva e } \\
\text { busca de água em } \\
\text { lugares próximos (2) } \\
\end{array}$ & $\begin{array}{l}\text { Instrumentos de } \\
\text { suporte à decisão para } \\
\text { a escolha de técnicas } \\
\text { de habitação (2) } \\
\end{array}$ & $\begin{array}{l}\text { Mapeamento da pobreza } \\
(8)\end{array}$ & $\begin{array}{l}\text { Autosustentação } \\
\text { financeira (2), (3) }\end{array}$ & \\
\hline $\begin{array}{l}\text { Colaboração entre } \\
\text { atores (8) }\end{array}$ & & $\begin{array}{l}\text { Modificação de peças } \\
\text { sanitárias (2) }\end{array}$ & $\begin{array}{l}\text { Reconhecer as falhas } \\
\text { no sistema de gestão } \\
(6)\end{array}$ & & $\begin{array}{l}\text { Capacidade } \\
\text { investimento de } \\
\text { municípios (2) }\end{array}$ & \\
\hline & & $\begin{array}{l}\text { Demanda de água de } \\
\text { abastecimento (2) }\end{array}$ & \begin{tabular}{|lc} 
Atualização & de \\
recursos humanos & $(2)$ \\
Capacidade & dos \\
Recursos Humanos (9)
\end{tabular} & & & \\
\hline
\end{tabular}

\section{Quadro 13. Dimensões e fatores necessários à melhoria do fornecimento dos serviços de saneamento às populações vulneráveis}
(1) HELLER; NASCIMENTO; PAIVA (2000)
(2) NASCIMENTO; HELLER (2005)
(3) MORAIS; FORTES; FERREIRA (1999)
(4) MOISĖS et al., (2010)
(5) GALVÃO JUNIOR (2009)
(6) WHO (2000)
(7) RALDA (2010)
(8) ALEGRE et al. (2006)
(9) PIZA (2000) 
Chegou-se a estrutura teórica do conjunto de indicadores de benchmarking voltados às populações vulneráveis. Esta estrutura está representada pela Figura 16, por meio de círculos que demonstram as dimensões. Todas as dimensões se interrelacionam no sistema.

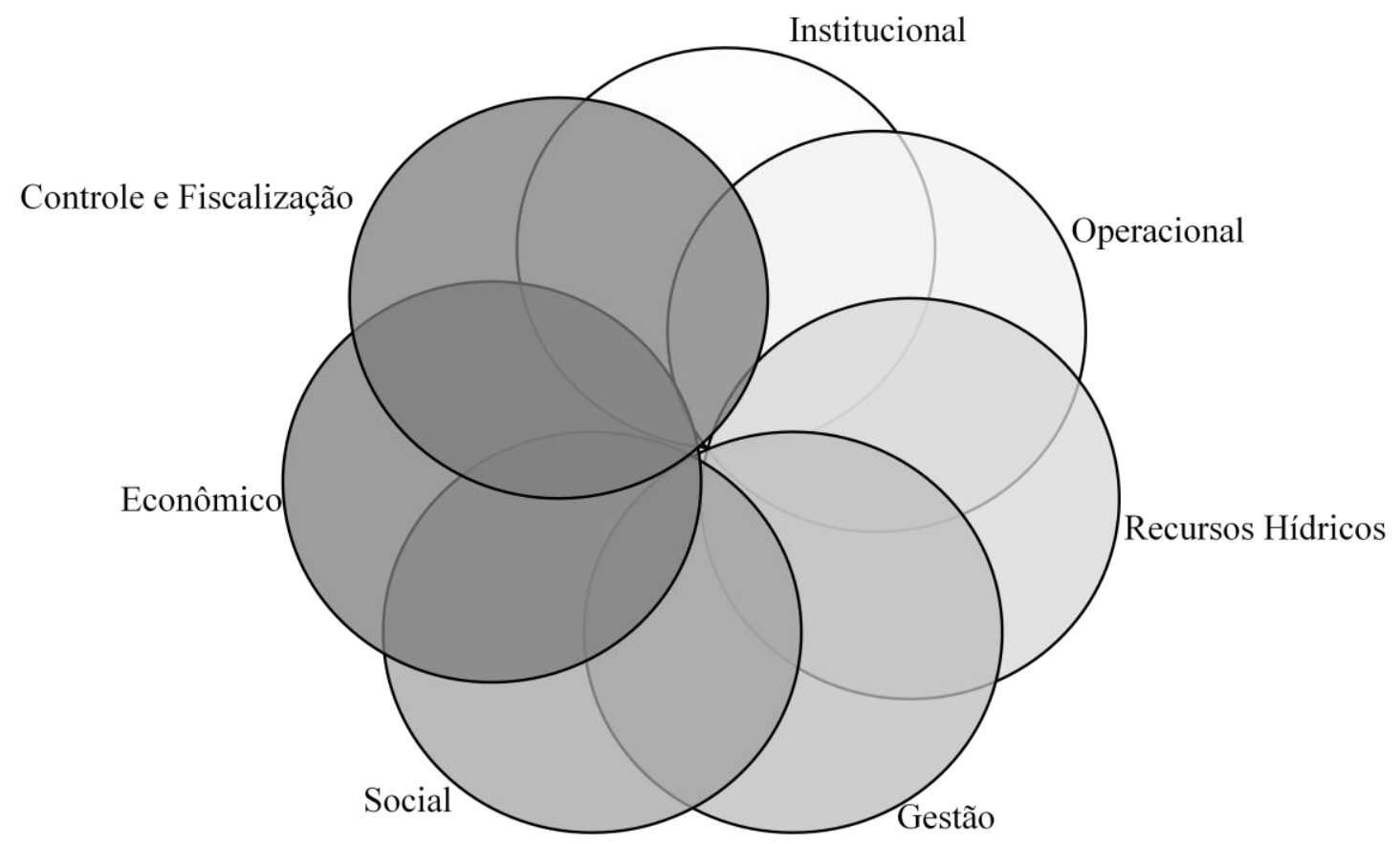

Figura 16. Estrutura teórica do conjunto de indicadores de benchmarking

Após a elaboração da estrutura teórica, deu-se continuidade à pesquisa com o processo participativo de validação da estrutura elaborada e proposição de indicadores.

No primeiro semestre de 2011 foram realizadas as reuniões de aproximação e engajamento dos atores (Quadro 14). No segundo semestre ocorreram o seminário e as oficinas. 


\begin{tabular}{|c|c|c|c|}
\hline & $\begin{array}{c}\text { Datas das } \\
\text { Reuniões }\end{array}$ & Parceiros envolvidos & Objetivo \\
\hline 1 & $\begin{array}{c}16 \text { à } \\
18 / 11 / 2010\end{array}$ & $\begin{array}{c}\text { Grupo de pesquisa do } \\
\text { Projeto PROBE (Holanda) }\end{array}$ & $\begin{array}{c}\text { Apresentação das pesquisas que compõem o } \\
\text { projeto e diretrizes da pesquisa junto aos parceiros }\end{array}$ \\
\hline 2 & $2 / 02 / 2011$ & $\begin{array}{c}\text { ARSESP, SABESP, } \\
\text { ARCE, UFCE, USP }\end{array}$ & $\begin{array}{c}\text { Apresentação do trabalho da reguladora no Ceará, } \\
\text { apresentação do projeto de mestrado }\end{array}$ \\
\hline 3 & $2 / 03 / 2011$ & ARSESP, USP & Apresentação da proposta prática \\
\hline 4 & $19 / 05 / 2011$ & ARSESP, USP & $\begin{array}{c}\text { Apresentação do modelo de indicadores/proposta } \\
\text { inicial }\end{array}$ \\
\hline 5 & $6 / 07 / 2011$ & SABESP, USP & Convite à participação no seminário e nas oficinas \\
\hline 6 & $8 / 07 / 2011$ & ARSESP, USP & Combinação de seminário conjunto \\
\hline 7 & $8 / 07 / 2011$ & SEADE, USP & $\begin{array}{c}\text { Convite à participação no seminário pela } \\
\text { experiência em mapeamento da pobreza }\end{array}$ \\
\hline
\end{tabular}

Quadro 14. Reuniões de engajamento dos atores

O seminário intitulado "Saneamento e Populações Vulneráveis" foi realizado no dia 5 de outubro de 2011 na agência reguladora (ARSESP). Contou com a participação de 60 pessoas e importantes palestrantes da área (APÊNDICE A), sendo 26 representantes das operadoras (principalmente SABESP), 22 representantes da agência reguladora, 6 representantes de diferentes secretarias do município de São Paulo (secretaria de habitação, recursos hídricos e saneamento) e 6 pesquisadores.

Para a preparação e mobilização dos participantes foram feitos convites eletrônicos (e-mails) enviados diretamente pela reguladora, esse método foi utilizado como estratégia de ação para aproximação das pessoas, como chamado oficial. Foram feitos também contato telefônico e envio de folder contendo a programação do evento.

O seminário teve início com a apresentação das atividades do dia. No período da manhã (Figura 17) foram feitas palestras relativas aos avanços e desafios da regulação do saneamento no Estado de São Paulo, à conceituação e mensuração das populações vulneráveis e benchmarking nos serviços de saneamento voltados às populações vulneráveis, e no período da tarde (Figura 18) foram apresentadas boas práticas da melhoria da qualidade dos SAA\&ES às populações vulneráveis. 


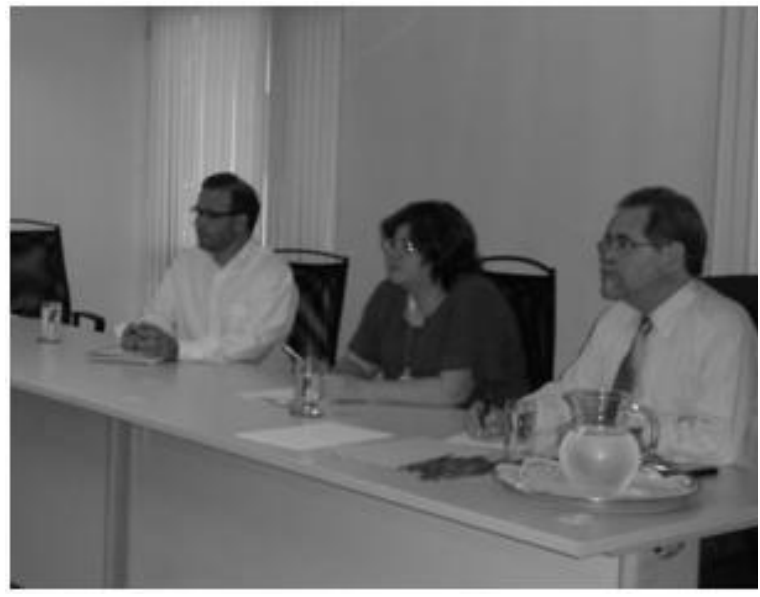

Figura 17. Palestrantes seminário. Fonte: própria, tirada no dia 05/10/2011.

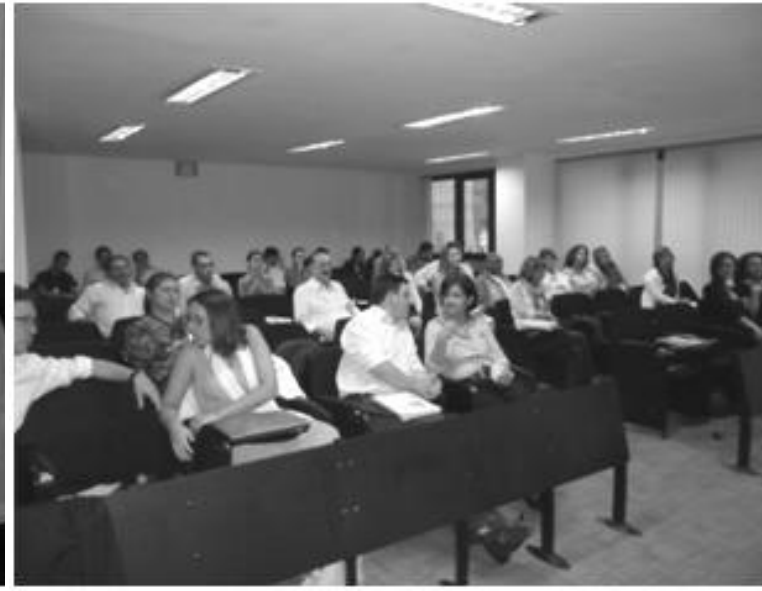

Figura 18. Público do seminário. Fonte: própria, tirada no dia 05/10/2011.

No final das apresentações foi feito o convite para a participação de todos na pesquisa, que seria iniciada com a oficina no dia 25 do mesmo mês.

A primeira oficina ocorreu no dia 25 de outubro de 2011, na Faculdade de Saúde Pública, contou com a presença de 45 participantes, sendo 22 representantes das operadoras, 7 representantes da ARSESP, 3 representantes da secretaria de saneamento e recursos hídricos, 3 representantes da sociedade civil organizada (ABES), 5 representantes do SEADE (Fundação Sistema Estadual de Análise de Dados) e 5 pesquisadores.

Para a preparação e mobilização dos membros foram enviados os convites eletrônicos pela agência reguladora antecipadamente, e posterior contato telefônico, para reforçar o convite. Foi feito o pedido de confirmação de presença.

A oficina teve início com a apresentação de objetivos, roteiro do trabalho e a metodologia utilizada (Figura 19). Os participantes foram divididos em cinco grupos para a discussão de ficha elaborada (APÊNDICE B) a respeito das dimensões que deveriam compor o sistema de indicadores. Cada grupo possuía um coordenador, que buscou controlar o tempo e a participação igualitária de todos os membros do grupo, e um relator, que se responsabilizou pelas anotações do histórico das discussões e a apresentação dos resultados encontrados no grupo nas plenárias (Figura 20). No final da manhã, realizou-se plenária onde foram apresentadas as conclusões de todos os grupos, 
houve diálogo, até que foram decididas as dimensões que deveriam compor o modelo de indicadores dos SAA\&ES voltados às populações vulneráveis.

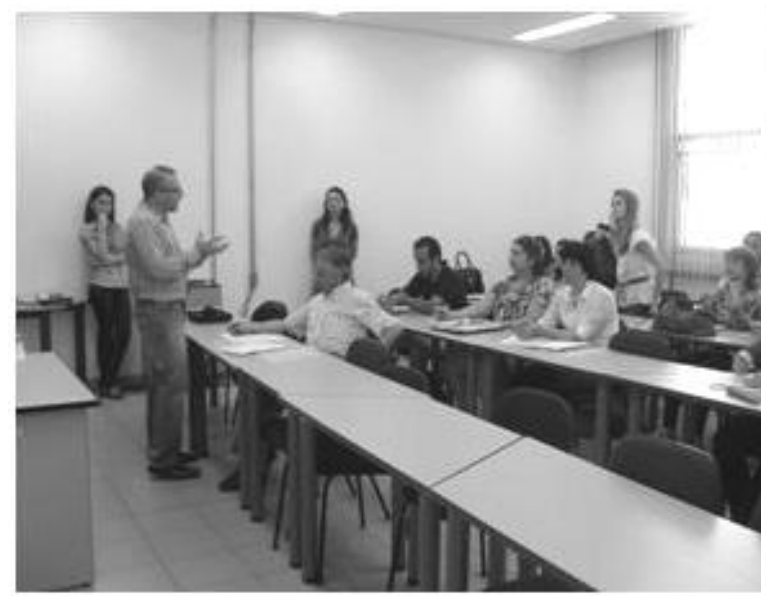

Figura 19. Apresentação da oficina. Fonte: própria, tirada no dia 25/10/2011.

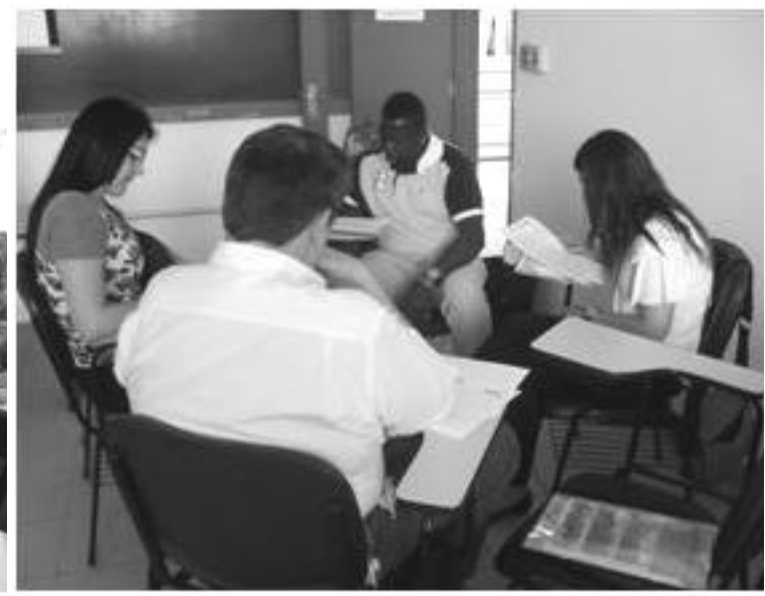

Figura 20. Grupo de trabalho.

Fonte: própria, tirada no dia 25/10/2011.

\subsection{Modelo validado}

O modelo validado é similar ao modelo teórico apresentado anteriormente, com o diferencial da inclusão de uma nova dimensão, Educação e Cidadania; todos os participantes concordaram com a inclusão. Lembrando que os itens foram discutidos. Está representado na Figura 21.

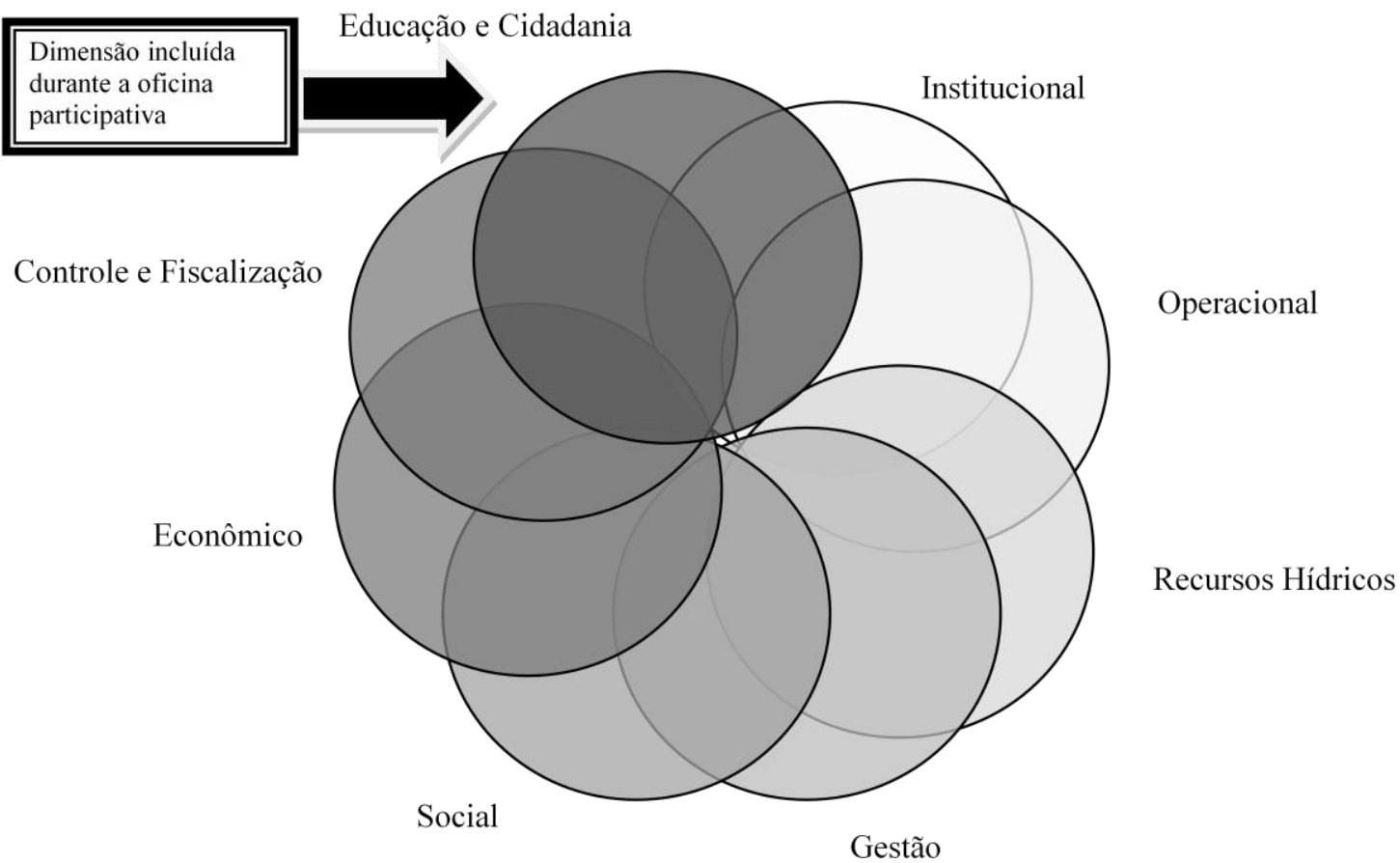




\section{Figura 21. Modelo validado}

A validação foi feita por meio da qualificação da análise dos graus de relevância das temáticas propostas, classificando-as como (1) sem relevância; (2) pouco relevante; (3) relevante e (4) muito relevante. Estas classificações foram dialogadas pelos grupos e chegou-se aos resultados da qualificação que estão expostos no Quadro 15, conforme segue:

\begin{tabular}{|c|c|c|c|c|c|}
\hline Tema & Grupo 1 & Grupo 2 & Grupo 3 & Grupo 4 & Grupo 5 \\
\hline Institucional & 4 & 3 & 4 & 4 & 4 \\
\hline Operacional & 3 & 4 & 3 & 4 & 4 \\
\hline Recursos Hídricos & 4 & 4 & 4 & 4 & 4 \\
\hline Gestão & 3 & 4 & 3 & 4 & 4 \\
\hline Social & 4 & 4 & 4 & 4 & 4 \\
\hline Econômico & 4 & 4 & 4 & 4 & 4 \\
\hline Controle e Fiscalização & 3 & 4 & 4 & 4 & 4 \\
\hline \multicolumn{6}{|l|}{ Proposta de inclusão } \\
\hline Educação e cidadania & \multicolumn{5}{|c|}{$\begin{array}{l}\text { Promover ações integradas de educação ambiental e cidadania } \\
\text { com foco na interdisciplinaridade, respeitando as culturas locais e } \\
\text { os arranjos sociais. }\end{array}$} \\
\hline
\end{tabular}

Quadro 15. Qualificação das dimensões realizadas pelos grupos durante oficina de trabalho

Houve a sugestão da inserção da dimensão chamada Situação Emergencial, descrita como a avaliação dos riscos à população e a eficiência no atendimento. Essa dimensão foi consenso de ser de pouca relevância na temática, em vista que a mesma encontra-se inserida em todas as outras temáticas, sem necessidade de separação.

Para todas as dimensões os grupos deveriam explanar da justificativa de manter a dimensão no sistema. Esse foi um momento enriquecedor no sentido de saber a magnitude prática do problema dos SAA\&ES e enriquecedor para a pesquisa visto que as dimensões haviam sido criadas de acordo com o referencial teórico, de forma teórica, esta avaliação de diferentes atores da gestão do SAA\&ES possibilitou a confirmação da importância destas temáticas.

Algumas das principais justificativas da permanência das sete dimensões expostas pelos grupos estão descritas a seguir: 
1. Dimensão Institucional. A permanência desta dimensão deve-se principalmente ao fato da seriedade do agente institucional agir como impulsionador das Políticas Públicas, integrando e realizando o alinhamento político entre o poder concedente, órgãos públicos e demais atores do setor dos SAA\&ES;

2. Dimensão Operacional. Esta dimensão caracterizou-se de suma importância de como operar a infraestrutura introduzindo um intercâmbio entre pesquisa e realidade prática, desenvolvendo quebra de paradigmas do modo que a tecnologia seja aplicada nas comunidades onde há populações vulneráveis, visto que cada comunidade tem uma especificidade, não podendo ser aplicada uma técnica única a todas.

3. Dimensão dos Recursos Hídricos. Esta dimensão apontou-se como base dos SAA\&ES, para garantir a continuidade do sistema quanto à qualidade, quantidade e disponibilidade, devendo-se estar atento às perdas excessivas: ligações clandestinas, rede degradada, gestão dos recursos hídricos, escassez de água em centros urbanos.

4. Dimensão da Gestão. Base das ações nos processos para a melhoria contínua (tecnologias, planejamento e capacitação de recursos humanos) dos SAA\&ES. A gestão deve estar embasada num bom planejamento e monitoramento.

5. Dimensão Social. A permanência desta dimensão deve-se à necessidade de atender a demanda social dentro das particularidades, juntamente com o alinhamento dos órgãos públicos. O sucesso do fornecimento dos SAA\&ES está ligado diretamente ao envolvimento da população.

6. Dimensão Econômica. A dimensão econômica está relacionada o equilíbrio financeiro da operadora, ajustes de subsídios, eficiência financeira, inadimplência, as quais, na prática, mostram-se ser ainda o que conduz a tomada de decisões nos SAA\&ES às populações vulneráveis, dessa forma, reconhecer as fontes de financiamento existentes e fazer a integração dos recursos, integração de projetos para estimular e incentivar o acesso aos serviços, incentivos a tarifas sociais.

7. Dimensão do Controle e Fiscalização. Nesta dimensão sugeriu-se a mudança do termo Abrangência, termo adotado anteriormente à realização da oficina, para Controle e fiscalização. A sugestão foi acatada por todos, pois percebeu-se que refletia 
de maneira mais clara o que esta dimensão quer abranger. Nela mostrou-se fundamental para conhecimento da situação de saúde, saneamento, vigilância sanitária, aspectos sociais e geográficos.

A partir das dimensões estabelecidas durante a plenária do período da manhã, deu-se continuidade à oficina. No período da tarde, realizou-se a construção de indicadores pelos grupos. Cada grupo tiveram duas dimensões para elaborarem indicadores. Para essa tarefa foram distribuídos fichas de criação de indicadores, estas fichas deveriam ser preenchidas e continham as características e dados necessários na composição do indicador (APÊNDICE C). No final da tarde, realizou-se plenária onde foram apresentados os indicadores.

Em seguida, a partir do modelo validado e dos indicadores propostos, elaborouse pelo pesquisador a sistematização, organização das informações e foi feita a análise da qualidade a partir dos critérios estabelecidos no item 7.1. Assim como buscou-se informações para preenchimento dos indicadores, para que pudessem retornar informações aos participantes e fossem feitas validações dos indicadores com a aplicação prévia dos mesmos, mas as informações não foram encontradas. Inclusive foi contatada a fundação SEADE, especialista em obtenção de dados e também diretamente com algumas concessionárias dos SAA\&ES. Esse resultado foi levado ao conhecimento do grupo na segunda oficina. 


\begin{tabular}{|c|c|c|c|}
\hline Dimensão & & Nome do indicador & Objetivo \\
\hline \multirow[b]{2}{*}{ Institucional } & 1 & Parcerias Institucionais & Existência de parcerias \\
\hline & 2 & Parcerias Institucionais efetivas & $\begin{array}{c}\text { Estabelecer existência de documentação, metas, } \\
\text { prazos, para avaliar a efetividade das parcerias } \\
\text { efetuadas }\end{array}$ \\
\hline \multirow{2}{*}{$\begin{array}{l}\text { Recursos } \\
\text { Hídricos }\end{array}$} & 3 & Tratamento de Esgotos & $\begin{array}{c}\text { Garantir a Qualidade dos corpos hídricos de onde } \\
\text { é captada a água de abastecimento }\end{array}$ \\
\hline & 4 & Índice de perdas de água & $\begin{array}{l}\text { Quantidade de água que é desperdiçada pelo mal } \\
\text { funcionamento do sistema }\end{array}$ \\
\hline \multirow{5}{*}{ Econômica } & 5 & $\begin{array}{l}\text { Índice de perdas comerciais de } \\
\text { água em populações } \\
\text { vulneráveis que não possuem } \\
\text { abastecimento de água } \\
\end{array}$ & $\begin{array}{l}\text { Verificar o valor não faturado que é gasto pelas } \\
\text { operadoras com águas que são utilizadas pela } \\
\text { população de maneira informal (fraude) }\end{array}$ \\
\hline & 6 & $\begin{array}{l}\text { Valor gasto no Atendimento da } \\
\text { população com tarifas sociais }\end{array}$ & $\begin{array}{l}\text { Verificar o valor que é utilizado no atendimento } \\
\text { para cada habitante }\end{array}$ \\
\hline & 7 & $\begin{array}{l}\text { Investimentos com populações } \\
\text { vulneráveis }\end{array}$ & $\begin{array}{l}\text { Verificar do total dos recursos investidos qual a } \\
\text { porcentagem é utilizadas com as populações } \\
\text { vulneráveis, visualizando a priorização desse } \\
\text { assunto na gestão da operadora }\end{array}$ \\
\hline & 8 & $\begin{array}{l}\text { Custo da ligação nas } \\
\text { populações vulneráveis }\end{array}$ & $\begin{array}{l}\text { Saber o valor que é necessário em média para o } \\
\text { atendimento das populações vulneráveis }\end{array}$ \\
\hline & 9 & $\begin{array}{l}\text { Consumo de água nas } \\
\text { populações vulneráveis }\end{array}$ & \\
\hline \multirow{2}{*}{$\begin{array}{l}\text { Controle e } \\
\text { Fiscalização }\end{array}$} & 10 & $\begin{array}{l}\text { Mapeamento da população } \\
\text { vulnerável }\end{array}$ & $\begin{array}{c}\text { Levantamento do número de famílias cadastradas } \\
\text { em programas assistenciais do governo, pois } \\
\text { assim pode-se definir as áreas e populações } \\
\text { vulneráveis }\end{array}$ \\
\hline & 11 & $\begin{array}{l}\text { População sanitariamente } \\
\text { Vulnerável (IPSV) }\end{array}$ & $\begin{array}{l}\text { Calcular a magnitude da população sanitariamente } \\
\text { vulnerável em relação à população total }\end{array}$ \\
\hline $\begin{array}{l}\text { Educação e } \\
\text { cidadania }\end{array}$ & 12 & $\begin{array}{l}\text { Programas educacionais } \\
\text { desenvolvidos pelas } \\
\text { operadoras/ mobilização da } \\
\text { operadora em programas } \\
\text { educacionais }\end{array}$ & $\begin{array}{c}\text { Grau de participação nas oficinas e cursos é } \\
\text { possível medir a importância e o grau de } \\
\text { influência dos programas de educação e } \\
\text { planejamento participativo }\end{array}$ \\
\hline
\end{tabular}

Quadro 16. Indicadores formulados na primeira oficina

A segunda oficina ocorreu em 1 de dezembro de 2011, na Faculdade de Saúde Pública, 22 participantes, sendo 8 representantes das operadoras, 3 representantes da secretaria de saneamento e recursos hídricos, 4 representantes da agência reguladora, 1 representante da sociedade civil organizada (ABES), 1 representante do SEADE, além dos 5 pesquisadores. A mobilização para essa oficina foi feita por meio de convite eletrônico e ligações telefônicas, solicitando a confirmação prévia da presença.

A oficina iniciou com a explanação acerca dos resultados obtidos na primeira oficina. Em seguida foi feita a explicação das atividades a serem desenvolvidas, dando 
as orientações das etapas, conforme estão relatadas na metodologia. Os participantes foram distribuídos em três grupos a fim de realizar análise e validar os indicadores propostos na primeira oficina. Foi entregue material para a realização desta análise (APÊNDICE E). Realizou-se plenária onde foi apresentado o diálogo realizado em grupo (Figura 22 e 23).

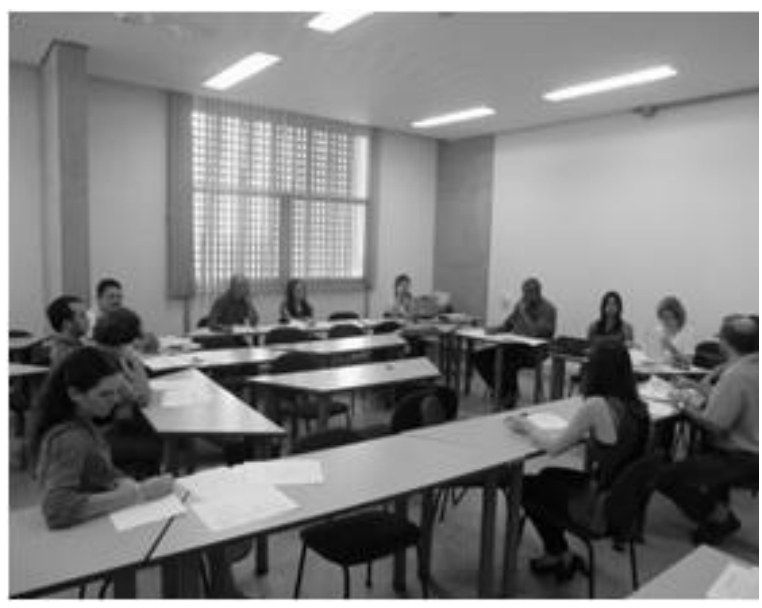

Figura 22. Discussão da segunda oficina. Fonte: própria, tirada no dia 01/12/2011.

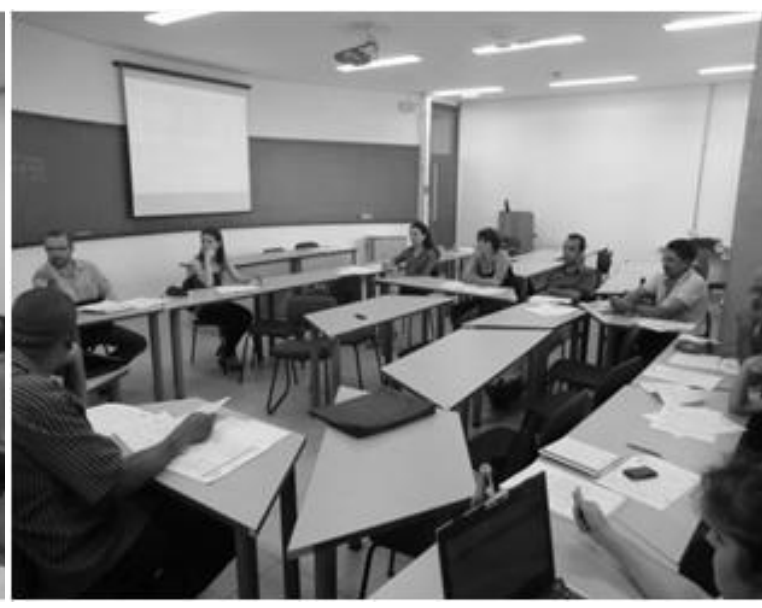

Figura 23. Plenária da segunda oficina. Fonte: própria, tirada no dia 01/12/2011.

Realizou-se a classificação dos indicadores de acordo com os dez critérios estabelecidos na revisão bibliográfica no Capítulo 6, item 6.3. Cada critério foi dialogado, e após a análise de atendimento aos critérios especificados, classificaram-se os critérios em: atende (cor cinza escuro), não atende (cor branca) ou atende parcialmente (listrado). Foi decidido pelo grupo também a permanência ou exclusão do indicador no sistema (Quadro 17). 


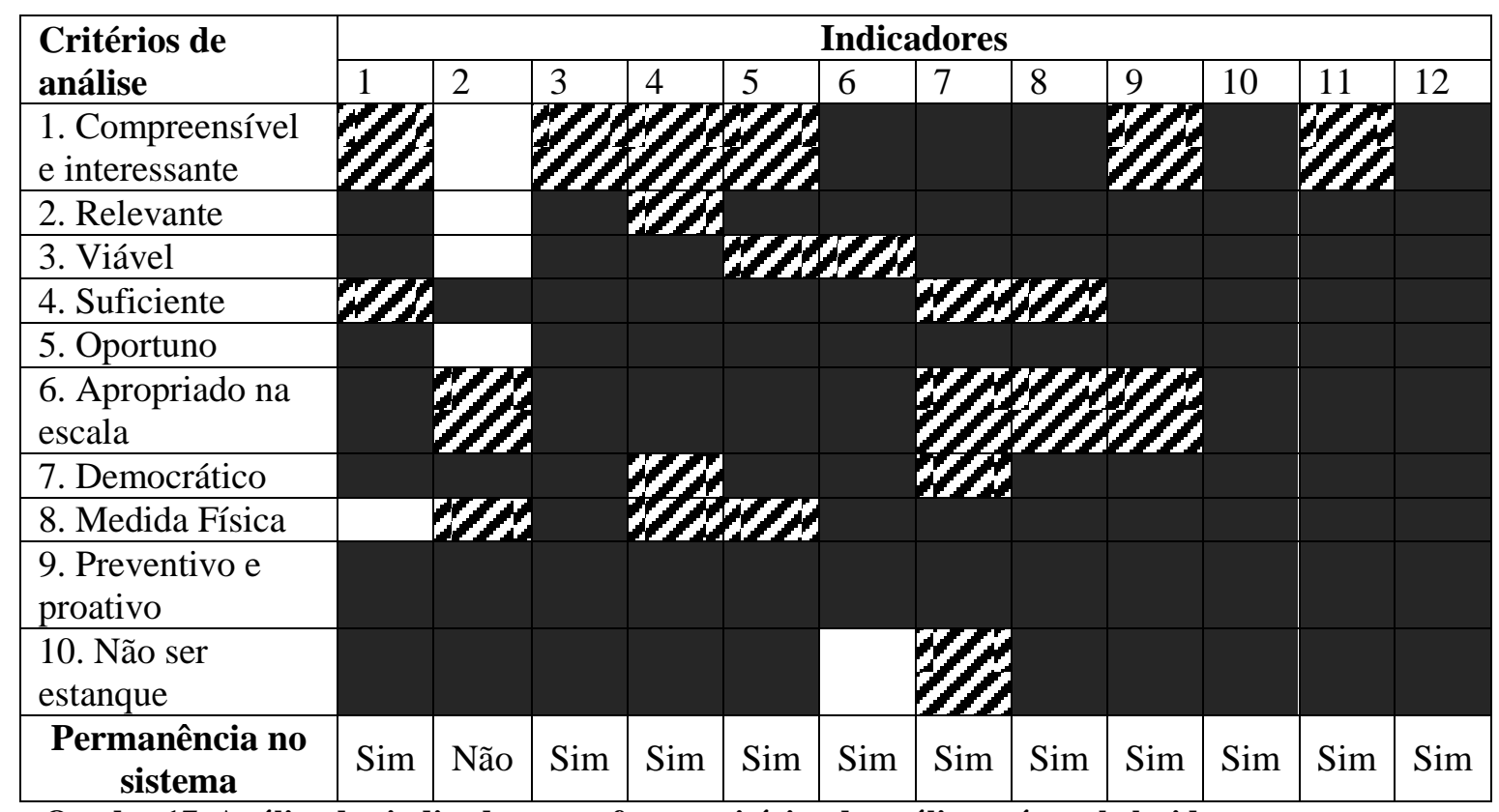

Quadro 17. Análise dos indicadores conforme critérios de análise pré-estabelecidos

Após esta qualificação da validação chegou-se ao conjunto final de indicadores. Excluiu-se um indicador do sistema, outros foram modificados e se mantiveram no sistema. Criou-se também a modalidade indicadores recomendados, que são os indicadores que não estão no sistema nesse primeiro momento, mas devem ser reelaborados e contidos no sistema futuro, pois precisam ser ajustados, aumentando o grau de detalhamento.

Em seguida a segunda oficina, o pesquisador organizou as informações e sistematizou o conjunto de indicadores propostos (Quadro 18), os quais serão objeto de reflexão no Capítulo 8. 


\subsection{Indicadores validados}

\begin{tabular}{|c|c|c|}
\hline Tema & & Nome do indicador \\
\hline Institucional & 1 & Parcerias Institucionais relacionadas às populações vulneráveis \\
\hline \multirow{3}{*}{$\begin{array}{l}\text { Recursos } \\
\text { Hídricos }\end{array}$} & 2 & Coleta de esgotos em áreas com populações vulneráveis \\
\hline & 3 & Tratamento de Esgotos em áreas com populações vulneráveis \\
\hline & 4 & Perdas de água em áreas com populações vulneráveis \\
\hline \multirow{5}{*}{ Econômica } & 5 & $\begin{array}{l}\text { Perdas de faturamento de água em áreas com populações vulneráveis que não } \\
\text { possuem abastecimento de água }\end{array}$ \\
\hline & 6 & Investimentos no Atendimento da população atendida por programas assistenciais \\
\hline & 7 & Custo da ligação para operadora nas áreas com populações vulneráveis \\
\hline & 8 & Custo da ligação para o usuário nas áreas com populações vulneráveis \\
\hline & 9 & Consumo de água pelas populações vulneráveis \\
\hline $\begin{array}{l}\text { Controle e } \\
\text { fiscalização }\end{array}$ & 10 & Famílias atendidas por programas assistenciais do governo \\
\hline \multirow{3}{*}{$\begin{array}{l}\text { Educação e } \\
\text { cidadania }\end{array}$} & 11 & Programas educacionais desenvolvidos pelas operadoras \\
\hline & 12 & Participação em programas educacionais desenvolvidos pelas operadoras \\
\hline & & Indicadores recomendados \\
\hline Institucional & 1 & Parcerias Institucionais efetivas \\
\hline Econômica & 2 & $\begin{array}{l}\text { Investimentos nas populações vulneráveis de implantação de ligações | outros } \\
\text { (especificar o investimento) }\end{array}$ \\
\hline \multirow{2}{*}{$\begin{array}{l}\text { Controle e } \\
\text { Fiscalização }\end{array}$} & 3 & $\begin{array}{l}\text { População vulnerável ao esgotamento sanitário (inclui pessoas com acesso a rede } \\
\text { mas que não podem pagar pelo serviço) }\end{array}$ \\
\hline & 4 & População vulnerável ao abastecimento de água \\
\hline
\end{tabular}

\section{Quadro 18. Indicadores formulados}

Cabe lembrar que três dimensões, operacional, gestão e social, não foram construídos indicadores. Isso deveu-se ao fato do tempo de duração das oficinas terem sido utilizados com a atenção maior ao diálogo e aproximação dos atores do que somente à produção de resultados, além disso, foi constatada a dificuldade de realização de novas oficinas tanto pela disponibilidade dos atores participarem de mais oficinas como pelo tempo de realização da pesquisa. Deste modo, a pesquisa seguiu na etapa do preenchimento de dados e análise dos indicadores. 


\subsection{Aplicação Piloto}

A aplicação piloto foi feita com a solicitação das informações junto a cinco concessionárias que operam diferentes municipalidades. Destas, três deram retorno, sendo que uma delas contribuiu fornecendo informações de três municípios. Os municípios possuem diferentes portes de tamanho e os operadores dos serviços são de formas distintas de administração. Aqui será feito apenas um breve resumo das características de cada município, visto que a aplicação dos indicadores é piloto, com o objetivo de ver a aplicabilidade e realizar a análise com vistas à melhoria do processo.

A seguir estão descritos algumas características dos municípios os quais os indicadores foram aplicados:

Município 1 - População de aproximadamente 12 mil habitantes, considerado um município de porte pequeno. Possui área territorial de 211,892 $\mathrm{Km}^{2}$ e uma densidade demográfica de 57,1 habitantes por $\mathrm{Km}^{2}$. O grau de urbanização é de 95,53\%. É classificado pelo Indíce Paulista de responsabilidade Social (IPRS) pelo SEADE como Grupo 5, ou seja, municípios mais desfavorecidos, tanto em riqueza como nos indicadores sociais. Com uma quantidade de 6,7 \% de domicílios com renda per capita até $1 \frac{2}{2}$ salário mínimo (SEADE 2012). A natureza jurídico-administrativa da operadora que executa os SAA\&ES nesse município é a autarquia, ou seja, entidade com personalidade jurídica de direito público, criada por lei específica, com patrimônio próprio, atribuições públicas específicas e capacidade de auto administrar-se sob controle federal municipal.

Município 2 - Município com porte de metrópole, com aproximadamente 1 milhão de habitantes. O município possui área territorial de 795,7 $\mathrm{Km}^{2}$, com uma densidade demográfica de 1.371,01 habitantes por $\mathrm{Km}^{2}$. O grau de urbanização é de 98,28\%. É classificado pelo IPRS como Grupo 2, ou seja, municípios que embora com níveis de riqueza elevados, não exibem bons indicadores sociais. Possui $8,12 \%$ domicílios com renda per capita até $1 \frac{1}{2}$ salário mínimo (SEADE 2012). A natureza jurídico-administrativa da operadora que executa os SAA\&ES nesse município é a autarquia, ou seja, entidade com personalidade jurídica de direito público, criada por lei 
específica, com patrimônio próprio, atribuições públicas específicas e capacidade de auto administrar-se sob controle federal municipal.

Município 3 - Município de porte médio, com a população de aproximadamente 65 mil habitantes. Faz parte da região metropolitana de São Paulo. A área territorial do município é de 128,36 $\mathrm{Km}^{2}$, com uma densidade demográfica de 510,38 habitantes por $\mathrm{Km}^{2}$. O grau de urbanização é de 97,99\%. É classificação pelo IPRS como Grupo 2, isto é, municípios com níveis de riqueza elevados, mas sem bons indicadores sociais. Possui 16,68\% dos domicílios com renda per capita até $1 \frac{1}{2}$ salário mínimo (SEADE 2012). A natureza jurídico-administrativa da operadora que executa os SAA\&ES nesse município é delegada a um terceiro, que é a uma empresa estatal (sociedade de economia mista com administração pública).

Município 4 - Município de grande porte, com a população de 154 mil habitantes. Faz parte da região metropolitana de São Paulo e possui a área territorial de 49,16 $\mathrm{Km}^{2}$, com densidade demográfica de 3.185,07em habitantes por $\mathrm{Km}^{2}$. O grau de urbanização é de 99,80\%. É classificado pelo IPRS como Grupo 4 - Municípios que apresentam baixos níveis de riqueza e nível intermediário de longevidade e/ou escolaridade. Possui 25,15\% dos domicílios com renda per capita até 1/2 salário mínimo (SEADE 2012). A natureza jurídico-administrativa da operadora que executa os SAA\&ES nesse município é delegada a um terceiro, que é a uma empresa estatal (sociedade de economia mista com administração pública).

Município 5 - Município de grande porte com 667 mil habitantes. Faz parte da região metropolitana de São Paulo e possui área territorial $64,94 \mathrm{Km}^{2}$, com densidade demográfica de 10.288,39 habitantes por $\mathrm{Km}^{2}$. O grau de urbanização é de $100 \%$. É classificado pelo IPRS como Grupo 1, isto é, municípios com nível elevado de riqueza e bons níveis nos indicadores sociais. Possui 10,47\% dos domicílios com renda per capita de até $1 / 2$ salário mínimo (SEADE 2012). A natureza jurídico-administrativa da operadora que executa os SAA\&ES nesse município é delegada a um terceiro, que é a uma empresa estatal (sociedade de economia mista com administração pública). 
Os resultados da aplicação piloto podem ser vistos a seguir, na Tabela 5. Estes resultados serão discutidos no Capítulo 8. Na sequência, está apresentado o conjunto de indicadores finais, que estão apresentados e detalhados no Quadro 19. 
Tabela 5. Aplicação piloto dos indicadores

\begin{tabular}{|c|c|c|c|c|c|c|c|}
\hline Tema & & Nome do Indicador & Município 1 & Município 2 & Município 3 & Município 4 & Município 5 \\
\hline Institucional & 1 & Parcerias Institucionais relacionadas às populações vulneráveis & 0 & - & - & - & - \\
\hline \multirow{3}{*}{$\begin{array}{l}\text { Recursos } \\
\text { Hídricos }\end{array}$} & 2 & Coleta de esgotos em áreas com populações vulneráveis & $100 \%$ & - & - & - & - \\
\hline & 3 & Tratamento de Esgotos em áreas com populações vulneráveis & $100 \%$ & - & - & - & - \\
\hline & 4 & Perdas de água em áreas com populações vulneráveis & - & - & - & - & - \\
\hline \multirow{5}{*}{ Econômica } & 5 & $\begin{array}{l}\text { Perdas de faturamento de água em áreas com populações vulneráveis que } \\
\text { não possuem abastecimento de água }\end{array}$ & 0 & - & - & - & - \\
\hline & 6 & $\begin{array}{c}\text { Investimentos no Atendimento da população atendida por programas } \\
\text { assistenciais }\end{array}$ & 0 & - & - & - & - \\
\hline & 7 & Custo da ligação para operadora nas áreas com populações vulneráveis & - & - & - & - & - \\
\hline & 8 & Custo da ligação para o usuário nas áreas com populações vulneráveis & $100 \%$ & $15 \%$ & - & - & - \\
\hline & 9 & Consumo de água pelas populações vulneráveis & - & $8,28 \%$ & $6,67 \%$ & $7,14 \%$ & $7,14 \%$ \\
\hline Abrangência & 10 & Famílias atendidas por programas assistenciais do governo & $33,40 \%$ & $17,90 \%$ & $36 \%$ & $47 \%$ & $29,20 \%$ \\
\hline \multirow{2}{*}{$\begin{array}{l}\text { Educação e } \\
\text { cidadania }\end{array}$} & 11 & Programas educacionais desenvolvidos pelas operadoras & - & 127 & - & - & - \\
\hline & 12 & Participação em programas educacionais desenvolvidos pelas operadoras & - & $\begin{array}{c}63 \text { pessoas/ } \\
\text { Atividade }\end{array}$ & - & - & - \\
\hline
\end{tabular}

Legenda: - Sem Informação 


\subsection{Conjunto de indicadores: modelo final}

Os indicadores propostos estão expostos a seguir, descritos de acordo com os objetivos os quais eles foram formulados:

Indicador 1. Parceiras Institucionais. Tem o objetivo de medir a quantidade de Parcerias Institucionais, pois, a princípio acredita-se que as relações institucionais podem auxiliar no gerenciamento e melhoria dos serviços.

Indicadores 2 e 3. Coleta e tratamento de esgotos em áreas com populações vulneráveis. Tem o objetivo de saber qual a quantidade de coleta e tratamento de esgotos para qual a quantidade de pessoas que não estão sendo atendidas e poder traçar metas a serem alcançadas. Nesse indicador, diferente do convencional, precisa mudar a lógica de apresentação dos resultados.

Indicador 4. Perdas de água. Tem o objetivo de medir a quantidade de água que é fornecida informalmente às populações vulneráveis. A exemplo disso, a SABESP entra nas favelas e faz a mensuração de domiciliar do consumo de água, mas essa metodologia é aplicada em apenas algumas unidades na capital paulista, ainda não tendo uma indicador abrangentemente utilizado.

Indicador 5. Perdas de faturamento. Tem o objetivo de mostrar quanto a operadora está tendo de gastos por fraude, utilização indevida dos recursos para verificar quais são as perdas da informalidade, e estimar que, se as populações forem atendidas, é possível haver um aproveitamento financeiro da operadora.

Indicador 6. Investimento em áreas com populações vulneráveis. O objetivo desse indicador é observar quais são os investimentos que a operadora coloca no atendimento das populações vulneráveis. Medir isso pode ser um passo importante para a melhoria, já que maiores investimentos podem significar maior interesse da operadora no atendimento. $\mathrm{O}$ indicador serve para ver se a empresa tem uma política social, se ela está investindo nas áreas com populações vulneráveis. 
Indicadores 7. Custo de ligação para a operadora. Esse indicador tem o objetivo de observar o valor de oferecimento dos serviços às populações que ainda não possuem, ou seja, a taxa que é gasta quando se faz uma nova ligação. Pois ainda não sabe-se o real custo do atendimento das populações vulneráveis, ou mesmo, quando deveria ser subsidiado para o atendimento dessas populações.

Indicador 8. Custo de ligação para o usuário. Os objetivos desse indicador é observar se existem incentivos de subsídios da operadora para a utilização dos serviços pelas populações vulneráveis, pois há operadoras que subsidiam a taxa de instalação (taxa domiciliar de ligação da rede), colocando um valor diferencial aos que não podem pagar. Ou seja, tem o objetivo de medir se as operadoras possuem incentivos de subsidiar os serviços.

Indicador 9. Consumo de água. O objetivo desse indicador é mensurar a quantidade de água que é utilizada pela população que possui abastecimento de água mas estão em áreas de vulnerabilidade, e comparar para observar se estas populações consomem mais ou menos água que as outras populações.

Indicador 10. Famílias atendidas com programas sociais. O objetivo desse indicador é mensurar a população vulnerável, por meio do mapeamento que já são feitos pelo governo federal. Observar em cada município quantidade de famílias que vivem em situação de precariedade.

Indicadores 11 e 12. Programas educacionais. O objetivo desse indicador é mensurar as atividades realizadas de cunho educativo, e observar o quanto a operadora se dedica a esse tipo de atividade, assim como avaliar o a participação dos cidadãos nessas atividades.

O Quadro 19 pode-se visualizar a compilação dos dados dos indicadores propostos. O Quadro contém os nomes dos indicadores, objetivos, fórmula, unidades de medição, variáveis, dados necessários e unidades de cada dado necessário. 


\begin{tabular}{|c|c|c|c|c|c|c|c|}
\hline & Nome do indicador & Função & Fórmula & Unidade & Definição & Dados Necessários & Unidade \\
\hline 1 & $\begin{array}{l}\text { Parcerias Institucionais } \\
\text { relacionadas às } \\
\text { populações vulneráveis }\end{array}$ & $\begin{array}{c}\text { Existência de parcerias voltadas às } \\
\text { populações vulneráveis, ou capítulo em } \\
\text { contrato específico. }\end{array}$ & CA & Número & $\begin{array}{c}\text { CA= Número de } \\
\text { parcerias que a } \\
\text { operadora possui com } \\
\text { outras instituições } \\
\text { voltados à } \\
\text { universalização (água e } \\
\text { esgoto) }\end{array}$ & $\begin{array}{l}\text { Número de parcerias } \\
\text { que a operadora possui } \\
\text { com contratos assinados } \\
\text { com outras instituições }\end{array}$ & Quantidade \\
\hline 2 & $\begin{array}{c}\text { Coleta de esgotos em } \\
\text { áreas com populações } \\
\text { vulneráveis }\end{array}$ & $\begin{array}{c}\text { Garantir a qualidade dos corpos hídricos } \\
\text { de onde é captada a água de } \\
\text { abastecimento }\end{array}$ & $\begin{array}{l}\text { Volume de água } \\
\text { gerado/volume de } \\
\text { água coletado }\end{array}$ & Porcentagem & $\begin{array}{l}\text { \% de coleta de esgoto da } \\
\text { população vulnerável }\end{array}$ & $\begin{array}{l}\text { Porcentagem de coleta } \\
\text { de esgotos }\end{array}$ & Porcentagem \\
\hline 3 & $\begin{array}{l}\text { Tratamento de Esgotos } \\
\text { em áreas com } \\
\text { populações vulneráveis }\end{array}$ & $\begin{array}{c}\text { Garantir a qualidade dos corpos hídricos } \\
\text { de onde é captada a água de } \\
\text { abastecimento }\end{array}$ & $\begin{array}{l}\text { Volume de água } \\
\text { tratado/volume } \\
\text { gerado de água } \\
\text { consumida } 80 \% \\
\text { (20\% evaporação) }\end{array}$ & Porcentagem & $\begin{array}{l}\% \text { tratamento de esgoto } \\
\text { da população vulnerável }\end{array}$ & $\begin{array}{l}\text { Porcentagem de } \\
\text { tratamento de esgoto }\end{array}$ & Porcentagem \\
\hline 4 & $\begin{array}{l}\text { Perdas de água em } \\
\text { áreas com populações } \\
\text { vulneráveis }\end{array}$ & $\begin{array}{c}\text { Mensurar o volume de água fornecido e } \\
\text { consumido }\end{array}$ & $=2$ & $\mathrm{~m} 3$ & Perdas (estimativa) & Índice de perdas & Porcentagem \\
\hline $5 ?$ & $\begin{array}{l}\text { Perdas de faturamento } \\
\text { de água em áreas com } \\
\text { populações vulneráveis } \\
\text { que não possuem } \\
\text { abastecimento de água }\end{array}$ & $\begin{array}{l}\text { Verificar o valor não faturado que é } \\
\text { gasto pelas operadoras com águas que } \\
\text { são utilizadas pela população de } \\
\text { maneira informal (fraude) }\end{array}$ & $\begin{array}{l}\text { valor não } \\
\text { faturado/faturamento } \\
\text { da empresa.100 }\end{array}$ & Porcentagem & $\begin{array}{l}\text { Perdas de faturamento } \\
\text { em locais com } \\
\text { Populações vulneráveis } \\
\text { onde não possui } \\
\text { abastecimento de água }\end{array}$ & $\begin{array}{l}\text { Perdas em locais com } \\
\text { Populações vulneráveis } \\
\text { onde não possui } \\
\text { abastecimento de água } \\
\text { (volume não faturado) }\end{array}$ & Porcentagem \\
\hline \multirow{3}{*}{6} & \multirow{3}{*}{$\begin{array}{l}\text { Investimentos no } \\
\text { Atendimento de } \\
\text { populações atendidas } \\
\text { por programas } \\
\text { assistenciais }\end{array}$} & \multirow{3}{*}{$\begin{array}{l}\text { Verificar o valor que é utilizado no } \\
\text { atendimento para cada domicílio para } \\
\text { ver o esforço de atendimento às } \\
\text { populações vulneráveis }\end{array}$} & \multirow{3}{*}{ TI/NA.100 } & \multirow{3}{*}{$\mathrm{R} \$ /$ habitante } & \multirow{3}{*}{$\begin{array}{c}\mathrm{NA}=\text { Número de } \\
\text { famílias atendidas por } \\
\text { programas sociais TI= } \\
\text { total Investimento em } \\
\text { áreas vulneráveis } \\
\text { (receita própria x outras } \\
\text { fontes) }\end{array}$} & $\begin{array}{c}\mathrm{TS}=\text { Número de } \\
\text { domicílios atendidas por } \\
\text { programas sociais }\end{array}$ & Domicílio \\
\hline & & & & & & $\begin{array}{c}\text { Estimativa de habitantes } \\
\text { por município }\end{array}$ & Habitantes \\
\hline & & & & & & $\begin{array}{c}\mathrm{TI}=\text { Total de } \\
\text { Investimento em áreas } \\
\text { vulneráveis (receita } \\
\text { própria } \mathrm{x} \text { outras fontes) }\end{array}$ & $\mathrm{R} \$$ \\
\hline
\end{tabular}

Continuação próxima página 


\begin{tabular}{|c|c|c|c|c|c|c|c|}
\hline & Nome do indicador & Função & Fórmula & Unidade & Definição & Dados Necessários & Unidade \\
\hline \multirow[t]{2}{*}{7} & \multirow{2}{*}{$\begin{array}{l}\text { Custo da ligação para } \\
\text { operadora nas áreas } \\
\text { com populações } \\
\text { vulneráveis }\end{array}$} & \multirow{2}{*}{$\begin{array}{c}\text { Verificar o valor necessário em média } \\
\text { para o atendimento às populações } \\
\text { vulneráveis }\end{array}$} & \multirow[t]{2}{*}{ CPV/CMx100 } & \multirow[t]{2}{*}{ Porcentagem } & \multirow{2}{*}{$\begin{array}{l}\mathrm{CPV}=\text { Custo médio da } \\
\text { ligação em Populações } \\
\text { Vulneráveis para a } \\
\text { operadora } \mathrm{CM}=\text { custo } \\
\text { médio da ligação }\end{array}$} & $\begin{array}{l}\text { Custo médio da ligação } \\
\text { em domicílio de uso } \\
\text { social para a operadora }\end{array}$ & $\mathrm{R} \$$ \\
\hline & & & & & & $\begin{array}{l}\text { Custo médio da ligação } \\
\text { em domicílios }\end{array}$ & $\mathrm{R} \$$ \\
\hline \multirow[t]{2}{*}{8} & \multirow{2}{*}{$\begin{array}{c}\text { Custo da ligação para o } \\
\text { usuário nas áreas com } \\
\text { populações vulneráveis }\end{array}$} & \multirow{2}{*}{$\begin{array}{l}\text { Verificar existência de incentivos em } \\
\text { atender a população vulnerável }\end{array}$} & \multirow[t]{2}{*}{ CPV/CMx100 } & \multirow[t]{2}{*}{ Porcentagem } & \multirow{2}{*}{$\begin{array}{c}\text { CPU= Custo médio da } \\
\text { ligação em Populações } \\
\text { Vulneráveis para o usuário } \\
\text { CM= custo médio da } \\
\text { ligação }\end{array}$} & $\begin{array}{l}\text { Custo médio da ligação } \\
\text { em domicílio de uso } \\
\text { social para o usuário }\end{array}$ & $\mathrm{R} \$$ \\
\hline & & & & & & $\begin{array}{c}\text { Custo médio da ligação } \\
\text { em domicílios }\end{array}$ & $\mathrm{R} \$$ \\
\hline \multirow[t]{2}{*}{9} & \multirow{2}{*}{$\begin{array}{l}\text { Consumo estimado de } \\
\text { água pelas populações } \\
\text { vulneráveis }\end{array}$} & \multirow{2}{*}{$\begin{array}{l}\text { Levantar custos para direcionar } \\
\text { investimentos }\end{array}$} & \multirow{2}{*}{$\begin{array}{l}(\mathrm{CPS}-\mathrm{CG}) \\
/ \mathrm{CG} \times 100\end{array}$} & \multirow[t]{2}{*}{ Porcentagem } & \multirow{2}{*}{$\begin{array}{c}\mathrm{CPS}=\text { Consumo da } \\
\text { população vulnerável por } \\
\text { ligação } \mathrm{CG}=\text { consumo } \\
\text { geral }\end{array}$} & $\begin{array}{l}\text { Consumo médio da } \\
\text { população sanitariamente } \\
\text { vulnerável por ligação }\end{array}$ & $\mathrm{m} 3$ \\
\hline & & & & & & $\begin{array}{c}\text { Média do consumo geral } \\
\text { da população }\end{array}$ & $\mathrm{m} 3$ \\
\hline \multirow[t]{2}{*}{10} & \multirow[t]{2}{*}{$\begin{array}{l}\text { Famílias atendidas por } \\
\text { programas assistenciais } \\
\text { do governo }\end{array}$} & \multirow{2}{*}{$\begin{array}{l}\text { Levantamento do número de famílias } \\
\text { cadastradas em programas assistenciais } \\
\text { do governo, pois assim pode-se definir } \\
\text { as áreas e populações vulneráveis }\end{array}$} & \multirow[t]{2}{*}{ FC/Tx100 } & \multirow[t]{2}{*}{ Porcentagem } & \multirow{2}{*}{$\begin{array}{c}\mathrm{FC}=\text { Número de famílias } \\
\text { cadastradas em programas } \\
\text { do governo } \mathrm{T}=\text { total de } \\
\text { famílias }\end{array}$} & $\begin{array}{c}\mathrm{NF}=\text { Número de famílias } \\
\text { cadastradas em programas } \\
\text { assistenciais do governo }\end{array}$ & Famílias \\
\hline & & & & & & Total de famílias & Famílias \\
\hline 11 & $\begin{array}{c}\text { Programas educacionais } \\
\text { desenvolvidos pelas } \\
\text { operadoras }\end{array}$ & $\begin{array}{l}\text { Atingimento das metas de controle } \\
\text { social contidas no teor Lei } 11.445 / 07\end{array}$ & - & $\begin{array}{l}\text { Número de } \\
\text { atividades }\end{array}$ & $\begin{array}{l}\mathrm{NR}=\text { Número de Reuniões } \\
\text { de participativas, oficinas e } \\
\text { cursos disponibilizados/ano }\end{array}$ & $\begin{array}{c}\mathrm{NR}=\text { Número de } \\
\text { Reuniões de } \\
\text { participativas, oficinas e } \\
\text { cursos } \\
\text { disponibilizados/ano } \\
\end{array}$ & Quantidade \\
\hline \multirow[t]{2}{*}{12} & \multirow[t]{2}{*}{$\begin{array}{c}\text { Participação em } \\
\text { programas educacionais } \\
\text { desenvolvidos pelas } \\
\text { operadoras }\end{array}$} & \multirow{2}{*}{$\begin{array}{l}\text { Em função do grau de participação nas } \\
\text { oficinas, cursos oferecidos é possível } \\
\text { cruzar a informação com indicador de } \\
\text { qualidade ambiental, podendo medir a } \\
\text { importância e o grau de influência dos } \\
\text { programas de educação e planejamento } \\
\text { participativo }\end{array}$} & \multirow[t]{2}{*}{ NR/NP } & \multirow[t]{2}{*}{$\begin{array}{l}\text { Participante/ } \\
\text { atividade }\end{array}$} & \multirow[t]{2}{*}{$\begin{array}{c}\text { NR = Número de Reuniões } \\
\text { de participativas, oficinas e } \\
\text { cursos disponibilizados/ano } \\
\mathrm{NP}=\text { Número de } \\
\text { participantes concretizadas }\end{array}$} & $\begin{array}{c}\text { NR= Número de } \\
\text { Reuniões de } \\
\text { participativas, oficinas e } \\
\text { cursos } \\
\text { disponibilizados/ano }\end{array}$ & Quantidade \\
\hline & & & & & & $\begin{array}{l}\text { Número total de } \\
\text { participantes }\end{array}$ & Pessoas \\
\hline
\end{tabular}

Quadro 19. Conjunto de indicadores finais, com o detalhamento dos objetivos, fórmula, unidade, definição e dados necessários. Estruturação da tabela baseada no modelo PNQS (2011). 


\section{CONTRIBUIÇÕES E APLICABILIDADE DO SISTEMA DE INDICADORES}

Neste capítulo pretende-se avaliar a qualidade do modelo construído. Porque ele é do jeito que é? Quais são suas potencialidades e fragilidades? E ainda perguntar: o que realmente ele consegue medir? O que ele não consegue medir? Coloca-se a necessidade de reflexão e sugestões de melhorias tanto no modelo como no processo de formulação, aprofundando na diversidade de implicações e possibilidades.

Procurou-se discutir os resultados segundo levantamento do referencial teórico estudado e dos atributos relevantes na percepção dos participantes das oficinas. O levantamento da pesquisa-ação possui resultados qualitativos, que parametrizam pesquisas futuras de dados quantitativos.

A sequência de apresentação dos aspectos discutidos está dividida em três partes: (1) Inicialmente é dissertado a respeito da ferramenta de benchmarking; (2) Posteriormente é feita uma avaliação do modelo final e as comparações com os diferentes modelos estudados; (3) E por fim, é feita a avaliação da qualidade e do processo de formulação dos indicadores, assim como, a discussão a respeito das implicações de algumas relações econômicas e políticas.

\subsection{Benchmarking no auxílio da melhoria dos SAA\&ES às populações vulneráveis}

Durante o seminário realizado "Saneamento e Populações Vulneráveis" e o desenvolvimento das oficinas, conforme relatado no Capítulo 7, as operadoras, os reguladores e o governo tiveram a oportunidade de mostrar as boas práticas desenvolvidas em relação aos SAA\&ES voltados às populações vulneráveis, e ao mesmo tempo, aprender uns com os outros. Esta atividade pode ser considerada um processo inicial da utilização da ferramenta de benchmarking.

Pondera-se que há uma diversidade da qualidade de gestão em diferentes municípios. Cada município possui particularidades de gestão dos SAA\&ES, há multiplicidade de formatos administrativos, dimensões populacionais e territoriais, formatos de urbanização, como pode-se observar nas visitas à campo, e apesar de ser 
possível realizar o benchmarking entre diferentes formatos de gestão, dependendo do indicador a ser utilizado, ainda mostra-se desafiador. Deste modo, no momento de implantação do processo de benchmarking dos SAA\&ES voltados às populações vulneráveis requer cuidados.

Mas ainda assim, percebeu-se que a utilização da ferramenta de benchmarking é uma boa solução para o setor, pois mostra-se uma oportunidade de observar algumas lacunas na gestão, e ao mesmo tempo, mostrar formas de auxiliar as municipalidades. Na prática de benchmarking, como processo de melhoria contínua conforme colocado por Camp (1993), Slack et al. (2002) e Bhutta e Huq (1999) não dependem de comparações nas mesmas proporções, mas adaptações de práticas. Manifestações iniciais da prática de benchmarking são utilizadas informalmente por algumas operadoras, em um caráter de conhecer outras formas de gerenciar, aprendendo com boas práticas e melhorando o próprio sistema, mas de forma isoladas e descontínuas.

\subsection{Sistema de Indicadores: Análise do Modelo Final}

O sistema proposto conseguiu alcançar o propósito de ter uma visão integrada do funcionamento dos serviços. Também alcançou a meta de contextualizar os indicadores e qualificá-los, conforme sugerem Meadows (1998), Bossel (1999) e Alegre et al. (2006).

Este mecanismo sistemático consegue observar diversas relações existentes e analisar a complexidade, mas de forma simples, organizada e enxuta. O sistema foi organizado utilizando-se paradigmas de diferentes autores, listando diferentes problemas, devido o sistema ter sido feito com a pluralidade de opiniões, tanto teóricas, como a pluralidade de opiniões de diferentes atores dos SAA\&ES, durante as oficinas. Essas características são o que permitem a boa qualidade de indicadores e do sistema conforme é descrito por Meadows (1998) e Bossel (1999).

Para melhor avaliação do modelo final, fez-se uma análise comparativa com os modelos pesquisados na revisão bibliográfica. A seguir são mostradas e discutidas estas comparações. 


\subsubsection{Estrutura de Benchmarking de Indicadores dos SAA\&ES voltados às populações vulneráveis do projeto PROBE}

A comparação mais detalhada foi necessária para esse modelo, por ele ser o sistema que mais se aproxima do modelo elaborado na presente pesquisa, por ser o único modelo que foi especificamente construído como estrutura de benchmarking dos SAA\&ES voltados às populações vulneráveis, o qual é fruto do projeto PROBE internacional. Esta pesquisa foi elaborada por meio de revisão bibliográfica por Ralda (2010), no Institute for Water Education (UNESCO-IHE), na Holanda, conforme detalhado no item 6.2.5.

O modelo elaborado por Ralda (2010) constitui-se de cinco dimensões: preparação, colaboração, ferramentas, sustentabilidade e prestação de serviços. Através da análise, foi feita a discussão se as dimensões estruturadas na presente pesquisa têm a mesma proposta, apenas apresentado em formato diferente, ou se realmente ele possui uma proposta inovadora e diferenciada. Portanto, a pergunta que se coloca é: a estrutura criada pela presente pesquisa é apenas uma maneira diferente de apresentar as mesmas dimensões utilizadas pelo Ralda ou realmente possui um diferencial? Quais são as similaridades e quais são as diferenças existentes entre os modelos?

Assim, as cinco dimensões do modelo de Ralda (2010) foram analisadas, descrevendo as similaridades e as diferenças em comparação ao modelo da presente pesquisa.

A dimensão da Preparação é similar à dimensão Institucional, ambas tem o foco em mensurar as iniciativas políticas e arranjos institucionais que apóiem no sentido da prestação dos SAA\&ES às populações vulneráveis. Ou seja, para ambas os modelos certifica-se que a capacidade do governo em produzir, implementar e monitorar projetos são necessários para proporcionar às populações vulneráveis o alcance aos SAA\&ES com mais facilidade.

Em relação ao operador é feito por Ralda (2010) a exigência de que eles possuam recursos humanos especializados no atendimento às populações vulneráveis, fundos de tecnologia, priorização de serviços e capacidade que podem ser úteis para 
impulsionar ações para alcançar um quadro institucional forte com a finalidade de aumentar a colaboração, a priorização de projetos nos orçamentos voltados às populações vulneráveis e, finalmente, a criação de ramo dentro da organização específico para o fornecimento dos serviços às populações vulneráveis. Estas exigências que são condizentes com a dimensão da Gestão.

A dimensão de Colaboração é contida nas dimensões Institucional, Social e da Educação e Cidadania. A colaboração entre as instituições descritas por Ralda (2010) é a colaboração interinstitucional, medida observando a rede formal que necessita ser feita de tal forma que as operadoras poderiam realizar parcerias com outras organizações que tivessem os mesmos interesses, como ONGs, comunidades do bairro, instituições do governo, etc. Todos estes aspectos contidos na dimensão Institucional.

Também é importante medir a promoção da participação dos usuários, facilitar os diálogos, para acompanhar e avaliar os esforços feitos de tal forma estas partes interessadas possam pressionar seus governos locais, bem como o operador dos serviços, e desta forma garantir todos os esforços nos projetos destinados aos SAA\&ES às populações vulneráveis estejam sendo direcionados no caminho certo. Estes aspectos estão inseridos da dimensão Educação e Cidadania.

Cabe lembrar que no modelo inicial da presente pesquisa, não havia a dimensão Educação e Cidadania, ela foi incluída durante as oficinas, mesmo sendo dialogado que a mesma já estava contida na dimensão Social. Foi justificado pelos atores, que é necessário haver uma dimensão específica para a educação, senão estaria sujeito a não ser valorizado pelos tomadores de decisão, sendo acobertada por outros indicadores, sendo a argumentação aceita por todos os atores, a dimensão foi inserida no sistema.

A dimensão Ferramentas está contida nas dimensões Social, Econômica e Operacional. Esta dimensão caracteriza-se pela mensuração de instrumentos de mapeamento das populações vulneráveis, para que se tenha uma imagem correta e completa da população que necessita ser priorizada, a fim de identificar as suas características econômicas, sociais, legais e geográficas. Estes aspectos estão incluídos na dimensão Social. 
Ralda (2010) coloca também nesta dimensão de Ferramentas os instrumentos financeiros que estaria na dimensão econômica no modelo da presente pesquisa. $\mathrm{Ou}$ seja, dar prioridade aos segmentos da população considerada vulnerável para a utilização de tarifas sociais, pagando menos do que as tarifas comuns, assim como a existência de instrumentos de diminuição das taxas de ligação, dentre outros subsídios.

Outro aspecto descrito por Ralda para a dimensão das Ferramentas e que estão contidas no modelo como a dimensão Econômica são as possíveis perdas de receitas que os operadores podem estar tendo em decorrência de não conectar as populações vulneráveis, ocorrendo que o operador está perdendo mais do que poderia realmente ganhar (em termos financeiros).

É citado por Ralda (2010) a necessidade de tecnologias voltadas às populações vulneráveis, produção de equipamentos e metodologias técnicas no sentido de adaptar os SAA\&ES às condições domiciliares das populações vulneráveis, que por vezes, vivem em lugares onde não há espaço suficiente para introduzir as tubulações de água e sistemas de esgotos convencionais, incluída como a dimensão Operacional na presente pesquisa.

A dimensão da Sustentabilidade é similar à dimensão dos Recursos Hídricos, pois diz respeito à qualidade da água e inclusão de um pacote de medidas de gestão da água e esgotos para mitigar desastres de contaminação e adaptar o sistema às mudanças climáticas, a qual faz parte do cenário atual a adaptação às forças da natureza, como secas e inundações, o sistema deve considerar a construção de reservatórios e a utilização de métodos alternativos e fontes alternativas de água, já que os padrões hidrológicos estão mudando devido ao aquecimento global. As populações vulneráveis sofrem maior impacto com essas alterações.

Ainda na dimensão da Sustentabilidade, Ralda (2010) inclui medidas sobre a existência de programas integrais de educação, formação e sensibilização, a fim de promover o controle social dos SAA\&ES, resolvendo os problemas de forma participativa, e os utilizadores finais devem estar envolvidos desde o início, esses aspectos são objeto de mensuração nas dimensões Educação e Cidadania e Social. Os programas devem ser de formação integral das populações vulneráveis, considerando 
aspectos de desenvolvimento econômico, de redução da vulnerabilidade e a sustentabilidade ambiental. Programas de educação e formação podem ser desenvolvidos com parcerias com os Ministérios da Educação e Saúde e com a Municipalidade.

Na dimensão da Prestação de serviços Ralda relata que nesta dimensão deve ser mensurada tanto a qualidade dos serviços (padrões de potabilidade) como a quantidade e continuidade, de tal maneira que o volume (litros por dia per capita) seja considerado e, a continuidade do serviço nas 24 horas do dia, sete dias por semana, e acessível a todos. Estes itens também foram considerados na dimensão Controle e Fiscalização no presente modelo. Assim como a cobertura de atendimento do esgotamento sanitário.

O Quadro a seguir mostra como os dois modelos se inter-relacionam (Quadro 21), visualizando um resumo do que já foi descrito.

\begin{tabular}{|c|c|}
\hline Dimensão do Modelo do Ralda (2010) & Dimensões do Modelo final PROBE Brasil \\
\hline \multirow{2}{*}{ Estado de Preparação } & Institucional \\
\hline & Gestão \\
\hline \multirow{3}{*}{ Colaboração } & Institucional \\
\hline & Social \\
\hline & Educação e Cidadania \\
\hline \multirow{3}{*}{ Ferramentas } & Social \\
\hline & Econômica \\
\hline & Operacional \\
\hline \multirow{3}{*}{ Sustentabilidade } & Recursos Hídricos \\
\hline & Social \\
\hline & Educação e Cidadania \\
\hline Fornecimento dos serviços & Controle e Fiscalização \\
\hline
\end{tabular}

Pode-se observar que os dois modelos contêm os mesmos aspectos, apenas citados e contextualizados de maneiras diferentes. Pois as dimensões são aspectos gerais por meio dos quais os modelos devem ser visualizados. O diferencial neste caso, do modelo produzido por Ralda e o modelo da presente pesquisa está na especificidade dos indicadores aplicados à realidade do Brasil, Estado de São Paulo.

Outro diferencial está no usuário do modelo, que no caso do Ralda é diversificado à municipalidade, operadores, usuários finais e no presente caso está voltado para utilização pela reguladora dos serviços. 
O modelo estruturado pelo presente trabalho foi validado participativamente, com a presença de diferentes atores, o que como será discutido no subcapítulo Construção de Indicadores. Podendo deste modo, visto que ambos modelos são similares, certificar ainda mais a validade do presente modelo. Vale ressaltar que a maneira que o presente modelo se estruturou, e é apresentado, está relacionado à maior facilidade de visualização e entendimento dos atores, isso foi considerado para que o processo participativo fosse facilitado.

\subsection{Indicadores}

Os indicadores foram construídos por meio da visão de mundo dos atores envolvidos no processo e não tiveram o objetivo de ser um sistema com indicadores completos e estanques, mas colocar a temática em pauta e um olhar através das lentes que unam e foquem a necessidade da universalização dos serviços, a complexidade sob o olhar simples, para se observar apenas o necessário.

Durante todo o processo de construção dos indicadores de benchmarking buscou-se utilizar as lentes da sustentabilidade, enfocando indicadores que se vinculassem. Os indicadores, e principalmente o sistema, foram pautados na visão da sustentabilidade. O sistema permite ser ao mesmo tempo de simples visualização e mostrar a complexidade, mostrando as diversas faces, as multidimensões, características dos indicadores de sustentabilidade, e só assim é possível observar a problemática dos serviços.

A partir dos resultados apresentados pode-se inferir que os indicadores têm potencial para mostrar e mensurar a situação em que se encontram os serviços em relação às populações vulneráveis. No entanto, a ausência de informações para o preenchimento dos indicadores foi um significante indício de que as operadoras ainda não possuam dados relacionados às populações vulneráveis. Isto já era previsto pelos atores durante a formulação dos indicadores, mesmo assim foram propostos pela necessidade de mensurar estas informações, e também com o intuito de recolhimento delas em momentos futuros. Por isso, ressalta-se a importância da coleta destes dados e do preenchimento dos indicadores propostos. 


\subsubsection{Qualidade dos indicadores}

A discussão da qualidade dos indicadores é feita aqui de acordo com os critérios estabelecidos na revisão bibliográfica (Item 6.3).

1. Claro, compreensível e interessante. Os indicadores foram feitos de forma que mostrassem interesses de todos os atores envolvidos, eles tiveram alguma dificuldade de esclarecer ao entendimento de todos, mas o resultado que chegou-se foi o mais claro possível. E durante, caso não estejam plenamente convictos, serem revistos e reformulados na continuidade de aplicação pelo operador.

2. Relevante. Estes indicadores são politicamente relevantes. Surgiram demandas emergentes da universalização dos serviços. E são relevantes politicamente, mostrando a orientação para futuras metas políticas.

3. Viável. O custo da aquisição, processamento de dados e comunicação não puderam ser avaliados, pois a maior parte das informações terá que ser fornecida pelos operadores e cada operador terá de verificar o custo desta informação. No entanto, durante as oficinas notou-se que alguns dos indicadores é o caminho para a melhor gestão dos serviços, e como necessidade da demanda emergente eles terão de verificálas. Ressalta neste caso também a possibilidade destas informações serem solicitadas às operadoras pelo regulador dos serviços.

4. Suficiente. Todos os indicadores foram revisados por técnicos da área e tentou-se ao máximo fornecer a medida certa de informação.

5. Oportuno. Os indicadores possuem um caráter inovador e que desde o início de sua formulação tem o objetivo de ser integrado ao planejamento e a gestão de melhoria contínua das operadoras.

6. Apropriado na escala. Os indicadores possuem o foco da utilização pelo regulador, no entanto são indicadores apropriados para a utilização do operador, igualmente pela municipalidade e usuário final, deste modo atende este critério, atingindo diferentes usuários potenciais. 
7. Democrático. Neste critério, pode-se diagnosticar que foi realizado com ampla participação. Apesar de não haver participação de representantes de comunidades e ONGs, ainda assim, contou com uma diversidade de atores. O critério diz respeito ainda à democratização do acesso aos resultados, esta avaliação só poderá ser feita quando os indicadores forem lançados e registrados oficialmente, inicialmente foi feita apenas uma aplicação piloto e obteve-se poucas informações.

8. Medida Física. As medidas físicas foram balanceadas, utilizando-se diferentes unidades físicas e monetárias, e na demonstração do indicador optou-se pela utilização de porcentagem, para que pudesse ser comparado em formato de proporção entre os diferentes municípios e operadoras.

9. Preventivo e pró-ativo. Os indicadores mostraram-se pró-ativos no sentido de verificar uma situação, e poder visualizar pelos próprios indicadores, melhorias do sistema. E também pode fornecer informação em tempo para poder agir.

10. Não deve pretender ser uma ferramenta estanque. Os indicadores foram formulados por meio de processo participativo o qual instituiu parcerias institucionais. Estas parcerias, como a parceria com a ARSESP (Agência Reguladora dos SAA\&ES), tem o objetivo do processo de reformulação, formulação de novos indicadores, seja continuamente discutido e atualizado.

O Quadro 22 mostra, resumidamente, a aplicação e avaliação dos critérios aplicados.

\begin{tabular}{|c|c|c|c|}
\hline & Critérios & Aplicação & Avaliação \\
\hline 1 & Claro, compreensível e interessante & Aplicado & ;) \\
\hline 2 & Relevante & Aplicado & ;:) \\
\hline 3 & Viável & Aplicação futura & - \\
\hline 4 & Suficiente & Aplicado & ;:) \\
\hline 5 & Oportuno & Aplicado & ;) \\
\hline 6 & Apropriado na escala & Aplicado & ;:) \\
\hline 7 & Democrático & Aplicado & ;) \\
\hline 8 & Medida Física & Aplicado & ;:) \\
\hline 9 & Preventivo e pró-ativo & Aplicado & ;:) \\
\hline 10 & Não deve pretender ser uma ferramenta estanque & Aplicado & ;:) \\
\hline
\end{tabular}

Quadro 21. Aplicação dos critérios e avaliação das boas práticas de indicadores 


\subsubsection{Implicações Regulatórias dos SAA\&ES}

É necessário enfrentar a situação dos serviços considerando as dimensões culturais e éticas no processo de tomada de decisão, pois esse é carregado de significados, valores e influencia o olhar sobre as situações.

Entender as redes de poder existentes permite enxergar o que está estabelecido como formas administrativas e de condução das políticas, porém não estão obviamente apresentadas. Caracteriza-se como uma construção social por meio das conexões complexas entre organizações distintas, onde a constituição de políticas pública se dá pela base e não pelo alto (GONÇALVES, 2003).

Estas redes de poder nos SAA\&ES podem ser observadas entre as relações institucionais, as quais não obedecem apenas a leis institucionais, mas ao mercado e à sociedade, em decorrência do processo de interação de atores sociais e econômicos em contextos democráticos e de forte liberalização econômica. Desta forma a formulação e implementação de políticas públicas são feitas por meio arranjos institucionais, que estão cada vez mais dependentes das relações sociais entre os atores (PAULILLO, 2001; GONÇALVES, 2003).

Neste caráter é que se discutiu a inserção dos indicadores, e a significância de implementação que eles terão nesse contexto, o qual é construído tanto pela razão (reconhecida pelas ideias de racionalidade e de ação intencional) como pela coerção (reconhecida nos processos de conflito e de articulação de interesses a partir do exercício da política) (PAULILLO, 2001). Deste modo, decisões políticas é o resultado final de uma sequência de decisões tomadas pelos atores situados em diferentes posições de poder. (AVILA; DUARTE; SABOURIN; MASSARDIER, 2010).

Dada estas circunstâncias, na discussão da presente pesquisa, percebe-se que o não oferecimento das informações para o preenchimento dos indicadores, reflete a condição em que se encontra o setor. Isto é, o fato de testar os indicadores durante a aplicação piloto e não encontrar os resultados em números, demonstra a lacuna que há na medição dos SAA\&ES voltados às populações vulneráveis, e que o assunto não assumiu a priorização e importância para ser levado a resultados de eficiência e eficácia 
da prestação dos serviços, no que tange a regulação e obtenção de resultados frente ao direito do usuário.

O fato de não obter os dados pode significar que as operadoras não estão medindo estes fatores levantados como relevantes para o atendimento das populações vulneráveis. Isso mostra a ineficiência do monopólio natural, pois a empresa decide o que quer dar importância. A regulação deve dar foco em sanar essa ineficiência, no propósito de atender os objetivos da regulação econômica.

Segundo Rouse (2007), a regulação externa foi um dos marcos de mudança no setor de saneamento nos últimos vinte anos, justificada pelas falhas de mercado inerentes ao setor de saneamento, que podem ter quatro origens: A primeira é a existência do chamado monopólio natural, onde os ganhos de escala e/ou de escopo são elevados de forma que é mais eficiente produzir mediante uma única empresa. A segunda fonte de falha de mercado está associada às externalidades que representam apenas custos ou benefícios de uma atividade, que não são devidamente internalizados pelas empresas. No caso do saneamento há diversas externalidades ligadas a situações de custos não equacionadas, como a condição de vulnerabilidade social e ausência de definição dos subsídios; e o próprio meio ambiente. A terceira fonte está ligada à existência de bens públicos, como saúde pública. No caso da saúde, os benefícios sociais do investimento em saneamento vão muito além dos eventuais ganhos de um agente, caracterizando retorno social superior ao privado. Por fim, a quarta origem de insuficiência do mercado decorre do fenômeno de assimetria de informação.

E deste modo, emerge o papel da regulação econômica, em "assegurar que o resultado da interação entre produtores e consumidores de determinado serviço seja eficiente, na perspectiva de alcançar adequados níveis de quantidade, qualidade e preço.” (SILVA, 2009, p.218). Ou seja, cria-se o papel do regulador para dirimir as falhas do mercado, ou ao menos, diminuí-las.

A constatação que se coloca é o próprio princípio da regulação econômica, que é necessário a intervenção regulatória para garantir o atendimento nas falhas de mercado. A pobreza é uma falha de mercado, onde o monopólio natural não atua com eficiência. Conforme coloca Scholze e Wimmer (2009, p. 163) “a regulação se justifica quando é 
necessária a disputa de um regime de concorrência, para a proteção contra falhas de mercado e a defesa dos interesses dos consumidores".

No entanto, conforme é citado por Galvão Jr (2009), alguns mecanismos regulatórios podem promover maior equidade no acesso aos serviços, como as definições de preços das tarifas, metas de eficiência, compartilhamento dos resultados com os usuários e a aplicação de penalidades pelo não cumprimento das metas.Além disso,evidencia uma constatação para atuação do regulador, que deverá instituir mecanismos para medir e normas para que a empresa implante e sistematize instrumentos de tecnologia da engenharia e de gestão de processos que promovam a universalização.

Para isto é necessário que a reguladora esteja estruturada, tanto em termos financeiros, como de recursos humanos e instrumentos de gestão. E é no sentido desse auxílio junto à regulação que surge o uso da ferramenta de benchmarking, que por meio de comparações podem estabelecer metas de melhoria.

A utilização da ferramenta de benchmarking, a qual regula por meio do "brilho" ou "constrangimento" nesse caso das operadoras, podem colaborar com a função da regulação, assim como deve-se instituir medições de perdas em áreas de vulnerabilidade, normas de investimento nessas áreas, além de indicações do que é necessário priorizar e realizar, dando as diretrizes para os passos futuros no setor.

\subsubsection{Processo de construção dos indicadores}

O número de indicadores é compacto, apesar de se observar a necessidade de criação de novos indicadores para as dimensões que ainda não foram preenchidas. $\mathrm{O}$ número compacto é colocado por Bossel e Meadows como qualidade do sistema, desde que não seja insuficiente, ocultando informações.

Por meio da aplicação piloto constatou-se que não há levantamento de dados especificamente de populações vulneráveis, e para o preenchimento desses indicadores é necessário esse levantamento. Os indicadores mostraram-se inovadores, pois conseguem apontar o que outros sistemas ainda não olham, mas as operadoras não estão prontas para isso, por isso inclusive, as operadoras ainda não possuem os dados para seu 
preenchimento. Se bem analisados e preenchidos os dados, eles permitem o mapeamento da população vulnerável que não possui atendimento aos SAA\&ES. As operadoras e prefeituras muitas vezes possuem esses dados, mas ainda não de forma que possam ser observadas as características específicas que eles mostram, muito menos compará-las, como a proposta de benchmarking.

Com a construção participativa, os indicadores refletiram os interesses e pontos de vista de diferentes atores conforme sugerem Gallopín, (1997), Meadows (1998), Bossel (1999), Santos (2004); Alegre et. al. (2005), Malheiros, Philippi Jr e Coutinho (2006) e Reed (2008). Preocupou-se durante a elaboração dos indicadores em observar as fragilidades descritas por Meadows, e procurou-se não cometer os erros descritos no item 6.3. Os atores tiveram o poder de influenciar as decisões, possuíam a capacidade teórica e entendimento da linguagem.

A realização do processo participativo de construção de indicadores proporcionou a inclusão dos atores no processo de desenvolvimento de indicadores, e dessa forma, construir indicadores condizentes com a realidade, mais facilmente aplicados, visto que foram construídos pelos mesmos atores que irão utilizá-los. Além disso, o processo participativo não exclui a importância e necessidade da visão teórica do processo, a qual possibilita o aprofundamento na temática, dando maior lucidez ao processo participativo.

A seguir estão expostos os aspectos observados segundo os itens da revisão bibliográfica em relação aos processos participativos.

\subsubsection{Avaliação do sucesso do processo participativo}

Em relação ao sucesso com o foco nos resultados, constatou-se uma boa quantidade de pessoas participantes, porém não se conseguiu desenvolver todos os indicadores necessários para a conclusão do sistema.

Em relação ao sucesso com o foco no processo, este se mostrou participativo, com os objetivos construídos coletivamente. O envolvimento no processo foi feito nas fases iniciais de elaboração e isso proporcionou maior sucesso ao processo e decisões de 
alta qualidade e duráveis, conforme já relatado por Estrella e Gaventa (2000), Chess e Purcell (1999) e Reed (2008).

A seguir serão discutidas as boas práticas do processo participativo estabelecidos no referencial teórico. Pois os processos participativos, se bem desenhados e utilizados os recursos disponíveis, há evidências crescentes de que os riscos podem ser percebidos a tempo de modificá-los, conforme alerta Reed (2008).

\section{Objetivos comuns}

O processo participativo contou com uma boa participação, tanto durante as oficinas como na elaboração e planejamento preliminares. A metodologia utilizada já foi proposital para isso - pesquisa participante. Ao longo do processo, houve alterações decorrentes de acatar opiniões e sugestões dos atores envolvidos, isso pôde ocorrer devido as característica da pesquisa participante, que dialoga continuamente com os atores envolvidos e se desenvolve no próprio decorrer da pesquisa conforme colocam Thiollent (1997) e Brandão (2005).

Conseguiu-se estabelecer objetivos claros desde o início do processo conforme adverte Reed (2008) e o envolvimento precoce das partes interessadas conforme aconselham Tippett et al. (2005). O processo participativo foi, dessa forma, influenciado pela experiência prévia com os participantes, e seus contextos culturais e institucionais.

\section{Participação dialogada}

Foi incentivado o diálogo e foi considerada a diversidade de opiniões durante as oficinas e durante o planejamento do seminário e das oficinas. Durante as oficinas podese observar que as pessoas participaram ativamente, dialogaram, entenderam a proposta, e a temática. Inclusive observou-se que a temática faz parte do cotidiano delas, o que facilitou o entendimento da importância dos indicadores e de observar a problemática dos SAA\&ES por diversas dimensões do problema.

Durante as oficinas perceberam-se algumas dificuldades para o diálogo, dos participantes aceitarem opiniões diferentes, e de alguns participantes quererem impor o seu conhecimento, mas essa dificuldade era esperada, pois o conflito faz parte de um 
diálogo democrático, e podem-se conduzi-los com tranquilidade. Outra dificuldade encontrada foi a pro-atividade da construção. As pessoas preferem atividades organizadas e sistematizadas anteriormente, e desta forma, o funcionamento participativo melhora, com possibilidades maiores de se obter resultados durante as oficinas. No entanto, deve-se ressaltar que a não participação pró-ativa abre espaço para que não haja um real pertencimento do conhecimento gerado, correndo o risco inclusive, de induzir respostas ou tendências.

\section{Facilitadores qualificados}

Durante o processo participativo não foi negligenciada a necessidade de facilitação altamente qualificada, conforme destaca Reed (2008). O processo contou com facilitadores qualificados no gerenciamento de conflitos, imparcial, aberto a múltiplas perspectivas e acessível, permitiu a dinâmica do grupo ser positiva.

A importância do facilitador foi considerada pela pesquisa e pôde-se observar que contribui com a qualidade da oficina. O processo contou com facilitados que desenvolveram experiência ao longo de anos em lidar com conflitos, mostraram-se capacitados e com segurança para realização das atividades.

\section{Compartilhamento dos saberes}

As decisões foram baseadas na diversidade de conhecimentos conforme sugerem Johnson et al. (2004), Chess e Purcell (1999), Reed et al. (2006), Stringer e Reed (2007), Healy (2009) e Reed (2008). Foi utilizada uma diversidade de ferramentas de comunicação para que facilitasse esse processo de aproximação dos conhecimentos e que todos fossem acessados com o tipo de ferramentas de comunicação que mais se aproximasse de sua realidade, além disso, o formato de apresentação das informações técnicas foi facilitado.

Uma das causas do processo de comunicação e troca de saberes ter sido bem sucedida e democrática deve-se ao fato dos atores terem aproximadamente o mesmo grau de escolaridade, a mesma linguagem por serem profissionais pesquisadores do mesmo ramo, inseridos no mesmo contexto dos SAA\&ES. Dessa forma o respeito e 
valorização dos saberem práticos e acadêmicos puderam acontecer, pois os participantes possuíam a mesma linguagem.

\section{Institucionalização da participação}

Buscou-se o apoio institucional para o sucesso do processo. $\mathrm{O}$ apoio institucional dado pela agência reguladora do Estado foi um dos aspectos de sucesso do processo. Com uma cultura organizacional sem limitações ao processo participativo, abertos e entusiasmados. Os atores comprometeram-se e criou-se um ambiente de aprendizado, mostrando unidade, conforme sugerem que deve ser feito Tippet et al. (2005).

O engajamento do ator central, a ARSESP, permitiu esta seriedade no processo, não mostrando ser apenas o interesse da pesquisa desenvolvida, mas um interesse de todos pela demanda de indicadores dos SAA\&ES voltados às populações vulneráveis. Inclusive o público da primeira oficina foi surpreendente ao que se esperava, com o número de 45 pessoas participantes, o que se pensou ser um interesse das profissionais da área pela temática.

A institucionalização do processo participativo assegurou e mobilizou os participantes e pode-se observar na prática a importância da institucionalização, além de necessária para a identificação e proposição dos indicadores, é necessária também na continuidade da utilização, aplicação e melhoria desses indicadores.

\section{Empoderamento e confiança}

Ficou claro a todos durante o processo participativo que eles poderiam, e inclusive era necessário, que influenciassem e dessem suas contribuições conforme sugerido por Reed (2008) e De Stefano (2010). Procurou-se manter durante o processo a implementação de ações em que todos contribuíssem, e ao mesmo tempo, ganhassem conhecimentos, conforme exposto por Tippett et al. (2005) a importância de uma relação de ganha-ganha (win-win). 
Esta confiança deveu-se também à institucionalização do projeto, pois com instituições respeitadas na área pode-se assegurar efetividade, responsabilidade e respeito.

O empoderamento ocorreu por meio da promoção da interação dos atores, durante a gestão de conflitos e incentivos ao desenvolvimento de soluções mutuamente benéficas, as quais potencializam o aprendizado social.

\section{Disponibilidade de tempo}

Colocou-se metas ambiciosas e não foi possível atingí-las no tempo disponibilizado para as oficinas. Esperava-se menos pessoas, uma maior agilidade e dinâmica. Foi proposto algo que não foi possível de realização. Ou seja, quesito tempo faltou disponibilidade de tempo. Isso deve-se ainda ao fato da dificuldade relacionada a delimitação de dois anos disponíveis para realizar a pesquisa de mestrado, como das instituições parceiras, considerando-se o tempo do engajamento da equipe, o tempo de entendimento do que quer alcançar e a conciliação entre os atores.

Os aspectos relacionados anteriormente estão sintetizados e demonstrado no Quadro 22 para melhor visualização do alcance das boas práticas do processo participativo.

\begin{tabular}{|c|l|c|c|c|}
\hline & Característica & Atende & $\begin{array}{c}\text { Atende } \\
\text { Parcialmente }\end{array}$ & Não atende \\
\hline 1 & Objetivos Comuns & $\mathrm{X}$ & & \\
\hline 2 & Participação dialogada & $\mathrm{X}$ & & \\
\hline 3 & Facilitadores qualificados & $\mathrm{X}$ & & \\
\hline 4 & Compartilhamento dos saberes & $\mathrm{X}$ & & \\
\hline 5 & Institucionalização da participação & $\mathrm{X}$ & & \\
\hline 6 & Empoderamento e Confiança & $\mathrm{X}$ & & $\mathrm{X}$ \\
\hline 7 & Disponibilização de tempo & & & \\
\hline
\end{tabular}

Quadro 22. Critérios de avaliação dos processos participativos

Pode-se observar que somente a disponibilidade de tempo não atendeu a demanda de boas práticas do processo participativo. Deste modo, o processo participativo pode ser considerado bem sucedido, e ainda, fazendo a análise por meio da escada da participação, elaborada por Arnstein (1969), atingiu-se níveis de participação 
de parceria, delegação de poder, degraus 6 e 7, ou seja, degraus elevados de participação. Para certificar que o processo realmente foi participativo, e descobrir o real interesse e a importância dada pelos participantes às oficinas, fez-se uma pesquisa de opinião. Os resultados seguem no Box 1.

\section{Box 1. Opinião dos participantes a respeito das oficinas de trabalho ou resultados qualitativos} avaliados nas oficinas

$\mathrm{Na}$ avaliação dos participantes que responderam ao questionário, aproximadamente $85 \%$ dos participantes das duas oficinas de trabalho, todos consideram importante a integração das pessoas do setor dos SAA\&ES. 92\% dos participantes conseguiram expressar suas opiniões durante a oficina e $96 \%$ consideram as oficinas um bom método de obter a participação das pessoas. $96 \%$ dos participantes também avaliaram a oficina como produtiva e importante para a melhoria dos SAA\&ES voltados às populações vulneráveis.

Os únicos itens avaliados que obtiveram algum tipo de avaliação que não foi plenamente positiva referese ao tempo de duração das oficinas e ao atendimento do conteúdo programático. $31 \%$ dos participantes acharam o tempo das oficinas curto e $2,5 \%$ dos participantes consideraram que não foi atendido o conteúdo programático. Apesar de ainda ser uma minoria na avaliação, colocou-se em destaque devido a serem os únicos itens que não tiveram avaliações plenamente positivas.

No gráfico a seguir podem ser visualizados alguns outros itens avaliados.

Continuação próxima página

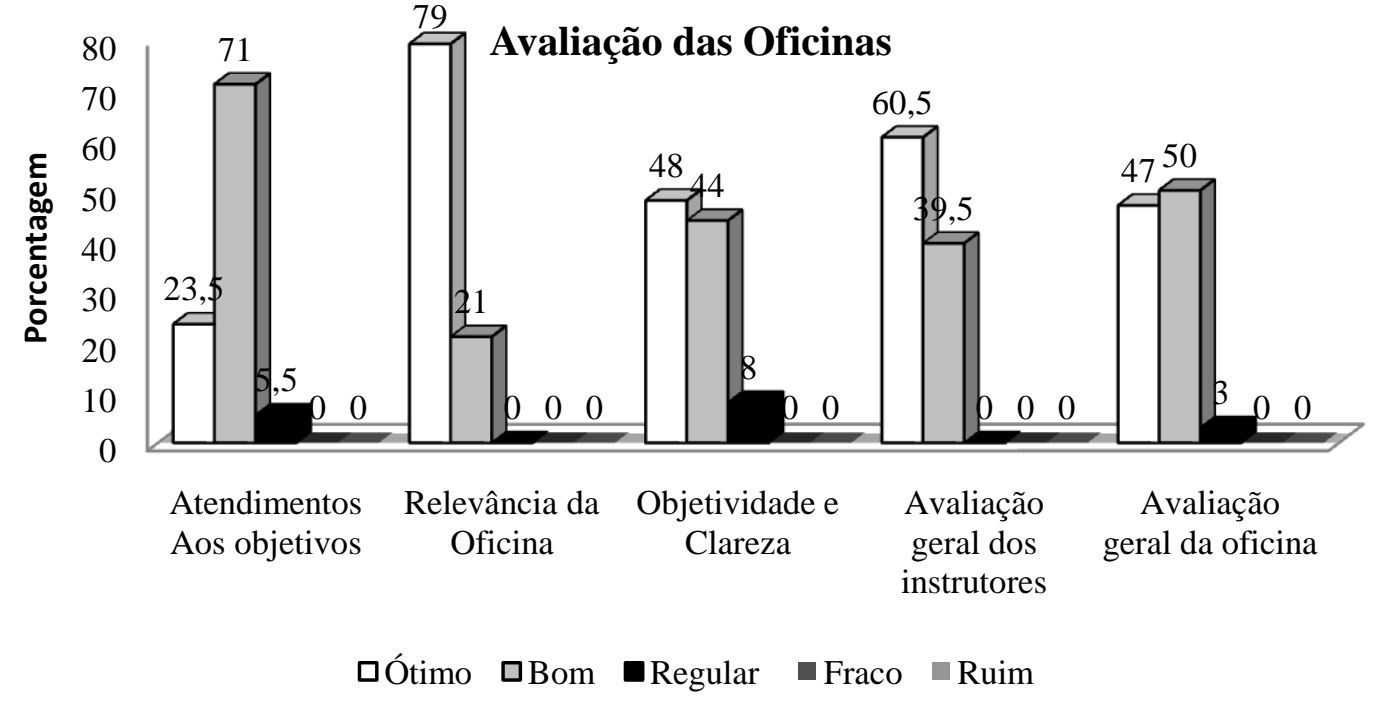

Pode-se observar no gráfico que, dos cinco itens expostos, mais de $90 \%$ dos participantes avaliaram como Ótimo e Bom.

Foi incluído no questionário a avaliação dos pontos fortes e pontos fracos, e a solicitação para que as pessoas escrevessem suas opiniões. As opiniões foram agrupadas e estão descritos conforme segue.

PONTOS FORTES DAS OFICINAS RELATADOS PELOS PARTICIPANTES

1. Aprendizagem mútua 
2. Possibilidade de troca de informações, conhecimentos e aprendizagem mútua

3. Relevância do assunto

4. Pessoas ativas no processo

5. Boa metodologia, com dinâmicas de grupos e participação direta das pessoas

6. Diversidade na formação das pessoas

7. Integração de diferentes instituições

8. Pessoas da mesma instituição tiveram a oportunidade de se conhecerem melhor

\section{PONTOS FRACOS DAS OFICINAS RELATADOS PELOS PARTICIPANTES}

1. Pouco tempo (Maior quantidade de citações)

2. Ausência de instituições

3. Não aprofundamento em alguns pontos citados

4. Falta de informações prévias, não oferecimento de material antecipadamente

5. Dificuldade de criação de indicadores

Foi questionada aos atores a importância da integração das pessoas do setor dos SAA\&ES, eles relataram e os resultados estão expostos conforme segue:

1. Troca de experiências, visões, perspectivas e tecnologias

2. Inserção das pessoas nos processos dos SAA\&ES

3. Área influenciada por muitas vertentes, com ligações entre todas as vertentes, A solução para a universalização passa por temáticas variadas

4. Efetividade das políticas públicas

5. Entender a complexidade

Mostrou-se positivo, envolvendo diferentes atores e visões de mundo, no entanto, talvez pela falta de planejamento, disponibilidade de tempo, necessitaria de novas oficinas, considerando-se que para o envolvimento, planejamento e estabelecimento claro dos objetivos foi requerido aproximadamente um ano e a elaboração e realização do seminário e das oficinas foram necessário seis meses. Vale lembrar que o tempo utilizado está diretamente relacionado aos tempos burocráticos, tanto acadêmico como profissionais da área, a demanda de tempo para organizar eventos também é longo, para cada evento foi necessário no mínimo um mês de antecedência de preparação, e em alguns casos, ainda mais. 


\section{CONCLUSÕES}

Neste capítulo apresentam-se algumas considerações sobre o desenvolvimento desta investigação que teve como objetivo propor indicadores de benchmarking dos sistemas de abastecimento de água e esgotamento sanitário destinados a apoiar políticas de ampliação de acesso e melhoria da qualidade dos serviços às populações vulneráveis no contexto do Estado de São Paulo.

Apresentou-se a utilização de benchmarking nos SAA\&ES e a maneira pela qual esta ferramenta pode auxiliar na melhoria destes serviços, por ser um instrumento simples e de fácil implementação e, ao mesmo tempo, proporcionar melhorias significativas às organizações.

Verificou-se que a ferramenta de benchmarking foi inicialmente utilizada pelo mercado competitivo, contudo, ao ser associada aos interesses de regulação do serviço pode ser utilizada para corrigir as falhas do mercado. Sua diversidade de aplicações no processo de melhoria contínua das organizações demonstra-se eficiente quando adequada a cada situação a ser aplicada, tendo em vista a priorização de atendimento às populações vulneráveis, contribuindo para a universalização do atendimento que ainda não foi alcançado.

Sobre os modelos de indicadores estudados pode-se dizer que estes responderam as diversas relações existentes nos cenários vividos. Foram notadas algumas similaridades entre eles, apesar de suas especificidades. Importante destacar que nenhum dos modelos foi desenhado especificamente para benchmarking dos SAA\&ES para o Brasil, com vistas às populações vulneráveis, contudo eles serviram como base para o estudo sendo discutidos e avaliados para a estruturação do novo modelo de benchmarking dos SAA\&ES.

Devido a não especificidade dos modelos estudados não foi indicado neste trabalho a utilização de modelos pré-arquitetados, uma vez que os modelos reuniam adequações e fragilidades em diferentes aspectos relacionados a necessidade das populações vulneráveis. O modelo elaborado pelo Ralda foi o único modelo que chegou mais próximo da demanda específica voltada às populações vulneráveis, contudo ele 
não facilita a participação dos atores que o utilizarão e não tem foco no regulador de serviços.

Com base nos estudos dos diferentes modelos é que surgiu a estruturação do novo modelo de benchmarking dos SAA\&ES direcionados às populações vulneráveis. Vale ressaltar que a criação e a validação deste modelo foram mais trabalhosas do que a utilização de modelos previamente formulados, porém considerou-se que para uma construção adequada dos indicadores, deveriam ser garantidos processos participativos, conforme incentiva a Política Nacional de Saneamento Básico (Lei 11.445/07). A criação coletiva dos indicadores incentivou a mobilização, além de auxiliar no aprendizado das boas práticas do setor, conforme inspira a ferramenta.

O processo participativo, apesar de imprescindível, apresentou limitações que devem ser superadas a cada processo, dentre elas a necessidade de maior tempo de trabalho na discussão, avaliação e elaboração dos indicadores, a necessidade de aderência dos participantes ao processo, a necessidade de parcerias institucionais, entre outros.

A partir disso, pôde-se compreender que a aplicação desses indicadores e a discussão dos mesmos é valiosa para o setor, em vistas a responsabilidade de universalização e de oferecimento dos serviços principalmente às populações vulneráveis.

Concluímos, portanto, que a proposição dos indicadores mostrou-se como um processo contínuo de observar o cenário em que encontra-se o setor e as perspectivas de mudança, pois muito além das informações que os indicadores podem mostrar, a proposição de indicadores e construção dos mesmos desencadeia uma dinâmica de diálogo, de integração dos atores do setor e de posicionamento dos tomadores de decisão. 


\section{RECOMENDAÇÕES}

Espera-se que este trabalho e os assuntos discutidos até aqui uma contribuição prática para a melhoria dos serviços às populações vulneráveis, de maneira que os mesmos sejam utilizados e aplicados pelo ente regulador.

Para que seja feita a utilização dos indicadores pelo ente regulador é necessária a continuidade do desenvolvimento participativo destes indicadores junto às instituições envolvidas, assim como a aplicação piloto para teste e aprimoramento dos mesmos.

Recomenda-se que seja feita a aplicação piloto com disponibilização de tempo para coleta dos dados em campo, e que a coleta seja feita com detalhamento para que os indicadores gerados possam ser devidamente aplicáveis.

Espera-se, a partir deste trabalho, a inclusão na pauta do setor de observação do cenário existente com a aplicação dos indicadores e o direcionamento com a utilização de instrumentos de gestão visando a universalização, e o atendimento em especial às populações vulneráveis, devido a maior suscetibilidade que estas populações se encontram. 


\section{BIBLIOGRAFIA}

ALEGRE et al. Guia de Avaliação de Desempenho das entidades Gestoras de Serviços de Águas e Resíduos. Instituto Regulador de Águas e Resíduos (IRAR) e Laboratório Nacional de Engenharia Civil (LNEC). 2005

ALEGRE et al. Performance Indicators for Water Supply Services. Second Edition. Manual of Best Practice. p. 312. 2006.

ALVES-MAZZOTTI, A. J. Usos e abusos dos estudos de caso. Cadernos de Pesquisa, v. 36, n. 129, p. 637-651, set./dez. 2006.

ARNSTEIN, S. R. A Ladder of Citizen Participation, Journal of the American Institute of Planners, 35:4, 216-224. 1969

ARSESP - Agência de Regulação dos serviços de Saneamento e Energia do Estado de São Paulo. Cartilha de Saneamento Básico: Cooperação entre Estado e Município. Disponível em http://www.arsesp.sp.gov.br/. Acesso: set de 2011.

AVILA, M. L., DUARTE, L. M. G. D., SABOURIN, E., MASSARDIER, G.. Redes políticas e freios ao desenvolvimento rural: o caso de Águas Emendadas. IV Encontro da Rede de Estudos Rurais, Curitiba, Paraná. 2010.

BAMIDELE, O. W. Providing Water and Sanitation Services to the Urban Poor: Outline for a Best Practices Toolbox. 218p. Institute for Water Education, UNESCO-IHE. Delft, Netherlands, 2010.

BANCO MUNDIAL. Novo relatório do Banco Mundial urge abordagem mais ampla para reduzir a pobreza. World Bank/world Development Report 2000/2001 - Comunicado à imprensa No. 2001/042/S - (12 de setembro de 2000) - http://www.worldbank.org/wdr

BARBOSA, C. Pro - poor incentives for water and sanitation services provision: A case study of Water Utilities in Sao Paulo, Brazil. 86 p. Institute for Water Education, UNESCO-IHE. Delft, Netherlands, 2010.

BARROS, R. P. de, HENRIQUES, R.; MENDONÇA, R.. Desigualdade e pobreza no Brasil: retrato de uma estabilidade inaceitável. Revista Brasileira de Ciências Sociais RBCS. Vol. 15 nº 42 . P. 123 - 142. Fev de 2000.

BERG, S. Conflict Resolution: Benchmarking Water Utility Performance. Public Admin. Dev. 27, 1-11. 2007

BHUTTA, K.S.; HUQ, F. (1999). Benchmarking - Best practices: an integrated approach. Benchmarking: an international journal, Bradford, v.6, n.3, p.254-268.

BLOKLAND, M. Lecture Notes on Benchmarking. UNESCO-IHE (Institute for water education), Delft, p. 15, 2009

BLOKLAND, M.; SCHOUTEN, M.; SCHWARTZ, K. Rejuvenating a Veteran Benchmarking Scheme: Benchmarking in the Dutch Drinking Water Sector. Competition and Regulation in Network Industries, Volume 11, No. 2, 2010.

BOHM, Dovid. Diálogo: comunicação e redes de convivência. São Paulo, SP: Palas Athena, 2005. 
BOSSEL, H. Indicators for sustainable development: theory, methods, applications: a report to Balaton Group. International Institute for Sustainable Development. Winnipeg, Manitoba, Canada, IISD, $124 p, 1999$.

BRANDÃO, C. R. Pesquisa Participante. In: FERRARO JR., L. A. (org.) Encontros e caminhos: formação de educadoras(es) ambientais e coletivos educadores. Brasília: MMA, Diretoria de Educação Ambiental, 2005. p. 257-266.

BRANDÃO, C. R., Pesquisar Participar. In: Pesquisa Participante, (Org.). $3^{\mathrm{a}}$ reimpr. Da $8^{\mathrm{a}}$ edição de 1990. São Paulo, Editora Brasiliense, 2006.

BUSSO, G. Vulnerabilidad social: nociones e implicancias de políticas para latinoamerica a inicios del siglo XXI. In: Semin ário Internacional Las Diferentes ex -presiones de la Vulnerabilidad en América Latina y el Caribe . Anais... Santiago do Chile: Cepal - Celade. 2001. Disponivel em: http://www.redadultosmayores.com.ar/buscador/files/ORGIN011.pdf 15 de junho de 2011

CAMP, R. Benchmarking: identificando, analisando e adaptando as melhores práticas da administração que levam à maximização da performance empresarial: o caminho da qualidade total. Tradução de Nivaldo Montingelli Júnior - São Paulo: Pioneira, 1993.

CAMP, R. Benchmarking: O caminho da qualidade total. 3.ed., São Paulo: Pioneira, 1998.

CARVALHO, A.M., RODRIGUES, C.S., MEDRADO, K.S. Oficinas em sexualidade humana com adolescentes. Estudos de Psicologia. Natal, vol 10, n.3, p.377-384, set-dez 2005.

CAVAlCANTE, G. T.; FARIA, R. da C.. O uso dos parâmetros de benchmarking da análise envoltória de dados (DEA) como instrumento de orçamentação. Revista Interdisciplinar Científica Aplicada, Blumenau, v.3, n.1, p.43-61 Sem I. 2009.

CHESS, C., PURCELL, K., 1999. Public participation and the environment - do we know what works. Environmental Science and Technology 33, 2685-2692.

CLARK, J., MURDOCH, J., 1997. Local knowledge and the precarious extension of scientific networks: a reflection on three case studies. Sociologia Ruralis 37, 38-60.

DE STEFANO, L. (2010): Facing the water framework directive challenges: A baseline of stakeholder participation in the European Union, Journal of Environmental Management, n ${ }^{\circ}$ 91, 13321340 .

ESTRELlA, M., GAVENTA, J., 2000. Who counts reality? Participatory Monitoring and Evaluation: a literature review. IDS Working Paper 70, Institute of Development Studies, Brighton

FERNANDES, D. R., Uma contribuição sobre a construção de indicadores e sua importância para a gestão empresarial. Rev. FAE, Curitiba, v.7, n.1, p.3-18, jan./jun. 2004

FERREIRA, M. P.; DINI, N. P.; FERREIRA, S. P. Espaços e Dimensões da Pobreza nos Municípios do Estado de São Paulo. São Paulo em Perspectiva, v. 20, n. 1, p. 5-17, jan./mar. 2006

FREIRE, P. Educação como prática de liberdade. 11 a Edição. Rio de Janeiro, Editora Paz e Terra, 1980.

FREIRE, P., Educação e Mudança. 26ª Edição, São Paulo, Editora Paz e Terra, 1979.

FREITAS, J. O Controle dos Atos Administrativos e os Princípios Fundamentais. $4^{a}$ ed. São Paulo:Malheiros, 2009. 
GALLOPÍN, G. Indicators and their use: information for decision making. In: MOLDAN, B.; BILHARZ, S. Sustainability Indicators. Chichester: Scientific Committee On Problems of the Environmente - SCOPE (Report on the project on Indicators of Sustainable Development)

GALVÃO JÚNIOR, A. C. Desafios para a universalização dos serviços de água e esgoto no Brasil. Ver. Panam Salud Publica. 2009; 25 (6): 589-556.

GALVÃO JÚNIOR, A. C. Regulação da Qualidade e Controle Social, p. 161 - 178. In: Regulação: indicadores para a prestação de serviços de água e esgoto. 2 ed. Alceu de Castro Galvão Júnior, Alexandre de Caetano da Silva, Editores. Fortaleza Expressão Gráfica e Editora Ltda, 204 p. 2006.

GEO Global Environmental Outlook. PROGRAMA DE LAS NACIONES UNIDAS PARA EL MEDIO AMBIENTE. Metodologia para a elaboracion de Informes GEO Ciudades: Manual de Aplicacion. Versiono 3. Panamá: PNUMA, 2008.

GIL, A. C., Como elaborar projetos de pesquisa 4 ediçao 12. reimpressao- Sao Paulo: Atlas, 2009

GONÇALVES, D. B. A contribuição do Novo-Institucionalismo para a elaboração de políticas públicas sócio-ambientais: o caso da atividade canavieira no estado de São Paulo. In: III Seminário Economia do Meio Ambiente: Regulação Estatal e Auto-regulação Empresarial para o Desenvolvimento Sustentável, 2003, Campinas. Disponível em: http://www.freewebs.com/danielbertoli/textos/texto09.pdf. Acesso em Agosto de 2011.

HEALY, S. Toward an epistemology of public participation. Journal of Environmental Management 90 (2009) 1644-1654. 2008

HELLER, L. Saneamento e Saúde, Editora Brasilia, 1997.

HELLER, L. Water and Sanitation Policies in Brazil: Historical Inequalities an Institutional Change, p. 321 - 337. In: CASTRO, J.E.; HELLER, L. (Org.) Water and Sanitation Services: public policy and management. Earthscan, UK and USA, 2009.

IBGE - Instituto Brasileiro de Geografia e Estatística. Censo 2010 aprimorou a identificação dos aglomerados subnormais. Comunicação Social, 15 de dezembro de 2011. Acesso disponível em 30 de janeiro de

2012. http://www.ibge.gov.br/home/presidencia/noticias/noticia_visualiza.php?id_noticia=2051

IPEA. Dimensão, evolução e projeção da pobreza por região e por estado no Brasil, 2010, Comunicados IPEA, $\mathrm{n}^{\circ} \quad 58 . \quad$ Disponível em: http://www.ipea.gov.br/portal/images/stories/PDFs/100713_comunicado58.pdf em 10 de junho de 2011.

JACOBI, P. Participação. Encontros e Caminhos: formação de educadoras(es) ambientais e coletivo educadores/ Luis Antonio Ferraro Júnior, organizador. Brasília: MMA, diretoria de Educação Ambiental, 2005. 358p.

JOHNSON, N., LILJA, N., ASHBY, J.A., GARCIA, J.A. Practice of participatory research and gender analysis in natural resource management. Natural Resources Forum 28, 189-200. 2004.

KAGEYAMA, A.; HOFFMANN, R. Pobreza no Brasil: uma perspectiva multidimensional. Economia e Sociedade, Campinas, v. 15, n. 1 (26), p. 79-112, 80 jan./jun. 2006. 
KAPLAN, R. S.; NORTON, D. P. The Balanced Scorecard: Translating Strategy into Action, Harvard Business School Press, Cambridge, MA. Boston. 1996.

LAKATOS, E. M. Metodologia do Trabalho Científico: procedimentos básicos, pesquisa bibliográfica, projeto e relatório, publicações e trabalhos científicos. $7^{\mathrm{a}}$ ed. São Paulo: Atlas, 2007.

LAKATOS, E. M., MARCONI, M.A. Metodologia Cientifica. $5^{\text {a }}$ ediçao - 2. reimpressao - Sao Paulo: Altas, 2008.

LEROY, J. P.; PACHECO, T. Democracia. Encontros e Caminhos: formação de educadoras(es) ambientais e coletivo educadores/ Luis Antonio Ferraro Júnior, organizador. Brasília: MMA, diretoria de Educação Ambiental, 2005. 358p.

MALHEIROS, T. F.; PHILIPPI JR, A.; COUTINHO, S. M. V. Interfaces dos serviços de água e esgoto. p. 91-122. In: Regulação: indicadores para a prestação de serviços de água e esgoto. 2 ed. Alceu de Castro Galvão Júnior, Alexandre de Caetano da Silva, Editores. Fortaleza Expressão Gráfica e Editora Ltda, 2006. 204 p.

MARANDOLA JR, E. Vulnerabilidade do lugar e riscos na Região Metropolitana de Campinas / Eduardo Marandola Júnior (Org.); Daniel Joseph Hogan (Org.). - Campinas: Núcleo de Estudos de População / Unicamp, 2011. 173p. TEXTOS NEPO 62.

MARQUES, R. C.; SILVA, D. As Parcerias Público-Privadas em Portugal. Lições e Recomendações. Revista de Estudos Politécnicos Polytechnical Studies Review. 2008, Vol VI, nº 10, 033-050 ISSN: 1645-9911

MARZALL, K.; ALMEIDA, J. Indicadores de sustentabilidade para agroecossistemas. Estado da arte, limites e potencialidades de uma nova ferramenta para avaliar o desenvolvimento sustentável. Cadernos de Ciência \& Tecnologia, Brasília, v. 17, n. 1, p. 41-59, jan/abr. 2000.

MAZO, E.M., Benchstar - Metodologia de Benchmarking para Análise da Gestão da produção nas Micro e Pequenas Empresas. Dissertação de Mestrado. Florianópolis 2003. Universidade Federal de Santa Catarina. PPG em Eng de Produção

MEADOWS, D. Indicators and information systems for sustainable development: a report to the Balalon Group. Hartland: The Sustentainability Institute, 1998. 78p.

MINISTÉRIO PÚBLICO Audiência pública. Disponível em: http://www.mp.go.gov.br/. Acesso em 9 de agosto de 2011.

MOISÈS, M, KLIGERMAN, D.C.; COHEN, S.C.; MONTEIRO, S.C.F.; A política federal de saneamento básico e as iniciativas de participação, mobilização, controle social, educação em saúde e ambiental nos programas governamentais de saneamento. Ciência \& Saúde Coletiva, 15(5):2581-2591, 2010 .

MORAIS, D. J., FORTES, S. A. M., FERREIRA, H. J. A. Evolução do Sistema de Esgotamento Sanitário no DF e Perspectivas para Universalização dos Serviços. ABES - Associação Brasileira de Engenharia Sanitária e Ambiental19o Congresso Brasileiro de Engenharia Sanitária e Ambiental p. 701$711,1999$.

MORIN, E., Os Sete Saberes Necessários a Educação do Futuro. São Paulo, Editora Cortez, Brasília, DF, UNESCO, 2000. 
MURDOCH, J., CLARK, J., 1994. Sustainable knowledge. Geoforum 25, 115-132.

MUTAI, P. Developing and testing indicators for pro-poor water and sanitation benchmarking: Case of Nairobi. 126p. Institute for Water Education, UNESCO-IHE. Delft, Netherlands, 2011.

NASCIMENTO, N.O.; HELLER, L. Ciência, tecnologia e inovação na interface entre as áreas de recursos hídricos e saneamento. Engenharia Sanitária e Ambiental. 2005;10(1):36-48. 20052

NDLOVU, H. N. Developing and Testing Indicators for Pro-Poor Water and Sanitation Benchmarking: Case Studies in Bulawayo and Pietermaritzburg. 125p. Institute for Water Education, UNESCO-IHE. Delft, Netherlands, 2011.

OECD, Core Set of Indicators for Environmental Performance Reviews, A synthesis report by the Group on the State of the Environment, Environment Mongraphs n. 83, Paris. 1993

OGERA, R. C. PHILIPPI JR, A. Gestão dos Serviços de água e Esgoto nos Municípios de Campinas, Santo André, São José dos Campos e Santos, no período de 1996 a 2000. Vol.10 - No 1 jan/mar 2005, 72-81. Eng. sanit. ambient. 2005

OLIVEIRA, R. D. de; OLIVEIRA, M. D. de. Pesquisa social e ação educativa: conhecer a realidade para poder transformá-la. Livro: Pesquisa Participante. Org. Carlos Rodrigues Brandão. São Paulo: Brasiliense, 2006. $3^{\text {a }}$ impressão da 8. ed. de 1990. P. 9-17

OPHI - Oxford Poverty and Human Development Initiative. Disponível em: http://www.ophi.org.uk/policy/multidimensional-poverty-index/. Acesso em Ago de 2010.

PAULILLO, L.F. Rede de Relações e Poder de negociação: Uma análise do Caso Citrícola brasileiro. Gestão e Produção. V.8, n.3, p. 250-270, dez. 2001.

PAUlilo, M. A. S. A Pesquisa Qualitativa e a História de vida. SERV. SOC. REV., LONDRINA, V. 2, N. 2, P.135-148, JUL./DEZ. 1999

PINTÈR, L.; ZAHEDI, K.; CRESSMAN, D. R. Capacity Building for integrated environmental Assessment and Reporting. Training manual. International Institute for Sustainable Development. Second edition. 144f. Winnipeg, 2000.

PIZA, F. J. de T. Indicador de Salubridade Ambiental - ISA. Trabalho apresentado no Seminário sobre indicadores de Sustentabilidade, realizado no âmbito do projeto "Redistribuição da População e Meio Ambiente: São Paulo e Centro-Oeste”, no período de 10 e 11 de abril de 2000. 26 p. 490-515.

PNQS 2011. Guia do Prêmio Nacional de Qualidade em Saneamento. Belo Horizonte - MG: Comitê Nacional da Qualidade CNQA-ABES, 1997 até hoje. Anual.

PNUD - Programa das Nações Unidas para o Desenvolvimento. Objetivos de Desenvolvimento do Milênio: $4^{\text {o }}$ Relatório Nacional de Acompanhamento. - Brasília: Ipea, 2010. 184p. Disponível em: www.pnud.org.br/odm. Acesso em agosto de 2010.

PNUMA - Programa das Nações Unidas para o Meio Ambiente. (2001) Metodologia para a elaboração de Relatórios GEO Cidades. Manual de Aplicação, Versão 2. Mexico.

PNUMA Programa das Nações Unidas para o Meio Ambiente e Consórcio Parceria 21. Metodologia para a elaboração de relatórios Geo-Cidades. Manual de aplicação. Versão 2. México: Pnuma; 2001. 
PROBE - Benchmarking for pro-poor Water Services Provision. Project full proposal, UNESCO-IHE. Delft, 2009.

QUIROGA, R. Indicadores ambientales y de desarrollo sostenible: avances y perspectivas para América Latina y el Caribe. División de Estadística y Proyecciones Económicas. CEPAL. Serie Manuales. Santiago de Chile, 2007.

QUIVY, R.; CAMPENHOUDT, L. V.; Manual de investigação em ciências sociais. $2^{\mathrm{a}}$ Ed. Lisboa: Gradiva, 1998.

RACHMADYANTO, H. Mapping pro-poor water supply and sanitation services in Accra City, Ghana. 55f. Institute for Water Education, UNESCO-IHE. Delft, Netherlands, 2010.

RALDA, A. P. S. Providing water and sanitation services to the urban poor: preliminary framework and indicators for performance assessment. 84p. Institute for Water Education, UNESCOIHE. Delft, Netherlands, 2010.

REED, M. S. Stakeholder participation for environmental management: A literature review. Biological Conservation 141 (2008) p. 2417-2431

RIBAS, R. P.; MACHADO, A. F.; GOLGHER, A. B. Flutuações e persistência na pobreza: uma análise de decomposição transitória-crônica para o Brasil. Anais do XXXIII Encontro Nacional de Economia, Natal, Anpec, 2005.

RIBAS, R.P. Vulnerabilidade à pobreza no Brasil: medindo risco e condicionalidade a partir da função de consumo das famílias. Pesquisa e planejamento econômico. V. 37. N.2. Ago, 2007.

RICHARDS, C., BLACKSTOCK, K.L., CARTER, C.E., 2004. Practical Approaches to Participation SERG Policy Brief No. 1. Macauley Land Use Research Institute, Aberdeen.

ROUSE, M. Institutional Governance and Regulation of Water Services. IWA Publishing, 2007

ROZADOS, H. B. F. Uso de Indicadores na Gestão de Recursos de Informação. Revista Digital de Biblioteconomia e Ciência da Informação,Campinas, v. 3, n. 1, p. 60-76, jul./dez. 2005 - ISSN:: 1678765X. http://www.salvador.arquivar.com.br.

SABATINI, F. (2001), "Residential segregation pattern changes in Chile's main cities: scale shifts and increasing malignancy". International Seminar on Segregationand the City, Cambridge, Lincoln Institute of Land Policy.

SAMPAIO, C. A. C.; FERNANDES, V. Manual de Dinâmica de Grupo e Aplicação das Metodologias PEP/SiGOS para o Planejamento e Gestão Estratégica Participativa da Companhia Integrada de Desenvolvimento Agrícola de Santa Catarina (CIDASC). Livro do Professor. Blumenau, 2007.

SANTOS, R. F. Planejamento ambiental: teoria e prática. São Paulo: Oficina de textos. 2004

SCHOLZE, S. H. C.; WIMMER, M. A Regulação das Telecomunicações no Brasil: Passado, presente e desafios futuros. P. 155-182. Desafios da regulação no Brasil. Organizadores: PROENÇA, J. D.; COSTA, P. V.; Montagner, P. Brasília: ENAP, 2009. 342 p.

SEADE - Fundação Sistema Nacional de Análise de Dados. Índice Paulista de Vulnerabilidade Social e Índice Paulista de Responsabilidade Social. Disponível em: http://www.seade.gov.br. Acesso em julho de 2010. 
SEADE - Fundação Sistema Nacional de Análise de Dados. Perfil municipal. Disponível em: http://www.seade.gov.br/produtos/perfil/perfilMunEstado.php. Acesso em fevereiro de 2012.

SLACK, N; CHAMBERS, S; HARLAND, C; HARRISON, A; JOHNSTON, R. Administração da Produção. Atlas, São Paulo, 2002. Capítulo 18 - Melhoramento da produção p. 589 - 626

SNSA - Secretaria Nacional de Saneamento Ambiental. Estudo sobre as deficiências de acesso e a probabilidade de cumprimento das Metas do Milênio nos serviços de Saneamento Básico no Brasil. Brasília: MCIDADES. 237 p, 2008.

SNSA - Secretaria Nacional de Saneamento Ambiental. Sistema Nacional de Informações sobre saneamento: diagnóstico dos serviços de água e esgotos - 2008. Brasília: MCIDADES. SNSA, 408 p, 2010.

SNSA - Secretaria Nacional de Saneamento Ambiental. Sistema Nacional de Informações sobre saneamento: diagnóstico dos serviços de água e esgotos - 2009. Brasília: MCIDADES. SNSA, 408 p, 2011.

SOARES, S.; RIBAS, R. P.; SOARES, F. V. Focalização e cobertura do Programa BolsaFamília: Qual o significado dos 11 Milhões de famílias? Texto do IPEA http://www.ipea.gov.br/sites/000/2/publicacoes/tds/td_1396.pdf. Disponível em 15 de junho de 2011. IPEA. Texto de discussão no 1396. Mar, 2009.

SPENDOLINI, M. J. Benchmarking. Tradução Kátia Aparecida Roque; Revisão técnica Eduardo Correa Moura. São Paulo: Makron Books, 1993.

STEINMAN, A., HAVENS, K., HORNUNG, L., 2002. The managed recession of Lake Okeechobee, Florida: integrating science and natural resource management. Conservation Ecology 6, 17.

STRINGER, L.C., REED, M.S., 2007. Land degradation assessment in southern Africa: integrating local and scientific knowledge bases. Land Degradation and Development 18, 99-116.

SUSSKIND, L., FULLER, B., FERENZ, M., FAIRMAN, D., 2003. Multistakeholder dialogue at the global scale. International Negotiation 8, 235-266.

THIOLLENT, M. J. M. Pesquisa-ação em organizações. São Paulo: Atlas, 1997.

THIOLLENT, Michel. Metodologia da Pesquisa-Ação. 14ª Edição. São Paulo, Editora Cortez, 2005.

TIPPETT, J., SEARLE, B., PAHL-WOSTL, C., REES, J., 2005. Social learning in public participation in river basin management e early findings from HarmoniCOP European cases studies. Environmental Science \& Policy 8, 287-299.

TOLEDO, J.C. e CARPINETTI, L.C. Gestão da Qualidade. Cap. 13 do livro: A Fábrica do Futuro, NUMA, Ed. Banas, 2000

TORRES, H. G. Segregação Residencial e Políticas Públicas: São Paulo na década de 1990 Revista Brasileira de Ciências Sociais. V. 19 n. 54, 2004

TYNAN N, KINGDOM B (2002) Effective water services provision: performance targets for a well run utility. Water supply and sanitation sector. World Bank, Washington D.C

UNDP United Nations Development Programme, Human Development Report 2011. Sustainability and Equity: A Better Future for All. Palgrave Macmillan, New York. p. 185, 2011. 
UNITED NATIONS. The Millennium Development Goals Report 2008, NEW YORK, 2008.

WHO; UNICEF. Meeting the MDG Drinking Water and Sanitation Target: the urban and sanitation challenge of the decade. Joint Monitoring Programme for Water Supply and Sanitation (JMP). Switzerland, 2006.

WHO; UNICEF. Progress on Drinking Water Supply and Sanitation: special focus on sanitation. Joint Monitoring Programme for Water Supply and Sanitation (JMP). EUA, 2008.

WORLD BANK. World developing report 2004: making services work for poor people. Washington, D.C., 2004.

WORLD BANK. World Development Report. Attacking Poverty. Washington, D. C. :The World Bank Group, 2000-2001. Disponível em: http://www.worldbank.org/wdr 


\section{APÊNDICES}

APÊNDICE A - Cartaz de divulgação e Folder com a Programação do Seminário Saneamento e Populações Vulneráveis
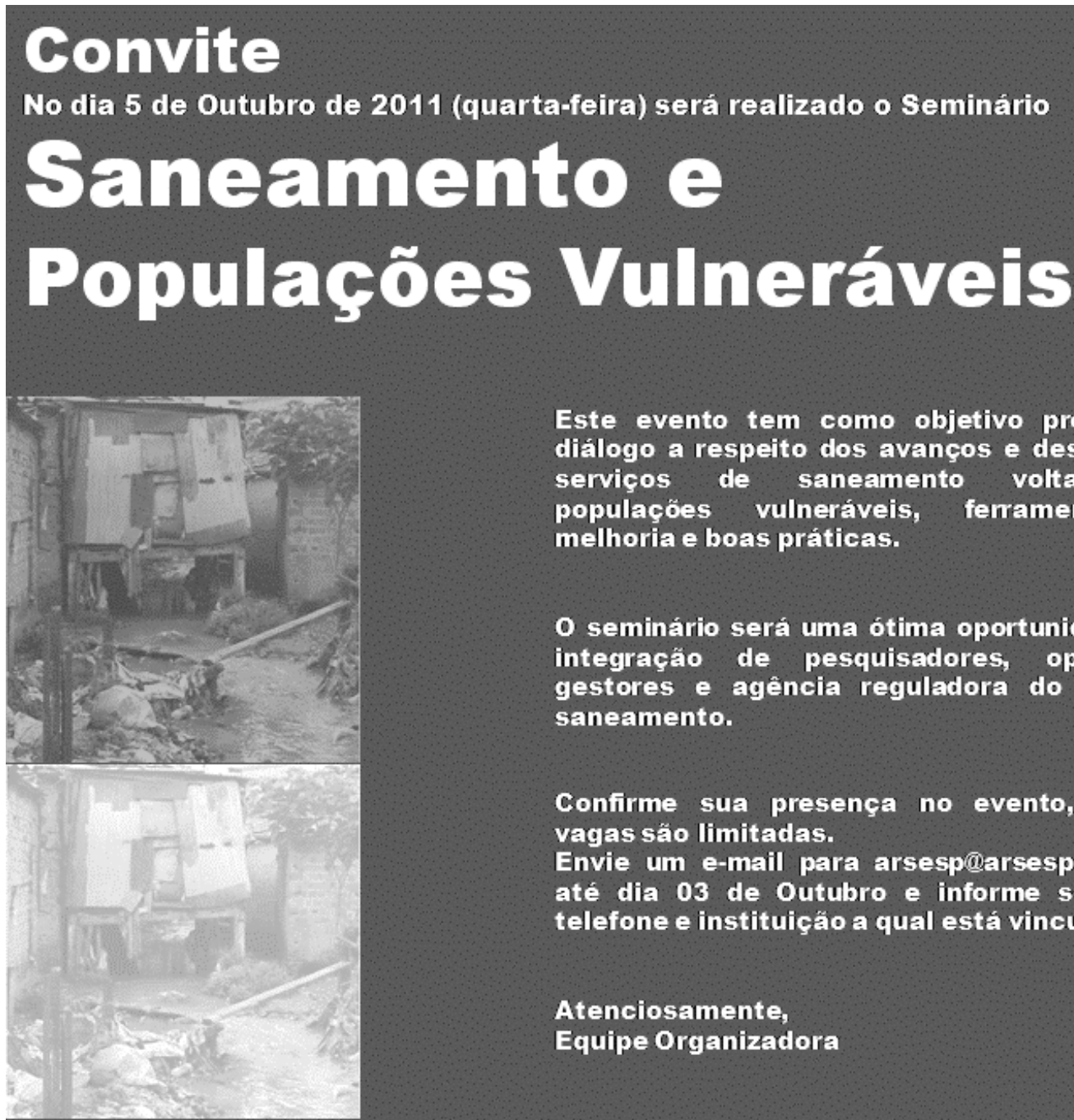

Este evento tem como objetivo promover o díálogo a respeito dos avanços e desafios dos serviços de saneamento voltados as populaçóes vulneráveis, ferramentas de melhoria e boas práticas.

- seminário será uma ótima oportunidade para integraça de pesquisadores, operadores, gestores e agência reguladora do setor de saneamento.

Confirme sua presença no evento, pois as vagas sáo limitadas.

Envie um e-mail para arsesp@arsesp.sp.gov.br até dia 03 de Outubro e informe seu nome, telefone e instituiçâo a qual está vinculado(a).

Atenciosamente,

Equipe Organizadora

Local: Agência Reguladora de Saneamento e Energia do Estado de Säo Paulo - ARSESP Avenida Paulista, 2313, Edifício Novavenida, Auditório, $1^{\circ}$ andar, Sáo Paulo - SP

organizaçāo:

Veja a Programaçāo Anexa

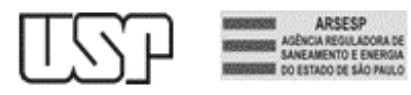

apoio:

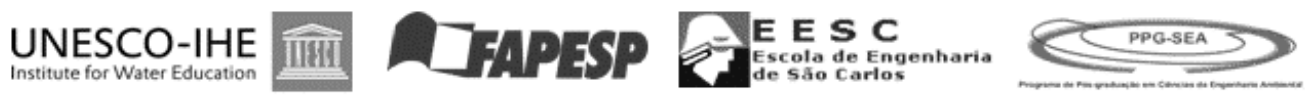




\section{Seminário}

Saneamento e Populações Vulneráveis

Este evento tem como objetivo promover o diálogo a respeito dos avanços e desafios dos servicos de saneamento voltados às populaçóes vulneráveis, ferramentas de melhoria e boas práticas.

- seminário será uma ótima oportunidade para integração de pesquisadores, operadores, gestores e agência reguladora do operadores, gestores

5 de Outubro de 2011

Local: Agência Reguladora de Saneamento e Energia do Estado de São Paulo - ARSESP

Avenida Paulista, 2313, Edificio Novavenida, Auditório. 10 andar, São Paulo - SP

Informaçōes e Confirmaçào de presença pelo e-mail: arsesp@arsesp.sp.gov.br Até o dia 03 de Outubro de 2011 | Vagas limitadas

organizaçäo:

TS1 Apsese

apoio:

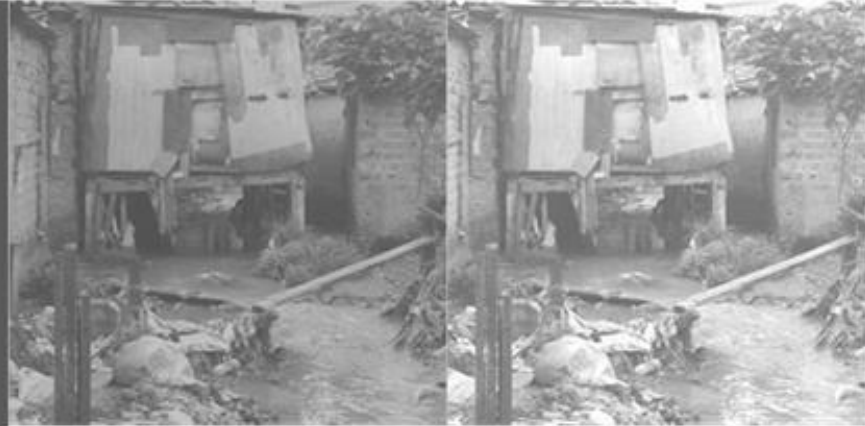

9:00 Abertura do Seminánio

Benchmarking. Saneamento e Populaşōes Vulneraveis

9:30 Regulą̧ăo do saneamento no Estado de São Paulo - Avanços desafios

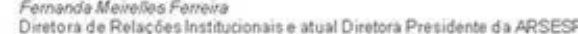

9:50 Parada do Cafe

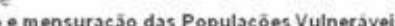

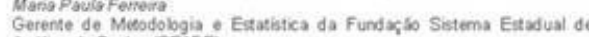

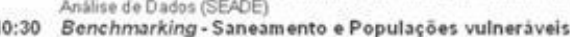

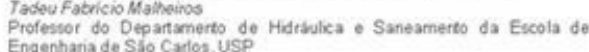

10:50 Discuss 50

12:00 Almoģo

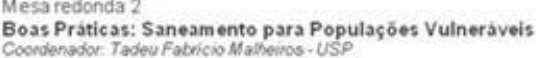

13:30 DAEE - Sāo Paulo

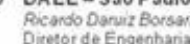

13:50 Empresa Foz do Brasil

Sansio Stroiek
Divetor da foz do Brasil Limeina

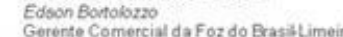

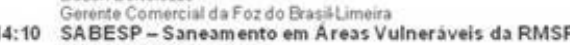

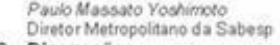

14:30 Discuss jo

16:00 Parada do Café

Benehmsrking Pro-poor Water Services Provision - PROBE

16:40 Plenaria de encerramento

UNESCO-IHE

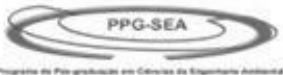




\section{APÊNDICE B - Material suporte da Primeira Oficina - Modelo de indicadores proposto teoricamente}

Temas chave a serem analisados no sentido da universalização dos serviços de abastecimento de água e esgotamento sanitário e em especifico às populações vulneráveis.

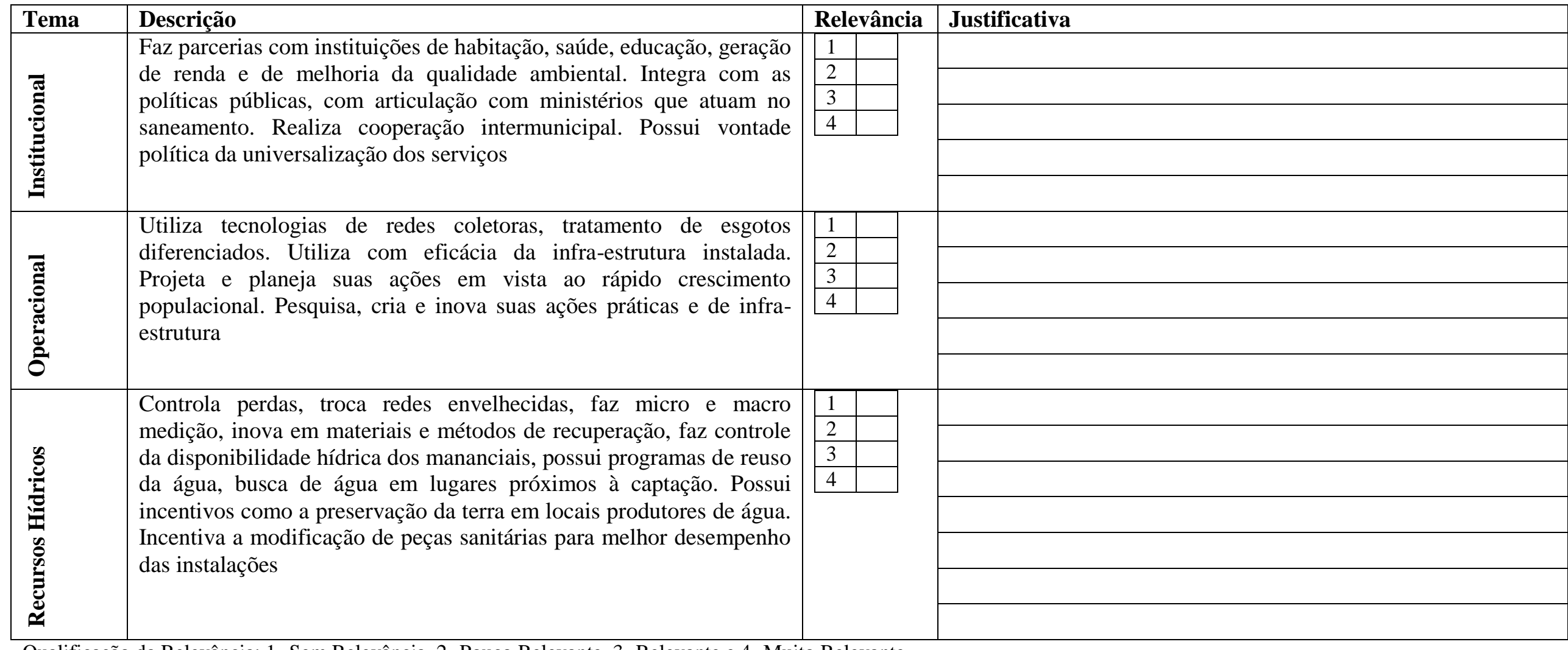

Qualificação da Relevância: 1- Sem Relevância, 2- Pouco Relevante, 3- Relevante e 4- Muito Relevante. 


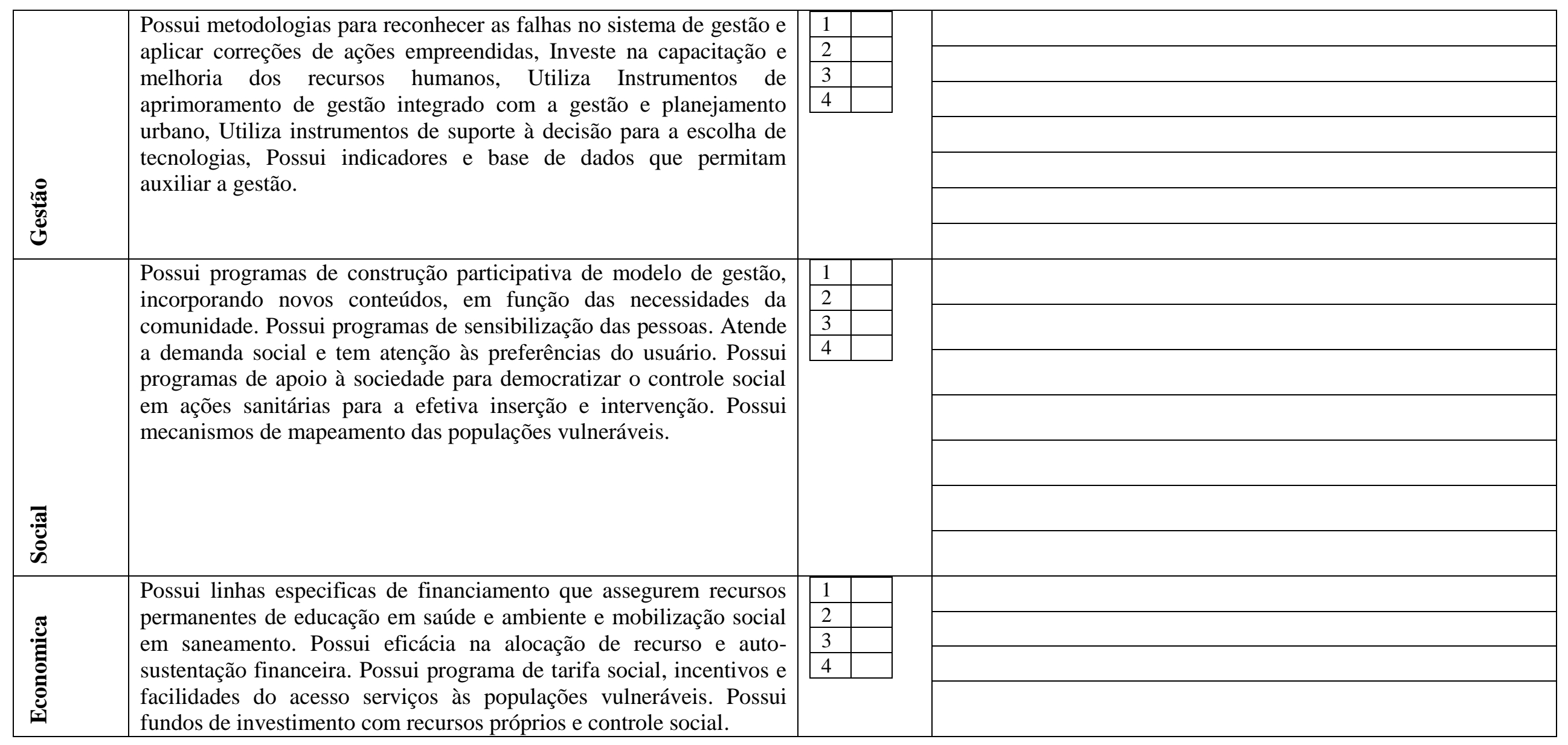




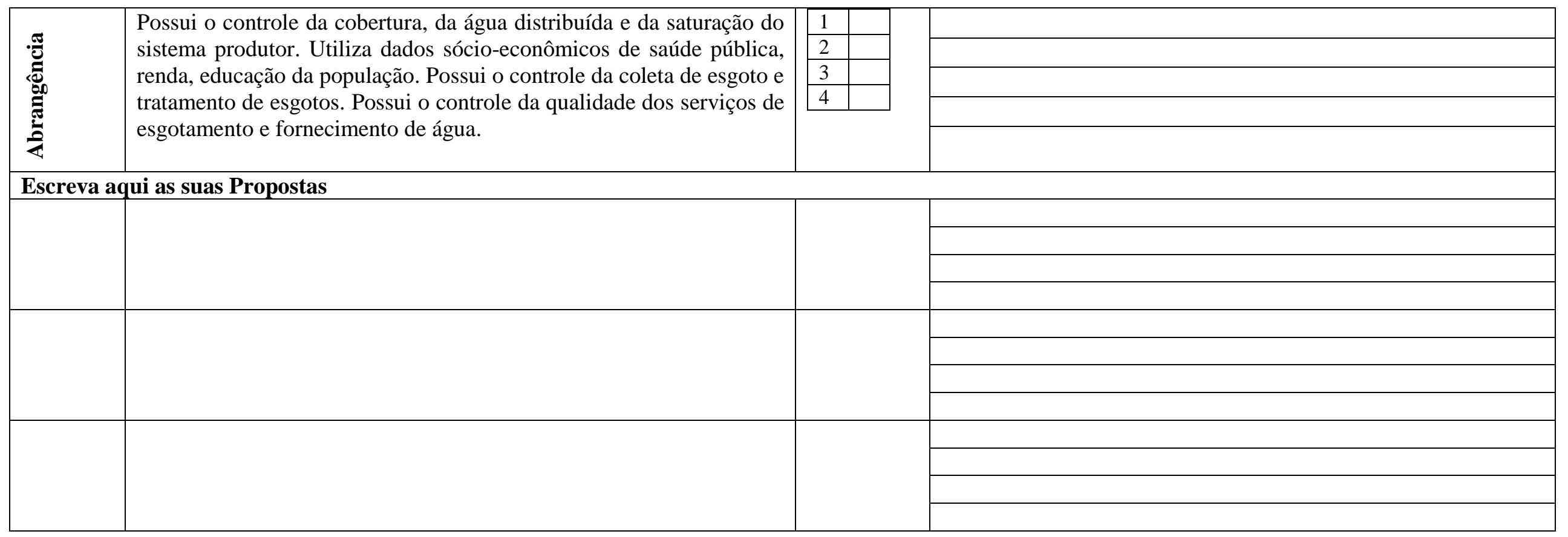


APÊNDICE C - Ficha Metodológica de elaboração de indicadores utilizada durante a oficina

Proposição de indicadores no sentido da universalização dos serviços de abastecimento de água e esgotamento sanitário e em especifico a populações vulneráveis.

\begin{tabular}{|l|l|l|}
\hline Tema & Nome e Descrição do Indicador & Justificativa \\
\hline Institucional & & \\
\hline Operacional & & \\
\hline $\begin{array}{l}\text { Recursos } \\
\text { Hídricos }\end{array}$ & & \\
\hline Gestão & & \\
\hline Social & & \\
\hline Econômico & & \\
\hline $\begin{array}{l}\text { Controle } \\
\text { Fiscalização }\end{array}$ & & \\
\hline Propostas & & \\
\hline & & \\
\hline & & \\
\hline & & \\
\hline & & \\
\hline
\end{tabular}


FICHA METODOLÓGICA DE ELABORAÇÃO DE INDICADORES

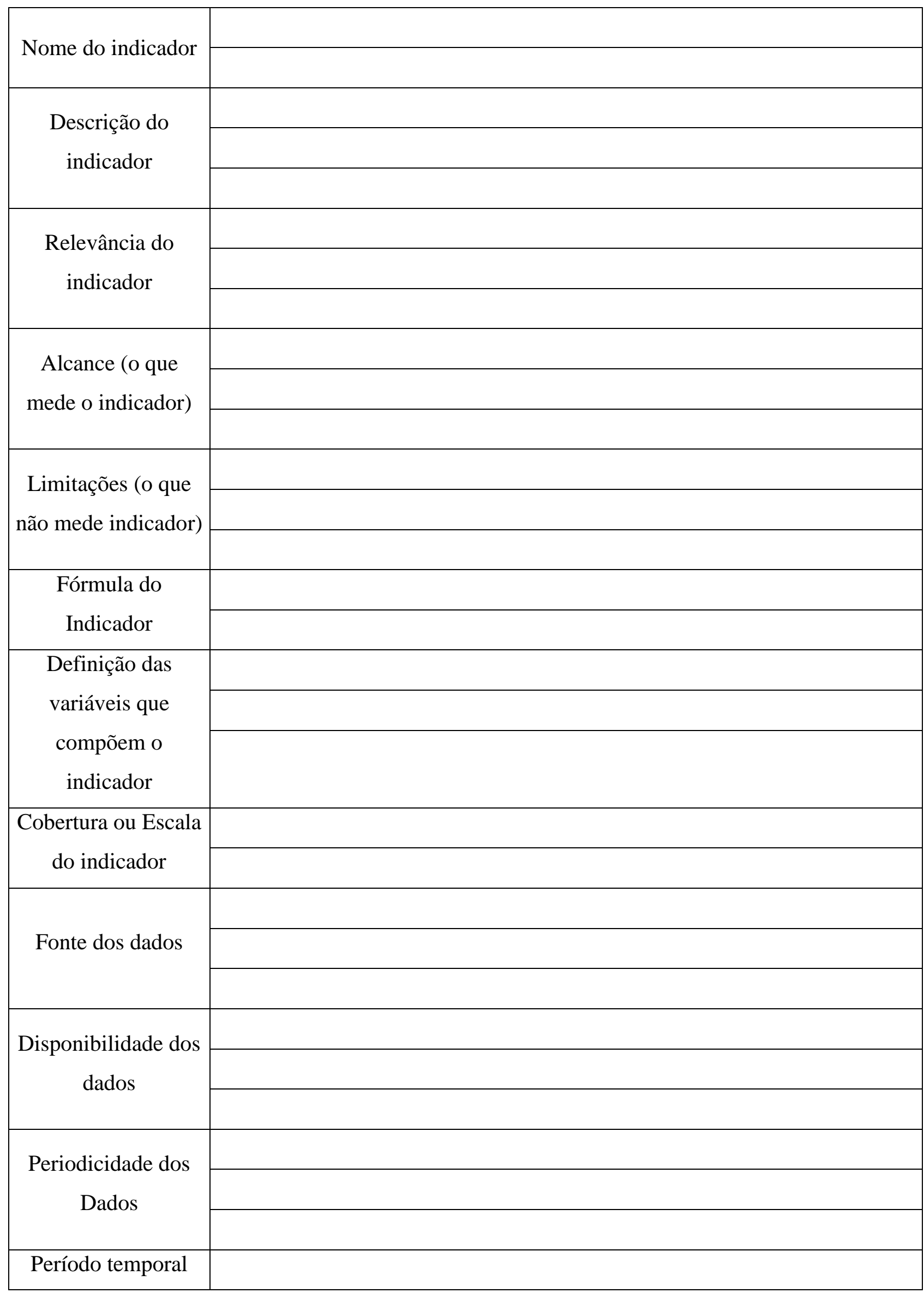




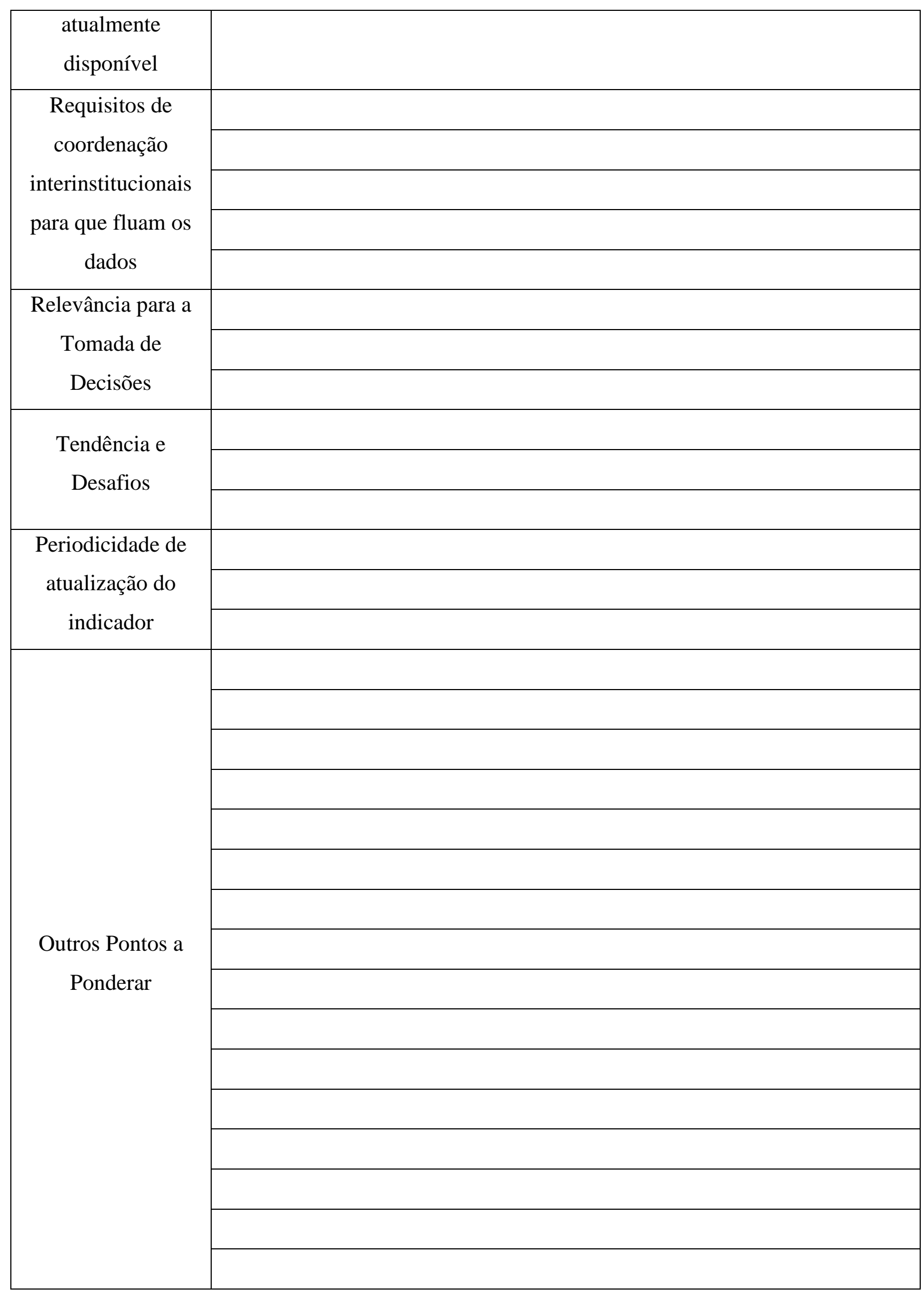




\section{DESCRIÇÃO DOS CAMPOS QUE COMPOEM A FICHA METODOLÓGICA}

\begin{tabular}{|c|c|}
\hline Nome do Indicador & $\begin{array}{l}\text { Deve-se colocar um nome, o mais claro, conciso e amigável ao usuário } \\
\text { ("Intensidade energética da produção") que defina exatamente o que mostra o } \\
\text { indicador. }\end{array}$ \\
\hline $\begin{array}{l}\text { Descrição curta } \\
\text { indicador }\end{array}$ & $\begin{array}{l}\text { Deve-se realizar una descrição curta do que mostra o indicador, sobre tudo } \\
\text { quando este recebe um nome mais científico ou técnico; utilizando uma } \\
\text { linguagem clara e simples que possa localizar o usuário em relação ao } \\
\text { indicador em questão. }\end{array}$ \\
\hline $\begin{array}{l}\text { Relevância do } \\
\text { indicador }\end{array}$ & $\begin{array}{l}\text { Deve-se especificar a importância que tem o indicador proposto na avaliação } \\
\text { a respeito dos serviços. Em essência trata-se de conectar os conteúdos do } \\
\text { indicador com os problemas e desafios da universalização. Isto implica } \\
\text { definir as variáveis que compõem o indicador, vinculando-a com os } \\
\text { problemas da universalização para que o usuário possa entender. }\end{array}$ \\
\hline $\begin{array}{l}\text { Alcance (o que mede } \\
\text { o indicador) }\end{array}$ & $\begin{array}{l}\text { eve-se especificar quais as dinâmicas que o indicador captura ou mostra. } \\
\text { Iostrar exatamente que coisas estaria nos dizendo o indicador em questão }\end{array}$ \\
\hline $\begin{array}{l}\text { Limitações (o que } \\
\text { não mede indicador) }\end{array}$ & $\begin{array}{l}\text { Deve-se deixar claro que outras dinâmicas ou dimensões não podem ser } \\
\text { capturadas ou vistas a partir do indicador. }\end{array}$ \\
\hline $\begin{array}{l}\text { Fórmula do } \\
\text { Indicador }\end{array}$ & $\begin{array}{l}\text { Deve especificar as operações e processamentos das variáveis que são } \\
\text { necessárias para obter o valor do indicador em cada ponto de observação } \\
\text { (territorial, histórica, etc). Assim, deve ficar perfeitamente estipulada a } \\
\text { unidade de medida em que se expressará o indicador. }\end{array}$ \\
\hline $\begin{array}{l}\text { Definição das } \\
\text { variáveis que } \\
\text { compõem o }\end{array}$ & $\begin{array}{l}\text { Cada uma das variáveis que compõem o indicador deve ser definida com } \\
\text { detalhe, de forma que não deixe espaço para interpretações. Adota-se em } \\
\text { geral a definição da instituição que produz o dado, por exemplo: "Se utiliza o } \\
\text { conceito de fragmentação de ecossistemas do Instituto de Conservação da } \\
\text { Biodiversidade do Ministério tal". }\end{array}$ \\
\hline $\begin{array}{l}\text { Cobertura ou Escala } \\
\text { do indicador }\end{array}$ & $\begin{array}{l}\text { A cobertura do indicador pode compreender escalas distintas, ou combinar } \\
\text { várias destas, em todo caso deve ficar bem especificada. Exemplos: } \\
\text { Municipal, regional, departamental, eco regional, bacia, nacional }\end{array}$ \\
\hline Fonte dos dados & $\begin{array}{l}\text { A fonte de dados deve ficar estipulada para cada uma das variáveis, de forma } \\
\text { detalhada: especificar não somente a instituição, mas também o departamento } \\
\text { ou escritório, e/ou a publicação física ou eletrônica de onde se encontra } \\
\text { disponível e o nome e email de contato da pessoa responsável. }\end{array}$ \\
\hline
\end{tabular}




\begin{tabular}{|c|c|}
\hline $\begin{array}{l}\text { Disponibilidade dos } \\
\text { dados (qualitativo) }\end{array}$ & $\begin{array}{l}\text { A disponibilidade dos dados se refere á facilidade ou dificuldade de acesso } \\
\text { sistemático do dado. Por exemplo, se pode dizer: "Plenamente disponível em } \\
\text { formato físico ou eletrônico", ou "Disponível de forma restrita aos órgãos } \\
\text { públicos", ou "o dado primário existe, mas requer processamento para gerar a } \\
\text { informação requerida" ou "informação reservada". }\end{array}$ \\
\hline $\begin{array}{l}\text { Periodicidade dos } \\
\text { Dados }\end{array}$ & $\begin{array}{l}\text { Deve-se especificar a periodicidade para cada variável que compõe o } \\
\text { indicador. Esta se entende como o período de tempo em que se atualiza o } \\
\text { dado. Poe exemplo: "cada } 4 \text { anos", "anual”, "bimensal, etc. Se possível } \\
\text { informe a periodicidade de levantamento, registro e publicação do dado. }\end{array}$ \\
\hline $\begin{array}{l}\text { Período temporal } \\
\text { atualmente } \\
\text { disponível }\end{array}$ & $\begin{array}{l}\text { Especificar o período de tempo que compreende a série atualmente } \\
\text { disponível, por exemplo: "Período 1987-2000". }\end{array}$ \\
\hline $\begin{array}{l}\text { Periodicidade de } \\
\text { atualização do } \\
\text { indicador }\end{array}$ & $\begin{array}{l}\text { Recomendação do grupo de quanto tempo se necessita e é possível para } \\
\text { recalcular o indicador para atualizar seu valor. }\end{array}$ \\
\hline $\begin{array}{l}\text { Requisitos de } \\
\text { coordenação inter- } \\
\text { institucionais para } \\
\text { que fluam os dados }\end{array}$ & $\begin{array}{l}\text { Devem ser especificadas as necessidades institucionais imprescindíveis para } \\
\text { que a informação flua desde a fonte até a equipe gestora dos indicadores. } \\
\text { Estes pré-requisitos podem incluir necessidades de coordenação, realização } \\
\text { de convênios, motivação no nível técnico e político, que são necessárias para } \\
\text { poder contar com o dado em forma sistemática para calcular o indicador. }\end{array}$ \\
\hline $\begin{array}{l}\text { Relevância para a } \\
\text { Tomada de Decisões }\end{array}$ & $\begin{array}{l}\text { Sempre que o sistema de indicadores tenha dentro de seus objetivos } \\
\text { promover a participação mais informada da cidadania (ou de qualquer grupo } \\
\text { de atores), deve-se identificar como o indicador proposto contribui para esse } \\
\text { fim. }\end{array}$ \\
\hline Tendência e Desafios & $\begin{array}{l}\text { Abaixo do gráfico, pode-se elaborar um breve parágrafo onde se transmita ao } \\
\text { usuário as implicações e desafios que mostra o comportamento do indicador. }\end{array}$ \\
\hline
\end{tabular}

Fonte: Taller de Diseño de Indicadores de Desarrollo Sostenible. Rayén Quiroga Martínez, 2005 
APÊNDICE D - Ficha de Avaliação das Oficinas

\section{Avaliação da Oficina}

Atendimento aos objetivos estabelecidos

$\square$ Ótimo $\square \quad$ Bom $\square \quad$ Regular $\square \quad$ Fraco $\quad \square \quad$ Ruim

Duração da Oficina

$\square$ Ótimo $\square \quad$ Bom $\square \quad$ Regular $\square \quad$ Fraco $\quad \square \quad$ Ruim

Atendimento ao Conteúdo programático

$\square$ Ótimo $\square \quad$ Bom $\square \quad$ Regular $\quad \square \quad$ Fraco $\quad \square \quad$ Ruim

Relevância da Oficina

$\square$ Ótimo $\square \quad$ Bom $\square \quad$ Regular $\square \quad$ Fraco $\quad \square \quad$ Ruim

Objetividade e clareza

$\square$ Ótimo $\square \quad$ Bom $\square \quad$ Regular $\square \quad$ Fraco $\quad \square \quad$ Ruim

Avaliação Geral dos instrutores

$\square$ Ótimo $\square \quad$ Bom $\square \quad$ Regular $\square \quad$ Fraco $\quad \square \quad$ Ruim

Clareza na apresentação da oficina e dos objetivos

$\square$ Ótimo $\square \quad$ Bom $\square \quad$ Regular $\square \quad$ Fraco $\quad \square \quad$ Ruim

Esclarecimento de dúvidas

$\square$ Ótimo $\square \quad$ Bom $\square \quad$ Regular $\square \quad$ Fraco $\quad \square \quad$ Ruim

Avaliação Geral da Oficina

$\square$ Ótimo $\square \quad$ Bom $\quad \square \quad$ Regular $\quad \square \quad$ Fraco $\quad \square \quad$ Ruim

Você acha que oficina é um bom método de obter a participação das pessoas?

$\square \quad$ Sim $\square \quad$ Não $\square \quad$ Parcialmente 
Você achou que essa oficina foi produtiva e importante para você?

$\square$ Sim $\square$ Não $\square \quad$ Parcialmente

Você conseguiu expressar as suas opiniões durante a oficina?

$\square$ Sim $\square$ Não $\square \quad$ Parcialmente

Qual(is) ponto(s) fortes da oficina?

Qual(is) ponto(s) fracos?

Você acha importante a integração das pessoas no setor de saneamento?

$\begin{array}{lll}\square & \operatorname{Sim} \quad \square \quad \text { Não } \quad \square \quad \text { Parcialmente } \\ \text { Por que? }\end{array}$ 


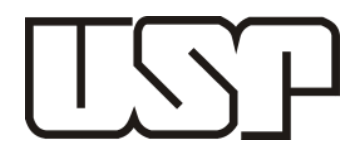

APÊNDICE E - Material da Segunda Oficina - Validação dos indicadores

Ficha 1. Indicadores propostos na oficina 1

GRUPO 1

\begin{tabular}{|c|c|c|c|c|c|c|c|c|c|}
\hline Tema & & & $\begin{array}{l}\text { Nome do } \\
\text { indicador }\end{array}$ & Objetivo & Fórmula & Unidade & Variáveis & $\begin{array}{c}\text { Dados } \\
\text { Necessários }\end{array}$ & Unidade \\
\hline \multirow[b]{2}{*}{ Institucional } & 1 & IP & $\begin{array}{c}\text { Parcerias } \\
\text { Institucionais }\end{array}$ & Existência de parcerias & CA & número & $\begin{array}{l}\text { CA= Número de } \\
\text { parcerias que a } \\
\text { operadora possui } \\
\text { com outras } \\
\text { instituições } \\
\text { voltados à } \\
\text { universalização } \\
\text { (água e esgoto) }\end{array}$ & $\begin{array}{c}\text { Número de } \\
\text { parcerias que a } \\
\text { operadora } \\
\text { possui com } \\
\text { contratos } \\
\text { assinados com } \\
\text { outras } \\
\text { instituições }\end{array}$ & quantidade \\
\hline & 2 & $\mathrm{IE}$ & $\begin{array}{c}\text { Parcerias } \\
\text { Institucionais } \\
\text { efetivas }\end{array}$ & $\begin{array}{c}\text { Estabelecer existência de } \\
\text { documentação, metas, } \\
\text { prazos, para avaliar a } \\
\text { efetividade das parcerias } \\
\text { efetuadas }\end{array}$ & CE/CAx100 & Porcentagem & $\begin{array}{l}\text { CA= Número de } \\
\text { parcerias que a } \\
\text { instituição possui } \\
\text { com outras } \\
\text { instituições } \mathrm{CE}= \\
\text { Número de efetivo } \\
\text { das parcerias, as } \\
\text { quais cumpriram } \\
\text { metas, prazos e } \\
\text { objetivos }\end{array}$ & $\begin{array}{l}\text { Número de } \\
\text { efetivo das } \\
\text { parcerias, as } \\
\text { quais } \\
\text { cumpriram } \\
\text { metas, prazos } \\
\text { e objetivos }\end{array}$ & quantidade \\
\hline $\begin{array}{l}\text { Recursos } \\
\text { Hídricos }\end{array}$ & 3 & RT & $\begin{array}{l}\text { Tratamento de } \\
\text { Esgotos }\end{array}$ & $\begin{array}{l}\text { Garantir a Qualidade dos } \\
\text { corpos hídricos de onde é } \\
\text { captada a água de } \\
\text { abastecimento }\end{array}$ & & Porcentagem & $\begin{array}{c}\% \text { tratamento de } \\
\text { esgoto }\end{array}$ & $\begin{array}{l}\text { Porcentagem } \\
\text { de tratamento } \\
\text { de esgoto }\end{array}$ & Porcentagem \\
\hline
\end{tabular}




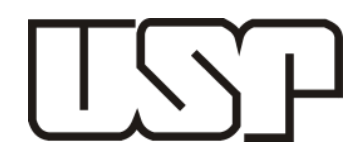

Ficha1. Qualificação dos indicadores

GRUPO 1

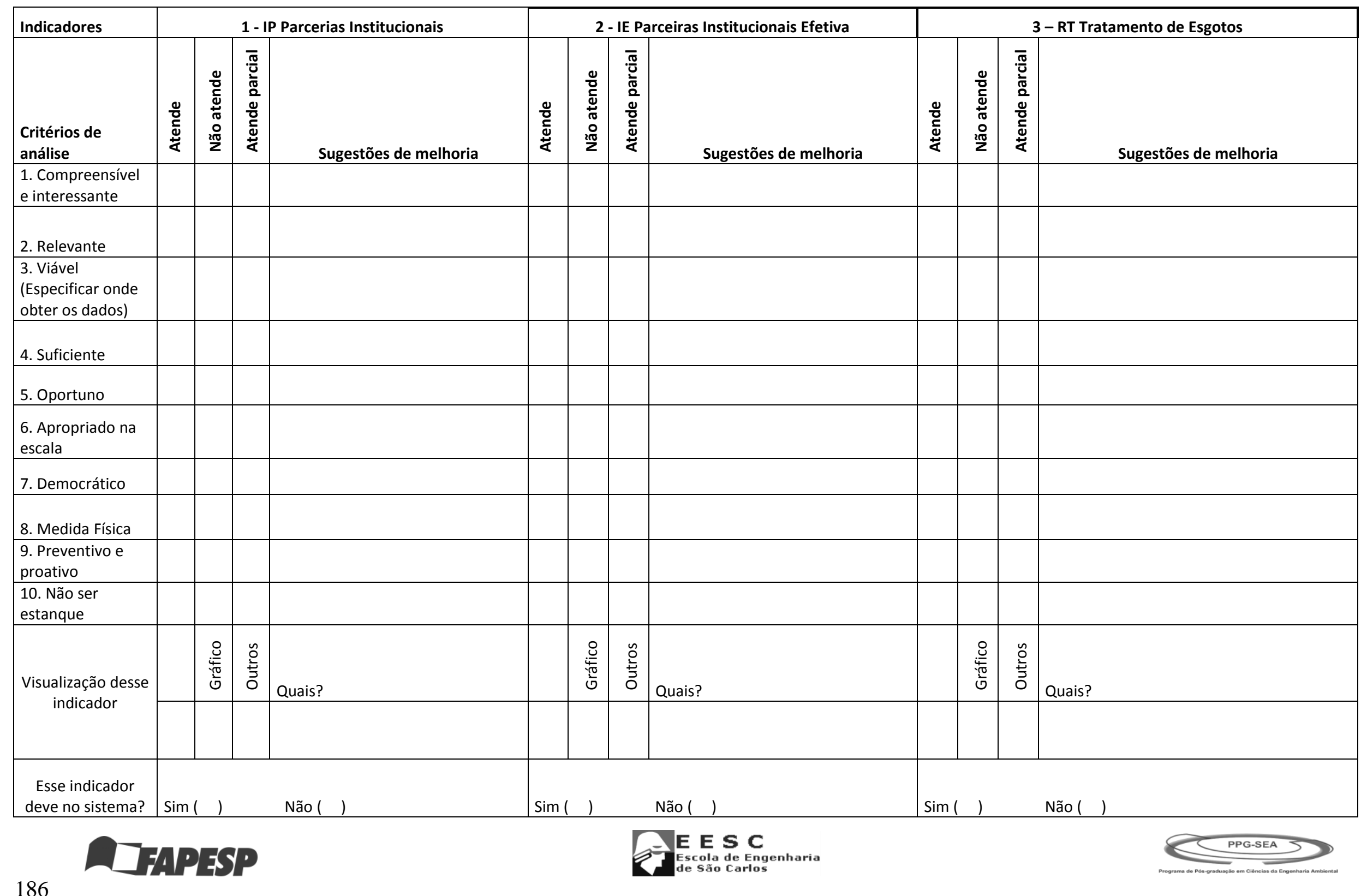




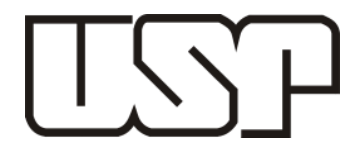

Ficha 1. Indicadores propostos na oficina 1

GRUPO 2

\begin{tabular}{|c|c|c|c|c|c|c|c|c|c|}
\hline Tema & & & Nome do indicador & Objetivo & Fórmula & Unidade & Variáveis & $\begin{array}{c}\text { Dados } \\
\text { Necessários }\end{array}$ & Unidade \\
\hline $\begin{array}{l}\text { Recursos } \\
\text { Hídricos }\end{array}$ & 4 & $\mathrm{RP}$ & $\begin{array}{c}\text { Índice de perdas de } \\
\text { água }\end{array}$ & $\begin{array}{l}\text { Quantidade de água } \\
\text { que é desperdiçada } \\
\text { pelo mal } \\
\text { funcionamento do } \\
\text { sistema }\end{array}$ & & m3 & $\begin{array}{l}\text { Índice de perdas } \\
\text { (I51 do SNIS) }\end{array}$ & Índice de perdas & Porcentagem \\
\hline \multirow{4}{*}{ Econômica } & 5 & FP & $\begin{array}{l}\text { Índice de perdas } \\
\text { comerciais de água } \\
\text { em populações } \\
\text { vulneráveis que não } \\
\text { possuem } \\
\text { abastecimento de } \\
\text { água }\end{array}$ & $\begin{array}{c}\text { Verificar o valor não } \\
\text { faturado que é gasto } \\
\text { pelas operadoras } \\
\text { com águas que são } \\
\text { utilizadas pela } \\
\text { população de } \\
\text { maneira informal } \\
\text { (fraude) }\end{array}$ & & $\mathrm{R} \$$ & $\begin{array}{l}\text { Índice de perdas } \\
\text { comerciais em locais } \\
\text { com Populações } \\
\text { vulneráveis onde } \\
\text { não possui } \\
\text { abastecimento de } \\
\text { água }\end{array}$ & $\begin{array}{c}\text { Perdas em locais } \\
\text { com Populações } \\
\text { vulneráveis onde } \\
\text { não possui } \\
\text { abastecimento de } \\
\text { água (volume não } \\
\text { faturado) }\end{array}$ & $\mathrm{R} \$$ \\
\hline & \multirow{3}{*}{6} & \multirow{3}{*}{ FT } & \multirow{3}{*}{$\begin{array}{l}\text { Valor gasto no } \\
\text { Atendimento da } \\
\text { população com } \\
\text { tarifas sociais }\end{array}$} & \multirow{3}{*}{$\begin{array}{l}\text { Verificar o valor que é } \\
\text { utilizado no } \\
\text { atendimento para } \\
\text { cada habitante }\end{array}$} & \multirow{3}{*}{$\mathrm{NA} / \mathrm{TI}$} & \multirow{3}{*}{ Habitante/R\$ } & \multirow{3}{*}{$\begin{array}{c}\mathrm{NA}=\text { Número } \\
\text { atendidos com tarifa } \\
\text { social } \mathrm{Tl}=\text { total } \\
\text { Investimento em } \\
\text { áreas vulneráveis } \\
\text { (receita própria } \mathrm{x} \\
\text { outras fontes) }\end{array}$} & $\begin{array}{l}\text { TS= Número de } \\
\text { domicílios } \\
\text { atendidas com } \\
\text { tarifa social }\end{array}$ & Domicílio \\
\hline & & & & & & & & $\begin{array}{c}\text { Estimativa de } \\
\text { habitantes por } \\
\text { município }\end{array}$ & Habitante \\
\hline & & & & & & & & $\begin{array}{l}\mathrm{Tl}=\text { Total de } \\
\text { Investimento em } \\
\text { áreas vulneráveis } \\
\text { (receita própria x } \\
\text { outras fontes) }\end{array}$ & $\mathrm{R} \$$ \\
\hline
\end{tabular}




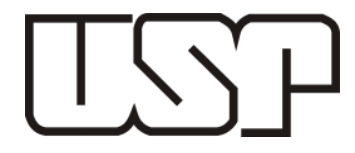

Ficha1. Qualificação dos indicadores

\section{GRUPO 2}

\begin{tabular}{|c|c|c|c|c|c|c|c|c|c|c|c|c|}
\hline \multirow[b]{2}{*}{$\begin{array}{l}\text { Indicadores } \\
\begin{array}{l}\text { Critérios de } \\
\text { análise }\end{array} \\
\end{array}$} & \multicolumn{4}{|c|}{4 - RP Índice de Perdas de Água } & \multicolumn{4}{|c|}{5 - FP Índice de Perdas comerciais } & \multicolumn{4}{|c|}{ 6 - FA Valor Gasto com Tarifas Sociais } \\
\hline & 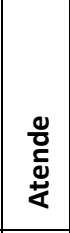 & 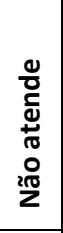 & 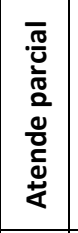 & Sugestões de melhoria & 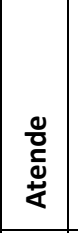 & 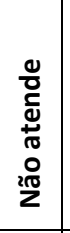 & 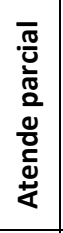 & Sugestões de melhoria & 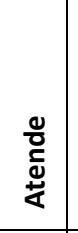 & 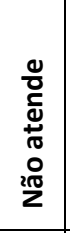 & 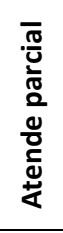 & Sugestões de melhoria \\
\hline \multicolumn{13}{|l|}{$\begin{array}{l}\text { 1. Compreensível } \\
\text { e interessante }\end{array}$} \\
\hline \\
\hline \multicolumn{13}{|l|}{$\begin{array}{l}\text { 3. Viável } \\
\text { (Especificar onde } \\
\text { obter os dados) }\end{array}$} \\
\hline \multicolumn{13}{|l|}{ 4. Suficiente } \\
\hline \\
\hline \multicolumn{13}{|l|}{$\begin{array}{l}\text { 6. Apropriado na } \\
\text { escala }\end{array}$} \\
\hline \multicolumn{13}{|l|}{ 7. Democrático } \\
\hline \multicolumn{13}{|l|}{ 8. Medida Física } \\
\hline \multicolumn{13}{|l|}{$\begin{array}{l}\text { 9. Preventivo e } \\
\text { proativo }\end{array}$} \\
\hline \multicolumn{13}{|l|}{$\begin{array}{l}\text { 10. Não ser } \\
\text { estanque }\end{array}$} \\
\hline $\begin{array}{l}\text { Visualização desse } \\
\text { indicador }\end{array}$ & 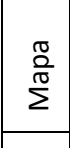 & $\underset{\substack{\stackrel{0}{*} \\
\frac{\pi}{0}}}{\frac{\pi}{0}}$ & $\begin{array}{l}\stackrel{n}{0} \\
\stackrel{ \pm}{0} \\
\end{array}$ & Quais? & $\begin{array}{l}\frac{\pi}{2} \\
\frac{0}{\pi} \\
\frac{\pi}{2} \\
\end{array}$ & $\underset{\substack{\frac{8}{*} \\
\frac{\pi}{0}}}{\frac{0}{0}}$ & 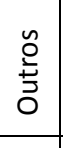 & Quais? & $\frac{\pi}{\frac{\pi}{0}}$ & 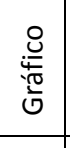 & 号 & Quais? \\
\hline $\begin{array}{l}\text { Esse indicador } \\
\text { deve no sistema? }\end{array}$ & $\operatorname{sim}$ & ) & & Não( ) & $\operatorname{sim} 1$ & 1 & & Não（） & $\operatorname{sim} 1$ & ( ) & & Não( ) \\
\hline
\end{tabular}




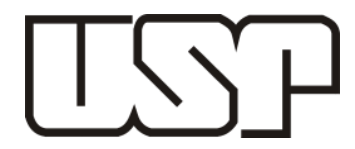

Ficha 1. Indicadores propostos na oficina 1

GRUPO 3

\begin{tabular}{|c|c|c|c|c|c|c|c|c|c|}
\hline Tema & & & Nome do indicador & Objetivo & Fórmula & Unidade & Variáveis & $\begin{array}{c}\text { Dados } \\
\text { Necessários }\end{array}$ & Unidade \\
\hline \multirow{6}{*}{ Econômico } & \multirow{2}{*}{7} & \multirow[t]{2}{*}{$\mathrm{FI}$} & \multirow{2}{*}{$\begin{array}{l}\text { Investimentos com } \\
\text { populações } \\
\text { vulneráveis }\end{array}$} & \multirow{2}{*}{$\begin{array}{l}\text { Verificar do total dos } \\
\text { recursos investidos } \\
\text { qual a porcentagem é } \\
\text { utilizadas com as } \\
\text { populações } \\
\text { vulneráveis, } \\
\text { visualizando a } \\
\text { priorização desse } \\
\text { assunto na gestão da } \\
\text { operadora }\end{array}$} & \multirow{2}{*}{ IV/Tx100 } & \multirow{2}{*}{ Porcentagem } & \multirow{2}{*}{$\begin{array}{l}\text { IV }=\text { Investimento } \\
\text { para Populações } \\
\text { vulneráveis T= total } \\
\text { da fonte de } \\
\text { recursos }\end{array}$} & $\begin{array}{c}\quad \mathrm{Tl}=\text { Total de } \\
\text { Investimento em } \\
\text { áreas vulneráveis } \\
\text { (receita própria } \mathrm{x} \\
\text { outras fontes) } \\
\end{array}$ & $\mathrm{R} \$$ \\
\hline & & & & & & & & $\begin{array}{c}T=\text { Total de fonte } \\
\text { de recursos de } \\
\text { investimentos }\end{array}$ & $\mathrm{R} \$$ \\
\hline & \multirow[t]{2}{*}{8} & FC & \multirow[t]{2}{*}{$\begin{array}{c}\text { Custo da ligação nas } \\
\text { populações } \\
\text { vulneráveis }\end{array}$} & \multirow{2}{*}{$\begin{array}{l}\text { Saber o valor que é } \\
\text { necessário em média } \\
\text { para o atendimento } \\
\text { das populações } \\
\text { vulneráveis }\end{array}$} & \multirow[t]{2}{*}{$\mathrm{CPV} / \mathrm{CM} \times 100$} & \multirow[t]{2}{*}{ Porcentagem } & \multirow{2}{*}{$\begin{array}{l}\text { CPV= Custo médio } \\
\text { da ligação em } \\
\text { Populações } \\
\text { Vulneráveis CM= } \\
\text { custo médio da } \\
\text { ligação }\end{array}$} & $\begin{array}{l}\text { Custo médio da } \\
\text { ligação em } \\
\text { Populações } \\
\text { Vulneráveis } \\
\end{array}$ & $\mathrm{R} \$$ \\
\hline & & & & & & & & $\begin{array}{l}\text { Custo médio da } \\
\text { ligação }\end{array}$ & $\mathrm{R} \$$ \\
\hline & \multirow[t]{2}{*}{9} & \multirow[t]{2}{*}{ FA } & \multirow[t]{2}{*}{$\begin{array}{l}\text { Consumo de água } \\
\text { nas população } \\
\text { vulnerável }\end{array}$} & & \multirow[t]{2}{*}{ CPS/CGx100 } & \multirow[t]{2}{*}{ Porcentagem } & \multirow{2}{*}{$\begin{array}{l}\text { CPS= Consumo da } \\
\text { população } \\
\text { sanitariamente } \\
\text { vulnerável por } \\
\text { ligação CG= } \\
\text { consumo geral }\end{array}$} & $\begin{array}{l}\text { Consumo médio } \\
\text { da população } \\
\text { sanitariamente } \\
\text { vulnerável por } \\
\text { ligação } \\
\end{array}$ & m3 \\
\hline & & & & & & & & $\begin{array}{c}\text { Média do } \\
\text { consumo geral da } \\
\text { população }\end{array}$ & m3 \\
\hline
\end{tabular}




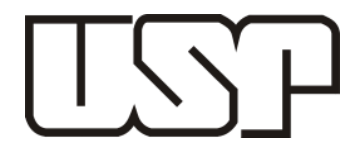

Ficha1. Qualificação dos indicadores

\section{GRUPO 3}

\begin{tabular}{|c|c|c|c|c|c|c|c|c|c|c|c|}
\hline \multirow{2}{*}{$\begin{array}{l}\text { Indicadores } \\
\text { Critérios de } \\
\text { análise }\end{array}$} & \multicolumn{3}{|c|}{ 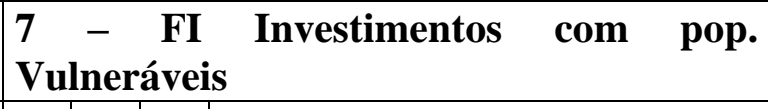 } & \multicolumn{4}{|c|}{$\begin{array}{l}\text { 8- FC Custo de ligação nas pop. } \\
\text { vulneráveis }\end{array}$} & \multicolumn{4}{|c|}{$\begin{array}{l}9 \text { - FA Consumo de água nas pop. } \\
\text { vulneráveis }\end{array}$} \\
\hline & 吾 & 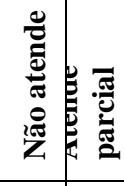 & Sugestões de melhoria & \multicolumn{4}{|r|}{ Sugestões de melhoria } & 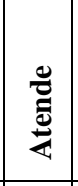 & 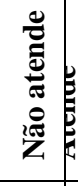 & 迹 & Sugestões de melhoria \\
\hline $\begin{array}{l}\text { 1. Compreensível } \\
\text { e interessante }\end{array}$ & & & & & & & & & & & \\
\hline 2. Relevante & & & & & & & & & & & \\
\hline $\begin{array}{l}\text { 3. Viável } \\
\text { (Especificar onde } \\
\text { obter os dados) }\end{array}$ & & & & & & & & & & & \\
\hline 4. Suficiente & & & & & & & & & & & \\
\hline 5. Oportuno & & & & & & & & & & & \\
\hline $\begin{array}{l}\text { 6. Apropriado na } \\
\text { escala }\end{array}$ & & & & & & & & & & & \\
\hline 7. Democrático & & & & & & & & & & & \\
\hline 8. Medida Física & & & & & & & & & & & \\
\hline $\begin{array}{l}\text { 9. Preventivo e } \\
\text { proativo }\end{array}$ & & & & & & & & & & & \\
\hline $\begin{array}{l}\text { 10. Não ser } \\
\text { estanque }\end{array}$ & & & & & & & & & & & \\
\hline $\begin{array}{l}\text { Visualização desse } \\
\text { indicador }\end{array}$ & 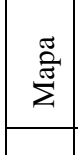 & 递 & Quais? & 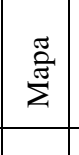 & 䢘 & 号 & Quais? & 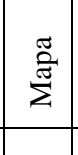 & 䢰 & $\stackrel{\substack{0 \\
0}}{0}$ & Quais? \\
\hline $\begin{array}{c}\text { Esse indicador } \\
\text { deve no sistema? }\end{array}$ & Sim & ( ) & Não（） & $\operatorname{Sim}($ & ( ) & & Não（） & Sim & ( ) & & Não ( ） \\
\hline
\end{tabular}


Ficha 1. Indicadores propostos na oficina 1

GRUPO 4

\begin{tabular}{|c|c|c|c|c|c|c|c|c|c|}
\hline Tema & & & Nome do indicador & Objetivo & Fórmula & Unidade & Variáveis & Dados Necessários & Unidade \\
\hline \multirow{5}{*}{ Abrangência } & \multirow[t]{2}{*}{10} & \multirow[t]{2}{*}{$\mathrm{AF}$} & \multirow[t]{2}{*}{$\begin{array}{c}\text { Mapeamento da } \\
\text { população vulnerável }\end{array}$} & \multirow{2}{*}{$\begin{array}{l}\text { Levantamento do número de } \\
\text { famílias cadastradas em } \\
\text { programas assistenciais do } \\
\text { governo, pois assim pode-se } \\
\text { definir as áreas e populações } \\
\text { vulneráveis }\end{array}$} & \multirow[t]{2}{*}{$\begin{array}{c}\text { FC/ } \\
\text { Tx100 }\end{array}$} & \multirow[t]{2}{*}{ Porcentagem } & \multirow{2}{*}{$\begin{array}{l}\mathrm{FC}=\text { Número de famílias } \\
\text { cadastradas em } \\
\text { programas do governo } \mathrm{T}= \\
\text { total de famílias }\end{array}$} & $\begin{array}{c}\text { NF= Número de famílias } \\
\text { cadastradas em } \\
\text { programas assistenciais } \\
\text { do governo }\end{array}$ & Famílias \\
\hline & & & & & & & & Total de famílias & Famílias \\
\hline & \multirow{3}{*}{11} & \multirow{3}{*}{ IPSV } & \multirow{3}{*}{$\begin{array}{c}\text { População } \\
\text { sanitariamente } \\
\text { Vulnerável (IPSV) }\end{array}$} & \multirow{3}{*}{$\begin{array}{l}\text { Calcular a magnitude da } \\
\text { população sanitariamente } \\
\text { vulnerável em relação à } \\
\text { população total }\end{array}$} & $\begin{array}{l}\text { PSVE / } \\
\text { Ptx100 }\end{array}$ & Porcentagem & $\begin{array}{c}\text { PSVE= População Sem } \\
\text { acesso a esgotamento } \\
\text { sanitário Pt = População } \\
\text { total }\end{array}$ & $\begin{array}{l}\text { População Sem acesso a } \\
\text { esgotamento sanitário }\end{array}$ & População \\
\hline & & & & & \multirow{2}{*}{$\begin{array}{l}\text { PSVA / } \\
\text { Ptx100 }\end{array}$} & \multirow[t]{2}{*}{ Porcentagem } & \multirow{2}{*}{$\begin{array}{c}\text { PSVA= População Sem } \\
\text { acesso a abastecimento } \\
\text { de água Pt= População } \\
\text { Total }\end{array}$} & $\begin{array}{l}\text { População Sem acesso a } \\
\text { abastecimento de água }\end{array}$ & População \\
\hline & & & & & & & & População Total & População \\
\hline \multirow{4}{*}{$\begin{array}{l}\text { Educação e } \\
\text { cidadania }\end{array}$} & \multirow{4}{*}{12} & \multirow{4}{*}{$\mathrm{EC}$} & \multirow{2}{*}{$\begin{array}{c}\text { Programas } \\
\text { educacionais } \\
\text { desenvolvidos pelas } \\
\text { operadoras/ } \\
\text { mobilização da } \\
\text { operadora em } \\
\text { programas } \\
\text { educacionais } \\
\end{array}$} & \multirow{2}{*}{$\begin{array}{l}\text { Qual a freqüência que coleta as } \\
\text { demandas da população? } \\
\text { Levantamento de } \\
\text { demandas/controle social que } \\
\text { tem na lei }\end{array}$} & \multirow{4}{*}{$\begin{array}{c}\mathrm{NR}+\mathrm{NO} / \\
\mathrm{NP}\end{array}$} & \multirow{4}{*}{$\begin{array}{l}\text { Participante/ } \\
\text { atividade }\end{array}$} & \multirow[t]{2}{*}{$\begin{array}{c}\text { NR= } \\
\text { Número de Reuniões } \\
\text { - Planejamento } \\
\text { participativo }\end{array}$} & $\begin{array}{c}\text { NR= Número de } \\
\text { Reuniões de } \\
\text { participativas, oficinas e } \\
\text { cursos } \\
\text { disponibilizados/ano }\end{array}$ & Quantidade \\
\hline & & & & & & & & $\begin{array}{l}\text { Número total de } \\
\text { participantes }\end{array}$ & Pessoas \\
\hline & & & \multirow[b]{2}{*}{$\begin{array}{c}\text { Participação em } \\
\text { programas } \\
\text { educacionais } \\
\text { desenvolvidos pelas } \\
\text { operadoras }\end{array}$} & \multirow{2}{*}{$\begin{array}{l}\text { Em função do grau de } \\
\text { participação nas oficinas e } \\
\text { cursos é possível medir a } \\
\text { importância e o grau de } \\
\text { influência dos programas de } \\
\text { educação e planejamento } \\
\text { participativo }\end{array}$} & & & \multirow{2}{*}{$\begin{array}{c}\text { NR= Número de reuniões } \\
\text { - Planejamento } \\
\text { participativo, NO= } \\
\text { número de oficinas e } \\
\text { cursos disponibilizados } \\
\text { NP= Número de } \\
\text { participantes } \\
\text { concretizadas }\end{array}$} & NR & Quantidade \\
\hline & & & & & & & & $\begin{array}{l}\text { Número total de } \\
\text { participantes }\end{array}$ & Pessoas \\
\hline
\end{tabular}




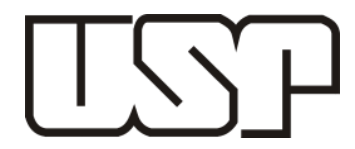

Ficha1. Qualificação dos indicadores

\section{GRUPO 4}

\begin{tabular}{|c|c|c|c|c|c|c|c|c|c|c|c|c|}
\hline \multirow{2}{*}{$\begin{array}{l}\text { Indicadores } \\
\\
\text { Critérios de } \\
\text { análise }\end{array}$} & \multicolumn{4}{|c|}{$\begin{array}{l}\text { 10 - AF Mapeamento da População } \\
\text { Vulnerável }\end{array}$} & \multicolumn{4}{|c|}{$\begin{array}{l}11 \text { - IPVS População Sanitariamente } \\
\text { Vuln. }\end{array}$} & \multicolumn{4}{|c|}{12 - EC Programas Educacionais } \\
\hline & 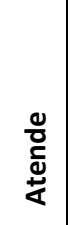 & 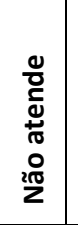 & 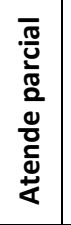 & Sugestões de melhoria & 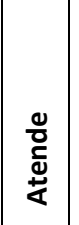 & 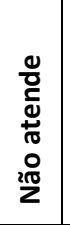 & 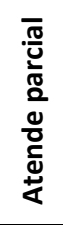 & Sugestões de melhoria & 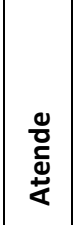 & 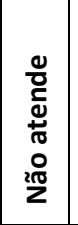 & 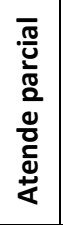 & Sugestões de melhoria \\
\hline \multicolumn{13}{|l|}{$\begin{array}{l}\text { 1. Compreensivel } \\
\text { e interessante }\end{array}$} \\
\hline \multicolumn{13}{|l|}{ 2. Relevante } \\
\hline \multicolumn{13}{|l|}{$\begin{array}{l}\text { 3. Viável } \\
\text { (Especificar onde } \\
\text { obter os dados) }\end{array}$} \\
\hline \multicolumn{13}{|l|}{ 4. Suficiente } \\
\hline \multicolumn{13}{|l|}{ 5. Oportuno } \\
\hline \multicolumn{13}{|l|}{$\begin{array}{l}\text { 6. Apropriado na } \\
\text { escala }\end{array}$} \\
\hline \multicolumn{13}{|l|}{ 7. Democrático } \\
\hline \multicolumn{13}{|l|}{ 8. Medida Física } \\
\hline \multicolumn{13}{|l|}{$\begin{array}{l}\text { 9. Preventivo e } \\
\text { proativo }\end{array}$} \\
\hline \multicolumn{13}{|l|}{$\begin{array}{l}\text { 10. Não ser } \\
\text { estanque }\end{array}$} \\
\hline $\begin{array}{l}\text { Visualização desse } \\
\text { indicador }\end{array}$ & $\sum_{\substack{\frac{\pi}{0} \\
\frac{\pi}{\pi}}}$ & 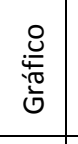 & 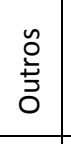 & Quais? & $\frac{\sqrt[\pi]{2}}{\sum^{\pi}}$ & 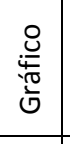 & 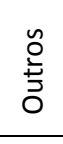 & Quais? & $\begin{array}{l}\frac{\pi}{2} \\
\frac{\pi}{2 \pi} \\
\pi\end{array}$ & 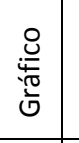 & 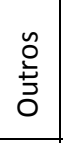 & Quais? \\
\hline $\begin{array}{c}\text { Esse indicador } \\
\text { deve no sistema? }\end{array}$ & $\operatorname{Sim} 1$ & $(1)$ & & Não( ) & $\operatorname{Sim} 1$ & 1 & & Não( ) & $\operatorname{sim} 1$ & 1 & & Não（） \\
\hline
\end{tabular}




\section{Critérios de análise na escolha dos indicadores}

\begin{tabular}{|c|c|c|}
\hline 1 & $\begin{array}{l}\text { Claro, compreensível e } \\
\text { interessante }\end{array}$ & $\begin{array}{l}\text { Evitar incertezas em relação ao que é bom e ruim, fácil de } \\
\text { entender, com unidades que tenham sentido, e sugestivos para } \\
\text { a efetiva ação }\end{array}$ \\
\hline 2 & Relevante & Politicamente relevantes para todos os participantes do sistema \\
\hline 3 & Viável & $\begin{array}{l}\text { Custo adequado de aquisição e processamento de dados e } \\
\text { comunicação }\end{array}$ \\
\hline 4 & Suficiente & Fornecer a medida certa de informação \\
\hline 5 & Oportuno & Oportuno temporalmente, integrado com o planejamento \\
\hline 6 & Apropriado na escala & Apropriado a diferentes usuários potenciais \\
\hline 7 & Democrático & $\begin{array}{l}\text { Diversidade e ampla participação na escolha e acesso aos } \\
\text { resultados. Os indicadores não devem ser determinados por um } \\
\text { pequeno grupo de especialistas, mas devem envolver } \\
\text { lideranças políticas e pessoas da comunidade. Especialistas são } \\
\text { importantes na definição de metodologias e cálculos, porém, } \\
\text { deve-se balancear o que é tecnicamente possível com o que é } \\
\text { politicamente desejável }\end{array}$ \\
\hline 8 & Medida Física & $\begin{array}{l}\text { Balancear, na medida do possível, unidades físicas (tonelada } \\
\text { de óleo, anos de vida saudável) e monetárias }\end{array}$ \\
\hline 9 & Preventivo e proativo & $\begin{array}{l}\text { Deve conduzir para a mudança, fornecendo informação em } \\
\text { tempo para poder agir }\end{array}$ \\
\hline 10 & $\begin{array}{l}\text { Não deve } \\
\text { uma pretender ser } \\
\text { estanque }\end{array}$ & $\begin{array}{l}\text { Deve estar inserido num processo de melhoria contínua, } \\
\text { passível de discussão, de aprendizado e de mudança }\end{array}$ \\
\hline
\end{tabular}

Malheiros, Philippi Jr e Coutinho (2006) 